
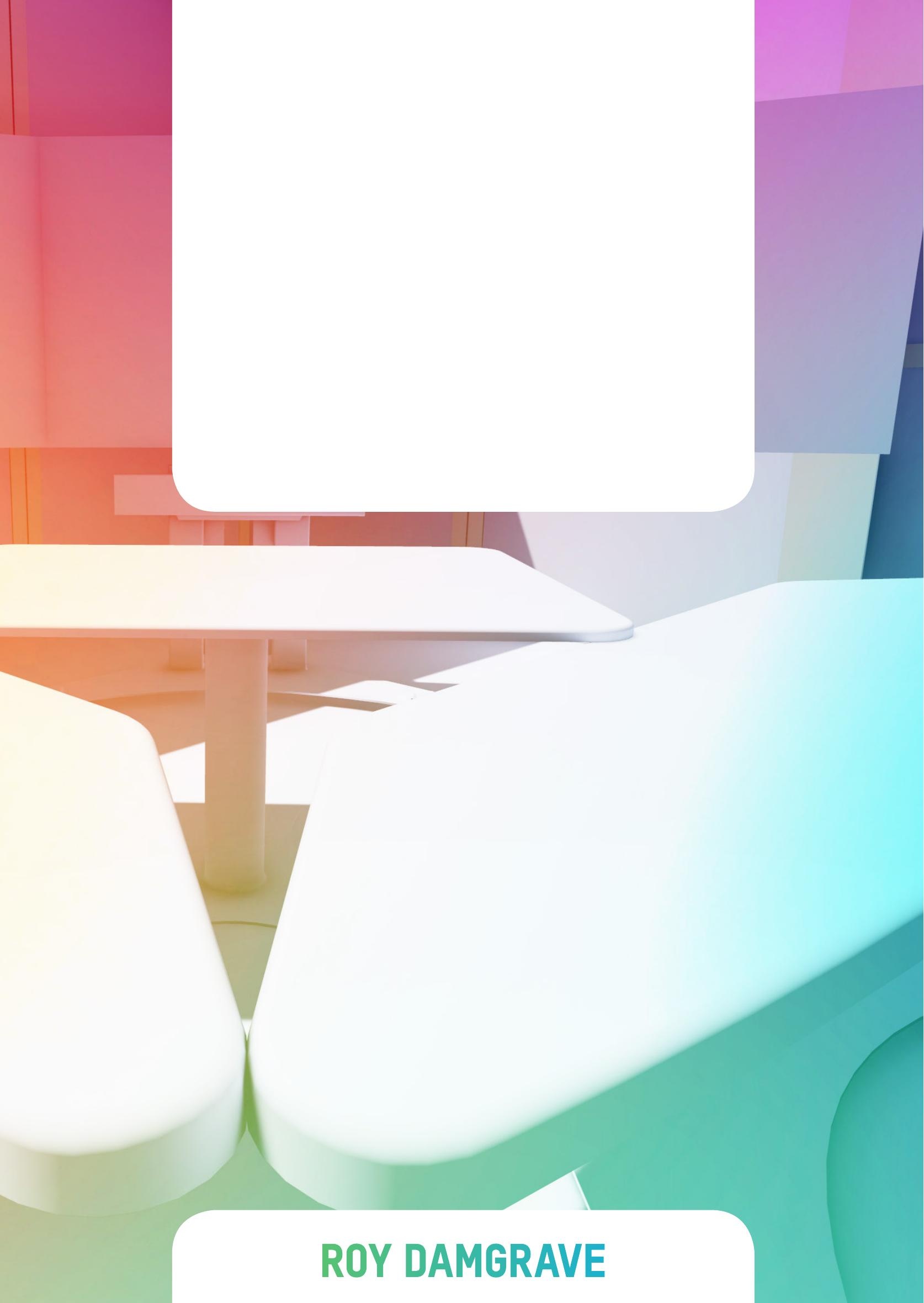

ROY DAMGRAVE 



\title{
ENHANCING THE EFFECTIVENESS OF DESIGN TOOLS IN SYNTHETIC ENVIRONMENTS
}

\author{
PROEFSCHRIFT
}

\author{
ter verkrijging van \\ de graad van doctor aan de Universiteit Twente, \\ op gezag van de rector magnificus, \\ prof. dr. T.T.M. Palstra, \\ volgens besluit van het College voor Promoties \\ in het openbaar te verdedigen \\ op donderdag 8 juni 2017 om 14:45 uur \\ door \\ Roy Gerhardus Johannes Damgrave \\ geboren op 25 oktober 1983 \\ te Oldenzaal
}


Dit proefschrift is goedgekeurd door:

Prof. dr. ir. F.J.A.M. van Houten (promotor)

Prof. dr. ir. D. Lutters (copromotor)

(c) Roy Damgrave, 2017

ISBN: 978-90-365-4341-5

DOI: $10.3990 / 1.9789036543415$ 
Dissertation committee:

Prof. dr. G. Dewulf

Prof. dr. ir. F.J.A.M. van Houten

Prof. dr. ir. D. Lutters

Prof. A. Bernard

Prof. dr. T. Tomiyama

Prof. dr. I. Horváth

Prof. dr. ir. E.W. Hans

Prof. dr. ir. A.H. van den Boogaard
University of Twente - Chairman/secretary

University of Twente - Promotor

University of Twente - Copromotor

Ecole Centrale de Nantes, France

Cranfield University, United Kingdom

Delft University of Technology

University of Twente

University of Twente

(c) Roy Damgrave, 2017

ISBN: 978-90-365-4341-5

DOI: 10.3990/1.9789036543415

Printed by Gildeprint

Cover design by Jornt van Dijk

All rights reserved. No part of this publication may be reproduced, stored in a retrieval system or transmitted, in any form or by any means, electronic, mechanical, photocopying, recording or otherwise, without the prior written permission of the author. 


\section{VOORWOORD}

Toen ik direct na mijn afstuderen de mogelijkheid kreeg om bij OPM te blijven werken als UD (ik was er namelijk al als student-assistent aan het werk), kwam ook de vraag of (of eigenlijk wanneer) ik ging promoveren. Totaal nog onbekend met de gevolgen van mijn antwoord koos ik voor de optie 'ja, liefst zo snel mogelijk'. Na bijna negen jaar werkzaam te zijn bij OPM is het dan toch zo ver: er ligt een boekje. Meerdere collega's heb ik zien ploeteren om een dergelijk boekje te produceren; ik snap nu pas hoeveel medelijden ik met hen had moeten hebben destijds...

Dit is natuurlijk het uitgelezen moment om iedereen te bedanken die, op welke manier dan ook, mee heeft geholpen aan de realisatie van dit proefschrift. De kans is meer dan reëel dat ik iemand ga vergeten, alvast mijn excuses, maar mijn ervaring is dat in de laatste weken van een promotietraject juist de meeste dingen vergeten worden.

Als eerste wil ik natuurlijk Fred en Eric bedanken. Zij hebben ervoor gezorgd dat ik op de UT mag werken, waar ik mij nog steeds bijna dagelijks met veel plezier laten verrassen door de dynamische omgeving en haar onvoorspelbaarheid. Gedurende de afgelopen jaren kreeg ik van hen de nodige vrijheid en verantwoordelijkheid voor de uitvoering van dit onderzoek. Menig discussie en goed overleg hebben we gevoerd, waarbij ik geregeld aan het einde van een overleg het gevoel had dat alles duidelijk was, en vijf minuten later geen idee meer had wat het resultaat was.

Zonder het secretariaat van OPM was dit proefschrift sowieso niet gelukt; bedankt voor het regelen van al het geregel! Daarnaast wil ik alle leden van de befaamde 'koffietafel'van OPM bedanken; de grote diversiteit in gesprekken en discussies helpen om alles weer in context te kunnen plaatsen. Het belang van deze tafel wordt door velen nog steeds onderschat, maar het behoud ervan is van groot belang voor de groep. Het laatste jaar is de voortgang van dit proefschrift in een stroomversnelling gekomen, mede dankzij de 'schrijfmaatjes' Jos en Ellen; menig dag hebben we ons verstopt op de UT om zodoende het schrijf-leed met elkaar te kunnen delen.

Verder wil ik de studenten bedanken die de afgelopen jaren voor mij allerlei opdrachten op het gebied van VR gedaan hebben; de verfrissende inzichten en verrassende resultaten hebben enorm bijgedragen aan dit proefschrift.

Een belangrijke groep mensen heeft indirect ook de gevolgen van mijn promotie-druk ervaren: mijn familie. Sorry dat ik een enorme lijst aan klussen heb laten liggen, ik zal ze zo snel mogelijk afronden! Een speciaal bedankje gaat naar mijn ouders; nu ik zelf kinderen heb zie ik pas echt in hoe geweldig mijn ouders zijn. Het is enorm jammer dat papa dit allemaal niet meer mee kan maken.

Als laatste wil ik mijn gezin bedanken, het schrijven van dit proefschrift heeft op hen de meeste impact gehad. Lynn en Sam: ik heb weer tijd om te spelen! En uiteraard Merian; jouw hulp is niet in woorden uit te drukken.

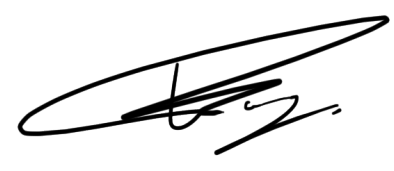

Roy Damgrave

Oldenzaal, a pril 2017 


\section{SUMMARY}

The use of Virtual Reality (VR) tools during product development processes has already been widely accepted for multiple decades in many industries. Especially in large enterprises, these VR tools are incorporated in custom-made Synthetic Environments (SEs), to provide support in dedicated product development activities. Often, these SEs are inflexible, require high investments and are applicable within limited bandwidths. For companies unfamiliar with SEs, (often SMEs), it is often unclear what the use of a SE can entail. Not only the result of use is hard to predict, also the consequences of implementation are vague. Therefore, more predictable, future-proof, robust, affordable and acceptable SEs are needed. Additionally, more insight in the effectiveness of a SE during product development processes can significantly improve the results of use.

During product development processes, it is of the utmost importance to make optimal use of the expertise of the different stakeholders involved. Efficient and effective communication and collaboration approaches are needed to facilitate these multidisciplinary and multi-stakeholder development projects. Many design tools are available to support such approaches, all with their own advantages and drawbacks. Many of them aim to provide support in the decision-making process, allowing stakeholders to acquire insight in, and understanding of, the consequences of the decisions on the future product or service. More often than not, such tools have digital or virtual elements to allow for faster iteration and better simulation of the expected result.

A SE can be considered as an enabler for communication and collaboration in multidisciplinary and multi-stakeholder development projects. To enhance the effectiveness of a SE, the selected (VR) design tools should be optimally integrated in a SE. This research describes the development and use of a support architecture that facilitates the gathering of requirements and preconditions for a SE, taking into account the perspectives of all stakeholders involved. The architecture provides multiple views on the same future targeted SE with different levels of aggregation. The architecture provides insight to make better predictions on the effectiveness of a (new) SE in specific product development phases. In this, the relations and interdependencies between different elements of the SE are more imperative than the selection of individual tools. The use of the architecture provides a better understanding of the consequences of changes and use of a SE, resulting in a more robust SE with a comprehensive flexibility. The threshold for use will become lower, resulting in an increased likelihood of usage, and higher appreciation of the SE.

Similarities are depicted between the preparation of a SE, and production preparation of a physical product. In process planning and factory layout planning, an enormous amount of knowledge is available to prepare and optimise the realisation of products. This knowledge can be used to increase the robustness of the SE, if the relations and interdependencies between individual elements that constitute the SE are known. The goal is to find alignment between the configuration of the used tools and technology and the selection of the functional specifications. Neither is leading in this process; both should be adjusted to one another until there is a purposeful match.

The involved stakeholders are positioned from three perspectives: strategic, tactical and operational. These perspectives are a way of perceiving, filtering, clustering or tagging information from a repository of requirements. Here, uncertainties and ambiguities arise or emerge by combining the perspectives. As such, the perspective 'strategic' yields a valid view, and the same applies for e.g. a view from the 'operational' perspective; however, this does not necessarily imply that both views conjointly represent a veracious view as well. To 
provide the stakeholders with an approach to gather and document their requirements to the SE, so-called blueprints are introduced. The blueprints provide a structure to categorise the information required in a SE, while simultaneously providing the stakeholders with a 'backbone', a 'checklist' and a 'notebook' to express any requirements. The blueprints are meant to stimulate all stakeholders to use the same terminology to document their requirements for a desired solution. The categorisation and the different perspectives contribute to the mutual understanding of each other's insights and opinions.

An architecture for SEs is introduced as the interconnection of blueprints. The architecture allows to review different configuration possibilities to realise a SE. Each of the selected blueprints act as a section in the architecture. The convex hull around the blueprints acts as the common ground and communication layer. This convex hull can be defined as the 'scouting space' of the SE. This scouting space is the most rudimentary form of the architecture. This fundament will not change during use, and therefore acts as the basic layer of the SE. On top of this layer, additional overlays can be added to visualise and interpret connections between different elements. The scouting space accommodates the potential of the solution, requiring additional steps to actually instantiate a solution. Subsequently, a discussion space combines all requirements, representing the maximum design freedom for the SE under development. The discussion space forms the basis on which the SE can be developed, and defines the outer-boundaries for this development. This discussion space contains all the blueprints from the stakeholders involved; visualised as a graph. This base graph contains all information ensuing from the blueprints. From this discussion space, a more consolidated space emerges, which contains the minimum information that is necessary to proceed with the construction of the SE. This consolidated space is referred to as the solution space. The solution space is a converging evolvement of the discussion space. The solution space is a sub-graph of the base graph that forms the discussion space. This sub-graph does not aim for adding new elements; it rather aims to converge the space by making decisions. The sub-graph is a consolidated maturation of the base graph.

The combined blueprints, scouting space, discussion space and solution space together project the supporting architecture. This architecture allows for filtering of information to prevent information overloads. Such overloads can occur if similarities between different blueprints are searched, or if the impact of requirements on a specific viewpoint or element is communicated amongst stakeholders.

The use of the architecture is projected on different case studies executed in the past years in the VR-lab of the University of Twente, and is currently utilised in ongoing projects in the research of the department of Design, Production and Management (faculty of Engineering Technology). The case studies show a lot of variation in the stakeholders of a SE, with the direct consequence that the need for collaboration between these stakeholders is one of the main challenges in realising a SE. Furthermore, it became visible that without a supporting architecture many decisions are made based on tacit information; while the results or qualities of the decision are not questioned. The case studies demonstrated that stakeholders explicitly and willingly are interested in solutions that have previously been developed in comparable circumstances or addressed similar aspects of development cycles, but this was considered challenging because the lack of (structured) documentation on the rationale of a SE.

The genericness of the architecture is assessed by reviewing different approaches of common characteristics that emerge in the development of SEs in the different case 
studies. The case studies substantiated that there is a benefit of not incorporating specific processes or process descriptions in the SE architecture, since this allows for perspectivedriven interpretations of support, and therefore can influence the acceptance of it. The resulting architecture is generic; it will steer the process as little as possible, but offers the stakeholders more insight in, and grip on, the most influential characteristics of a SE development process. It supports realising an overview by facilitating a structure, while providing more insight in the complexity of the process. This also helps the stakeholder to learn from previous projects, and to reuse elements from it. Furthermore, it creates stakeholder awareness as concerns the different perspectives and levels of aggregation of the other stakeholders involved, and indicates the necessity of making tacit information explicit. Eventually, this will lead to a more predictable situation, which is flexible in the use, but at the same time robust.

One the key characteristics of the proposed architecture, and one that distinguishes it from the innumerable other available approaches, is the ability to allow each stakeholder to use the shared information repository on different levels of aggregation at the same time. There is no predetermined level of aggregation in this approach, and stakeholders are even allowed to change their level during use. The architecture can always be extended with new theoretical and practical knowledge on techniques, tools, and working methods. The architecture remains flexible, yet structured, predictable and transparent. Multiple researchers can use the tool for various projects, simultaneously complementing the architecture with best practices. 


\section{SAMENVATTING}

Het gebruik van Virtual Reality (VR) tijdens productontwikkelingsprocessen is in vele industrieën al decennialang algemeen aanvaard. Vooral in grote ondernemingen zijn deze VR-gereedschappen onderdeel van op maat gemaakte Synthetic Environments (SE's), die als doel hebben om ondersteuning te bieden voor specifieke productontwikkelingsactiviteiten. Vaak zijn deze SE's niet flexibel, vereisen ze hoge investeringen en functioneren ze binnen een beperkt kader. Voor bedrijven die niet bekend zijn met SE's (vaak MKB), is het geregeld onduidelijk wat de toegevoegde waarde van een SE voor hen is. Niet alleen het resultaat van het gebruik is moeilijk te voorspellen, ook de gevolgen van de implementatie zijn niet eenduidig. Daarom zijn meer voorspelbare, toekomstbestendige, robuuste, betaalbare en doelmatige SE's nodig. Bovendien kan meer inzicht in de effectiviteit van een SE tijdens productontwikkelingsprocessen de resultaten van het gebruik aanzienlijk verbeteren.

Tijdens productontwikkelingsprocessen is het van het grootste belang om optimaal gebruik te maken van de expertise van de betrokkenen. Efficiënte en effectieve communicatieen samenwerkingstechnieken zijn nodig om deze multidisciplinaire en gezamenlijke projecten te vergemakkelijken. Er zijn veel ontwerpgereedschappen beschikbaar om dit te ondersteunen, allemaal met hun eigen voor- en nadelen. Veel gereedschappen hebben als doel het besluitvormingsproces te faciliteren, waardoor de stakeholders inzicht kunnen krijgen in de gevolgen van de beslissingen (en deze gevolgen te begrijpen) voor het toekomstige product of dienst. Vaak hebben dergelijke hulpmiddelen digitale of virtuele elementen om snellere iteratie mogelijk te maken en om een betere simulatie van het te verwachten resultaat te kunnen weergeven.

Een SE kan gebruikt worden als ondersteuning in de communicatie en samenwerking in dergelijke multidisciplinaire ontwikkelingsprojecten. Om de effectiviteit van een SE te verbeteren, moeten de ontwerpgereedschappen die hier deel van uitmaken optimaal geïntegreerd zijn in deze SE. Dit onderzoek beschrijft de ontwikkeling en het gebruik van een ondersteunende architectuur die de documentatie van eisen en voorwaarden voor een SE mogelijk maakt. Daarbij wordt rekening gehouden met de verschillende perspectieven van alle betrokkenen. De architectuur biedt meerdere weergaven op dezelfde SE met verschillende aggregatieniveaus, en biedt daarbij het inzicht om voorspellingen te maken over de effectiviteit van een (nieuwe) SE in specifieke productontwikkelingsfasen. Hierbij zijn de relaties en afhankelijkheden tussen verschillende elementen van de SE van groter belang dan de keuze van de individuele elementen. Het gebruik van de architectuur geeft een beter begrip van wat de gevolgen van wijzigingen zijn in het gebruik van een SE. Dit resulteert in een robuuste SE met uitgebreide flexibiliteit. De gebruiksdrempel wordt lager, wat tot gevolg heeft dat er een grotere kans is op het gebruik van een SE, met daarbij ook een hogere waardering van de effectiviteit van de SE.

Tussen de voorbereiding van een $\mathrm{S}$, en de productievoorbereiding van een fysiek product zijn meerdere overeenkomsten te vinden. In de onderzoeksgebieden van werkvoorbereiding en fabrieksinrichting is er al een enorme hoeveelheid kennis beschikbaar om de realisatie van producten zo goed mogelijk voor te bereiden en te optimaliseren. Deze kennis kan gebruikt worden om de robuustheid van een SE te vergroten, als de relaties en afhankelijkheden tussen afzonderlijke elementen die de SE vormen, bekend zijn. Het doel is om de configuratie van de gebruikte techniek en de selectie van de functies op elkaar af te stemmen. Geen van deze twee is leidend, beide moeten aan elkaar worden aangepast totdat er een balans gevonden is. 
De positie van een stakeholder wordt aangegeven met behulp van drie perspectieven: strategisch, tactisch en operationeel. Deze perspectieven zijn een manier om gegevens waar te nemen, te filteren, te clusteren of te markeren. Door de perspectieven te combineren worden onzekerheden en dubbelzinnigheden zichtbaar. Om de stakeholders te ondersteunen bij het verzamelen en documenteren van hun eisen aan de SE, is er een zogenaamde 'blueprint' ingevoerd. De blueprints geven een structuur om de voor een SE vereiste informatie te categoriseren, terwijl de stakeholders tegelijkertijd een 'kern', een 'checklist' en een 'kladblok' hebben om eventuele eisen te definiëren. De blueprints zijn bedoeld om alle stakeholders te stimuleren om dezelfde terminologie te gebruiken bij het vastleggen van hun eisen aan de gewenste oplossing. De categorisatie en de verschillende perspectieven dragen bij aan wederzijds begrip van elkaars inzichten en meningen.

Een architectuur voor SE's is geïntroduceerd als de verbinding tussen de blueprints. De architectuur maakt het mogelijk om verschillende configuratiemogelijkheden (om een SE te realiseren) te beoordelen. Elk van de geselecteerde blueprints is onderdeel van de architectuur. Een demarcatie rond de blueprints fungeert als de gemeenschappelijke communicatielaag. Deze demarcatie kan worden gedefinieerd als de 'scouting space' van de SE. De scouting space is de meest rudimentaire vorm van de architectuur. Dit fundament zal niet veranderen tijdens het gebruik, en fungeert daarom als de basislaag van de SE. Bovenop deze laag kunnen extra lagen worden toegevoegd om verbindingen tussen verschillende elementen te visualiseren en te interpreteren. De scouting space biedt ruimte voor het potentieel van de oplossing, daarnaast zijn aanvullende stappen nodig om daadwerkelijk een SE te kunnen realiseren. De discussieruimte combineert vervolgens alle vereisten, om zodoende de maximale ontwerpvrijheid voor de SE te bepalen. De discussieruimte vormt de basis waarop de SE kan worden ontwikkeld en definieert de buitengrenzen voor deze ontwikkeling. Deze discussieruimte geeft alle blueprints van de betrokken stakeholders weer als een graaf. Deze graaf bevat alle informatie die voortvloeit uit de blauwdrukken. Uit deze discussieruimte ontstaat een meer geconsolideerde ruimte, die de minimale informatie bevat die nodig is om verder te gaan met de bouw van de SE. In deze geconsolideerde ruimte wordt de oplossingsruimte genoemd. De oplossingsruimte is een sub-graaf van de graaf die de discussieruimte vormt. Deze graaf is niet bedoeld om nieuwe elementen toe te voegen; het heeft eerder tot doel de ruimte te convergeren door beslissingen te nemen. De sub-graaf is een geconsolideerd gevolg van de basisgraaf. De gecombineerde blueprints, scouting space, discussieruimte en oplossingsruimte samen vormen de ondersteunende architectuur. Deze architectuur maakt het mogelijk om informatie te filteren om overdadigheid aan informatie voorkomen.

De architectuur is getoetst op verschillende casestudies die de afgelopen jaren in het VRlab van de Universiteit Twente zijn uitgevoerd, en wordt daarnaast momenteel gebruikt in actuele projecten van het departement "Design, Production and Management". De casestudies tonen de vele variaties aan stakeholders die betrokken zijn bij een SE aan. De samenwerking tussen al deze verschillende stakeholders is een van de belangrijkste uitdagingen bij het realiseren van een SE. Verder is het zichtbaar dat zonder een ondersteunende architectuur veel beslissingen worden genomen op basis van impliciete informatie. Uit de casestudies blijkt verder dat de stakeholders geïnteresseerd zijn in het gebruiken van oplossingen die eerder in vergelijkbare omstandigheden zijn ontwikkeld. Dit werd echter beschouwd als problematisch omdat (gestructureerde) documentatie over de motivering van een SE ontbreekt. De algemene toepasbaarheid van de architectuur wordt getoetst door verschillende benaderingen van gemeenschappelijke kenmerken die zich voordoen in de ontwikkeling van de SE's, in de verschillende casestudies te 
vergelijken. Uit de casestudies is gebleken dat het een voordeel is dat er geen specifieke processen of procesbeschrijvingen worden opgenomen in de architectuur, aangezien dit een perspectiefgerichte interpretatie van de ondersteuning mogelijk maakt en derhalve de acceptatie ervan kan beïnvloeden. De resulterende architectuur is generiek; het zal het proces zo weinig mogelijk sturen, maar het biedt de stakeholders meer inzicht in en grip op de meest invloedrijke kenmerken van een SE-ontwikkelingsproces. Het ondersteunt het realiseren van een overzicht door het faciliteren van een structuur, terwijl het meer inzicht geeft in de complexiteit van het proces. Dit helpt de belanghebbende ook om te leren van eerdere projecten en om elementen daaruit te hergebruiken. Bovendien creëert het bewustwording bij de stakeholders met betrekking tot de verschillende perspectieven en aggregatieniveaus van andere stakeholders, en benadrukt het het belang van het expliciet maken van informatie. Uiteindelijk zal dit leiden tot een meer voorspelbare situatie, die flexibel is in het gebruik, maar die tegelijkertijd robuust is.

Eén van de belangrijkste kenmerken van de architectuur, en één die het onderscheidt van de ontelbare andere beschikbare benaderingen, is de mogelijkheid voor elke stakeholder om tegelijkertijd de gedeelde informatieopslag op verschillende aggregatieniveaus te gebruiken. Er is geen vooraf vastgelegd niveau in deze architectuur en de stakeholders mogen zelfs tijdens het gebruik hun aggregatieniveau veranderen. De architectuur kan altijd uitgebreid worden met nieuwe theoretische en praktische kennis over technieken, gereedschappen en werkmethoden. De architectuur blijft flexibel, maar is toch gestructureerd, voorspelbaar en transparant. Meerdere onderzoekers kunnen deze architectuur gebruiken binnen verschillende projecten en ze kunnen daarbij tegelijkertijd de collectie van blueprints aanvullen. 


\section{CONTENTS}

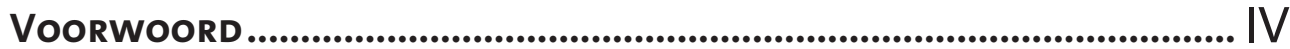

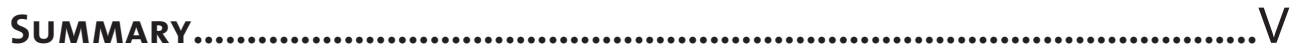

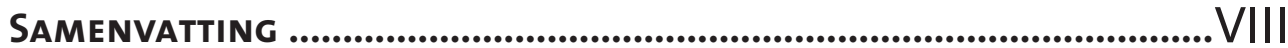

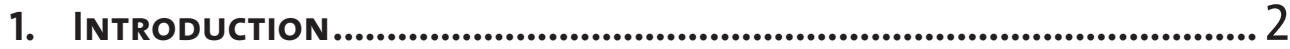

1.1. Virtual Reality and Synthetic Environments 3

1.1.1. The VR-lab of the University of Twente 3

1.2. Multi-stakeholder decision making 4

1.3. Research objective 5

1.4. Research overview and approach 5

2. VR IN PRODUCT DEVELOPMENT .....................................................8

2.1. Product development 8

2.1.1. Characteristics 9

2.1.2. Design Tools 14

2.1.3. Collaboration and communication 14

2.1.4. Decision making 16

2.1.5. Information management 17

2.2. Virtual Reality 18

2.2.1. Definition 19

2.2.2. Immersion \& Interaction 21

2.2.3. Interfaces 23

2.2.4. Assessed experience 27

2.3. Applications of VR in product development 27

2.3.1. Opportunities 28

2.4. Synthetic Environments 35

2.4.1. Observations and scoping 37

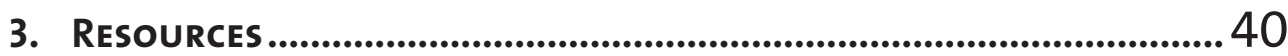

3.1. Integration and adaptation 40

3.1.1. Interaction 40

3.1.2. Data 41

3.1.3. Adaptability 42

3.2. Dependencies of, and causal relations between elements 43

3.3. Feasibility and fitness for use $\quad 45$

3.4. SE as a factory environment 46

3.4.1. Environment 47

3.4.2. Process planning 49

3.5. Industrial revolutions and the implications for VR 50

3.5.1. Industrial revolutions 50

3.5.2. Chronology 51

3.5.3. Practicability 54

3.5.4. Consequences 55 
4. ARChitecture elements for SE deVelopment

4.1. Selecting VR tools in relation with their use context $\quad 59$

4.1.1. Development of Virtual Reality tools, techniques and facilities $\quad 61$

$\begin{array}{ll}\text { 4.1.2. } & \text { Selection and implementation } \\ \text { 4.1.3. }\end{array}$

4.1.3. Tool selecting approach 62

$\begin{array}{lll}\text { 4.2. } & \text { Requirements on the SE } & 63\end{array}$

4.2.1. Requirement specifications $\quad 64$

4.2.2. Knowledge rules 66

$\begin{array}{lll}\text { 4.2.3. } & 67\end{array}$

$\begin{array}{lll}\text { 4.2.4. } & \text { Robustness and flexibility } & 67\end{array}$

4.3. Directives for the architecture 68

4.3.1. Development of the architecture 69

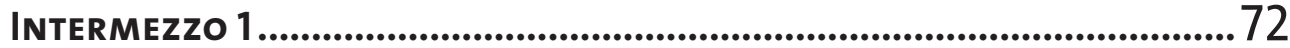

5. Se as a Product Service Combination...........................................78

5.1. Comparison of SE and PSS 79

5.1.1. Identifying a SE as a PSS 81

5.2. $\quad$ Addressing a SE as a PSS 82

5.3. Resulting Approach 83

5.3.1. Product Service Experience $\quad 84$

5.3.2. Expected experience 84

5.4. SE as an enabler 86

5.4.1. $\quad$ Expected impact $\quad 87$

5.5. Robustness and flexibility 88

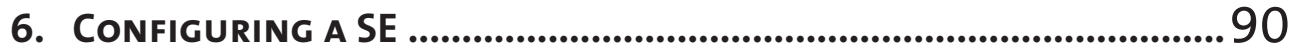

6.1. Process planning $\quad 92$

6.1.1. Optimising the development process 95

6.1.2. Process planning approach 97

6.2. Assess technical possibilities and limitations 98

6.3. Consequences and predictability of combining tools 101

6.4. Scheduling 102

7. SETUP FOR SE SOLUTION.............................................................. 106

$\begin{array}{lll}\text { 7.1. } & \text { Recognise the needs } & 107\end{array}$

$\begin{array}{lll}\text { 7.2. VR-lab approach } & 109\end{array}$

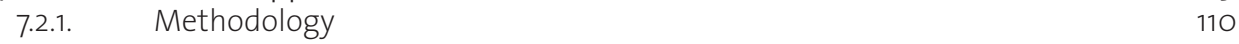

7.2.2. The VR-lab as a SE 111

7.2.3. Approach 112

7.2.4. Projects 113

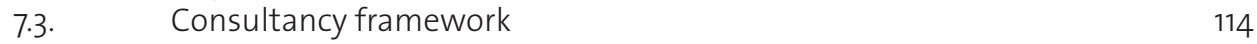

7.4. Scenario based product design $\quad 116$

$\begin{array}{lll}\text { 7.5. } & \text { User-centred design \& participatory design } & 118\end{array}$

7.6. Mapuse possibilities 120

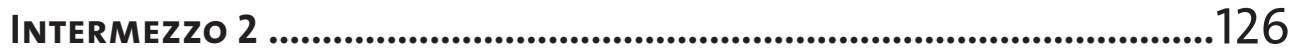




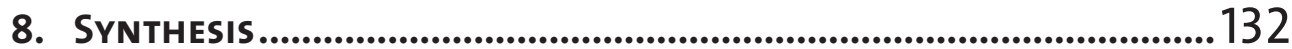

8.1. $\quad$ Evolvement in SE development $\quad 132$

8.1.1. Support in mapping efforts 134

8.2. SE Profile 137

8.3. Requirements and architecture for implementation 142

9. IMPLEMENTATION AND CASE STUDIES ............................................. 146

9.1. Validation in research in the department of DPM $\quad 146$

9.2. Implementation 149

9.2.1. Approach 151

9.3. Case studies 151

9.3.1. BroadReach Healthcare 153

9.3.2. VISIONAIR roadmap 155

9.3.3. VR master course IDE 158

9.4. Evaluation and future scenarios $\quad 161$

$\begin{array}{ll}\text { 9.4.1. Evaluation } & 161\end{array}$

9.4.2. Future scenario 162

9.4.3. Feasibility of the architecture $\quad 167$

9.4.4. Impact for SME 168

10. Conclusions \& RECOMMENDATIONS .............................................170

10.1. Conclusions 170

10.2. Recommendations 173

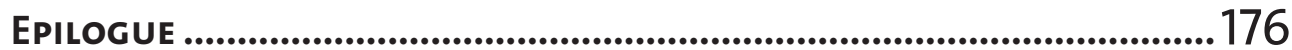

REFERENCES .................................................................................. 180

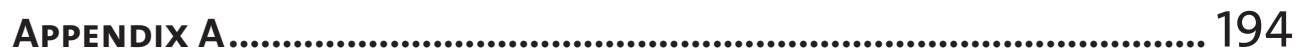




\section{INTRODUCTION}

Product development is a competitive industry confronted with an increasing speed in the development of new product. Consumers demand faster improvements and more personalised products, and companies struggle keeping up with the pace while maintaining the desired quality and revenue. Product development companies are always in search for optimisation, effectiveness and efficiency in their product development process. In this area of expertise, many tools are available that aim on facilitating and supporting specific tasks in a product development process. In product development processes (PDP) the search and selection for the best tool to support or facilitate the stakeholders in their task is time consuming, many options are available, but knowing on beforehand what the consequences of a new tool will be is often unclear. Since there are many stakeholders with different background and expertise involved in the process, finding a coherence between the offered tools is challenging.

There is a great need for supporting tools in product development processes; from physical tools, to documentation tools, to process steering tools. A product development process can be considered to be a constant trade-off between problems and solutions, and can be described as a continuous decision making process. To support and facilitate this tradeoff, it is important that all stakeholders share an aligned vision on both. This starts with the definition of the actual design problem, rendering a shared understanding between the various stakeholders. With this, everyone can assume that the defined problem is interpreted in the same way by all participants. This synchronised start creates a situation where different backgrounds and expertise of the various participants come together and where even end-users can be involved in the process. By providing each stakeholder with the possibility to directly and explicitly communicate in his or her preferred way, the risk of misinterpretations is minimised. Each stakeholder should be involved in the process and supported with a tailored method to contribute. Based on the supplied input, the interests and bias of each stakeholder within each stage of the process can be depicted, in which this preference is strongly related to the actual circumstances. Based on all supplied input purposeful and continuous iteration between problem definition, solution generation and the assessment is feasible.

Virtual Reality (VR) and Augmented Reality (AR) are already used for many years in all kinds of development phases, but there are still many prejudices toward the potential of VR. Many stakeholders still expect a limited usability, high investment costs and specialistic tool that requires a lot of preparation in order to use. Furthermore the potential benefit and use conditions are often unclear, or the available tools are consider too much distracting.

Currently the speed of development of new VR technology offers new opportunities for the integration of VR in PDP. The rapid succession of tools lead to cost reduction of individual elements, which provide more people access to the tools, resulting in a higher acceptance. Also the change towards complete digital workflows and the possibility to easier share data, provide a working environment that could benefit more than ever from new VR tools.

The issues at this moment is that many VR tools require expertise or experience in the use of it. Many VR tools demand a predefined environment to function in, while these preconfigured solutions will not provide benefit to every stakeholder. Adjusting the tools to fit the demands of an individual company, project or even stakeholder demand great effort and time, and are even sometimes impossible. The result of the use of VR is therefore often unclear for a long period of time; only after implementation the consequences for the stakeholders and the process become visible. 
There is a certain need to achieve an overview of the consequences, relations and changes connected to the use of VR. Not only for the stakeholders in a PDP, but also for the developers of VR tools: there is a need for more insight in the requirements for (new) tools. The challenge is to improve the develop process of VR tools that facilitate a PDP, and to integrate and tailor them easier in current processes. Important in this is knowing on beforehand what the use conditions are, who the involved stakeholders are, and what the layout and architecture of a VR solution will look like.

During a PDP, an initial and evolving set of requirements is translated into an adequate solution. Many stakeholders have influences on different levels of the development cycle. This cycle is actually an amalgamation of activities, resulting in a network of influences, decisions and assumptions that together shape the end-result. In this, the available capacity and capability of resources play significant roles. Synthetic Environments (SES) are used to bring together all influences on product development cycles, while achieving synthesis between information, resources and control mechanisms to reach an adequate solution.

\subsection{Virtual Reality and SYNTHETIC ENVIRONMENTS}

Within the engineering industry, virtual prototyping is used extensively to evaluate (parts of) the design at a lower cost than real prototyping. The main benefit is that it enables engineers to detect and recognise possible issues earlier in the process. Within an average engineering process, the main use for VR is on the area of communication since it facilitates better communication among other engineers of varying backgrounds (Cecil \& Kanchanapiboon, 2006). To create the synergy needed to maximise the quality of the outcome, the work of many different engineers and other stakeholders should be combined during the project. Due to the fact that engineering processes often require much, and intrinsically complex, communication between different stakeholders with their different backgrounds, the need for supporting those processes is very high. The main benefit of using VR in product development environments is sharing knowledge by transferring information among other stakeholders within the project or communicating ideas and results to outsiders.

The concept Synthetic Environments employs working methods that support the exploitation of VR and AR technologies. The tools used in a SE allows for the engendering of new objects, spaces and interactions. It does not need actual construction, thus providing the possibility to experience these objects, spaces and interactions even in the very early stages of the design process.

Generally speaking, a SE can be described as any deliberately constructed artificial environment that gives more insight in the real and natural environment; allowing an operator to navigate or interact as if in the real world. As a SE simulates a real world situation, its construction is usually based on VR and AR technologies. It is obvious that the development of a SE also requires extensive preparation before its use can actually provide significant results in product development cycles.

\subsubsection{THE VR-LAB OF THE UNIVERSITY OF TWENTE}

Within the VR-lab of the University of Twente (Houten, Damgrave et al., 2013), product developers are encouraged to address and optimise the development processes they employ in daily practice. The scope and emphasis is on supporting the decision-making processes that involve multiple stakeholders who aim to understand the implications of 
the many decisions that have to be made. Within these processes, many choices have to be made that involve multiple stakeholders. This immediately leads to complex dependencies between the choices made and the consequences thereof. These consequences are not always clear for every stakeholder involved. The VR-lab aims to give insight in the relations between and dependencies of all decisions, and to present them in the most purposeful and adequate manner.

The VR-lab can be compared to a workshop, in which the available (VR/AR) tools are exposed and can be addressed as utensils in a toolbox. The methodology and working methods that constitute the basis for the VR-lab allow for structured, transparent and straightforward use of different tools during product development life cycles. Usage of these tools ranges from scenario development and serious games to what-if design and information management. During the development and assessment of a product or environment, more information can be obtained about the potential risks, the expected maintenance costs, life cycle analysis or guidelines for suggested improvements.

Research in relation with the VR-lab is already performed for over a decade. The scope of this research is extremely broad, for this thesis the work of (Miedema, 2010; Thalen, 2013; Tideman, 2008) is most relevant. A more extensive impression and explanation of the VRlab can be found in Appendix A.

\subsection{MULTI-STAKEHOLDER DECISION MAKING}

Decision making can be seen as one of the main, and most complex, tasks within a design team. Structuring the decision making process can be a challenge due to several occurrences. First of all, a multi-disciplinary team has to deal with the different viewpoints of the team members with different expertise. This makes good communication of knowledge important. Another challenge in decision making is the information that has to be taken into account. With a lot of information from different expertise available to take into account in the decision process, several conflicts may occur, to the detriment of the decision making process.

Decision making is part of the development process that works toward selecting the best possible option from a set of alternatives. The key characteristic of decision making is that the process is a deliberate act that has been well thought out. A product development process can be recognised as a decision-making process (Krishnan \& Ulrich, 2001). A general decision-making process in product design consists of the following activities (Avramenko, 2008):

- Definition of the problem

- Identification of requirements

- Establishments of goals

- Generation of alternatives

- Determination of criteria

- Evaluation of alternatives against criteria

- Validation of solution

In current product development cycles, the need for fast decision making, incorporating external expertise and collaborating with other (remote) stakeholders is crucial. In order to utilise the expertise of all different stakeholders to its fullest extent, the way of mutual interaction should be as little disrupting and distracting as possible. This presupposes an 
effective connection between different stakeholders during the various phases of a project. Decision making is mostly used to make design reasoning more correct, consistent and thorough by prescribing the 'method of reasoning' that is considered to be appropriate (Lutters, Houten et al., 2014).

\subsection{RESEARCH OBJECTIVE}

Synthetic Environments are established based on a wide variety of available tools, techniques, hardware and software components. To ensure that a SE meets all functional specifications and requirements with adequate quality, the process to configure such a SE requires structure, vigour, predictability and flexibility at the same time.

Currently, establishing and using SEs is hindered by the lack of insight in the consequences of implementation, and indistinctness in the possibilities relevant for the different involved stakeholders. This thesis aims to optimise and enhance the process of selection and integration of design techniques and tools in Synthetic Environments. This encompasses the entire product development process, both as concerns the phases in the process and as concerns the level of aggregation (i.e. strategic, operational or tactical).

The objective of the research is to develop an architecture that facilitates all stakeholders involved by providing guidance and support throughout the entire process of developing a SE. Multiple stakeholders and multiple disciplines must be involved in this process, and the communication and collaboration between them should be facilitated in such a way that it enhances mutual understanding. Moreover, the rationale of decisions made throughout the development needs to be documented and accessible in such a way that all stakeholders can review and comprehend these decisions and the preceding and underlying decision making processes.

Stakeholders should be able to gain more insight in the relation, dependencies, influences and interactions among virtual entities and the real world. These insights allow for a better understanding of the flexibility and robustness of the SE. The resulting SE should have a predictable outcome and should be effective in the proposed context. The composition of design tools that form a SE should adequately be tailored to the needs of the stakeholders. In this the architecture should be a stable basis for a large variety of SE development processes, while not limiting any potential use condition on beforehand. The architecture should not dictate or predefine the SE development process, but should function as a tool for enhancing this process. Furthermore, the architecture should be able to reuse and build upon the developed methods and processes from earlier and other development or research projects.

So, in summary, this research aims to enhance the effectiveness of design tools in SEs, by providing insight and understanding in the configuration of the different elements that form a SE.

\subsection{RESEARCH OVERVIEW AND APPROACH}

This thesis constitutes of three main parts. The first part focusses on the application area. The second part addresses different approaches as seen from the different stakeholders' viewpoints. Finally, the third part describes the construction of the architecture as well as its implementation.

The suggested sequence of reading this thesis may be dependent on the perspective of the 
reader. Especially in part two, the three chapters (5, 6 and 7 ) do not presuppose a specific sequence in reading; ideally, they can be read in parallel (see figure 1.1).

Part I provides an introduction on the current state of the research area. Chapter 2 outlines the current state of VR in product development, which merges into to the determination and valuation of an assessed experience. This is followed by chapter 3 that addresses the resources that constitute the fundament of a Synthetic Environment, and recognises the similarities in the development of a SE and the approaches known from the manufacturing industry (e.g. process planning). The research in chapter 4 explains the required functionality of a supporting architecture, resulting in a requirements specification.

Intermezzo 1 outlines a first blueprint to summarise the essential elements that form a SE.

Part II describes three different perspectives on Synthetic Environments. Chapter 5 uses a product service system approach to research how a SE providing company should handle the development of new SE. Chapter 6 addresses the similarities between the configuration of a SE and the process planning of physical products, in order to learn from the experience and expertise in the manufacturing domain. The facilitation of decision-making processes by clients and end users in establishing SEs is elaborated in chapter 7. None of these chapters has a dominant role; therefore, the realisation of an architecture for SEs can start from each of these perspectives.

Intermezzo 2 combines the strategic, tactical and operational perspectives from part 2 into an overview that highlights the dependencies of the different perspectives.

In part III, the different perspectives from part 2 are combined with the vision from both intermezzos to work towards the SE development architecture. Chapter 8 provides the synthesis between all the different perspectives, and works towards a SE profile that incorporates a scouting space, discussion space and solutions space. Chapter 9 focusses on the implementation of the architecture, by means of validating the result in multiple case studies, and subsequently sketching a future scenario.

Chapter 10 concludes this thesis with the conclusions and recommendations, and is followed by an epilogue.

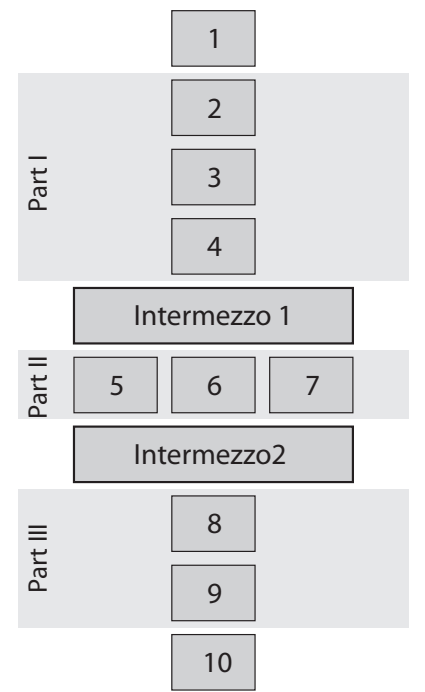

Figure 1.1 | Overview of the chapters 


\section{VR IN PRODUCT DEVELOPMENT}

Virtual Reality can be embedded and used in different product development environments, even without an explicit, clear or pre-defined approach. The approach for selecting, integrating and controlling the use is largely influenced by the origins and strategy of the company. At the same time, the intricate domain of product development demands continuous optimisation to keep up with the ongoing advancement of technologies. Therefore, new tools to support product development processes habitually emerge from evolving technologies. This chapter aims to make the dynamics and interdependencies between product development, Virtual Reality and the underlying information content instrumental. The focus of the research in this thesis is on using VR in feasible solutions available in industry (SME), rather than on cutting-edge technology.

This chapter starts with a brief introduction into the basics of product development and Virtual Reality, to indicate how these fields of expertise are considered further throughout this thesis. Based on this fundament the applications of VR in product development are highlighted, followed by an explanation how this results in Synthetic Environments.

\subsection{PRODUCT DEVELOPMENT}

Since the field of product development is extremely broad, and the term is subject to interpretation, an adequate description of how the notion is interpreted in this thesis is desirable. As the research in this thesis stems from a background in design engineering and manufacturing, the perspective on product development used here is accordingly. From this perspective, product development can be seen as "the transformation of a market opportunity into a product available for sale" (Krishnan \& Ulrich, 2001). Or, more specific, as "the creation of products with new or different characteristics that offer new or additional benefits to the customer" (Ulrich \& Eppinger, 2012). Product development is not limited to the development of entirely new products, as it can also address the modification and redesign of existing products. The notion 'product' here refers to the physical elements of a product as well as any non-physical elements of a product. Such non-physical elements of a product often characterise it as a 'service'. With this, the research depicted here does not distinguish between e.g. products or product-service systems.

Product development processes are complex collaborative activities, bringing together different fields of expertise and different stakeholders. A nearly infinite number of approaches to product development processes are described in literature, all with their own characteristics (Andreasen \& Hein, 1987; Pahl \& Beitz, 2013; Tomiyama, 1994; Ullman, 1992). These product development processes contain a combination of relevant activities. Many methods are available, all with their respective benefits and position in the market. Most of these methodologies define certain development stages that contain multiple activities; usually the process consists of several phases which are executed in sequential or concurrently order (figure 2.1). These phases, and the order in which these are executed, differ per design method. Since the PDP is a highly researched area, and the available research contains a large collection of delimited aspects and possible approaches, not a single method can be assigned as the foundation for this thesis. Also, the number and scope of cross-phase iterations and the number of review moments differ, while the methods can be very generic or very specific (Unger \& Eppinger, 2011). In general they can be clustered in the following stages: 
- Recognising and understanding the (market) need

- Planning/Preparation

- Concept development

- System-level design

- Detail design

- Manufacturing preparation

- Testing and refinement

- Production ramp-up

This list resemblance the broad scope of product development; a decent product development process (PDP) requires multiple expertise and perspectives throughout the different stages. Clustering of these activities in different stages provides insight in the activities that can be considered most related to each other. A risk involving this clustering is that the different stages will be treated as stand-alone activities without interaction with other stages. To indicate the commensurable elements relevant for product developers, the upcoming paragraphs will characterise the product development process, and highlight different components that are typically relevant for product development.

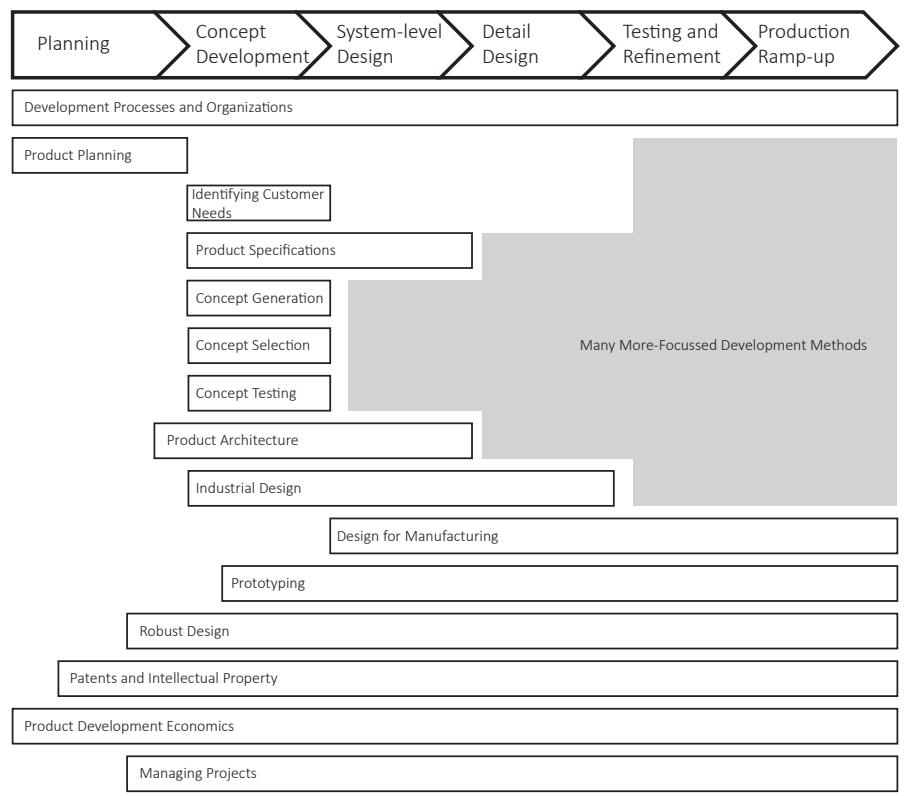

Figure 2.1 | The product development process according to (Ulrich \& Eppinger, 2012)

\subsubsection{CHARACTERISTICS}

The purpose of the different methods is to optimise the PDP, but not every method is suited for every situation. By characterising product development, an overview of relations can be provided to understand the different elements that contribute to a successful PDP. For any organisation (with the exception of non-profit organisation) the main purpose for starting a product development process is to develop products that can be sold profitably. Since it is hard to assess the performance of a PDP, the following main characteristics can be recognised (Ulrich \& Eppinger, 2012): 
Part I

- Product quality

- Product cost

- Development time

- Development cost

- Development capability

All these characteristics have their respective approaches and difficulties, but for research of this thesis the main challenges in any product development process are considered the following (Ulrich \& Eppinger, 2012);

- Trade-offs

A product development process is a set of activities that consist of continuously making trade-offs. The process is an ongoing pursuit for the most appropriate solution. Making decisions on what the next step in the process will be, forms the base of product development, since there are always multiple ways to achieve a goal. Those decisions are often made without exactly knowing what the impact on the long term or on other product development trajectories will be, and decisions are often made with incomplete information.

- Dynamics

Throughout the development process, the environment keeps on changing. All decisions made are based on the state of knowledge of that moment of time. The longer a process will take, the more issues may occur with changing aspects in the environment and context of the product.

- Details

On beforehand, it is not always clear if a small phenomenon will indeed dissolve into a small detail. Some unforeseen details can e.g. significantly influence the production process, although they were considered irrelevant in the design phase.

- Time pressure

Every product development process has a time schedule, which is often at least as tight as possible. Steps have to be made quickly, and the result of each step should meet the expectations after the first attempt.

- Economics

The eventual product often asks for a large investment, the return on investment is a factor that needs constant attention in order to get to an affordable product. This means focussing on realising an appealing product that is inexpensive to produce.

Many of the above-mentioned characteristics are related to two major properties of product development: dealing with uncertainty (see section 4.2) and the presence of human actors (see section 2.1.5). Uncertainties can be seen as anything between merely falling short on certainty, and a complete lack of conviction or knowledge. The human actors (stakeholders) are experts in their respective field, but cannot be expected to have the capabilities of determining the risks in other expertise areas, which results in uncertainties about how others will interpret their work. Without any uncertainties, the whole process of product design would be superfluous, and the production of an item can directly be started. Every product development process involves at least one human actor, but most trajectories are a collaborative team effort. This directly incorporates the essence of communication and collaboration. Team members need to convince each other, and must complement and strengthen each other's capabilities. All stakeholders have their own unique and individual view on the project, and will tend to aim for optimisation of that area of expertise. 
Nevertheless, the integration and synthesis of multiple fields of expertise, and realising synergy, is often seen as the key to successful product design.

Besides differences in approaches, there are multitudinous aspects influencing product development processes and their outcomes. Constantly evolving technologies transform product development thoroughly, often with a focus on efficiency, effectiveness or quality. The various tasks in product development are increasingly interrelated and the amount of information to be managed herein is expanding. According to du Preez (du Preez, Lutters, \& Nieberding, 2009) there are four different factors that influence the product development process; project, organisation, product and personnel. Each of these factors contain multiple variables, as visualised in figure 2.2.

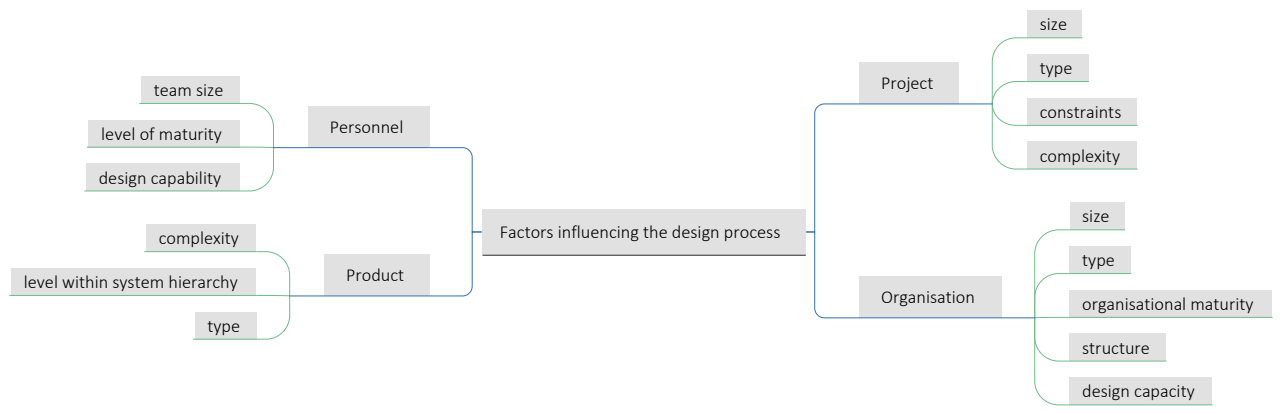

Figure 2.2 | Factors influencing the design process (du Preez, Lutters, \& Nieberding, 2009)

It becomes clear that the aspects involved in product development and the extent to which specific product development processes can vary, have a great amount of differences. Consequently, there is not one universal approach suitable for all product development processes. These distinctive characteristics of any design process provide the information for selection processes of which design methods, tools and techniques may be useful in that specific situation.

The product development process can be divided in several stages, multiple divisions are possible, but in general the process contains the following stages (Lutters, Houten et al., 2014).

1. Idea generation (also referred to as "fuzzy front end")

2. Idea screening

3. Concept development and testing

4. Business analysis

5. Beta testing and market testing

6. Technical implementation

7. Commercialization

8. Product pricing

The order of these stages can differ, depending on the circumstances and the context of use. In research and industry, a considerable amount of prescriptive design methods have been developed over the last decades, to postulate relations between the use contexts. These methods can be ordered in a number of categories to describe the distinction between them. The first division can be made between generic and specific methods. This sliding scale varies from methods that require tasks to be executed completely sequential, 


\section{Part I}

up to methods in which tasks ought to be executed well-nigh concurrently (figure 2.3). A comparable sliding scale is visible as regards the possibility, and significance, of iteration throughout the process. Some methods incorporate iteration as a fundamental aspect of the development cycle, while others leave any form of iteration implicit.

The project size, product complexity, design team configuration and the available expertise all influence the design method and the extent to whether this is a prescribing method allowing for cross-phase iterations. Especially the factors time, complexity and experience can influence the design method. In projects with large complexity and long development times, often a more sequentially approach is required. Short and less complex projects often allow for more simultaneous execution of tasks. The product development process is complex since it contains many dependencies between different expertise, and has relations with the context it operates in. Market complexity, process complexity, product complexity and organisational complexity induce a lot of the uncertainties in the product development process (EIMaraghy, ElMaraghy et al., 2012). These aspects are related to the type of market, business and product the PDP is situated in. Each of the many PDP methods is more or less suitable for different product development processes.

Even carefully pre-specified design methods or methodologies can cause unforeseen issues in product development trajectories. Many of such issues related to prescriptive methods in product development are addressed in literature (EIMaraghy, ElMaraghy et al., 2012; Tomiyama, Gu et al., 2009). There is a strong focus on functional and embodiment design in prescriptive design methodologies. Systematic design is well addressed but innovative design is not. Also, complex multi-disciplinary product development is insufficiently addressed, just like advances in digital and virtual engineering, globalisation of product

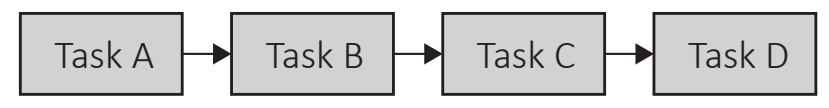

a. Sequential execution of tasks
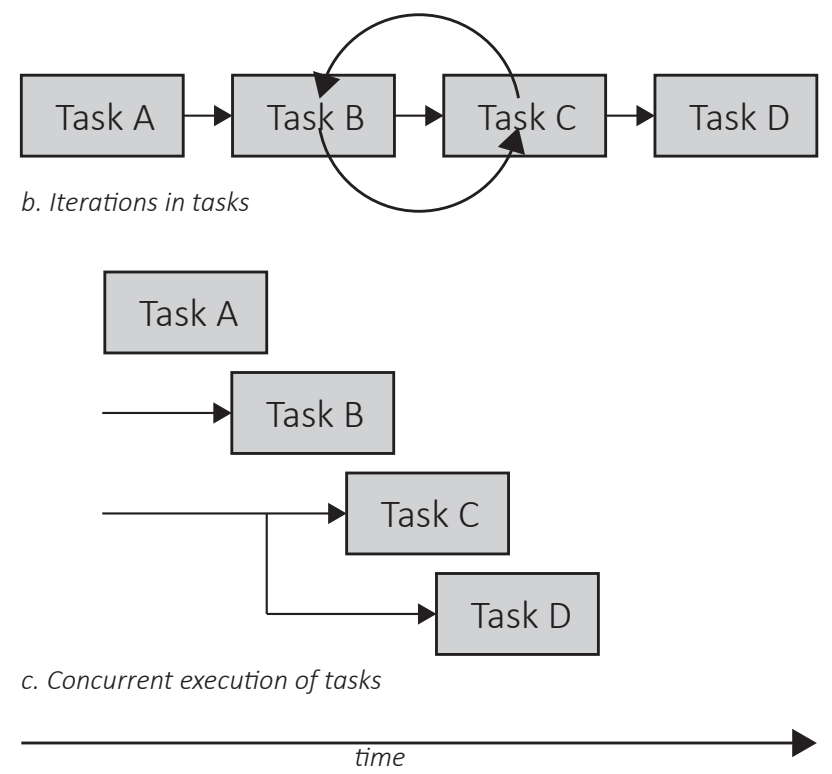

Figure 2.3 | Execution of tasks 
development, behavioural and organisational aspects of product development. Full potentials of ICT technologies are not considered in these methodologies (Tomiyama, Gu et al., 2009). In other words, the reality of product development evades the limited vigour of existing (prescriptive) design methods.

Issues specifically related to design methodologies with sequential phases are for instance market risk; market demands may evolve during the process and if early specifications or assumptions are poor, the outcome of the product development process is inadequate. Another property related to sequential phased design methodologies is technical risk. In early stages of the product development process technological feasibility is uncertain. These risks lead to two additional risks: schedule risk and financial risk. Following these risks, the developers also have to manage the intellectual property of the product, which is highly dependent on timing and budget.

The most demand for methodology is in the projects where the design problem cannot be clearly and straightforwardly described in the early stages of the design process. The methodology should bring structure to the approach, and reduce the uncertainty and risk. These projects have a constant reciprocity between determining problems and finding solutions and many of the currently available design methods target these situations. Many of the currently used methods can be identified as (a variant of) concurrent engineering. The concurrent engineering paradigm (Sohlenius, 1992) is in contrast to sequential engineering methods, such as (Pahl \& Beitz, 2013), less dependent on a predefined order of task and sequence of phases. Even the selection of the phases that will occur during the project is not determined on beforehand. This requires more flexibility by each stakeholder, and demands insight into the consequences as seen from each stakeholder's perspective. To support and facilitate this in the different phases of a PDP, a large variety of design tools is developed over the years, and many of them are available and used during a PDP.

\section{Manufacturing}

The main purpose of any product development process is the realisation of a product that has added value for the customer. Nearly each physical product starts with raw material that undergoes changes to form (a component of the) final product. These changes imposed on the raw material add value to the final product. The most commonly used definition of manufacturing is, "the making of products from raw materials using various processes, equipment, operations and manpower according to a detailed plan" (Scallan, 2003a). According to the same author, a manufacturing system is often defined as " $a$ system in which raw materials are processed from one form into another, known as a product, gaining a higher or added value in the process and thus creating wealth in the form of a profit". As seen in these examples, often the term 'manufacturing' is used as a synonym for 'production'. In this thesis the definition is broader than this, according to CIRP (Chisholm, 1990; Segreto \& Teti, 2016) the definition of manufacturing encompasses more activities in the product development process: "The entirety of interrelated economic, technological, and organizational measures directly connected with the processing/machining of materials, i.e., all functions and activities directly contributing to the making of goods". Consequently, manufacturing in this thesis is defined as "the series of all interrelated activities and operations conjointly and directly aimed at the engendering of products and accompanying resources, methods and procedures" (Lutters, 2001). 


\subsubsection{DESIGN TOOLS}

In the context of product development, the use of design tools is considered a combination between a tool and a technique. A tool offers the possibility (with use of a physical element, or a method) to increase the efficiency in one or several phases of the PDP, while a technique describes the way to perform a specific activity (with use of a tool). In the context of this thesis, tools and techniques in product design are defined as "The combination of tools and techniques is a means to apply and exploit the skill and craftsmanship of product designers and design teams in order to examine a solution path (or alternative) while pursuing a specified aim in the context of a chosen or enforced design method or approach." (Lutters, Houten et al., 2014). In this definition the expertise and experience of the individual stakeholder is highly valuated, and indicates that a tool or a technique requires skills and craftsmanship of the user in order to be valuable to the process. For the research in this thesis the focus is on design tools with a digital element, without ignoring the physical tools.

Design tools are available for a large variety of phases throughout the development process. In a product development process the use of design tools is high, and most of them are used in combination with other tools. These design tools support the designer by adding hardware, software, models or processes to the project in order to support, enhance, improve and facilitate the different development process. The use of these design tools is often fully embedded in the method and environment of the PDP.

Many of the available tools are very general, and the precise way of using it is largely dependent on how the stakeholder interprets its added value. This is in contrast with very specialised tools that are aimed on providing support in a specific phase and/or a specific stakeholder. Many variables determine when and how a tool is (and can be) used: e.g. scope, background, aim, flexibility, adaptability and level of aggregation. In literature, many lists and comparisons of individual tools and techniques are available to characterise the overall impact of tools and techniques (Gu, Hashemian, \& Nee, 2004; Holston, 2011; Silverstein, Samuel, \& DeCarlo, 2013). Some tools influence the process more than others; sometimes even the development completely relies on the outcome of the tool.

As a developer it is important to know what the limits of a tool are, and what the logically next step will be. Given the range of available tools and techniques, effective ways of selecting and implementing them is necessary. The selection of an appropriate design tool cannot be made without incorporating the context and environment it will function within. This process requires an overview on the (inter)dependencies and relations between different tools. Furthermore, the use of a design tool requires data which needs to be processed and functions as the input for the design tool (see section 2.1.5).

\subsubsection{COLLABORATION AND COMMUNICATION}

As mentioned, the design team is an important aspect of the product development process. Collaboration in a team is an emergent process during the product development project, a learning process relying on the quality of information exchange (Citera, McNeese et al., 1995). The composition of the team depends on the type of project (du Preez, Lutters, \& Nieberding, 2009), and there is no limit in the number of involved stakeholders, any person that has an interest in and influence on a product development cycle can be considered as a stakeholder. Not each stakeholder has to be a (active) member of the team, in some cases a stakeholder has a certain interest in the project but will not participate in the development (e.g. investor). Generally, design teams are multidisciplinary. This comes with some challenges to a successful design process, especially related to communication 
and decision making. In order to utilise the expertise of all different team members to its fullest extent, any interaction should be as little disrupting and distracting as possible. This presupposes an effective connection between different stakeholders during the various phases of a project. Traditionally, this results in consequential efforts to meet, often including significant travelling. In reducing the inefficiencies involved in travel and doing justice to the relevance of collaboration amongst (global) stakeholders, the need for adequate remote collaboration tools increases. Tradition entails that the most common way of interaction in a project is by means of a meeting. These are often organised with a specific goal in mind, based on the available participants and the current state of the product definition. This implies that different meetings require different set-ups, working methods and tools.

A clear distinction, which is independent of the goal and aim of the meeting, can be made between meetings taking place at one location (sharing the same environment) and meetings that involve stakeholders at multiple locations (i.e. not physically in the same environment). The purpose of the meeting has direct consequences for the required types of communication; the challenge is to define on beforehand what communication and interaction possibilities are necessary and useful.

Currently, research efforts are directed towards nullifying the differences between 'local' and 'remote' meetings. As such, the intent is to address 'remote' meetings as if they were 'local'. Technical means are employed to get across the disadvantages of not being in the same environment. Yet, there still is a substantial difference between local and remote meetings; in general, a local meeting (with participants sitting in the same environment, experiencing the same equipment, around the same table) is experienced to be more efficient and natural.

The challenge of working in a design team is to combine the knowledge and abilities of each stakeholder (Tomiyama, D'Amelio et al., 2007). The knowledge of an individual team member consists of explicit and implicit knowledge, routines and understanding. It is not always obvious what the knowledge, experience and abilities of a team member are. This is one of the pitfalls in the design team communication process. Key in combining the knowledge and expertise in a design team is decision making for interdependent items of the project. Each team member has his or her own knowledge and abilities, which can be exploited in separated design tasks. Many design tasks however, are interrelated through interdependencies in parameters and data, leading to numerous constraints in design tasks that should be taken into account. To achieve collective comprehension in the design team concerning interdependencies in the design, communication of aspects related to this and decision making is important. The diversity in a multi-disciplinary team can merely be exploited with proper communication (Anderson, McEwan et al., 2007). Team members have to gain a shared understanding of the problem through exchanging information to overcome the differences in knowledge among disciplines (Stechert \& Franke, 2009). In order to do this successfully, it is important that team members obtain confidence in each other. This can be done through team members providing justifications with their input such as from previous experiences and concept demonstrations. Also, compromising and negotiating are important in multi-disciplinary design teams (Ren, Yang et al., 2011). 


\subsubsection{DECISION MAKING}

In current product development cycles, the need for adequately decision making, incorporating external expertise and collaborating with other (remote) stakeholders is crucial to keep up with the competition. The product development process is characterised by the constant activity of decision making. Within a PDP some decisions are made based on predefined decision models that already limit the possible outcomes and the criteria need to make the selection. But not all decisions can be captured in models, often stakeholders utilise their expertise in order to make a decision that will influence the next steps in the process, and the level of product definition (Dankers, 2013). The complexity of this process is visualised in figure 2.4.

As there are as many perspectives on the decisions as there are stakeholders involved in the project, there is not one undisputable model that supports decision making. (Krishnan \& Ulrich, 2001) organise the product development decisions in two categories. First the decisions made within the context of the development of a single product. The second category is the decisions made as a company strategy in establishing an organisational context and in planning of the process. Within the development of a product, the decisions are among all the phases of the chosen product development method. Even though the scope of decision making is extremely broad, (Lutters, Houten et al., 2014) states that "As a common denominator, formally, decision-making can be regarded as the act or process of consideration and deciding, resulting in a conclusion or resolution especially as to future action".

Decision making is an inherent part of a product development method, and often the main contributor to indistinctness and discussion in the project. Many decision making support tools have been developed, most of them with the goal to make decision making a more underpinned, communicable and documented process (Buchert, Neugebauer et al., 2015; Oude Luttikhuis, Lange et al., 2015). Nevertheless the majority of design methods pay little to no attention to the decision making process. Decision making, and documenting the rationale behind decisions, are surprisingly often not facilitated.

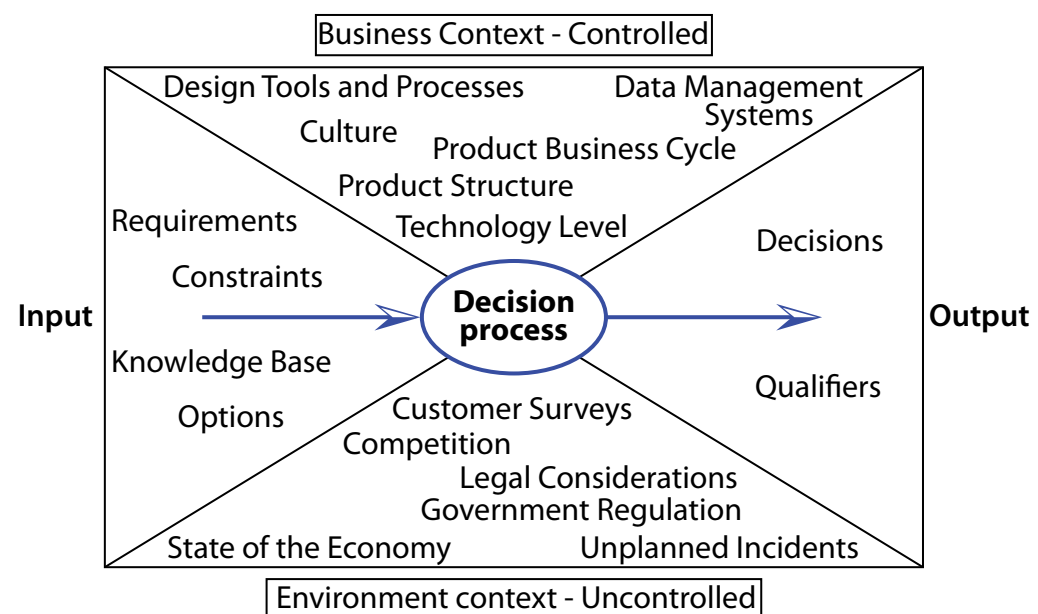

Figure 2.4 | Factors influencing the decision making process, redrawn from (National Research Council, 2001) 


\subsubsection{INFORMATION MANAGEMENT}

Information management is decisive for the complicated fields of communication and decision making in design teams and is thereby crucial in the product development process (Brinke, Lutters et al., 2000). Information in a design process comes in a wide variety of formats. This makes the process of retrieving information and combining different sorts of information very difficult. In addition, product development becomes increasingly knowledge-intensive and collaborative, and thus relies more on information. To reduce product development time and increase the efficiency of the product development process, solutions for effective and efficient information storage and exchange is of utmost importance. In order to fully benefit from the collected and generated information, it is crucial that information is stored in a meaningful and accessible manner. Means to formalise the collected design information are explored by many researchers. For instance, research is done on how ontologies can be used to formalise design knowledge to allow for re-using the information in an efficient and practical manner. Knowledge can be considered to consist of formal and tacit knowledge (Nonaka \& Takeuchi, 1995). Formal knowledge is easily accessible, clearly defined knowledge. Tacit knowledge is valuable in the design process, yet it is difficult to capture. Unfortunately, it is especially the tacit knowledge that allows any stakeholder to understand and experience a product design (cycle); also contextualising this product design (cycle) heavily relies on tacit knowledge. Therefore, knowledge exchange in general between stakeholders in a product development team is also arduous (Chandrasegaran, Ramani et al., 2013).

Taxonomies can differ in contents, but they are in general hierarchical models consisting of objects with properties or attributes that exist in various relations to each other. Ontologies make knowledge explicit by expressing the relations between concepts, and bring structure to improve communication in a design team and improve inter-operability between different systems. The most important aspect in this is that product development processes generally concern multiple disciplines, multiple departments and systems. The main challenge with structuring design information is structuring the information to enable digital systems to use it and herewith maintaining flexibility for design adjustments by the users. From the research of (Chandrasegaran, Ramani et al., 2013; Lutters, Houten

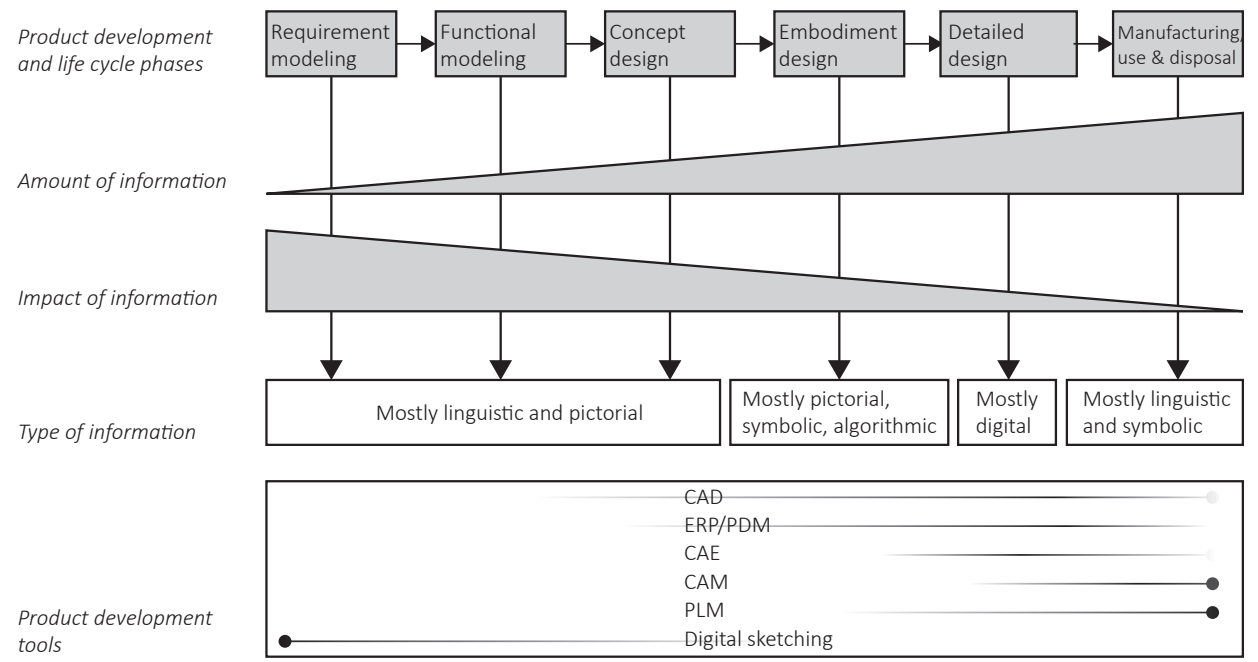

Figure 2.5 | Information management 
et al., 2014; Rachuri, Subrahmanian et al., 2008; Wang, Shen et al., 2002) an overview of knowledge representations, information input and acknowledged digital design tools can be drawn (figure 2.5).

The information established in the early phases of the design process is consequential, because many decisions that influence the further process are made in this phase. This information is often hard to manage due to the high degree of ambiguity/uncertainty and the little information available to act as fundament. The amount of information will increase over time, as will the difficulty to retrieve information. The type of information will gradually convert from more generic and linguistic to more detailed and digital. Many of the digital product development tools target the later stages of the product development process, which is in line with the available type of information, and the desired outcome of the use.

The information that underlies a product development process can be structured in different ways. Structuring large quantities of data enhances information visualisation and re-use of information in general. The most common information structures are the following types (North, 2012):

- Document collections. E.g. digital libraries or shared folders.

- Tabular structure. Tables with a structure of rows and columns.

- Tree structure. Hierarchically nodes and links like the network structure, with one root element.

- Spatial and temporal structures. Information related to one or more axes.

-1D examples: time lines, video streams, lists

-2D examples: maps, images, blueprints

-3D examples: architectural plans, CAD/CAM models, virtual environments

- Network or conceptual graph. A structure of 'nodes' and 'links' in which

information is represented as nodes, with relations amidst represented as links.

Throughout the product development process, this information management must function as a support for the whole development process, and should - clearly - not hinder this process. Since the use of design tools (and even Virtual Reality, discussed in the next section) in any phase of product development is also dependent on the available of the information (and the underlying data, see section 3.1.2), facilitating information management is considered throughout this thesis.

\subsection{ViRTUAL REALITY}

Virtual Reality (VR) is a comprehensive term, which describes the technology and the field of application of this technology. VR is the linkage between reality, behaviour (partly real, partly simulated), and artefacts (Cobb \& Sharkey, 2007). It enables users to interact with nonexisting environments in real time. Virtual environments are artificial digital environments that can be experienced by one or more users, with use of various interaction and feedback devices. One of the key characteristics of VR is immersiveness; the more immersive a virtual environment is, the easier it is accepted as a real environment. The main purpose of VR is showing an artificial reproduction of a future reality. The degree to which the real and virtual experience are comparable depends on the composition of elements that form a VR experience. The relation between the real world/product and the virtual representation needs to be in harmony to achieve a realistic experience. 


\subsubsection{DEFINITION}

Virtual Reality essentially simulates an environment to allow users to immerse in that environment. As the context, level/type of immersion and type of simulation can vary considerably; accordingly, a wide variety of definitions of the notion Virtual Reality is available. (G. Kim, 2005; Sherman \& Craig, 2003). This thesis aims on the use of VR in the engineering environment. The focus is on utilising VR as a design tool throughout product development processes, and not on the gaming or entertainment area of use. VR handles the real-time integration between computer-simulated environments and human interaction. A VR environment stimulates the users to experience an envisaged reality or use condition by stimulating the right senses at the right moment, to generate the right perception of the situation. The envisaged reality is not a completely predefined setting, but allows the user (or creator of the environment) to modify it over time. The main difference between a rendered 3D movie and Virtual Reality, is the possibility for the user to interact with the content; the VR system will respond to the given information and two, or more, objects have effect upon each other. The notion "Virtual Reality" depicts all kinds of products and services that support or enrich the real world through enhancing it with virtual presentation or interaction with information. Virtual Reality therefore ranges from simple (touch enables) displays to full-blown 3D environments using holograms and from motion capturing systems to haptic interaction and object recognition, and all related ways to interact with them (Koleva, Benford, \& Greenhalgh, 2002).

The envisaged reality in the simulated environment can be a best possible copy of the real world, for use in simulation or training purposes, or it can differ significantly from the real environment (when the link with the real world is unwanted), in for example a virtual representation of a complete new factory.

VR applications can be characterised with the "3 I's of Virtual Reality": immersion, interaction, and imagination (Grigore \& Philippe, 2003). Immersion to let the user feel to be a part of the actions taking place in the virtual environment, interaction for the response of the VR environment to the given user input, and imagination refers to the human capacity to perceive non-existent objects (figure 2.6). The following key properties are important in that sense: 3D-representation and perception, spatial interaction in real-time, sense of presence and immersion. These properties originated from a visual VR experience; for this thesis these properties also have to apply on other senses which can be stimulated (section 2.2.3).

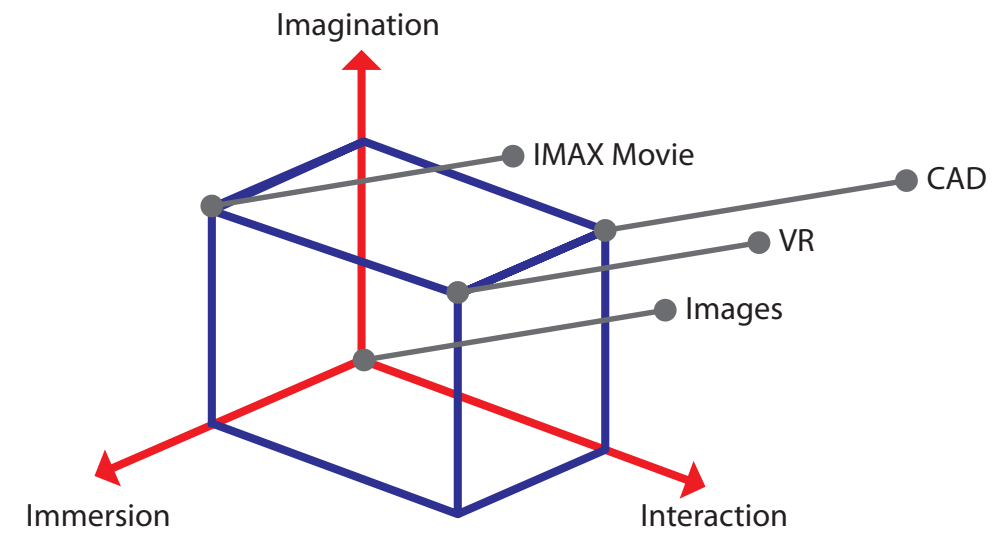

Figure 2.6 | Immersion, Imagination and interaction as characteristic of VR 


\section{Part I}

The combination of different VR tools form a VR system; a functional configuration of elements that can be used in specific situations. These VR systems can form a complex combination of possibilities and limitations. To understand the different characteristics of a VR system, and to gain insight in specifications, to following classification of elements can be used (Blach, 2008):

- Interaction modalities: Humans are capable of receiving and (in some cases) sending signals to the VR system using the five senses; the VR application provides stimulants for one or more of these modalities.

- Spatiality: The interaction and representation of the VR system can have various forms of spatiality; this combines 1D, 2D, and 3D input and output.

- Degree of embedding the physical reality: Interactions take place in both the real and the virtual world, VR can be seen as a form of mixed reality (as Augmented Reality).

- Collaboration level: VR can enable collaboration between multiple users, this also includes the impact of different methodologies used in, and to create, the VR applications.

- Space and time mapping: VR applications allow for scaling of objects (increase and decrease of size), as well as different time mappings.

- Fidelity of the content: This describes the requirements for the output components, and what level of representation is needed for the desired goal.

- Content dynamics: A VR application can respond to the input of the user; the reactivity and to what extent the user can change the virtual environment are described here.

(Blach, 2008) states that a VR system needs to be composed of three components: hardware, software, and applications. The hardware used in VR applications can roughly be divided into visual displays, tracking devices, auditory feedback, and haptic feedback. The software part is the software used to link the different inputs from the user to the output possibilities of the VR system (Miedema, 2010), while the application determines the context and environment in which the system needs to function. For the research in this thesis a fourth component is added: models. The models provide the algorithms necessary to use the system. Models contain data and information from different sources, some of this data is produced within the product development process, while some data is extracted from external sources.

The most purposeful application of VR is to communicate experiences that could not be experienced in real life at that moment, due to time, costs, practical, or other limitations.

- Experience objects that are invisible (or less visible) normally.

- Experience a location different from the current location of the user.

- Experience circumstances that are unattainable (for the user) at this moment.

In the notion of most people, VR provides them with a solution for their problems. This is an incorrect assumption, because no VR application will provide a solution on its own, it can only facilitate and stimulate the creation of possible solutions by the user of the tool. Additionally, VR might also be able to simulate the possible consequences of choices and guide users in the process. It goes without saying that without a good integration in the product development cycle, Virtual Reality will by no means be able to offer significant result, nor results that are demonstrable applicable. A consideration should be made when it is worthwhile to consider VR. The border between the actual adjustment of the reality to 
identify the impact of changes, and the effort it takes to convert the situation to a virtual experience, is a constantly moving line. This is one of the reasons for the research in this thesis.

In this thesis VR is seen as an "artificial dynamic reproduction of a potential reality or use condition that enables users to experience and/or modify and/or to interact with" (Damgrave, 2014b). This definition highlights the relation with reality, which is essential for VR in the field of product development. Furthermore, the three main characteristics (experience, modification and interaction) are mentioned and the different characterisations by Blach are observed (Blach, 2008).

\subsubsection{IMMERSION \& INTERACTION}

According to (Philippe, Guillaume, \& Pascal, 2011), VR should be both immersive and interactive to some degree, and there are certain activities that a user of a VR environment should be able to do:

- Observe the virtual world

- Move around in the virtual world

- Act in the virtual world

- Communicate with others or with the application

Seldom VR applications are perfectly immersive and interactive (Bowman \& McMahan, 2007), this is more an objective that can be aimed to achieve but this depends on the purpose of the application. Often intentionally not the best available immersive or interaction possibilities are selected, this is done to prevent losing the connection to the real world and context, or to prevent overshooting the mark.

Not only VR provides an artificial reproduction of potential product or environment, also 'augmented reality' (AR) is considered as a technology which enables this. Augmented reality is a form of mixed reality where the live view of a real-world environment is enhanced by virtual (interactive) overlay techniques. Unlike VR, the user is with AR not completely immersed in a virtual environment. The characteristic of AR is that the user can see the real world, as it is at that moment, with virtual objects projected on or combined with it. $A R$ is used in situations in which the user must be able to relate virtual information to the real situation. Both real and virtual information complement each other; therefore, we can

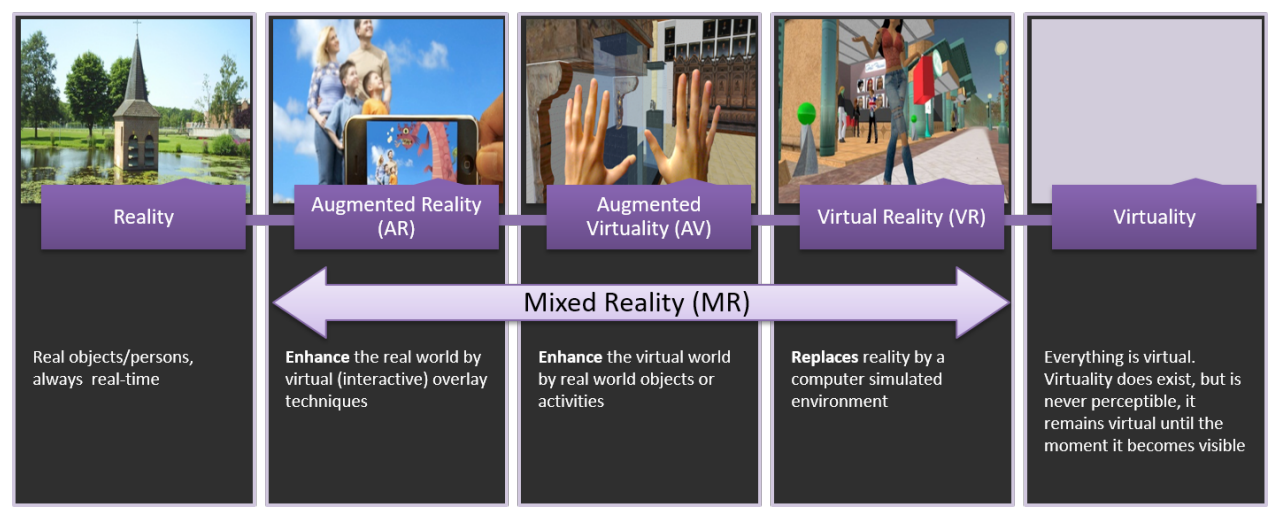

Figure 2.7 | Mixed reality continuum, redrawn from (Milgram \& Kishino, 1994) 
say that AR supplements reality, rather than completely replacing it as VR does. The term 'Virtual Reality' is often used as a comprehensive term for all forms of mixed reality. Blach describes virtual environments as a range of embedding computer mediation in reality (Blach, 2008), based on the mixed reality continuum of Milgram (Milgram, Takemura et al., 1995) (figure 2.7).

Figure 2.8 shows the integrated technologies upon which VR systems are based according to Blach. The core elements of a VR system are at the corners of the triangle, and at the edges are examples of specific technologies related to the elements. The multiplicity of domains involved with VR stretches even further than these examples. Without models this VR system cannot function, only the combination of different elements will not lead to a working system. The models provide a simplified representation of the reality by offering the algorithm, context, information and data that are needed to enable the use of this VR system.

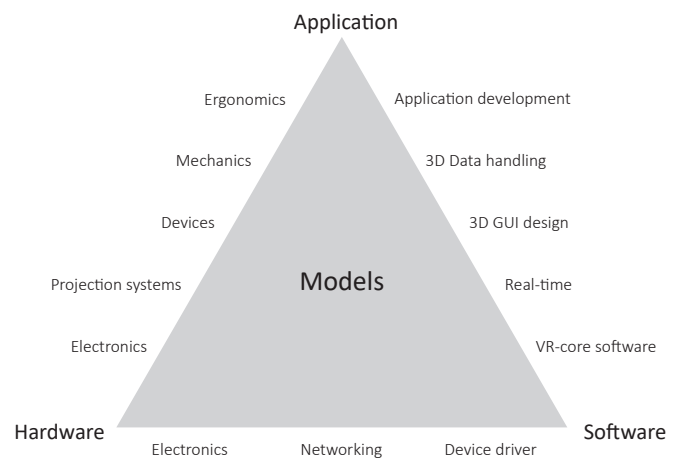

Figure 2.8 | The Virtual Reality system based on (Blach, 2008)

To achieve a certain quality of a VR system, a coherence should be found between the perception of the situation, the possibilities to alter the situation and the response of the system to the given information. This balance will not be the same for every VR system, or even every specific user of the VR system (Milgram \& Kishino, 1994). Finding this coherence is needed to get a better insight in the prediction of the results of the VR system. Without a coherence the VR system will not function as an integrated whole, and as such the way the user experiences the combination of all outputs (influences of the senses) of the system is difficult to design. Furthermore, to make a VR system usable, this is not the only precondition that should be met. The experienced output of the VR system, should be more than the sum of the inputs. If there is no increase in quality (in the broadest sense of the term) of the interpretation of the original information, the need for using VR diminishes. With use of VR, significance and value should be added to the PDP in order to utilise the VR system as a tool. One of the major possibilities with such a system is enabling observation and interaction with the data on multiple stakeholder perspectives. These different aggregation levels provide the ability to review the input (of interaction and data) from the viewpoint of a different perspective. This allows communication and understanding between different fields of expertise. Often, this is achieved by only showing the data relevant for a specific user or stakeholder, nevertheless, all the data is available if needed. This filtering of information is one of the main reasons VR can be considered a potential useful tool in a professional development environment. This allows the users to have a learning process based on their own input. The virtual representation of the world offers opportunities for alternation, and provides reaction on the (calculated) consequences. This 
approach, which is the basis for many VR simulators, makes it easier to perform iterations in a PDP. The effort needed to make an iteration can be minimised by preventing physical models, and the consequences of the iteration can be directly reviewed from multiple perspectives. But this requires a predictable and robust VR system.

There is a difference between offering a simulation, an animation or a visualisation. These terms are often used interchangeably, but they are definitely not the same. The visualisation of a (non-existing) world is a far more passive and retrospective experience than a simulation. In visualisation, the interaction between different systems (or the interaction with the real world) is often neglected, and assumptions on the interaction between real and virtual are made as regards to the preconditions of the environment in which the experience takes place. In animation, only, motion possibilities of specific elements are utilised, also without relation to the input and context. In simulation, the virtual model responds to changes in the environment, which can be based on human to machine interaction or machine to machine interaction. The rationale of using VR often dictates the specific type of interactions required and used. For this thesis the focus is on simulation rather than on visualisation or animation, since interaction with the virtual world is considered an essential element in providing an immersive experience.

The (quality of the) resulting experience can be indicated by using the model introduced in section 2.2.1. With this overview characteristics of the experience can be expressed in terms of immersion, simulation and interaction (figure 2.9). The criteria of each axis is debatable between the team members, but it is the first step in visualising and comparing different solution.

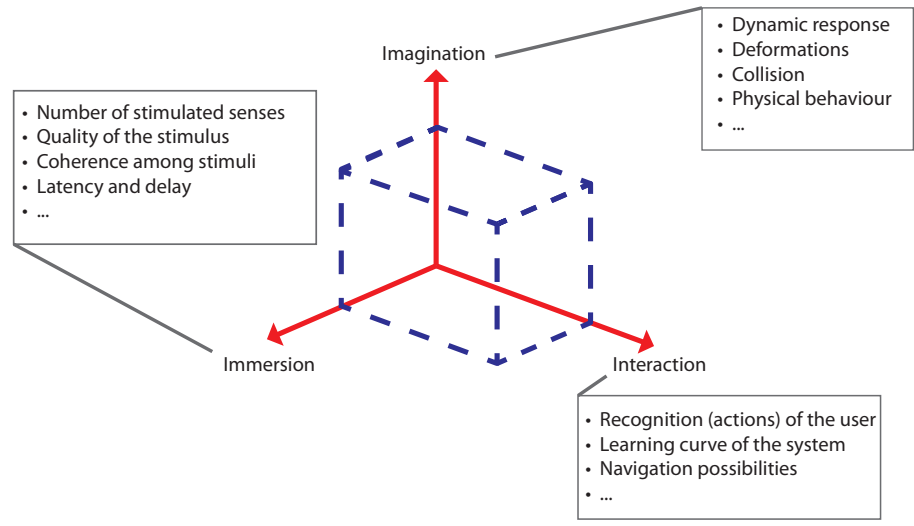

Figure 2.9 | Characteristics of the VR experience

\subsubsection{INTERFACES}

Within every VR system, three types of interactions occur. There is (1) an interaction between the user and the real world, (2) between the user and the virtual world and (3) between the virtual and the real world. An example of the first type of interaction is the tactile feedback the user receives when pushing a button. The second interaction are the changes occurring in the virtual world based on actions of the user. Examples of the interaction between the virtual world and the real world are the (automatic) adaptations the virtual world makes in order to align itself to the real world (merging in), or vice versa: dynamic elements in the real world adjust themselves to the virtual world. In this thesis, all these different forms of interactions will be approached on a standardised way, and are therefore defined as interfaces. 
The (interfaces of the) VR system acts as the mediator between the user and the perception of the virtual and real world by the user (Philippe, Guillaume, \& Pascal, 2011). These different types of interfaces capture data from the real world and allow the user to perceive and interact with the virtual world. In the virtual world, the user acts in an environment where actions are captured by interfaces capturing information on physical entities. This information is transferred to the computer, which interprets this change in input as a demand to modify the virtual world. The computer evaluates the information and provides sensorial stimuli with output to the user in the real world. In this process (figure 2.10), actions performed by the user in the real world lead to an (often real-time) reaction in the virtual world; changes in this environment provide the user with immediate sensorial feedback to its action. This also explains the sensitivity of when VR is experienced as 'comfortable'. Any delay caused by a digital system must be minimal to avoid disturbance to the user, therefore allowing a rather natural behaviour in the virtual environment. If a VR system has a high latency on providing feedback, the user will perceive this as disturbing. Furthermore the synchronisation between the stimuli of different senses is important, any mismatch in this directly lowers the feeling of being immersed; e.g. when the sound and video of a VR system are not synchronised the user will be distracted rather than being supported by the system.

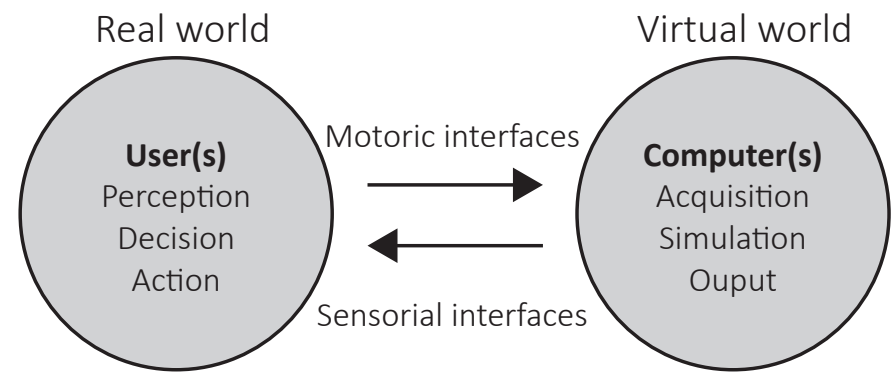

Figure 2.10 | Interfaces between the real and virtual world according to (Philippe, Guillaume, \& Pascal, 2011)

In the realisation of a VR system, a selection of interfaces has to be made at a certain point. This thesis also focusses on facilitating this selection process. The availability of interfaces is constantly expanding, and consequently new ways of interaction will occur. Therefore it is not desirable to make a collection of interfaces, since it will be outdated at any time. But based on the research of (Blach, 2008; Milgram, Takemura et al., 1995; Philippe, Guillaume, \& Pascal, 2011), a taxonomy of VR control interfaces can be created. In this taxonomy all generally applicable application control interfaces are discernible, specific interaction devices can be categorised based on this overview.

- Physical tools

Physical tools are the most well-known way of interacting with a VR system. The most basic form of this tools is a button (or combination of buttons: a keyboard), but it can also include other physical objects that allow an interaction by physically moving. Besides general available interaction tools (such as a joystick, mouse or keyboard) also custom made physical tools can be used.

- Graphical selection

Graphical selection is the most used approach in controlling applications. Virtual menus or buttons are the most common way to interact with a virtual world. 
Often these interfaces are two dimensional, three dimensional is theoretically feasible but seldom applied in practice. Two dimensional graphical selection can be further subdivided into categories with or without physical support, e.g. the use of a button to select an item versus selecting an item by looking at it.

- Verbal

Verbal application control is based on natural behaviour, namely verbal expression. Verbal application control also has disadvantages. It is fatiguing for the user and inconvenient in noisy environments or group meetings.

- Gestural

Gestural application control is also based on natural behaviour, and requires technologies to accurately capturing hand movements. The advantage is that it is not necessary to have physical contact with a device. In complex virtual user interface environments, the user may have to memorise a lot of gestures to carry out tasks, in that case the intuitiveness of this type of interaction is rescinded.

- Bio- and neural sensors

Bio- and neural sensors allow the user to provide interaction without any physical or visible action. This type of control is not (yet) used very much, as it is in an early state of development. The advantage is that there is high potential of possible commands, and that it is personal. The drawback (at this moment) is that a certain device has to be put on the body of the user.

An essential component of a VR system is how the user perceives the experience. The only way to perceive the sensory output from a VR systems is by means of the users' senses. The human perceptual system has at least five senses to experience the world: sight (vision), hearing (audition), touch (somatosensation), smell (olfaction) and taste (gustation). Current VR tools offer the most options to stimulate three of these five traditional human senses, namely: sight, hearing and touch.

A distinction can be made between senses that can be stimulated individually to a user without involving others (touch, hearing with headphones, sight with a head mounted display, etc.) and stimuli that are aimed at providing a collective experience (smell, displays, hearing through speakers, etc.). Most output in VR is customarily directed at the visual and auditory senses, because of the low threshold and high acceptance. The quality of the experience, and the controllability of the output, that can be achieved through visual and auditory information have arisen significantly. Therefore more attempts are made to increase the overall realism of VR by stimulating other senses in virtual environments as well. The inclusion of additional senses almost always improves the immersiveness (Sherman \& Craig, 2003). The research aimed at providing haptic feedback to the user includes stimulating both the tactile sense and the parts of the human nervous system dealing with kinetics (the vestibular system in the inner ear and the muscular and nervous system) (Abidi, Ahmad et al., 2015). Table 2.1 provides a list of the three most commonly used senses in VR tools, complemented with sensorial VR output devices, object fidelity and environment. 


\begin{tabular}{|c|c|c|c|}
\hline Sensorial output & $\begin{array}{l}\text { Examples of output } \\
\text { devices }\end{array}$ & Object fidelity & Environment \\
\hline Visual & $\begin{array}{l}\text { - Stereoscopic } \\
\text { screen systems } \\
\text { for single user or } \\
\text { multiple users with } \\
\text { or without the use } \\
\text { of special glasses } \\
\text { - Projection on flat } \\
\text { or curved surface }\end{array}$ & $\begin{array}{l}\text { - Wireframe, flat or } \\
\text { smooth shading } \\
\text { - Textures } \\
\text { - Material surface } \\
\text { shading } \\
\text { - Volume parameter }\end{array}$ & $\begin{array}{l}\text { - Local lighting } \\
\text { - Specific object } \\
\text { shadowing } \\
\text { - Generalised } \\
\text { shadowing } \\
\text { - Global lighting } \\
\text { - Reflection } \\
\text { - Refraction }\end{array}$ \\
\hline Aural & $\begin{array}{l}\text { - Surround sound } \\
\text { systems } \\
\text { - Multi-channel } \\
\text { audio }\end{array}$ & $\begin{array}{l}\text { - Ambient object } \\
\text { sound } \\
\text { - Objects with } \\
\text { localised sound } \\
\text { - Object audio } \\
\text { effects } \\
\text { - Object sound } \\
\text { reflection and } \\
\text { absorption effects }\end{array}$ & $\begin{array}{l}\text { - Ambient sound } \\
\text { environment } \\
\text { - Local directed } \\
\text { sound environment } \\
\text { - Global sound } \\
\text { rendering for single } \\
\text { listener } \\
\text { - Global sound } \\
\text { rendering for } \\
\text { multiple listeners }\end{array}$ \\
\hline $\begin{array}{r}\text { Somatosensation } \\
\text { (Tactile/Kinetic) }\end{array}$ & $\begin{array}{l}\text { - Gloves with } \\
\text { integration of } \\
\text { haptic feedback } \\
\text { - Haptic simulation } \\
\text { devices } \\
\text { - Haptic input } \\
\text { devices } \\
\text {-1D or 2D treadmills } \\
\text { - Floor rotatable } \\
\text { around one or } \\
\text { multiple axis }\end{array}$ & $\begin{array}{l}\text { - Object has } \\
\text { collision behaviour } \\
\text { - Object has surface } \\
\text { properties for tactile } \\
\text { rendering } \\
\text { - Object has } \\
\text { dynamic properties } \\
\text { (inertia, etc.) }\end{array}$ & $\begin{array}{l}\text { - Environment } \\
\text { has no dynamic } \\
\text { behaviour } \\
\text { - Physical } \\
\text { environment } \\
\text { parameters that are } \\
\text { included in force } \\
\text { rendering (gravity, } \\
\text { etc.) } \\
\text { - Environment has } \\
\text { overall coupling to } \\
\text { user (motion based) }\end{array}$ \\
\hline
\end{tabular}

Table 2.1 | Sensorial output interfaces with corresponding object and environmental properties 


\subsubsection{ASSESSED EXPERIENCE}

Virtual Reality aims on providing the user a certain experience, constructed from digital data and physical elements. This is an assessed experience; the way the experience is perceived cannot be described in absolute values (see figure 2.9). Every user of the solution will make a personal interpretation of the provided experience. This means for the developer of a SE, that prior to the development the capability of the users have to be mapped out. Capability profiles of different stakeholders can be used to formulate the aspects they can have an opinion on. In addition, this must be related to the experience that the user hopes to perceive. The various stakeholders will all have a different view of the solution, and thus perceive a different experience. But ultimately, the experience should meet the expectations of all stakeholders as good as possible. The developer will keep in mind that the different interpretations of the information can affect each other; by adjusting one interpretation, others will be affected to. Only if the assessed experience matches the expected experience, a stakeholder can give a constructive opinion about the solution. As long as this connection is not present, the feedback will not be about the solution expected by the developer, but on a different interpreted solution. Thus, only if the experience meets the expectations a constructive collaboration with the end user can be realised. The developer can than set the assessed experience as benchmark for the VR solution.

What often nowadays is called VR does no justice on what the user wants to experience in a professional setting. The experience should always be related to reality (to prevent creating a stand-alone game). The media hype of consumer oriented VR often profile the available tools as enablers for detaching with reality. In a professional setting, where VR and $\mathrm{SE}$ is used as a design and development tool, this connection with reality is fundamental. The virtual environment always has a relation to the real world; this can be based on the previous, current or future real world. For a professional tool the focus must be on realising mixed reality instead of Virtual Reality, and on Synthetic Environments instead of virtual environments. In industry, and in this thesis, VR is used as comprehensive term for mixed reality.

\subsection{APPLICATIONS OF VR IN PRODUCT DEVELOPMENT}

In literature a large collection of examples of the use of $V R$ throughout all phases of product development is described (Amditis, 2004; Amditis, Karaseitanidis et al., 2008; Bernard, 2005; Lorenz, Spranger et al., 2016; Nee \& Ong, 2013). Many of such examples aim to improve the collaboration and communication among stakeholders; see section 2.3.1. Moreover, the quality of the resulting product is likely to increase as well. This leads to the assumption that by improving the configuration, realisation and implementation of VR in a PDP, the quality of the product and/or the process will improve.

The typical product development cycle brings together the efforts of many different designers, engineers and other stakeholders to create the synergy required to maximise the quality of the outcome. Each of them is an expert in his respective field of expertise, and as such has a valuable contribution to the overall development cycle. To fully exploit the expertise, the adequate collaboration, and thus communication between the different stakeholders, is imperative (Chryssolouris, Pappas et al., 2007; Gerwin \& Barrowman, 2002). Product development processes often require much and intrinsically complex communication between different stakeholders with their different backgrounds; consequently the need for supporting those processes is very high. The intention of the stakeholders is to understand, simulate or test the product definition under consideration and to communicate issues and thoughts among team members (Cecil \& Kanchanapiboon, 
2006).This interaction is needed to realise the desired synergy in the development cycle, for example because pitfalls can better be foreseen and communication errors can be prevented. With the increasing amount and complexity of information the demand for methods to exploit the available information has risen. The main benefit of using VR in a PDP is sharing knowledge by transferring information among other stakeholders within the project or communicating ideas and results to outsiders (Jimeno \& Puerta, 2007). As VR offers broad and highly interactive ways of representing information its potential seems significant in the area of product development. Remarkably, the high potential of VR does not directly lead to more use of VR tools. Some opportunities can be indicated that align with the characteristics of a PDP as mentioned throughout this chapter.

\subsubsection{OPPORTUNITIES}

Based on the possibilities of VR and the characteristics of a PDP many opportunities come to light. These opportunities are aimed on providing the developers and designers of a PDP support throughout the entire development lifecycle. These opportunities are partly available, but are mainly still in development. The reason for this can be found in the configuration problem occurring while realising a SE. Selecting the most appropriate way to use VR in any kind of product development process is currently a vague activity. Current VR tools are often inflexible because they are developed dedicated for a specific purpose. To adjust the VR tool to fit the needs of other methods, stakeholders or processes requires expertise in the area of VR. Proper use of VR nowadays often requires VR craftsmanship. Currently an expert can often achieve more with the system than a new user, this sounds not desirable at first, but it sometimes also has a benefit. The more people use the system, the more they appreciate the results because the quality will increase over time, while the learning curve for use is not too steep. The constantly lowering prices of VR equipment, encourage the use of low-tech equipment which can make VR easier to use. The lower needed investment for using VR can lower the threshold for trying it. Furthermore this will increase the flexibility of the solution because the consequences of wrong choices have less impact. This allows for performing tests and try-outs without an obligation to produce a certain result. But it will not change the statement that the solution only functions properly (fast/good) if used with 'standard' activities. The main advantage is that this 'standard' can be defined by the stakeholders themselves.

\section{Collaborative work (based on (Damgrave \& Lutters, 2011))}

The interaction between the stakeholders in the product development cycle can be supported in many different ways, based on a variety of working methods and (computer based) tools. The overall term for the contact between the stakeholders is (computer supported) collaborative work, or CSCW. In general, computer supported collaborative work can be defined as the activities that combine the understanding of the way people work in groups with the enabling technologies of computational power, computer networking, and associated hardware, software, services and techniques. During collaborative work sessions, several (VR) tools are capable of stimulating and facilitating the collaboration between the team members. To enhance the efficiency of a PDP, communication between different stakeholders should be done in real-time. The waiting time between question and answer should be minimised. Furthermore VR can offer representations of information tailored to the expertise and interest of the stakeholder; this prevents an information overload.

Allowing multiple persons to simultaneously interact with computer systems foremost requires the system to allow multiple inputs. Technologies like multi-touch screens make 
such multiple inputs possible. However, although this allows for multi-touch, it is not obvious to assume that it also facilitates multi-user interaction. The main key for success in the use of CSCW tools is increasing the users' willingness to use the tool. New tools must offer a solution for a recognisable problem or issue. VR tools can stimulate to work simultaneously with multiple users at the same time at the same (or similar) task, this is beneficial for a PDP since indistinctiveness in the understanding of the information can be directly discussed with the other participants. This can be extended with the possibility for conjoint use at multiple locations, which can lower the travel costs and time for the team members.

The successful application of information technology (IT) to support cooperative work in an organisation not only depends on characteristics of the technology but also on characteristics of the organisation. The latter includes e.g. organisational structure or organisational culture and management strategy. Moreover, the end-users must be willing (motivation) and capable (cognitive factors) to handle IT solutions. Consequently, merely making a set of tools available will definitely not result in adequate synthesis between stakeholders. This is all the more true in realising that collaborative work may be considered to occur in four different circumstances:

- Same time/same place

- Same time/different place

- Different time/same place

- Different time/different place

Each of these circumstances dictates different interaction types between the stakeholders (Tomiyama, D’Amelio et al., 2007). For example, in addressing collaborative work at different time, the focus will be on the registration of generated information and making it available to others. Tools for the support of this type of operation range from extremely simple solutions, like white-boards to leave messages behind, to complex full-featured knowledge management systems (Mas, Menéndez et al., 2013). In any case, these systems boil down to off-line communication, for which a wealth of solutions is already available. VR can provide especially a benefit in the for the 'same time' situations, since VR offers the possibility to facilitate the (direct) communication between different stakeholders. Most solutions realise generic communication possibilities for stakeholders (like chat or video conferencing) or facilitate decision making processes (Sabaei, Erkoyuncu, \& Roy, 2015; Zhou, Hu et al., 2016). Another category of supporting tools aims at improving the one-way communication in the form of e.g. presentation tools (such as online videos).

Considerable enhancements to conjoint product development and the required synthesis can be achieved by better facilitating the way in which stakeholders can interact in realtime situations. Independent of their location, they should be supported in collectively working towards engendering the best possible product. This implies that no prevalent hierarchy can be assumed, the tools are equally accessible for everyone and the underlying technology should not hamper the process. The latter suggests that the used hard-and software is not only used for decision making, but also for creating variants and assessing alternatives while continuously employing everybody's input in the appropriate manner. In other words, focus has to shift from 'deciding together' to 'realising together'. This calls for a situation where multiple stakeholders can work together in a virtual setting (Aronoff \& Messinaa, 2007). This virtual setting (that can be anything from a shared notepad to a full-blown 3D environment) brings a shared perspective to all stakeholders involved. This perspective allows for the integration of the different fields of expertise, while doing 


\section{Part I}

justice to all the independent viewpoints. Based on effective solutions for a virtual setting, team members can more easily incorporate the norms for collaborative work in their development projects.

In looking at the currently used tools for collaborative work within product development teams, multiple aspects can be distinguished that hamper the quality and speed of the process. By dividing parts of the project among the team members, an environment is created in which every team member executes his part of the project, while applying an individually most preferable method. The advantage is that during the individual work the chance of translation error or noise is minimal, because the user chooses the best suitable method for his part of the research. Obviously, this method will often align with the skills and experience of the user. This immediately addresses the main problem in collaborative work: making all the research available and understandable for other team members requires additional translation steps. This translation step is often done during meetings where all the team members discuss the progress of the project. The translation is based on a summary of the work done and is guided by a direction for future development. Therefore, only the discussion is collaborative, the research itself will often remain individual. Communication with colleagues is mainly done using computer software. Only during the meetings, face-to-face communication is possible; currently used software tools require computer based communication. Therefore, the communication between stakeholders in PDP is more often face-to-computer and vice-versa than real interaction and face-to-face discussion. A VR system can offer a setting in which a fluctuating number of users is able to simultaneously interact with one system, independent of their physical location. The wide variety of interaction possibilities, create a setting where users from different fields of expertise can generate and use their most preferable input method.

\section{Distance collaboration}

If stakeholders cannot be/meet at the same location, they depend on tools to allow collaboration. Such tools have been designed for separate aspects of communication, e.g. auditive or visual. Currently, remote meetings often only use video and audio communication equipment to enable visual and aural communication. With these video conferencing systems, a combination of camera and microphone on each location is used for recording, while playback is done on monitors or televisions. The availability of tools to facilitate this form of communication is increasing continuously, even as the quality of the video and audio. Interestingly enough, above a certain threshold, the quality of the video and audio signal no longer seem to increase the quality of the meeting. Communication tools often allow for the integration of additional functionality like screen sharing, virtual white-boarding and file sharing. Such additional functionalities enable participants to extend collaboration beyond merely audio and video, thus addressing for example sharing of information, documents and even haptic feedback. The need for such possibilities stems from the wish to present and discuss digital and physical content belonging to the project, rather than only having a spoken discussion (Fechter, Damgrave, \& Wartzack, 2015).

Nevertheless, no video conferencing tool covers the entire spectrum of all the phenomena and (sub)conscious impressions that contribute to an effective and efficient face-to-face meeting. Most video conferencing systems show a video of the participants as if looking through a window, while in face-to-face meetings the participants are not cooped in a rectangular frame. During remote meetings, people are often distracted by background activities of both the local and the remote locations (D. Nguyen \& Canny, 2005). This also implies an interesting requirement to how immersive a distance collaboration support 
system needs to be, since people get a distant feeling if differences in environment, weather or time are visible during a meeting. Moreover, it is usually not clear what every other participant can see and observe. This results in a lack of feedback from the other participants since they feel not completely confident on their interpretation of the information, causing them to doubt if others actually heard and understood what has just been said and if others are paying attention and are focused. Participants often complain that a lack of feedback from other participants, either aural or visual, caused much repetition and explicit confirmation request (Ståhl, 1999). Frequent repetition of statements and frequent meta-interactions ("did you hear what I just said") obviously distract from the content and hamper the progress of the meeting. As such, the organisation and execution of the meeting often becomes one of the most important topics of the meeting. Therefore, in many meeting it is infeasible to separate the means and ends of it.

Not only the lack of feedback from other participants due to indistinct and distracting technology can cause a feeling of distance, the awareness of the communication system itself is likely to create a feeling of distance as well (Kauff \& Schreer, 2002). This awareness can, for example, arise if the users experience the system as an explicit interface between them, or when dynamics in the meeting (e.g. with respect to the number of participants) imposes a physical rearrangement of equipment. A meeting with the use of video conferencing equipment is often experienced as less personal, because participants felt as if the speaker was addressing them as a group, and not as individuals (Credé \& Sniezek, 2003). This mainly occurs when eye contact is not possible, and when the sound direction is independent from the source of the sound. The risk of misinterpretation of communication is always present due to misreading body language. This can have technical causes, e.g. by lag or hiccups in the connection; more often than not the cause is non-technical, as traditional video and audio equipment are simply incapable of transmitting the signals related to body language. This can also be caused by receiving an incomplete image of the remote participants, because a face can express a lot of emotion but it does not reveal nervousness visible by shaky hands (Natyavidushi, 2011). Furthermore, reviewing and discussing shared objects can be problematic, because it is impossible to physically point at (shared) objects, which makes it difficult to discuss specific, assignable parts of the objects. This issue especially occurs when reviewing digital data with more than two persons, or when explaining a specific point on a physical object that is available at only one location. In these cases, the need to see the arms and hands of the participants is a first prerequisite.

Based on these fundamentals of digital communication and collaboration, VR can be used to overcome the shortcomings in current available digital collaboration tools. Combining stimuli of multiple senses provides a better feeling of immersiveness, see section 2.2.3, which can be used to make the user focus less on the collaboration system, but more on the collaboration activity. These characteristics are the foundation of the VR opportunity described in the upcoming section, and illustrated in the next case. 
Case : Distance collaboration environment

For a PDP that incorporates developers on different physical location, a solution is desired that facilitates the communication between team members without being confronted with the physical distance.

Supporting distance collaboration can be done by confining the environment of the meeting, to enable the participants to know what to expect. In a support environment the participants should not be seen as remote stakeholders 'connected by wire', but a virtual environment should be created where all stakeholder seem to participate in. This confined environment (Buisine, Besacier et al., 2012), can be present in all remote locations and other stakeholders can virtually 'join' this environment. The environment should virtually project all stakeholders on each other's real-world setups. The complete shared environment will look the same from every location, and therefore requires having the same basis setup on each location.

In this distance collaboration environment it is essential to not only see the face and facial expression in real time, but also physical activity of all persons at the local and the remote table. The perspective of this visual feedback of the remote location should closely resemble the perspective of the local table. Furthermore the ability to share physical items to the meeting will increase the clarity of such objects under review/discussion. In addition to visual feedback, it is also of great importance to hear the voices of all participants, where any participant must be able to locate the origin of the sound. To achieve this, the audio playback location should closely resemble the source of the sound. To further enhance the cooperation the environment should offer a digital workspace that is shared by all persons at the local and remote table (Buisine, Besacier et al., 2012; Wigdor, Penn et al., 2007). This offers the opportunity to see in real time what other persons are working on in project documents, from everybody's own perspective.

With VR, a dedicated distance collaboration environment to facilitate meetings can be composed that creates a physical setting in which remote meetings are experienced and executed similar to local meetings.

In the example of figure 2.11 , the image of the virtual participants is processed to remove all the background, leaving only the character. This image is projected on a half-transparent fabric at one side of the table. The projected image of the participants has the same physical dimensions as the captured image, to achieve a real-size view of the remote location. This results in a projection where only the participants are visible, and the viewer appears to see the participants in his own local setting. This avoids distraction by the background of the remote location. Also, the feeling of looking at a screen is minimised because there are no clear boundaries to the projection. Because of the fixed configuration, it is possible to see

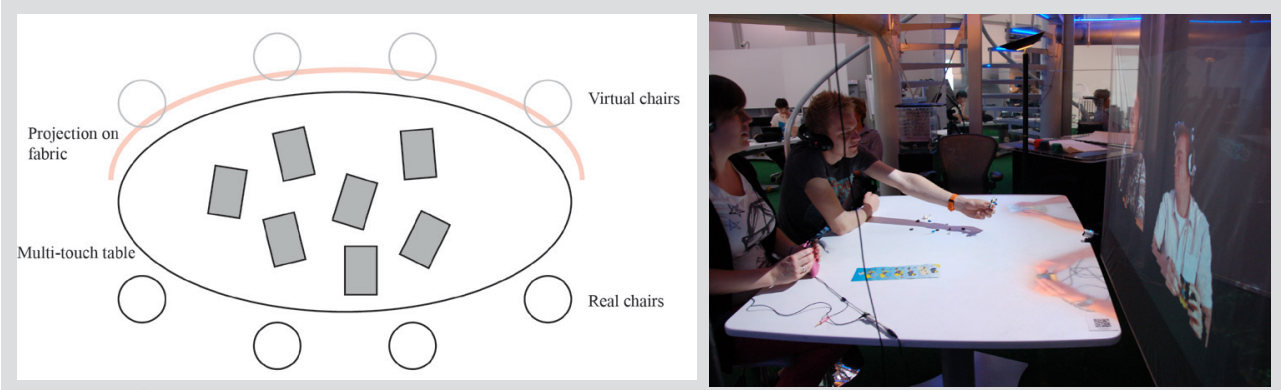

Figure 2.11 | Distance collaboration example (Damgrave \& Lutters, 2013) 
who is looking at who, and to have eye contact. Furthermore, the voice of each participant is recorded individually and played on a speaker that approximates the direction of the source. This makes it easier to discern what sound comes from which participant, even without having to look at the screen to see which mouth is moving or to know the voice of every participant.

To add to the realism of the meeting, the envisaged environment facilitates more than only an audio and video connection. The tabletop contains a large multi-touch screen, which shows the same content at both locations. Both locations have the ability to manipulate content on the surface by touching it. While using the touch screen, the arm and hand of the user are captured using a camera placed above the screen, and projected on the tabletop at the remote location. This makes it possible to point at a virtual object projected on the tabletop, while the participants at the remote location see the viewers arm and hand moving over the screen. This also allows the users to place physical objects on the tabletop, varying from paper documents to $3 \mathrm{D}$ objects, and point at them with a finger or adding comments to it using the touchscreen. Future developments are likely to incorporate holographic visualisation of participants and models (figure 2.12).

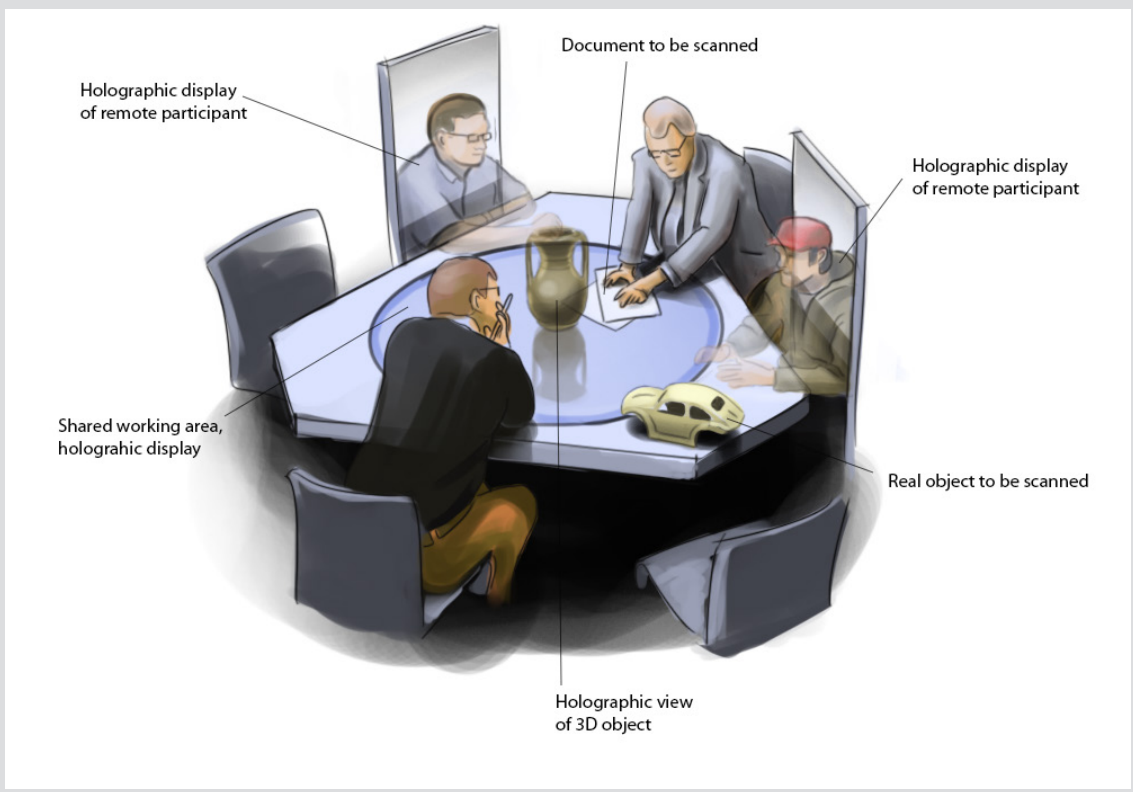

Figure 2.12 | Distance collaboration future vision 
The suggested distance collaboration environment illustrated in the case incorporates several VR tools, and is based on achieving a certain goal, rather than on incorporating certain technology. The aim is to combine the most appropriate (currently available) technology to facilitate collaboration to overcome the drawbacks of not working side to side with the other stakeholders. The configuration of this environment will change if better suiting tools occur, this allows for tailored solutions to the stakeholder. This opportunity of VR is an example of how the synergy between different individuals appear; but it also shows the complexity and interdependencies between the different elements. Realising these types of VR solutions, which are technically already possible, requires a lot of effort, time and resources. Facilitating and supporting this activity would increase the quality and speed of development.

\section{Visualisation of information}

Visualisation of information makes large amounts of data comprehensible to the user. The transformation of information into understandable visualisations provides the freedom of tailoring the representation of information to the needs and expertise of the stakeholder. For the viewer of the visualisation the information is more understandable in his context. For example: providing actual temperature-data about a machine is easier to understand if this data is visualised in relation to the actual machine; by using a visualisation of the machine with an overlay of actual temperatures. This information is put more into context than representing the data in a table with coordinates of the temperature sensors.

Furthermore, it provides the user with an instrument to interact with information (Lau, Chan, \& Wong, 2008). Information visualisation also assists in concretising mental models through support of ideas and hypotheses verification. Based on (Card, 2003) some main advantages of visualising information can be highlighted. First, the visual information is easier to process, and consequently increases the memory capacity and available processing resources. Secondly, the search for information is reduced because organising and sharing data can be achieved with little effort compared to only text based information. Another benefit is that pattern detection is enhanced through visual representations. Visual representations may provide new insights in the information because relationships or dependencies can become visible that are not explicitly discernible in the raw data, stakeholders are more stimulated to transfer the raw information into personally usable information. Moreover, perceptual attention mechanisms are used for monitoring information, this makes it easier to find information because relevant information can be effortlessly recognised. At last the information can be encoded in a medium that can be manipulated, enabling users to interact with information, and directly review consequences of manipulating the data. Although not all information in the product development process is visual, visualisation of other types of information may enhance information management in the product development process.

The choice of what information should be represented by which type of visualisation is also subject to the research in this thesis. This selection process is part of realising a VR solution, and the consequences of these decisions influence the effectiveness of the information visualisation; for a developer understanding these interdependencies supports the rationale of the selected visualisation.

\section{Recap}

VR has the potential to support a product development process, but the configuration, 
realisation and implementation of VR in a PDP lacks decent support and facilitation. The stakeholders involved in the selection of an appropriate VR solution desire insight in the consequences to the development process when implementing VR. The selection process of the different VR tools that form a VR solution needs a communicable overview of the decisions made. Furthermore, the robustness and flexibility of the targeted VR solution should be more predictable than currently.

\subsection{SYNTHETIC ENVIRONMENTS}

The combination of hardware, software, application and models is in the context of this research referred to as a Synthetic Environment (SE). This artificial environment represents an alternative reality, which acts as commensurable to a real environment as required (Miedema, 2010). The term 'synthetic' is used instead of 'virtual' since the SE also incorporates real objects. Furthermore, 'synthetic' also relates to 'synthesis'; meaning "the composition or combination of parts or elements so as to form a whole" ("Synthesis", 2017). Since this combination of real and virtual environments is set up specifically to support designated goals in the PDP, a SE is purposefully put together. The term 'environment' encompasses both the physical location of the SE (which is considered a part of the SE), as well as the virtual items.

The following definition of a Synthetic Environment is used throughout this thesis: "A Synthetic Environment is a natural design environment enriched with one or more artificial environments that are purposefully constructed in such a way that the real and virtual elements of the environment reinforce each other's contributions to the way shared information is experienced. Synthetic Environments aim to improve the effectiveness and efficiency of the design activities occurring in and around the environment. To simulate the real, natural world, Synthetic Environments make use of VR technologies." (Miedema, 2010)

Various stakeholders are involved with a SE, the most interested (and likely to be involved) stakeholders are the following:

- Designers

- Developers

- Manufacturer of a SE

- Operator of the SE

- (project) Managers

Every stakeholder can have a different interest in the SE, and will have its own perspective on what a SE should offer.

To allow for natural behaviour, enabling intuitive use, the interaction possibilities provided in the Synthetic Environment correspond to real world interactions as adequate as is appropriate. This alternative reality uses mixed reality (both virtual and augmented reality) (Azuma, 1997; Damgrave, 2014a; Milgram, Takemura et al., 1995) techniques to allow the various stakeholders to interact with it (e.g. make adjustments to it) in a way that is easier, more transparent, more purposeful and more controllable than in reality, while requiring less effort. A realistic SE must provide sensory information that imitates at best real world sensations. This makes it possible to quickly evaluate multiple configurations, and also to review the consequences of possible choices. Actors in SEs are real stakeholders or virtual representations of people whose actions influence the use of a product.

While in (Meijer, van den Broek et al., 2010) the focus is on the visual aspect of a SE, in this 


\section{Part I}

thesis also other stimuli of senses (section 2.2.3) are incorporated in a SE. A SE provides several possibilities that traditional methods in product design do not facilitate. It visualises a virtual context for the future use of a certain product, and (several) objects in this environment can be adjusted while it is in use in real time. This allows stakeholders to deal with design information in an interactive way and (virtual) prototypes can be tested in the earliest stages in its development (Broek, Meijer et al., 2008). Possible problems with the product are uncovered when adaptations are still easily made. Therefore, it is easier to evaluate features and experiences under a wide variety of circumstances. As a result, the stakeholders become more conscious of their decisions and the related interdependencies, and are stimulated to communication with other stakeholders in the PDP (Jenkins, Stanton et al., 2011). This is mainly because the information is presented to every stakeholder in an understandable format/way that is independent from the background or expertise of the stakeholder who provided the information. A SE should realise a setting where the stakeholders are less concerned about the interpretation of information.

These SEs prove their usefulness best in development processes of complex products, involving many stakeholders with various backgrounds. They can be used in nearly all phases of development processes; especially in the early stages SEs may well help to describe current and future scenarios. The main characteristics and objectives of SEs are to ensure validity of decisions by using realistic interactions, to simulate effects in a familiar context in order to achieve a realistic image of the future environment, and to present corresponding images of future situations to facilitate negotiations about consequences of their characteristics (Dankers \& Lutters, 2013).

A SE can be depicted as an enabler to experience well-considered compositions of possible future environments, used to give more insight into the consequences of the choices in such compositions. To enable stakeholders to experience this environment as veracious as possible, extensive use is made of the most appropriate mixed reality technologies. Bringing such tools to industrial practice becomes increasingly relevant, as the cost of hardware and software tend to decrease. Therefore, the ability to use SEs in smaller companies (SME) increases continually.

Although every SE is case specific, and custom made to support a certain activity, they do have generic characteristics (Lutters, Houten et al., 2014). The following (non-exhaustive) list provides the most typical characteristics of a SE (Miedema, 2010):

- Considerable sense of presence: the stakeholder must have the feeling of being immersed (section 2.2.2).

- Plausibility illusion: realistic experience of virtual interaction, ensuring validity of decisions in the real world (section 2.2.4).

- Real-time interaction: the SE directly reacts to the interaction of the stakeholder (section 2.2.3).

- Explicit product behaviour: simulated effects in a familiar context to stimulate stakeholders to develop a realistic mental image of a future product or situation (section 2.3.1).

- Shared experience: congruent mental images of the future of a product or situation, facilitating negotiations about the consequences of their characteristics (section 2.1.5).

- Narrative potential: the provided information should stimulate the generating of new related information (section 2.1.6). 
- Transformation capability: stakeholders responds realistically when temporarily taking the perspective of other stakeholders (section 2.3.1).

The configuration and realisation of a SE tends to be a complex activity, which involves many stakeholders, technologies, methods, processes, models, etc. Especially the interdependencies and relations between these elements determine how much added value a SE will have for the PDP.

Synthetic Environments are used to improve the communication between stakeholders in a PDP, and can be assigned to the following roles in a PDP (Miedema, 2010):

- Mediation: to bridge the gap between the practiced course of design processes and envisioned applications of VR tools, SEs mediate between design contributions and deployment conditions of VR in such a way that the combined organisational effectiveness and efficiency is optimised.

- Reflection: to establish a seamless integration of VR tools in the course of design processes, the part of the design process that takes place in a SE incorporates a realistic and adequate reflection of the information status and information needs of adjacent design activities.

- Contextualisation: to help stakeholders develop a conceivable shared mental model of each other's assessments, a SE places product information in explicit representations of future contexts.

- Stimulation: VR tools stimulate the imagination of stakeholders, the tools share this objective with many organisational approaches. SEs improve the perceived realism of a product representation through a combination of mutually reinforcing virtual and real (organisational) stimuli.

A SE unites the information available in a PDP (e.g. product models, user behaviour, context analysis, etc.) in one comprehensive experience that facilitates the stakeholders in interpreting the information. This emphasises that no one ideal SE can be prescribed that generates the experience to serve all product development processes. It also indicates the difficulty of the realisation of a SE. The objective of this thesis is to support and facilitate this process of realising a SE.

\subsubsection{OBSERVATIONS AND SCOPING}

For the research in this thesis, some boundaries and core values are set. First, the target group of this research are the small and medium enterprises (SME) in the field of product development, and research institutes. Large enterprises are less influenced by the expanding availability of low-cost VR/AR equipment, since their budgets often allow for cutting-edge technology. The focus area of use is the field of product development. A SE also has potential for other industries, but the expertise of the researcher and the research department is in the field of design engineering. Since a SE is considered a combination of virtual and real attributes, an assumption can be made that it shows similarities to the development of a physical product containing a digital element. To enhance the effectiveness of design tools in SEs, more support and facilitation for the involved stakeholders is needed during the decision making process in the realisation of a SE. During the development of a SE, more information should be available concerning the robustness, flexibility and agility of the future SE. This information can increase the acceptation of new SE, allow for more tailored solutions, with better understanding of the involved risks. In a PDP, the SE should lead to an increase in quality of the process and/or the product. 
Part I

\section{2}



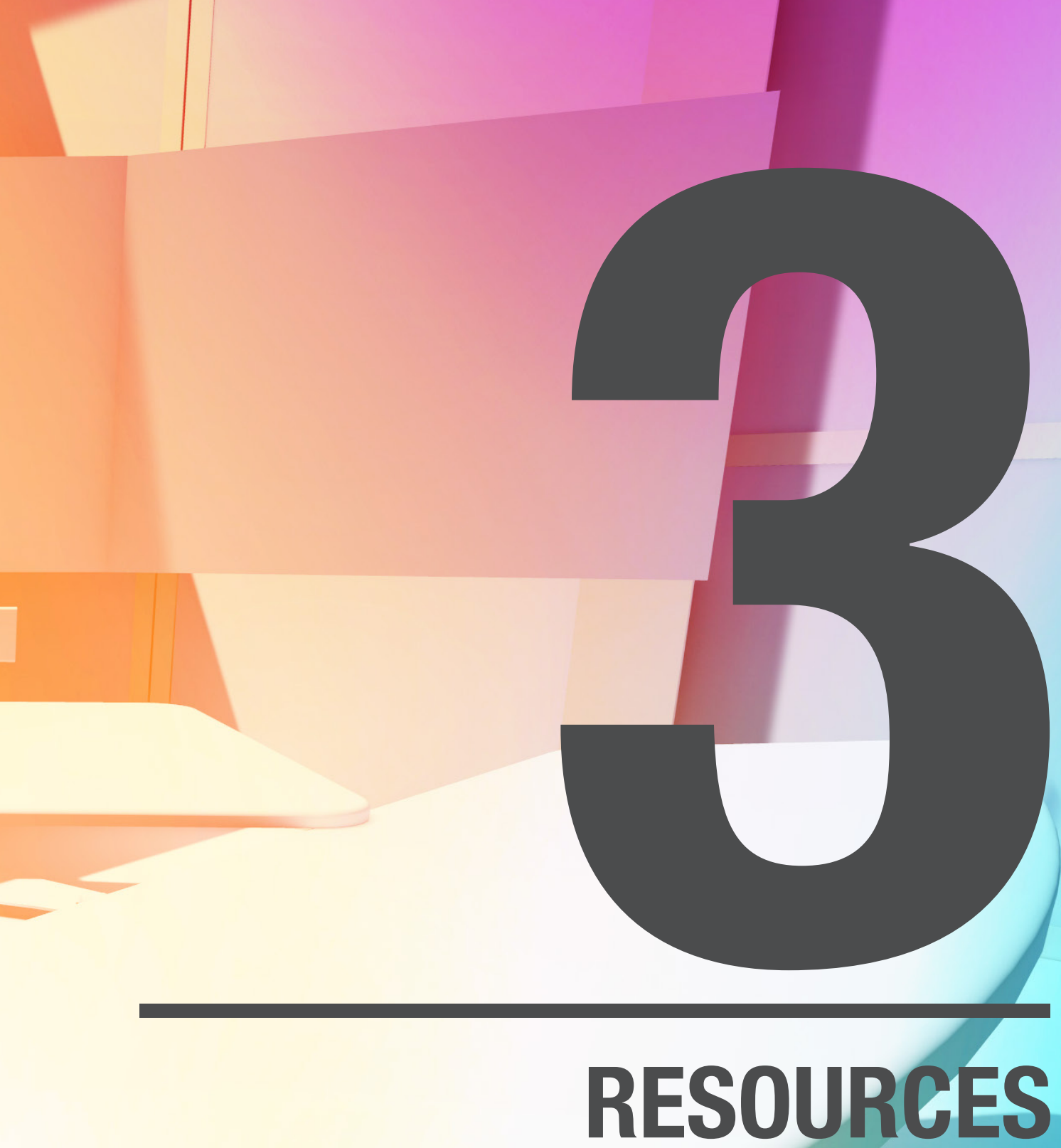


\section{RESOURCES}

This chapter expounds the different resources related to Synthetic Environments. It covers the integration of the different elements and depicts how to make (optimal) use of (available) resources. The definition of resources by (Stevenson, 2010), “A stock or supply of money, materials, staff, and other assets that can be drawn on by a person or organization in order to function effectively.", al ready highlights the broadness of the different resources. An addition has to be made to this definition, since the resources used in a SE are committed to use in that specific SE, and cannot be used elsewhere.

Based on the envisaged use situations, there are resources necessary in order to construct a SE, but this also applies the other way round: if the resources are available; what are the possibilities to realise a SE with them.

The next sections in this chapter will first discuss the integration and adaptation of the available resources. Selecting the most optimal tool is a constant trade-off between what is available, and what should be made available. Furthermore, it handles the different forms of adaptation; a SE can be adapted to the available resources, or the resources can be adapted to the (desired) SE. Dependencies and causal relations help the developers of a SE to understand what the consequences of changes in the SE configuration are, and can improve the argumentation of certain decisions. This is followed up with a section discussing to what extend a SE can be tailored to the user.

Since the realisation of a SE shows similarities with configuration problems occurring during manufacturing (see section 2.3), the assumption is made that the expertise of manufacturing can be used for the benefit of SE development, and can perhaps be used as a foundation for the realisation of a SE. In this chapter the relation between a SE and manufacturing is further discussed.

\subsection{INTEGRATION AND ADAPTATION}

\subsubsection{INTERACTION}

One of the main characteristics of VR is the ability to modify and interact with a non-real environment. Being able to manipulate the content of this virtual environment is part of the feeling of being immersed, rather than being a spectator (Bowman \& McMahan, 2007). This is essential to achieve the feeling that the SE (which incorporates VR tools) acts as a tool specifically for the actual user, instead of providing a predefined settings to which the user has to adjust. Especially with the use of virtual elements in a SE, not only encountering the output of the SE realises immersion, also enabling input and interaction is essential to perceive a strong relation between the real world and the virtual world. The interaction possibilities for users are countless. A difference can be made between purposeful interactions (active operation), and the interactions the user itself is unaware of. The latter category contains interactions that for example result from the detection or recognition of certain activities by the user (like head tracking or emotion recognition), or by external interventions in the simulation.

Because SEs are a tool for the designer and developer, there is a clear need for adequate input and interaction. The tool should support and facilitate the user during an activity; additionally, it should adopt and respond to the needs of the user. A SE in itself will not make any decisions, nor will it create content if no input is provided (Damgrave, Lutters, \& Van Houten, 2013). Even automatically generated solutions are triggered by an anticipated 
or pre-programmed activity or status (by the user or even by the creator of the tool). In order to obtain any kind of (desirable) output, the user of the system has to interact with the information provided in order to modify it or respond to it. To get a more usable and predictable output, the user should be able to observe predictable reactions of the system, in order to understand the possibilities and variabilities (Becker, Salvatore, \& Zirpoli, 2005).

In VR, often the focus is on physical interactions with a device (Peltonen, Kurvinen et al., 2008), while this is only one of the possible enablers to modify a certain parameter of the experienced data. Other options are for example the change of parameters based on environmental changes, such as changes in temperature, time or even the heartrate of the user. The experience is also altered by interpreting or changing digital data by the system itself, or changes to the context. In a SE these other elements that influence the visualisation or simulation are explicitly taken into account (Miedema, 2010). Over the past years, interaction possibilities have extensively been researched and developed. A key element to a successful SE is having multiple stimuli of senses simultaneously (see section 2.2). This combination of multiple interaction elements, and the effective stimulation of different senses provides a more natural interaction with a SE, and as such a lower threshold for use. To enhance this, during the development of a SE, information has to be acquired to know what kind of interaction fits to the desired experience and the capabilities of the user.

During the configuration of a SE, selections have to be made regarding the interaction possibilities. Since this is depending on multiple aspects, such as the (expertise of) the user, the context and the available resources, no standard advice on this can be given. To support this process, more insight should be available about the relation between the interaction elements and the results of the eventual SE.

\subsubsection{DATA}

Data and information are two different terms, which are related to each other. Data is a raw value and by itself and has no meaning. Information is data that has been given meaning by placing it in a context. This meaning can be useful, but does not have to be, since in a different context the information may be different. The meaning of the information also depends on the viewer and the reason for viewing.

Every SE has the goal to combine data, compiled from multiple sources, into one environment (Bruno, Caruso et al., 2006) to work toward providing information. This immediately highlights the - possibly never ending - issue of handling different data formats. A SE will not alter the original data before being able to use it, since a SE itself will not make the decision to change data, this is an outcome of the use of a SE. If data is already altered before use, it will be more difficult to undo the use of a SE. Neither will a SE make a copy of the available data, because this will lead to a situation that there is no guarantee that the latest version of the data is used. The intent of working with multiple people in one SE is that the data is extracted in real time from the available sources, so that any change of data - inside or outside the SE - is directly visible in the information provided to the users. To prevent errors with version management, any SE should preferably work with primary data sources.

For a SE, there are two types of sources that provide data. Firstly the user (on site) who has a certain interaction with the information, and consequently the data, provided by the SE (and thus already available in the SE). This is a direct individual manipulation of information based on existing data. Secondly, any SE utilises digital data that previously has been stored in other systems. The SE will be selective in the use of this data, based on the desired 


\section{Part I}

functionality. This data includes textual, graphical or model information (see chapter 2.2). Where necessary, this data will be translated without the specific request from the user. A major obstacle with digital data is the variety of digital systems. This varies greatly in both $2 \mathrm{D}$ and $3 \mathrm{D}$ systems; almost none of the data is plainly interchangeable between different software solutions (see chapter 3.3). Consequently, a lot of effort is needed to convert the data between different software solutions without loss of data.

Therefore unconsciously many limitations and requirements are already applied to the possible SE in a very early moment of time, often without clear criteria of how this data will be used in the complete lifecycle of the project. The functionality of the SE is greatly dependent on the available data; but contrary the generated data from the SE must again be directly useful for other phases of the process.

The data generated (and already available) in the PDP is the foundation of a SE. The SE functions as a portal to access this data and to put it in context. Navigating through different data sources, and finding the right data is part of the SE development process. Eventually, the SE makes a translation of data into information, therefore, the system must know which data is available, and what information is desired (at that moment). The selection of interaction possibilities is based on what data should be made understandable to the users of the SE, and what parameters may be changed during the use of the SE.

\subsubsection{ADAPTABILITY}

During the development of a SE concessions have to be made regarding the resources that will be needed for the SE. Often this result in choosing between two options: adapt the SE to the available resources, or adapt the resources to the (desired) SE. It is important to know what is relevant at that time for that specific user; the responsibility for this decision must remain with the user, not with the system. Therefore the user has to have insight in the consequences the decision has for the adaptability of the SE.

During the early stages of the development of a SE, not all requirements and specifications for the SE are already known. Even though, at that moment the development of the SE should start in order to collect those requirements and specifications. At a certain moment the first delineations will be made, which will influence the functionality of the SE. If the SE can be adapted at a later stage with little effort, the significance of the decisions in the early phases will be little, and will therefore be easier to make. This does require a certain degree of adaptability in the final SE. In the early stages of product development, the stakeholders want to predefine as little as possible in the way of working. Therefore, it is important that the solution can be adapted (to a certain degree) to the use. This adaptive behaviour ensures that over time the solution can be disposed of unnecessary elements. In addition, that offers the possibility to use the same tools across multiple projects; as long as the adjustment does not require too much resources (e.g. time and costs). VR has the potential to be adaptable; but it is however important to know what the effects of these adjustments are (see section 3.2). The composition of various components determines the functionality, but also the necessary information required to work. This reciprocity between functionality and required data determines the boundaries of adaptability.

To support all envisaged stakeholders, the system cannot rely on the characteristics of individual or specific users. Consequently, not every user sees the same information, nor in the same way. Different users also have to be presented with different interaction or customisation options. During the use of a SE the assessed experience has to be monitored constantly to the expected experience (see section 2.2.4). This information is needed to 
tailor the SE better for the current stakeholder. There is a limit in the adaptability of a SE, this limit can be set by multiple criteria, such as:

- Technological possibilities

- Costs

- Time

- Available data

- Available (human) resources

- ....

With every change of the SE the appraisal has to be made whether to adjust the SE to the expected experience, or to change the expected experience (and thereby indirect the user). In some cases it is more beneficial to alter the expectations of the user, the method of use or the available data, rather than adjusting the functionality of the SE. A critical element in this appraisal is the difficulty in understanding each other's perspectives (of different stakeholders) on the solution, and acknowledging the interdependencies between stakeholders. Therefore, the interdependencies and causal relations between elements that form a SE should be made visible, that way each stakeholder can see what the consequences of a decision will be for the other stakeholders.

\subsection{DEPENDENCIES OF, AND CAUSAL RELATIONS BETWEEN ELEMENTS}

Each SE is composed of several elements that work together. It is the cooperation between these different systems that allows a SE to be more than just a combination of separate elements. Complexity in the development of a SE arises due to the intertwined relationships between the different elements and their requirements to the system. Especially the observation that relations between resources are dependent on the specifics of the SE in which they co-occur, add to the complexity of combining separate elements. For the realisation of a SE, it is primarily of interest to know to what extent systems depend on each other, and the extent to which they influence each other. To make the development of a SE a process with less unpredictable outcomes and less random events, all critical knowledge gaps must be located and closed at the earliest possible moment (Gustafsson, Raudberget, \& Ström, 2016). If the components reinforce each other, in fact a combined system can also be more than one combination of separate systems, real synergy can be achieved. And a SE is only interesting if the output is more than the sum of the inputs. The influence different systems have on each other are not always clear in advance, and are also sometimes not able to be controlled completely. In the selection of elements that will form a SE the focus is primarily on inter-linkages; rather than on the specific individual tools. Through taken this relationship also in consideration during the configuration, more insight can be provided into the adaptability of the solution. In the longer term it may therefore be possible to deal more efficiently and effectively with available resources, since the maximum flexibility is distinguishable from each combination of elements.

Since any event can have an infinity of possible causes, some support is desirable during the realisation of a SE configuration. According to (Hanafy \& ElMaraghy, 2014), Bayesian networks can be used to design (complex) product together with multiple stakeholders. The process of designing new tools can be divided in two known domains: analysis and synthesis. The analysis domain is aimed on decomposing the solution into smaller parts that are easier to understand and manage. Synthesis conversely integrates the smaller parts into one bigger whole that performs a certain functionality. Bayesian networks are an 
acyclic graph representation of the relations between elements, and can be used to describe the uncertainty of a configuration (figure 3.1). The nodes (vertices) describe the propositions or events, and the edges (arcs) describe the relations between them. The direction of the edge indicates the causal relationship between different events, however, this is not a necessity. The root(s) of the graph have variables that show how often they occur. Each node is associated with a probability function, which estimates what the chances are that the associated events occur, given the different possible configurations of their parents.

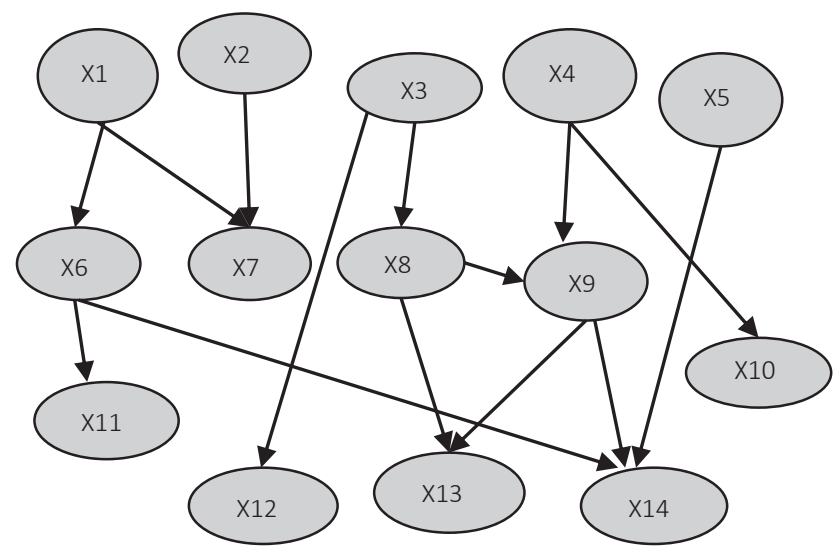

Figure 3.1 | A Bayesian network example, redrawn from (Hanafy \& ElMaraghy, 2014)

The Bayesian network can be built in one of the two ways; based on expert knowledge or on available data. With this overview the relations between individual elements can be visualised at every stage of the development (Abramovici \& Lindner, 2013). This allows the design of a SE to start on both the complete solution side (synthesis), as on the individual part level (analysis).

Also in the field of 'engineering change management' many research can be found that handle these configuration problems. (Gustafsson, Raudberget, \& Ström, 2016) describes an example of a causal diagram that shows four kinds of information (figure 3.2):

- Properties that characterise the products (square boxes)

- Interaction between the properties (lines between the boxes)

- The causality of each interaction (arrows at the end of the lines)

- The nature of each interaction (a plus or minus sign on each line)

These causal diagrams are a well-known framework for visualising the important dependencies between attributes that form a solution. While these examples mainly focus on the relation between the different attributes, they often do not incorporate the stakeholders or users as an element. Research into actor networks (Lange, Oude Luttikhuis, \& Lutters, 2014; Lutters, Dankers et al., 2014), also integrate the dependencies and relations between the stakeholders involved in the solution. This is essential for a SE, as it incorporates users all the time. Formulating the desires of these stakeholders, in relation to what element will enable that, provide for more grip on the solution. While setting the requirements for a SE, it is therefore important to steer on the causes and deal with the effect. As such, the followed route should be assessed, instead of prescribing the process. Reflecting on this progress can prevent falling in the same pitfalls multiple times. In addition, research in 
production preparation has much experience in dealing with the adaptability of physical environments, especially in the field of factory layout and process planning. This involves finding the most optimal configuration of physical elements. For a SE this knowledge can be important, a SE also has a physical element; it can be approached as a workshop with shared tools. In section 3.4 and section 3.5 more detail on the approach from that field will be discussed, and how these methods deal with the trade-offs between the adaptation of the process and adjustment of the tools.

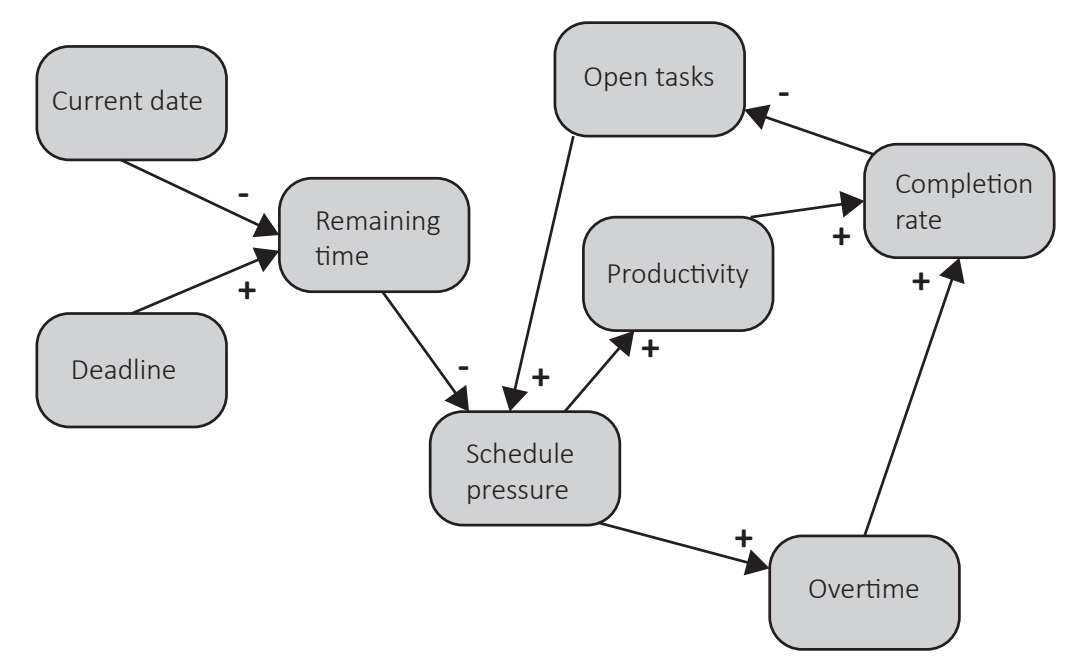

Figure 3.2 | An example of a causal diagram as an illustrative example

\subsection{FEASIBILITY AND FITNESS FOR USE}

Implementing a SE in a design or development process requires a well-thought and underpinned approach. A SE is treated as tools or enabler for the employees, and should thereby support or facilitate the process and activities of those employees. This implies that multiple stakeholders (of one or more companies) can be involved in the use of that SE (Garcia, Kunz et al., 2004), and that consequently the use of the SE should be an integrated element of the design or development process (Germani, Mengoni, \& Peruzzini, 2012). These implementation challenges should be considered during the development of the SE itself.

The degree of adaptability of a SE may be determined to a large extent during the design and configuration of the SE. Each stakeholder will have a different desirable degree of adaptability and fitness for use; a user that only works once with the SE can find it totally irrelevant to have any form of adaptability in the system. While this can be for a company that owns several SEs be of the utmost importance. In addition to the degree of adaptability, the manner of adaptability is also something to steer on during the development. Up to a certain level, a system can be self-learning, whereby the adjustments can largely be automated. Experience shows that these complex systems are more difficult in development, and often require a larger initial investment. For the stakeholders of a SE it is especially important to know when it is necessary to make adjustments to the SE. The goal is always to strive for the most appropriate solution. This immediately gives a damping factor; it is not the goal to develop a best solution in a single criteria (such as the most usage scenarios, the most affordable, the highest resolution or the least number of parts). These criteria must be in balance; so that the SE for all stakeholders together provides the 
best solution. The best solution will therefore be different for each stakeholder, and the rationale for certain decisions will therefore have to be expressed in the resulting quality for each individual stakeholder. The result of best solutions on an individual level should be combined in one solution that will form the most appropriate (and therefore tailored) solution. The design rationale is the main reason to select a certain approach. Why things are not done is more important that why things are done.

To give a value judgment to what extent something is fit for use, and being able to communicate this, existing techniques like quality functional deployment (QFD) can be utilised (Akao, 2004; Falk \& Schmitt, 2014; Moubachir \& Bouami, 2015). The QFD is a successful method often used in the product design process, often in combination with the use of the House of Quality, to translate the costumer's requirements into design specifications. For the development of a SE, it is desirable to work with knowledge rules (Chou, Lin, \& Chun, 2014), these can be defined with the aid of the above mentioned techniques. The knowledge rules can be used to explain the need for certain functions, and how they relate to the available knowledge. This makes it possible to automate parts of processes and thus to optimise the solution. This is directly in line with making the distinction between the expected experience (expected degree of fitness for use), and the assessed experience (experienced degree of fitness for use). Formulating knowledge rules for the desired solutions are essential, but remain very difficult and require a certain hierarchy or ontology, this will be further described in chapter 4 .

\subsection{SE AS A FACTORY ENVIRONMENT}

A Synthetic Environment can be seen as a kind of ecosphere. As is the case for every ecosphere, a SE relies on the stability of the structure, content, internal as well as external interactions and the scope of events taking place in it. From a broader perspective, the same circumstances apply for multiple domains in the manufacturing environment, regarding layout, planning and logistics. In product development, the similarities between factory layout activities and establishing a SE are striking, although the type of resources addressed is quite dissimilar. This section addresses these similarities, aiming at rendering well-known and established working methods in factory layout and process planning instrumental for developing Synthetic Environments.

As a SE acts as an enabler for the product developer, the adaptability to existing (or available) resources is extremely relevant, since in a PDP multiple design tools will be used. These often use the output of previous used design tools and realise input for upcoming design tools. In essence, this is a configuration problem, which has many parallels in factory layout. By comparing the evolvement of the manufacturing industry of the last century to the evolvement of the way in which VR solutions are currently developed some remarkable similarities emerge. For example, current VR equipment still requires a high level of craftsmanship to achieve the optimal results (chapter 2), and often equipment is specially build for a dedicated process or project (section 3.1). This accords to the artisanship observed in the manufacturing industry before the industrial revolution. After this revolution, the manufacturing industry experienced a turnaround in which more generic production equipment were used in a structured configuration. For the foreseeable future of VR developments, a well-nigh identical turnaround is almost demonstrable. This implies that identifying the pitfalls, dead ends and challenges that have been encountered in the evolution of the manufacturing environment over the last decades can be helpful in preventing comparable issues in VR development. With this, development of SEs can become faster, more effective and more efficient. (Damgrave, Lutters, \& Drukker, 2014). 
The purpose of a manufacturing process has never changed over all these years: effectively and efficiently employ processes and resources to realise products that are in alignment with the product definition as established by the designer. As concerns possibilities, flexibility and efficiency, the main advancements that have been realised over the years follow from adequately integrating different production methods and tools in a more efficient and more intelligent way. Simultaneously, quite some vulnerabilities and pitfalls within production environments have been identified. More often than not, such inadequacies have a direct relation to the preparatory processes rather than to the production processes themselves. Commonly, there is a misalignment between what designers conceive possible and what is actually feasible. This stresses the need for close cooperation between the design, process planning and manufacturing departments. Such cooperation concurrently aims at early assessment of design decisions as well as at bringing manufacturing knowledge and abilities to the design stage (Chandrasegaran, Ramani et al., 2013).

In considering SEs as a kind of workshop where processes, resources, intentions, capabilities and capacities come together, the similarity with the manufacturing environment are obvious. This not only yields true for the more traditional production environments, also developments in reconfigurable manufacturing systems (Koren, Heisel et al., 1999; Mehrabi, Ulsoy, \& Koren, 2000) can be compared to how several VR tools can be combined in specific clusters to work towards a pre-defined end result, and allow for opportunities not possible with individual tools. At the same time, this implementation of several VR tools within a single process is still in its infancy, and the consequences of adaption in existing design methods is not predictable enough. Nevertheless, given the experiences in reconfigurable manufacturing systems, the developments in VR can certainly be accelerated.

This process of developing a SE is similar to the way in which physical products are designed in general product development processes. At a given moment the developers will start making a planning of the manufacturing process of the SE. In this process planning (Chryssolouris, Chan, \& Suh, 1985) there is also the aim to predict the future (i.e., the production of the product) as good as possible, and as completely as possible, in order to bring all the preconditions of the reality into consideration.

\subsubsection{ENVIRONMENT}

Obviously, there is no such thing as a standard production environment. Neither is there a standard SE. At the same time, there is no reason to deny or neglect approaches, processes or methods that clearly find an application in a variety of environments. A production environment generally consists of the combination of different production stations in a shared environment. Next to the capacities and capabilities of the individual resources, it is especially the combination and arrangement of tools that determines the possibilities within the facility. The production planning determines the scheduled routing, and sets the requirements to the stations. Each stations should perform (a) specific step(s) in the production process. The different parts that together form a manufacturing process, are related to the function and control, or can be described based on a large number of terms. The establishment of these terms is mainly based on the functional specification of the tool and the description needed by the designer. Partly thanks to this terminology, it is possible to specify any production process using the same set of terms. This enables developers to communicate about production facilities in an organised matter. The terminology visualised in figure 3.3 is relevant in this comparison of processes. 


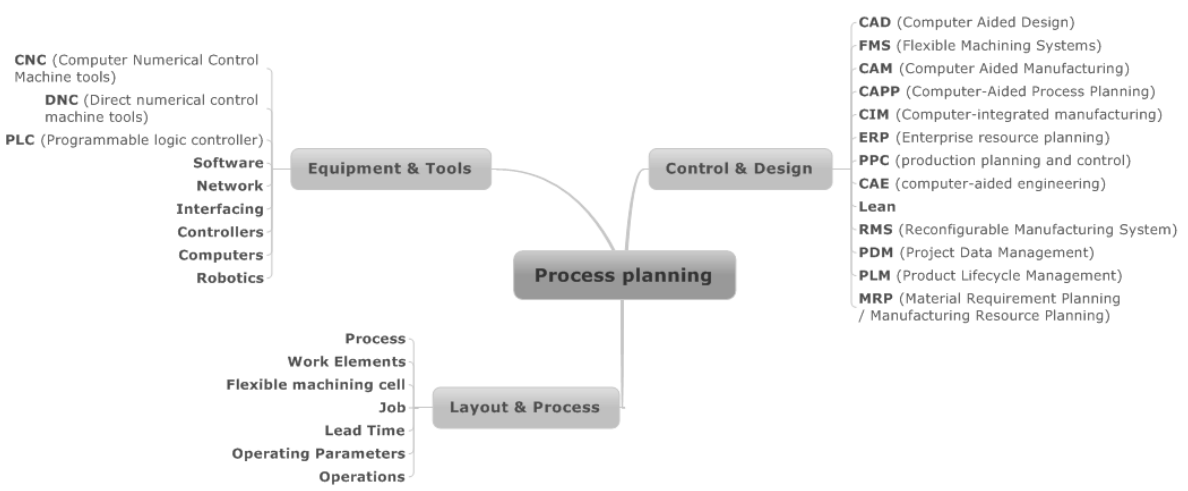

Figure 3.3 | Example terminology in manufacturing (Damgrave, Lutters, \& Drukker, 2014)

Compared to manufacturing environments, SEs are even less standard(ised) environments, due to the broad scope of available tools, and the non-generic origin of most tools. Moreover, the tradition and history that underlies the available tools vouches for the lack of standardisation in these tools. But also the ignorance of the available possibilities of VR for the developer and the lack of standardised methods for combining equipment plays a significant role. This makes combining tools/equipment even more challenging than in manufacturing environments. Basically, this strengthens the importance of adequate 'process planning' for SEs.

In the vast majority of VR tools, the use of the tool is exactly defined by the manufacturer of the tool. The tools only provide benefit for a limited number of potential scenarios. An example of such tool is a CAVE (Cruz-Neira, Sandin et al., 1992). This multiple-sided projection cubicle only functions optimal if the content and context of use are perfectly aligned with the specifications set by the manufacturer. Originating from the development of a single and stand-alone tool, which is not directly related to other available equipment, the manufacturer proposed $a$, at that moment and situation ideal, working method. This results in a predefined process on how to use the tool. In the example of the CAVE this results in a solution aimed on providing an immersive experience to a single user, in a fixed physical location. The dimensions of this physical setup cannot be changed; the content and users have to adjust to this specification. In the underpinning for purchasing the equipment this working method is the only available integration example to base the decision on. Integrating a tool this way has the consequence that the pre-defined working method is implemented without any adjustment, and if the integration succeeds there is no need or willingness to explore further possibilities.

The same phenomenon has been visible within manufacturing environments, where in the first half of the twentieth century rigid production machinery was only used to fulfil one specific task. The machinery was designed to acquire the highest efficiency based on performing a single task, and combining multiple machines was needed to integrate multiple production steps in a manufacturing process. This is in great contrast to modern (flexible) production environments, where each machine can be programmed to perform a large selection of tasks (Carpanzano \& Jovane, 2007). The biggest difference with VR is that manufacturing equipment lacks an 'undo' function; with every production step, the material is irreversibly processed. In VR, the base material is never destroyed, and every process step can iteratively or repeatedly act on the same input. This does not imply that a specific user will be able to relive the same 'new' experience in an 'updated attempt'. All 
the added value in VR tools are additions to a base set of information; and there is always the option to go back to that state; more specifically: this can be done without destroying significant investments. This also enables the developers to try-out multiple actions simultaneously and compare the results to select the best option. Even in a number of combined tools the effect that the different tools have on each other can be researched, e.g. if a manipulation on the data is done on step 1, how much effect will that have on step 4. In a factory layout this undo-function is not present; and therefore more requirements are fixed, to secure a certain result.

\subsubsection{PROCESS PLANNING}

In the comparison between a factory layout (Seidel \& Arndt, 1988) and the way a SE can be handled some resemblances can be resolved which can indicate similarities in the planning and configuration approach. First both are (single) environments in which a collection of devices enables a specific process. In addition, the possibilities are directly related to its composition, and possibly even positioning, of the tools. This configuration directly depends on the schedule and the strategy of use; the desired end result dictates the sequence in which the tools should operate (Zhang \& Merchant, 1993). Planning this sequence is based on a translation and breakdown of each part of the product into possible manufacturing methods. Within process planning, the reliability is greatly improved over the years by implementing a better translation of product requirements to machine capabilities. Automated transition from design to process planning have also contributed to this (Boogert, 1994; Erve, 1988; Ham \& Lu, 1988; Houten, 1991). The risk of automating transition processes is that any choice in the design will directly affect the production. Thus it may be that a designer underestimated the impact of a design choice as there is theoretically more possible than the available or existing environment can offer. Unnecessary costs can be made as too accurate and literal translations from design to product are made, and new tools may be required for a design detail which is not accounted for such an investment. This occurs most often with parts of a product which doesn't have an important role in the usage or design. For example the shape of an internal ventilation hole inside the product. This shape is not related the use or the visual shape of the product, so the designer can only provide a functional specification for it (in terms of area for example). But during the drawings of the CAD files the designer has to make the decision of the geometry and material, although it should be completely dependent on what the easiest and cheapest option is based on the production line of the future product (which is not determined yet).

Not only in terms of specifications and reasoning comparisons between SE and manufacturing are allowed to be drawn. Also the layout of a SE can be considered as a manufacturing environment. In a SE the structure and configuration of the tools is not bound to a fixed setting. Depending on the wishes and demands of the user at a specific moment, the tools can perform a required task in a certain order. In this setting, the different parts of the SE directly relate to the terminology and configuration of a factory layout or job shop. Each process in the SE consists of a number of tools that together allow for fulfilling multiple purposes. The combination and configuration of these individual tools, or the complete process, can be changed with little effort. This implies that the use of a specific process (and tool) can be adjusted to the need of the user at that moment. With every change, the consideration has to be made if the process or the tools must be changed.

The terminology used in manufacturing processes is mainly based on functional capabilities of a process, or to describe the process of realising a product. Hence, it can also be possible to use this terminology for a SE. The goal of both environments is in fact the same; realising 
the ideas of the developers and designers. A SE should be based on the means that are at our disposal at this moment; in case new options appear, first the complete setting has to be reviewed - something that is definitely more cumbersome in manufacturing environments.

\subsection{INDUSTRIAL REVOLUTIONS AND THE IMPLICATIONS FOR VR}

The industrial revolution led to other use (and acceptance) of technology; and can be seen as a major overhaul in the way of thinking about the role of technology in manufacturing. The same change of technology can be recognised in VR, the indicators that this change can happen should be recognised in order to predict and encourage this change (Damgrave, Lutters, \& Drukker, 2014). Based on reflecting how manufacturing coped with these changes, a better forecast of consequences of upcoming changes can be made. For this reason, a short overview of the main changes in the industrial revolutions are depicted here.

\subsubsection{INDUSTRIAL REVOLUTIONS}

Since roughly the second half of the 18th century, three technological revolutions have taken place. The first one introduced the use of steam engines in large scale industries. Furthermore, the increased use of cast iron resulted in the ability to build larger constructions, composed of standardised parts. Larger factories arose, where the production process was characterised by division of labour and specialisation, and so, ousted the craft-type workshops. With both the increased need, and manufacturing possibilities for transport, national and international transport was undergoing revolutionary changes with the advent of railways and ocean liners.

The second technological revolution took place at the end of the 19th century. The most conspicuous technological breakthroughs have been the development of the internal combustion engine, the use of electricity as an energy carrier and revolutionary innovations in the field of chemistry. The use of new construction techniques in building, such as concrete and steel framing, opened up the possibility of unprecedented high building, while sewage systems, purified water and electricity improved the formerly poor living conditions in the cities. The technical revolution led to a turnaround in which more generic production equipment were used in a structured configuration. As a consequence, less artisan staff was required to operate the machinery, and machinery could be used to produce multiple products depending on the configuration. This led to the introduction of e.g. the assembly line by Ford in 1913.

The third technological revolution can be summarised as "the digital revolution in information sciences". The development of new materials and the implementation of automated production processes are all part of this revolution. The ability to make extreme miniaturization of products, especially electronic components, leads to making, what was used to be high-end, technology available to every person (Drukker, 2009). In the current revolution, 'Industry 4.0', the focus is mainly on autonomous systems with decentralised decision making (Oin, Liu, \& Grosvenor, 2016), and less on the direct physical interaction with devices. Together with the upcoming connectivity of devices to the internet (internet of things), this revolution is often characterised as cyber-physical systems (I. Horváth, 2014).

The main observation from these revolutions is that it is striking that not only the technology itself changed, but foremost its contextualisation in organisations and society. As such, the technological changes have been the catalysts for the real changes. 


\subsubsection{CHRONOLOGY}

In order to create a chronological overview of the developments with in production processes, the available terminology can be placed at the time when the term originated on a timeline of the last century, see figure 3.4. Next to this timeline of manufacturing terminology, a timeline of developments in VR is placed. With use of this overview, relations can be drawn between different occurrences. It is visible that developments in VR can be related to what already has been found in manufacturing, with of course a delay of some decennia. The sequence of origin of some processes can sometimes even be directly compared, for example the transition of craftsmanship to assembly line to flexible manufacturing. This sequence of processes is also visible in the VR industry; from craftsmanship to CAVE to Cloud Computing.

Comparing the past and current use of manufacturing systems with the way in which VR is currently used, some remarkable similarities come to light. This starts with the combination of multiple separate production tools which are initially dedicated to a specific task. In the early twentieth century the production possibilities and the quality of products was highly dependent on the skill of the employee, only a craftsmen was able to make complex products, and often the craftsmen was also the designer of the product (design while manufacturing). In VR the same was visible with the first available computer supported tools for designers. Only experts knew how to use it, and the use of the tool often had large consequences for the design, both as concerns the process and the outcome (Houten, 1991). In this situation, the computer expert becomes an important stakeholder in the design and development process, which could also mean that the designer has to perform an additional translation step in the development process.

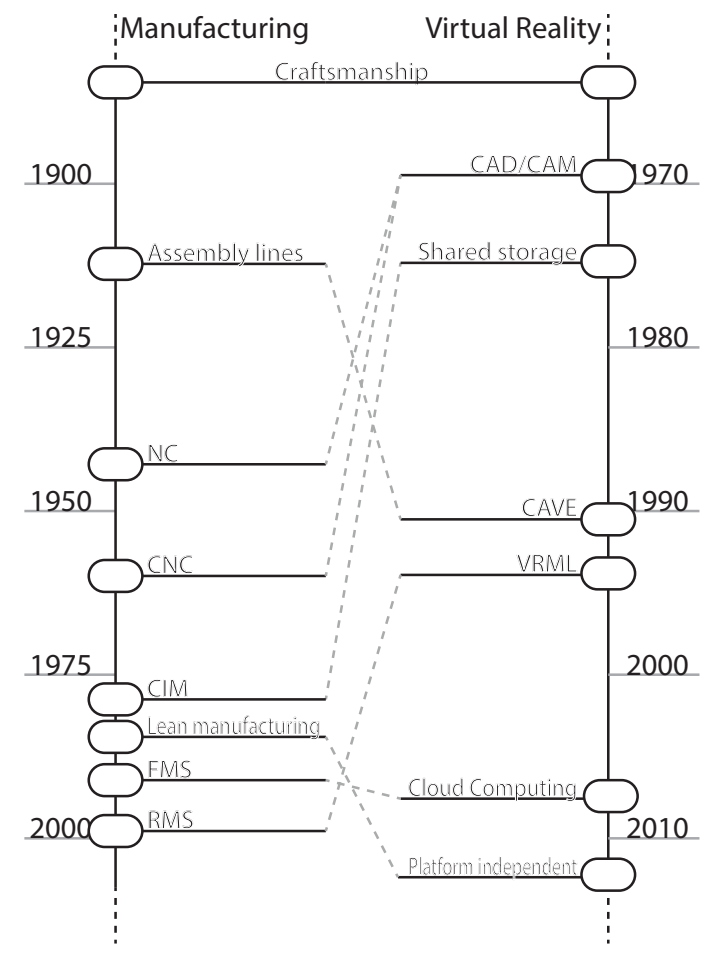

Figure 3.4 | Timeline of Manufacturing and VR (Damgrave, Lutters, \& Drukker, 2014) 
With the introduction of automated machinery in manufacturing, the physical labour became lighter, but the use of the machines still required extensive expertise. Due to the introduction of machines made to perform only one specific type of task, it became possible to use lower skilled people to operate the machinery, while simultaneously production numbers increased and production costs decreased. Also, the quality of the delivered products became higher, more predictable and more consistent. However, at the same time, the flexibility of the tools decreased, and there was no or only little variation possible in the produced products. Because of this transition into a rigid, mechanistic process, the production costs decreased, which made it possible to fabricate products for a larger group of people. Adjusting each individual product to the wishes of the customer was, at that moment, not possible. The diversity of producible products was thereby very limited because the design was adapted to the possibilities of the functions of the available tools. And even those available tools had to be adjusted to the specific product being produced at that moment; specific parts of the machines had to be fabricated or changed if another product has to be produced. So not only the product itself had to be designed, but also the necessary tools needed to be able to produce the product using an automated process with unskilled people. Most designs had to be adjusted to these rules and limitations to fit to the available knowledge and equipment.

A similar event happened with the use of VR in development processes. For example the rigidity of a CAVE (Cruz-Neira, Sandin et al., 1992) visualises this issue in VR (see section 3.4.1). By more affordable and more powerful computers, the implementation of such equipment became more realistic. The possibility arose to automate specific actions using special software (e.g. CAD software) (McMahon \& Browne, 1993). With that, it was useful to integrate specially designed VR hardware in certain development processes to achieve benefits related to higher quality, increased predictability and more consistency. However, as was the case with the automated machinery, this came at the price of reduced flexibility and decreased variability of the solutions. Moreover, the available hardware and software also brought new limits and boundary conditions to the designer, resulting in adjustments of the design to the capabilities of the computer systems. For example, the available CAD/ CAM software was sometimes more limited in modelling capabilities as compared to what the production machines could actually produce. Even though the developments of CAD are still going on, most innovation steps are incremental and not radical (Horváth \& Vroom, 2015).

Within the use of VR a similar event occurred when for example the first motion capturing tools became available (figure 3.5). These specific tools made it possible to capture the movement of people in a pre-defined and limited (in size and location) environment. Because of these limitations, not all aspects of a design could be tested using VR, and the emphasis was on the testable aspects. Because only parts of a product could be tested, often, unjustified the assumption was made that test results of individual parts were also valid in the overall design.

The development of more generic tools that could perform a wide variety of actions, without too drastic adjustments, made it possible to allow designers and developers to have more variety in design - both in manufacturing and in VR. The transition into flexible production environments (Wiendahl, ElMaraghy et al., 2007) led to a major change in the development process. With the use of autonomous systems the conversion from design to production could be done easier and faster (EIMaraghy, 1993). This all led to a shortened development time, with multiple processes executed simultaneously. As a result, it is often unclear for the designer what process is responsible for each stage of production. 


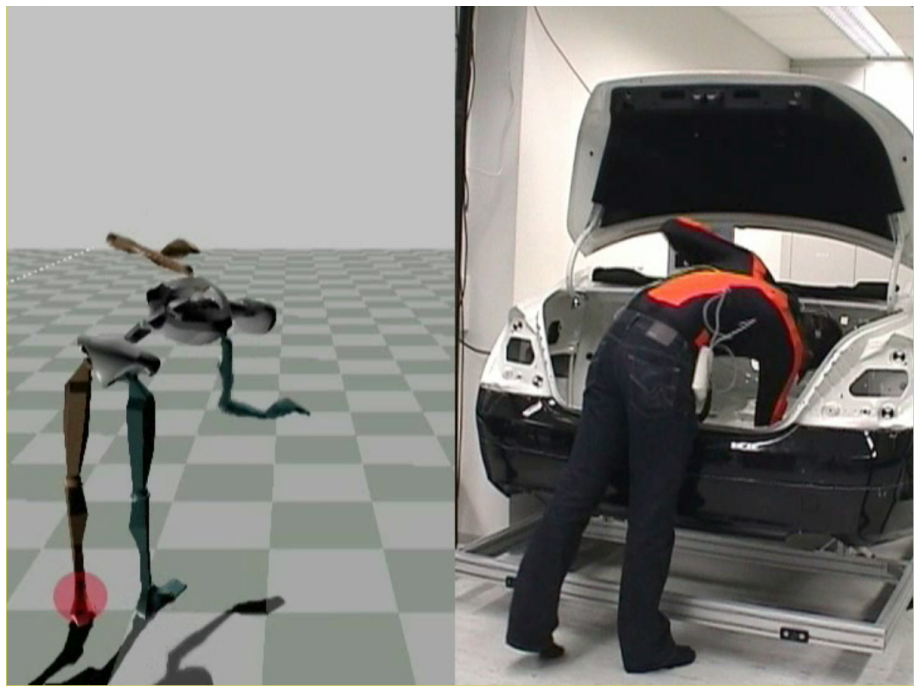

Figure 3.5 | Motion capturing example

Consequently, the designer has less control over the method of production, and thus is less able to possibly implement improvements in the design/definition of the product that will lead to production or other downstream benefits. These production environments seem extremely flexible, but in practice they offer just more rigid borders in which the designer has to manoeuvre within. The flexibility within these borders is high and is anticipated on this, but anything outside these borders is not taken into account. And only within these borders the designer has more freedom during the design and development phase. No extremely different approaches or designs are possible in the preconditions of this setting, and a kind of pseudo-flexibility is created. The result may be that the specifications of the borders defined within the available production processes are more important than the conditions and functionality of the final product. A similar effect is visible when new (VR) equipment is added to an existing PDP, without making clear connections with the input and output of other stages in the development lifecycle of the product. The risk occurs that VR equipment is handled as a separate entity within the PDP, and that the flexibility is limited within the boundaries of that specific tool. The output of the tool has to fit the input of the next phase, so without the adjustment of adjoining processes and the entire environment, not more flexibility is realised or created.

In the pursuit for a lean production environment (Womack, Jones, \& Roos, 1990), flexibility in itself is not enough. Within a flexible environment, there are always elements of a process or machine that are not used at a specific moment. In a lean production environment there should be an optimisation of products as well as processes; there should be a mutual adjustment, and the necessary tools, resources and techniques should be used most efficient with as little 'unused' as possible. The possibility to adjust the production process to fit the produced product is essential. This adaption creates an optimal way of producing, in which only the tools that are needed are available and are used, or could be reused at another site (Ziout, Azab et al., 2013). The aim for a lean environment in VR is something that is still in an early phase; this is mainly due to future perspectives on the usage of equipment. Within the manufacturing equipment, a (stand-alone) machine tool will function invariably over the years as long as the supplied material is the same. Within VR, the equipment often makes use of digital data created by other devices or stakeholders. These 
dependencies have the consequence that with future software updates compatibilities can be invalidated. Often this can be fixed by other software updates, which can lead to a snowball effect and does require higher hardware specifications due to new functionality. Therefore, the equipment is often over-specified at the implementation phase. The first clear signs of a lean VR environment were recognisable in the use of computer thin clients, which all utilise the capacity of a shared central server. In this situation the server can be used at its most efficient workload all the time, spread over a best fitting number of clients (Tang, Lee et al., 2011).

\subsubsection{PRACTICABILITY}

In order to make optimal use of the possibilities of a SE, currently, a lot of domain expertise is required for implementing the different steps and using the tools in the process. In other words, current VR equipment still requires a high level of craftsmanship to achieve the maximum results possible with the equipment. What the maximum result can be also depends on the desired goal of the current user, the limitations imposed by other stakeholders and what the expectations are. The same used to be true for production processes for a long time. Examining and comparing how the research and development in the field of process planning made the translation of a rigid environment to a reconfigurable manufacturing can be used to prevent fallen into the same pitfalls with SE. By making use of existing and tested systems from the production industry in VR, allows for a better integration of VR in the whole product development chain. This integration is improved by allowing the designer to use the best fitting tool for his purpose (Tolio, Sacco et al., 2013; Lutters, 2014), without the consideration if it should be a virtual or a mechanical process.

An example of a comparison between a VR setup and a manufacturing setup is the VR CAVE setup (Cruz-Neira, Sandin et al., 1992). A CAVE can be compared to early assembly lines, like introduced by Henry Ford in 1913. Such assembly lines are very consistent and efficient in producing one type of product. As long as each product on the line is exactly the same, there is a maximum efficiency achievable with the available combination of tools. Even more, the product and the production line can be fully adjusted to one another. In case a product that deviates from the standard specifications has to be produced, a lot of costs, time and energy have to be invested in the production/assembly line. The same can be said of a CAVE, which is also an environment specifically intended for performing a predefined process. Again, it is possible to optimise a CAVE against the type of product it is developed for. At the same time, a CAVE is flexible in the presented data and content, but the use possibilities are confined due to a number of very strict limitations, such as physical size, number of participants and location. To use the tool, a lot of preparation is needed, which is made by others than the intended user, and during the use experts should be available to support and improve the process, but for using the tools there is no expertise required. This results in a set of quite limited possibilities for the use of a CAVE. Due to the high investments, it is also difficult to justify such investments for only one purpose. This can lead to a solution that is enforced to be use in order to justify the investment.

Just as in manufacturing, new developments in VR offer new tools and techniques to improve, simplify or facilitate a certain part of the workload. Nevertheless, these developments often will not inherently impact the development process. This implies that only the content and execution of a single or multiple development phase will change, but that the overall steps in the whole process will remain the same. This is partly due to the fact that the development of many new tools is based on the currently used methodology, while there might be greater profit to be achieved by adapting to whole process to the new 
technologies. In other words, technology push may lead to local optimisation; obviously this is no guarantee for global optimisation.

Due to the major risks associated with adjusting a complete development process, there are few innovations that address this entire process. The combination of independent alterations in manufacturing led to a significantly different process over the years (Váncza, Monostori et al., 2011), in the development of VR the same is happening.

A designer often has the goal to design a product which has the least commitments in it; "Design by least commitment" (W. EIMaraghy, ElMaraghy et al., 2012; Suh, 1990). This allow for more freedom in the way of producing the product. Consequently, it will become more important to clearly define the main functional requirements and specifications of (parts of) the product, instead of the production process. In the development of a SE, functional requirement are more relevant for the end result than technical requirements (Miedema, 2010). By documenting this clearly, it is possible to define the final product as a 'solution'. These solutions are enabled and created using a combination of 'tools', which are built from multiple techniques (Damgrave, Lutters, \& Thalen, 2012), see section 4.1.

With the use of a SE, the accessible and available tools are not always known on beforehand, and also the layout is largely flexible. In addition, the modular environment offers the possibility to set up an alternative machine for each tool or technique. This allows for changing tools and techniques (which are part of the solution), without visible or noticeable consequences for the final product. This way, the production preparation is directly related and derived from the design. To stimulate and facilitate this flexible and reconfigurable integration of VR tools in the $\mathrm{SE}$, a real-time conversion from functional specification to practical implementation without a lot of preparation time is needed. The knowledge that is already available in the manufacturing industry can help speed up this process. Translating the fundamental way of thinking of these developments to how it should be applied for VR equipment, offers a good starting point to create an environment of virtual solutions that adopts to the preferred goal of the actual user in real-time (S. Jiang \& Nee, 2013).

\subsubsection{CONSEQUENCES}

Given the similarities between the development of manufacturing environments and the developments of SEs, there are clear reasons to base decisions in the development of new SEs on the experiences gained in manufacturing. This mainly focuses on the predictability of the process, the application, flexibility and agility of tools as well as on manufacturability analysis and the prevention of pitfalls.

By approaching the use of SEs in product development processes in the same way as the integration of the production process, some advantages can be obtained. For example, the best practices experienced in the developments in production can be translated to how that will influence the use of new VR tools. In addition, the possible pitfalls can be bypassed through addressing the reasoning behind the different phases of manufacturing. Furthermore, the results of analysing and reviewing the rationale of best practices in manufacturing developments, can provide information about the logical next steps in VR development.

Partially, the future vision of the use of VR can lean on the experiences gained in the field of process planning. Especially in the flexible and seamless integration of multiple tools with dependencies between them, a lot of developments are already available in the 


\section{Part I}

manufacturing industry. It can also give insight into the possible effects of implementing new techniques on beforehand. For this, it is important to discover similar steps already made in manufacturing. This can lower the threshold for using new technology, and could improve the justification of certain investments.

Another, not to be underestimated, possibility and advantage with the comparison is to prepare and anticipate on major alterations. These changes are not always predictable, but with the current high speed of tool development it is a necessity to quickly respond to these occurrences. Especially within VR, continuously new technology becomes available whose usefulness and integration within design processes is not obvious at the moment of introduction. Drawing a comparison between how the manufacturing industry handled, for example, the introduction of plastics can possibly predict what the impact of new technologies could be. At first, the introduction of plastics resulted in products which could be properly made easier into a mass product (e.g. injection moulding). Only after several decades the same material brought the ability to allow for extreme customised to the needs of the customer (e.g. 3D printing). These consequences remain unpredictable, but provide insight and consciousness in the broad scope of affects.

From the research in this chapter follows that in the development of a supporting system for SE-development, the knowledge and experience of manufacturing should not be neglected. It is likely that this information will lead to a more underpinned supporting architecture. 


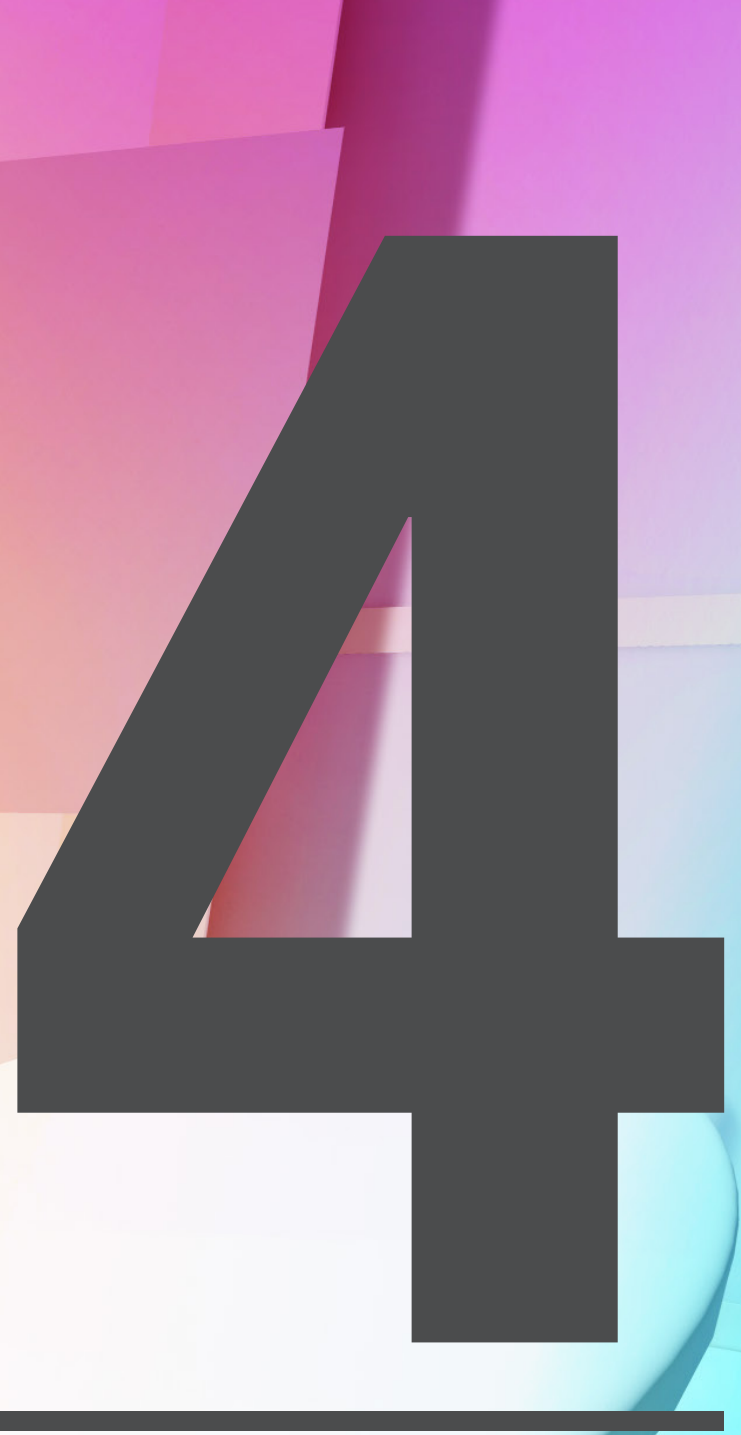

ARCHITECTURE ELEMENTS FOR SE DEVELOPMENT 


\section{ARCHITECTURE ELEMENTS FOR SE DEVELOPMENT}

This thesis works towards the realisation of a foundation (supporting architecture) on which a SE can be build. One of the main purposes of this architecture is underpinning the rationale of the decisions on which tools have to be integrated in the SE. This decision making process should be supported and facilitated by the architecture. To achieve this, the next sections discuss the properties of selecting and implementing the most appropriate tools, based on the requirements from the stakeholders.

The potential benefits of using Synthetic Environments during the entire product development cycle become more visible and accessible due to the better availability and increasing (best) practices, not only for large enterprises but mainly for SME. Due to the improved availability and increasing acceptance, also small and medium enterprises can see and access the potential benefits. There is an unstoppable flow of new VR related tools introduced on a daily basis; hundreds of companies develop techniques and tools that facilitate specific scenarios with VR (Chandrasegaran, Ramani et al., 2013; SangSu, Kiwook, \& Sang, 2015; Wiederhold, 2016), see figure 4.1 for an impression of the broad variety of VR tools. Often, these companies are specialised in, or even arise from, providing Virtual Reality techniques and tools for one specific, predefined, use environment (see section 3.4). Development of these techniques and tools is therefore frequently based on issues or requests from a small number of companies and addressing specific types of problems. This is not beneficial for the visibility and acceptance of a SE. The threshold for completely relying on a SE as an enabler for processes in the product development process is still high. Therefore, VR is often seen as an interesting and convenient addition to currently available tools and methods, but rarely has the lead role. This may be caused by the fact that current product development cycles often allow for flexibility in the approach and execution of the design process, and consequently require tools with predictable results based on non-static use conditions. Predictability is important in this, because that results in a lower threshold for changing systems. Due to the constantly increasing number of potential use situations, the development of VR tools to support designers has to focus on one of the following two directions (Lutters, Houten et al., 2014):

- Development of more specific tools: only usable in a pre-defined setting and with preconditions. Therefore, having a more predictable result and being easy to use, but requiring adaptations to the process and therefore long-term planning.

- Development of more generic tools: usable in multiple situations, without clear boundaries or requirements. Therefore, requiring VR expertise to select and adjust the tools to meet the desired goals. It is not necessary to plan the use of these tools at the start of a PDP.

Most available professional VR tools are specific to a narrow application area, and consequently influence only certain phases of the product development process. As a result, the potential market for those tools is small, and the price is high. Due to the constantly decreasing costs (Nee \& Ong, 2013) of VR equipment aimed at the consumer market, also smaller companies can take the risk of introducing new VR approaches, and consequently a $\mathrm{SE}$, in their processes. Subsequently, the necessity to know on beforehand exactly which SE is suitable for the upcoming process becomes less relevant (Damgrave, Lutters, \& Houten, 2013).

However, selecting and realising the best fitting SE is still mainly based on experience, and is often influenced by the results of previous use. The developments in the availability of VR equipment call for a new fundamental objective in the research field of SE. This chapter 


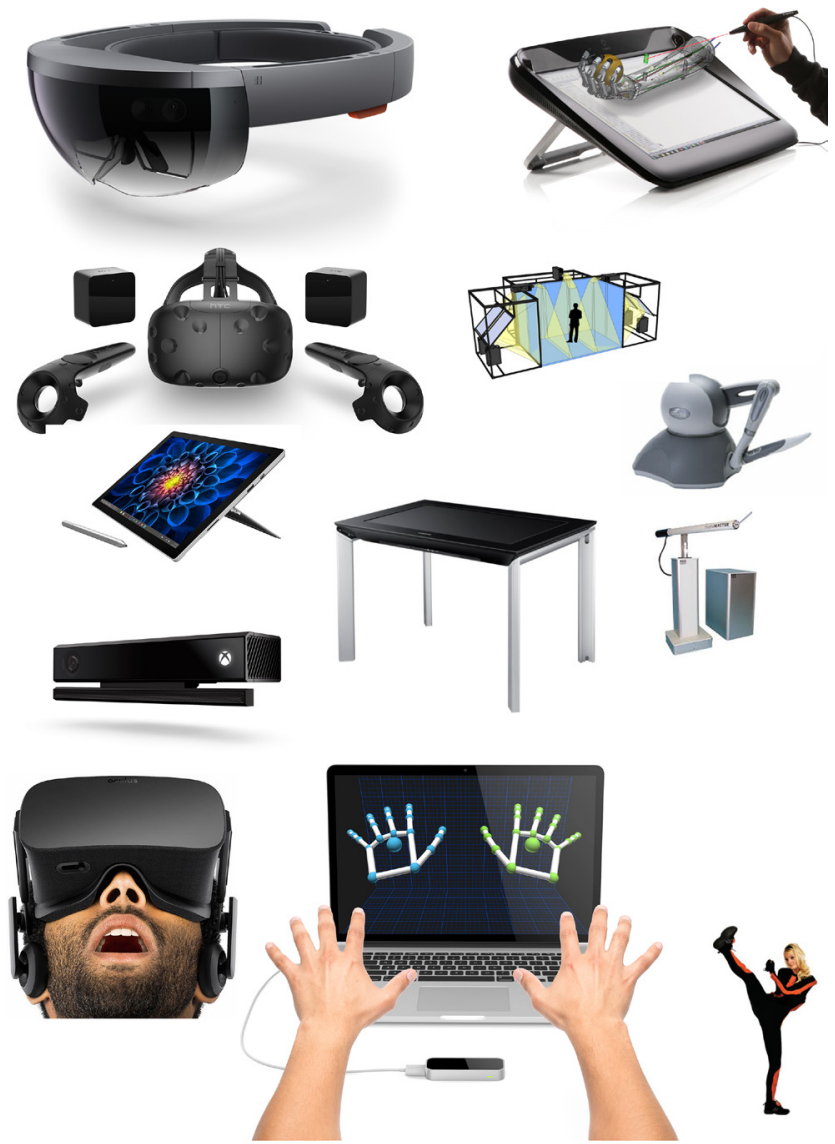

Figure 4.1 | Impression of the broad variety of VR tools

explains the desired functionality of a supporting and facilitating system, and the alongside requirements of it.

\subsection{S Selecting VR tOOls In RELATION With their USE CONTEXT}

Since the number of available tools and technologies for product development increases every day, the employment of the tools (as well as their underlying technologies) is embedded in the use context by means of working methods that make the tool applicable for the eventual users and purposeful for the development cycle in which it is used. Unfortunately, this frequently results in misalignments between the intended use and proposed working method by the manufacturer on the one hand, and the actual usage scenario as defined by the user on the other hand. More often than not, new tools are developed and introduced against the background of one specific use case or environment. With the implicit inscription of the use case or environment in the tool by the manufacturer, the alignment with other systems is not catered for (see section 2.3). Nor is interaction with those systems inherently allowed for. In looking at current developments in the field of VR, three categories can be distinguished, as illustrated in figure 4.2 (Damgrave, Lutters, \& Thalen, 2012): 
Part I

- Techniques; new techniques allow for new possibilities to acquire or present data.

- Tools: means to render techniques applicable in a specific Virtual Reality in a specific scenario.

- Solutions: a solution (Synthetic Environment) is a Virtual Reality facility that combines multiple tools.

At this stage a strict distinction between technologies fitting a certain level of virtuality, as described in the reality-virtuality continuum of Milgram (Milgram \& Kishino, 1994; Milgram, Takemura et al., 1995) (chapter 2.2.2), cannot be made anymore. The combination, implementation and use of selected tools define in what kind of mixed reality environment a selected tool will be used. This application area ranges from augmented reality (in which the real world is enhanced by virtual overlay techniques) to a virtual environment in which reality is completely replaced by a computer simulated environment.

The possible combinations of techniques, tools and solutions are myriad. This is all the more true with the advent of cheaper and easier to use tools and devices. As these tools enter the market as generic devices, sometimes even aimed at use by consumers, they are much more flexible because their functionality is less determined on beforehand.

Often, the combinations are created by trial-and-error or by (partially) copying combinations that proved to be successful earlier. Consequently, the results are hard to predict and difficult to implement in scenarios for future projects. Moreover, the investments related

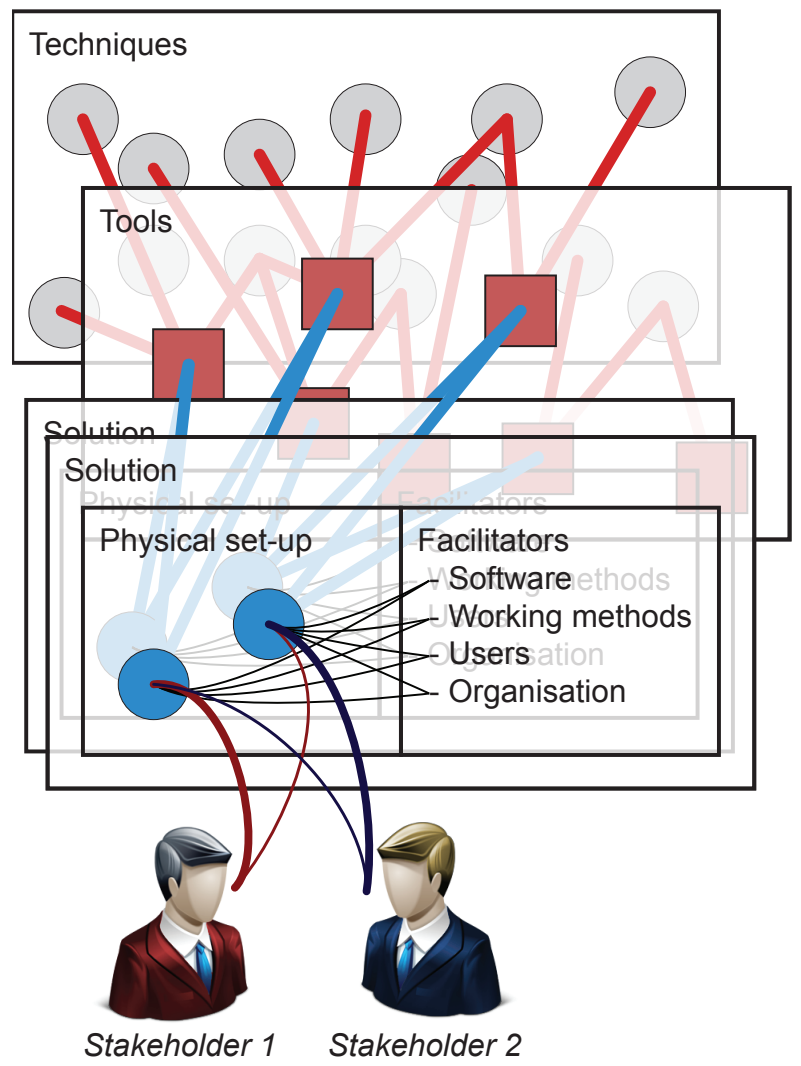

Figure 4.2 | Relation between techniques, tools and solutions (Damgrave, Lutters, \& Thalen, 2012). 
to implementing new VR tools are consequential. Not only does this influence the applicability of a SE for smaller companies, also the entire investment often can only be substantiated after the finish of the entire project. Consequentially, there is definitely a need for facilitation of development processes by a SE, but the step to indeed start using them is often too big, as adequate, reliable and accurate approaches for establishing SES while taking into account the perspectives of all stakeholders are lacking. A first attempt aims at bridging the gap between available VR techniques, tools and solutions and straightforward, structured and adequate use of a SE in product development processes. Pointedly, attention is on the earlier phases of product development, where ideas can still be rather vague, and investment decisions are even more difficult to justify.

\subsubsection{DeVelopment of ViRTual Reality tools, teChnioues and facilities}

Due to the fact that companies and developers have their own specialisation in certain areas, the consequence is that new Virtual Reality techniques are developed within the scope of that specific area. This approach leads to high quality new techniques of which the full use potential is initially not evident. Even multiple companies can develop the same type of technology with completely different starting points but resulting in the comparable VR techniques.

This approach results in tools and techniques that can support processes as long as they are in line with the proposed use environment of the manufacturer. If the eventual use context differs, the results of the VR facility might become unpredictable or erroneous.

The resulting challenge is to combine different, separately developed, techniques into a $\mathrm{SE}$, in such a way that their combination allows the end user to perceive a higher quality of results, as compared to the individual techniques. The same yields true for assembling a VR solution from the tools that are currently available inside, and perhaps even outside, the company. Recognising the full potential of certain techniques and tools, but especially of their combination is essential, yet extremely difficult. Best practices described in literature indicate that techniques and tools often excel in usage situations that completely differ from the one proposed by the manufacturer (Lee, 2008; Stowers, Hayes, \& Bainbridge-Smith, 2011). For example, tools for virtual clay modelling are successfully used for simulation of surgical procedures (Sanders, Luursema et al., 2006).

Techniques that have been developed for a specific, small, market have the risk to merely serve that niche market and to become investments that are hard to justify, especially for smaller companies. By finding new use situations and extending the potential market, the costs of purchase can be spread amongst multiple projects. Furthermore, the total costs of ownership of a SE are not limited to the purchase costs of the individual tools. They also include the costs of the necessary adjustments to existing tools and software to make the combinations work, and even the costs of adjusting the working methods and training the users should be taken into account. The total costs of the SE can be divided in the following part:

- Costs of purchase

- Costs of first use

- Costs of use

- Cost of maintenance/upgrading 


\subsubsection{SELECTION AND IMPLEMENTATION}

From a user perspective, a VR tool provides them with a solution for their problems. This is an incorrect assumption, because no VR tool will provide a solution on its own. A VR tool can only facilitate and stimulate the creation of possible solutions by the user of the tool. It might also be able to simulate the possible results of choices and guide the user in the process. It goes without saying that without a good integration in the process, VR will not by no means offer the best achievable result, or even offer results that are demonstrable applicable.

Merely the availability of a large collection of VR tools, and perhaps even experience in using them, is not enough to achieve adequate results from it. Nor does is give enough underpinning for selecting the most suitable tool(s). Every usage of a tool should be in line with the current state of the product development process. However, even the alignment of the tools and the process is not enough to make a well-considered choice on the available tools and how they can facilitate the process. Without a reference framework or a collection of best practices, it is extremely difficult to select the appropriate set of techniques, tools and solutions. A tool in itself cannot be identified as a solution without knowing at what stage of the process the tool will be used, by what users, in combination with what other tools, making use of what working method, and what all the further requirements of the possible VR solution are. This also includes the use environment and the number of, and backgrounds of, the stakeholders. Stated differently, a framework is required that brings together a requirement specification for applying VR techniques, tools and solutions as well as means of combining them and the required facilitation in a product development process.

In order to make optimal use of the combination of VR tools that form a SE, (at least) the following aspects should be taken into account, and should also be reflected in the composite approach (Damgrave, Lutters, \& Van Houten, 2013).

- Hardware

- Software

- User

- Environment

- Information

- Knowledge

- Methodology

- Resources

- Working methods

These nine aspects of a SE are carried out throughout this thesis as the main (but not the only) specifications that form a SE.

\subsubsection{TOOL SELECTING APPROACH}

The selection and implementation of VR techniques, tools and solutions requires an approach that differs from the currently common practice. The envisaged situation has to be more in line with the expected result of all stakeholders. This approach aims at assembling sets of VR tools with their underlying technologies, based on all criteria that depict the project with its development cycle and methodology and the company or companies involved. Establishing the most appropriate set of tools is related to the 
goals of the stakeholders in a specific phase of the development process. These goals should be deduced together with the stakeholders and should be defined as functional requirements of the facilitating solution. These functional requirements are the starting point for composing a SE that consists of different VR techniques, tools and also includes the environment, users, methodologies and working methods (Broek, Meijer et al., 2008).

Resulting from the defined requirements that depict the intended facilitation, the selection and tuning of work- and development methodology is carried out concurrently and in close co-operation with the selection and tuning of techniques, tools and solutions. Again, this activity is executed in close connection with the stakeholders involved. This not only ensures that the possible SE is comprehended by the future users, it also does justice to the different role that different stakeholders can play in different phases of the overall project.

During the selection phase, a new or existing combination of VR techniques, tools and solutions is arranged based on the - at that time - available building blocks in the company, if required and when sensible, completed with new building blocks. Essentially and ideally, the building blocks are modules in a configurable overall solution. Although the building blocks can be rearranged and recombined as needed, a collection of prior practices should be available to reflect and assess previously used combinations, whether they were successful or not. These prior practice combinations can be SEs from earlier projects, combinations proposed by manufacturers or situations used by other companies. Together with the combinations of physical entities, proposed working methods must be available to lower the threshold for using new solutions, and also to give more insight in the possible result (and the quality thereof) that can be expected. Manufactures and suppliers of VR techniques and tools should realise that successful introduction of techniques, tools and solutions is strongly dependent on the way in which the client can understand and oversee the feasibility and opportunities. This approach makes SEs also accessible to small and medium enterprises (SMES), as they are less likely to - and capable of - developing or ordering custom build SES.

In essence, the client needs to be facilitated in making purposeful choices on the way in which existing and new VR techniques and tools can be used to the benefit of the overall project. Currently, this is not possible in an adequate manner. The reasons for this encompass for example the gap between technology push and technology pull, the lack of documented prior practices at the appropriate level of aggregation, the opaque justifications in Virtual Reality investments and the inability to relate project results to the use of VR solutions. Consequently, a framework is required that brings together these aspects, and gives development teams insight in when and how the use of which VR solution can be beneficial.

\subsection{REOUIREMENTS ON THE SE}

Although the integration of (new) VR techniques, tools and facilities in our daily work is constantly increasing, an integral approach for their application and implementation is lacking. As tools, technologies and working methods emerge, it is difficult to select the appropriate combination of these tools, technologies and working methods. Moreover, selected combinations have to be in line with the methodologies, knowledge and currently available (VR) tools and resources in the company (Li, Huang et al.,2008). Possible advantages of new tools are visible only after implementation, whereas criteria and argumentation during selection are based on prognoses at the start of the trajectory. Based on the (often premature) assumption that SE implementations require high investments and inevitably 


\section{Part I}

give rise to problematic integration within existing situations, individual companies are hesitant to embark on a risky adoption of new or changed facilities (Bowman \& McMahan, 2007; Wilson \& Dcruz, 2005).

The phase in which the question is asked if, what, when and how to use any kind of SE is often the initial phase of the project. At that moment, the composition of the project team is often not yet completely defined, let alone that the team members already became acquainted to each other and that there is already collaboration between them. At that early moment in the project, decisions have to be made that will affect the further progress of the entire process, while there is a lot of uncertainty.

Moreover, the eventually chosen composition of VR objects that form a SE is made at an unfounded base, due to a missing frame of reference and opportunities are overlooked. During the product development process (too) many decisions are taken with implications that are later on in the process handled as indisputable although the decisions, the input of those decisions and the decision model itself can be doubtable. The consequence is that in that phase, the question is not yet completely recognised or not properly assessed. This influences the specification, demands, requirements and expectations assigned to different tools and techniques. The acceptance of a new SE is in such circumstances less than desirable, since they will not form an inherent part of the project, or are available too late. To partly solve this issue, the use of best practices is an opportunity for providing future users with insights on previously made combinations along with the achieved goals and requirements. These best practices can be related to a platform that provides the user with - a part of - the preferable methodology. This directly implies that a best practice is not only a combination of physical hardware elements, but always includes the related working methods as well. The advantage of making the decisions regarding the development of the SE by a project team that is not yet settled in the project (since these decisions are made at the earlies stages of the PDP), is that they do not suffer from tunnel vision or profession-blindness.

Consequently, not only the background and expertise of the stakeholders determine the requirements, but also in which phase of the PDP the requirements have to be set influences the requirements of the SE. Furthermore, all the involved stakeholders have their personal and individual requirement for the SE, but also in the context of the team they have to work with. The architecture should not determine the process of when and how these requirements are gathered, since that can lead to an influence of the requirements. The architecture should facilitate and document the gathering.

\subsubsection{REQUIREMENT SPECIFICATIONS}

The requirements formulated in a project serve, in first instance, mainly the aim to be able to communicate with all relevant stakeholder of the project. To allow for sufficient freedom in the development of the solution, these specifications should not be fixed too early in the project, to prevent forming a constraint in the development (Lutters, Dankers et al., 2014). In contrast, the communication between different stakeholders should be instigated and facilitated as soon as possible and as effectively as possible. This may sound contradictory; specifications are effective to trigger the discussion about the properties of the solution, while these discussions are mainly about setting these requirements.

Consequently, it should be clear to the stakeholders that the requirements mainly aim to provide insight into the argumentation that underlie the choices made. The specifications are thus a dynamic set of information, which are specified and modified over the entire 
course of the project. In this, already defined requirements can serve as a rationale for new requirements. This dependency and origin of choices must be maintained throughout the project; the requirements can change, so the related or subsequent requirements should be revised as well (Lutters \& Klooster, 2008). The manner in which specifications are documented should allow for some flexibility. On a different level of aggregation, different information can be extracted from the requirements. Every stakeholder has the need to interpret them in their own way. The requirements may refer to specific values that the solution has to meet, or to more generic descriptions that are of importance in the development of the product.

Functional requirements provide a description of desired future behaviour. In general, they express concrete demands to an abstract model (e.g. of a SE). The difference between requirements and specifications is that requirements describe what should be achieved, and specifications describe how it is achieved. Technical requirements are complete and unequivocal expressions of demands imposed on the SE. They address e.g. the type of interaction, the resolution of the visualisation or the maximum numbers stakeholders. In general, technical specifications express quantitative or easily quantifiable demands.

There are many reasons why the application of specific tools and techniques can be successful or disappointing. Aspects involved with the choice of tools and techniques are described by (Lutters, Houten et al., 2014). An overview is shown in figure 4.3. The figure illustrates the complexity of the implementation of tools in practice. Broadly speaking, it is obvious that a tool has added value for a company or design team when the benefits exceed the costs. The problem is, as illustrated by the number of aspects involved in figure 4.3 , that it is difficult to measure costs or benefits accurately.

In order to acquire the requirements most relevant to the development of the SE, some form of distillation has to take place. This activity is similar to multi-stakeholder decisionmaking; first the differences between stakeholders has to be made clear. The vision from those different perspectives on the same solution provide insight in the broadness of the scope for the solution. Here, each individual stakeholder will make its own selection of what the core of the solution should be in his perspective. Ultimately, the combination of all these different perspectives should lead to a common description of the requirements. Whether a tool is worth the investment in resources is subject to so many variable aspects that it is unattainable to determine this by specification of a ready-made formula. Therefore, it is

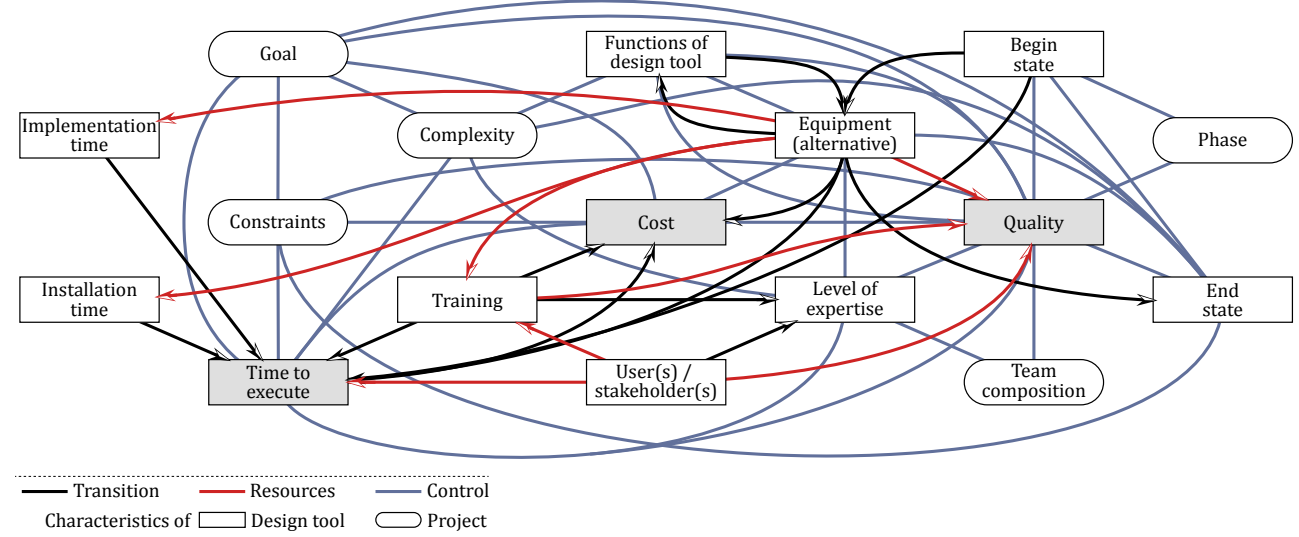

Figure 4.3 | Aspects of using tools and techniques (Lutters, Houten et al., 2014) 
advised to consider the aspects as presented in figure 4.3 for each specific SE and individual function separately.

Managing these requirements is one of the main challenges in multi-disciplinary product development (Stechert \& Franke, 2009). The developer of a SE has to find harmony between the configuration of the setting (technology) and configuration of the functions (functional specifications). None of them is leading in the development phase, and both should be adapted until they match/link. This results in a large number of iterations to come to the most appropriate solution. The process of starting the combination of all requirements into one solution can start with an educated guess from the developer, or from best practices already available. At the end, this has to result in the development of an environment; which is more elaborate than a single product, and therefore often needs more connections to existing situations. The requirement specifications should be leading in determining what should be needed in order to realise the desired SE. Managing these requirement specifications is consequently one of the supporting activities needed in the development of a SE.

\subsubsection{KNOWLEDGE RULES}

Capturing the envisaged functionality of a SE is not a straightforward activity. Moreover, the requirement specifications steer on the defined requirements that the solution must satisfy, but offer little guidance in determining the direction of the design. Besides, the risk occurs that the way of documenting the specifications of a SE influences the decision-making, or rather imposes limitations on the possibilities. To overcome this the requirements to the SE should be formulated using knowledge rules. Knowledge rules are used to store and manipulate knowledge to interpret information in a useful way (Chou, Lin, \& Chun, 2014). In the context of developing SEs, this implies that also the rationale why a function at all is desirable can be documented. For the developer it also takes into account the type, level and extent of the knowledge of all stakeholders. The use of knowledge rules prevents only discussing in technical specifications; it encourages describing the needs of a certain function of the solution. To handle that information on a sufficient level is also important to take into account the knowledge of the (future) users.

For the stakeholders of a SE the main challenge while realising a SE is to select the apposite virtual techniques, tools and solutions that form the SE, based on the captured knowledge rules. The developer of a SE should be able to plot potential solution paths, while continuously providing an overview of the requirements on and impact of that solution and its accompanying working methods against the background of theory, technological possibilities and available prior practice. It therefore enables structured, transparent, unambiguous, effective and efficient decision making on the selection and combination of VR objects. The selection and implementation processes will be accelerated and simplified by providing insight in the consequences certain choices will have; moreover, alternatives can be compared, allowing for deliberate trade-offs between for example leadtime, complexity, quality, risks and investments. The architecture provides a reflection on the consequences of specified goals on combination, integration and methodology in a development project. In addition, the knowledge rules provide steering in the determination of the direction of the development. Setting clear and understandable knowledge rules will benefit the development; the more knowledge rules required to describe the desired SE, the more vulnerable it is to misinterpretation and changes in the context or environment. Consequentially, the architecture can be instrumental in improving the effectiveness and efficiency of establishing a SE in a PDP. The relation between individual techniques and tools 
is made explicit and visible and the consequences of the selection for the requirements of the used methodologies are depicted. In this, the aims of the stakeholders are defined in terms of functional specifications imposed on the desired result, rather than on current and potential future technical capabilities of facilities. This will lead to leaner and more transparent interfaces between activities of the user and characteristics of the selected tools. In line with this, it will enable the possibility to exchange individual tools and already having an expectation of how other stakeholders will be affected by that.

\subsubsection{UNCERTAINTIES}

Throughout the process of setting the requirements for a SE, the stakeholders have to deal with uncertainty. There are always things 'not exactly known or decided, not definite or fixed' ("Uncertainty", 2017). In the realisation of a SE this hampers the decision making process, since the rationale of the decision is based on things that can change. There are many things that obstruct making a specific decision in the development of a SE, the most obvious is a lack of information. This uncertainty can lead to confusion in the communication between stakeholders, and in the decision making process. The benefit of uncertainty is that it provides the freedom to employ creativity in the development process. A precondition for this to be true is that the uncertainty is manageable: it must be credible that the uncertainty is 'closed' in the sense that it concerns a lack of knowledge of facts that are indeed obtainable (Lutters, Houten et al., 2014). A developer of a SE may be uncertain about the result of a configuration of elements, but with further analysis and experimentation this uncertainty can decrease. However, this is often hampered by the limited time/resources available to product developers.

Decreasing or removing uncertainties is often a matter of continuing the development, by making assumptions and generate and evaluate the consequences. Based on this information alternatives can be developed, until the moment the assumption is proofed by information. In the development of a SE this stresses the relationship between uncertainties and the requirement specifications. Both address the scope in which the SE has to be developed, where more information can lead to better, more accurate and more underpinned solutions (Lutters, Houten et al., 2014).

\subsubsection{ROBUSTNESS AND FLEXIBILITY}

The requirement specifications and the knowledge rules are necessary to work towards a model that meets the expectations of reality, which in a SE is of great importance since it involves the development of a new tool that should fit within an existing environment. A configuration of VR elements that together form a SE must be able to withstand changing circumstances. Especially in product development, such changing circumstances are abundant, extensive and hardly predictable. As such, these changes originate from all the different aspects that are part of any product development process. For example, the user or client can formulate other goals along the process, or require other use conditions. The technique (hardware and software) will also be subject to continuous change, thus stressing the consistency and coherence of the components. In addition, the (physical and virtual) context and environment in which the SE functions is not constant; even the data that serves as input cannot be determined with certainty (Masood, Erkoyuncu et al., 2014). The more flexible and easy to use the SE is, the higher the probability that realising the solution adds another dimension to the configuration problem: the reuse of the equipment/setting in other projects. 
By embracing this uncertainty as a characteristic of SEs, preliminary fixation of any element or aspect of the solution can be prevented. With this, the SE remains sensitive to an element that only later in the process appears to be an (un)intentional controlling function in the selection and use of that SE. This additionally stresses the observation that no SE is ever complete nor finished; moreover, by accepting changeability, there is no need for full comprehensiveness; this not only allows for earlier use and testing of the SE, it also allows for more implicit, efficient and foreseeable adjustments and maintenance. Even more, while developing a SE; already overhauls, maintenance and adjustments can be part of the development of that SE. In the ideal SE, this will be an essential part of the solution, and making changes or performing maintenance completely facilitated (and even stimulated) (Houten \& Kimura, 2000). Finally, the solution will also gradually be better tailored to the conditions of use.

During the development of a SE, choices have to be made as concerns how much flexibility is envisaged; the more flexibility, the more interdependencies the SE needs to cover, potentially resulting in increased complexity. With this, it must be able to adequately predict the robustness of the SE; this robustness addresses the quality of the solution rather than the impregnability of the constituents of the SE. The reason for this is that a stakeholder that considers using a SE is convinced by the end result, not by considerations on the hardor software used. Given the fact that all stakeholders have different perspectives and interests in the development of a SE, for every stakeholder the point where the scale tips in favour of a SE over means that are more traditional is interpreted differently. Consequently, a trade-off in the collective of all stakeholders needs to be prevailing.

\subsection{DIRECTIVES FOR THE ARCHITECTURE}

The preceding shows that much communication is needed between the various stakeholders (section 2.4), and that it is obvious they all have their own perspective to the SE. That is on the one hand the great advantage of, or even the reason for, the collaboration between multiple stakeholders, but on the other hand it is the main pitfall. The different perspectives of all stakeholders can broadly be divided as follows:

- Strategic (e.g. company perspective)

From this perspective the aim is to realise a lean SE, that allows the use of the SE in multiple projects. The SE should be affordable, have a predictable return on investment and is assessed against long-term criteria.

- Tactical (e.g. operator perspective) In this perspective the physical manifestation of the SE is most important. The SE should be easy to maintain, easy to adjust and exhibit a predictable robustness under use conditions.

- Operational (e.g. user perspective) From this perspective, the actual use of the SE is most leading. The focus is on the functionality and embedding in existing processes and everyday use.

These different views from different stakeholders with different perspectives require a thorough overview and guidance to vouch for reliable solid solutions. Given the amount and granularity of the constituents of a SE and taking into account the interchangeability of many of these constituents, an architecture that consists of interrelated modules is preferable. To achieve this, aspects like the following are relevant: 
- Changing market situations (section 2.1); The way in which product development is executed will change considerable, for example because of the availability of (less expensive and more generic) design tools will increase drastically.

- Integration (chapter 3); With the current paradigm shift in the way in which people interact with computers and digital media, the gap between user requirements and technological solutions is bridged quickly. Therefore, the way in which a SE can be employed in development cycles will change drastically as well, rendering actual 'integrated design' more feasible.

- Guidance and support (section 2.3); The use of a SE will (have to) become less expertise-dependent. As more people will have access to those solutions, the way in which they get acquainted with them will undergo changes. Therefore, more attention has to be paid on simplifying interactions while reducing the need for training.

- Prior practice (section 4.1); To use the SE to its fullest extent, it is essential that prior practice in using such solutions is captured and made available. This encompasses best practices, but explicitly also information on solutions that did not meet the requirements or did not produce the expected results. The architecture must therefore inherently be capable of adequately capturing case studies.

- Interaction (section 2.2); With the increased use of SEs, more people will interact with these solutions. This will require both new design tools as well as new working methods for e.g. multi-user interaction.

- SE suggestions (section 4.2,4.3); While gaining knowledge on the use of SEs and establishing new working methods, the architecture will be able to come up with suggestions for e.g. techniques, tools or working methods that would effectively fit in the prior practice that is already available. In other words, the architecture will allow for suggestion of tools to buy or to develop.

\subsubsection{DeVElopment OF THE ARCHITECTURE}

In the previous chapters the requirements for the development of a SE are sketched. These requirements have to be translated into a supporting architecture. The upcoming parts of this thesis will utilise this information in the construction of the architecture. The architecture should support a broad range of PDPs, and must be future proof. The foundation of the architecture should not be based on current available technologies or methodologies, since these are sensitive to progress in time. Therefore the architecture should not incorporate a dedicated process, but should provide preconditions needed to work towards a SE.

Important in the elaboration of the architecture is that its foundation will remain flexible, yet structured and transparent. This issue is tackled by improving the insight into which combinations of elements that form a SE are possible. This insight should be given explicit to the development team itself; there is not one specialist who is responsible for the selection. The construction of the solution is handled as a supplying task, all stakeholders determine the requirements. This process starts at the earliest identifiable demand and continues constantly during the whole lifecycle of the project. The requirements of the stakeholders are linked to possible suitable SE building blocks containing a certain technique, tool or solution. The combinations of different building blocks are not pre-defined and can be created custom for a specific goal. Along with the individual building blocks best practises or combinations-experienced internally in the company or externally at other companies- 


\section{Part I}

are available to simplify the selection and visualise already composed possibilities. These best practices should also include working methods for implementing the solution both as push and pull strategy. To determine the best suitable composition, what-if analyses need to be made of the requirement specifications (what should the toolset offer) versus the available techniques, tools and solutions.

Intermezzo 1 combines the information from this first part of the thesis into the first step of realising the architecture. The focus is first on facilitating and documenting the requirements for the $S E$. 



\section{INTERMEZZO 1}

In the research as described in part I of this thesis, the desired support in the process of realising a SE is described, and the requirements for the architecture that structures this support are outlined and analysed. This intermezzo converts these requirements into the first steps towards the development of the supporting architecture. Moreover, it provides directives for the upcoming chapters in this thesis. The requirements of a SE can be explained in multiple ways, this Intermezzo will also provide an overview of three different terms used to classify or cluster requirements: Element, Perspective and Viewpoint.

The first step to come to a functional SE is to provide the stakeholders with an approach to gather and document their requirements to the SE. This is facilitated by means of a so-called blueprint, which simultaneously provides the stakeholders with a 'backbone', a 'checklist' and a 'notebook' to express the requirements. To make this process as efficient as possible, while also allowing for collating the work of multiple stakeholders, templates for such blueprints are provided, as illustrated in figure I1.1.
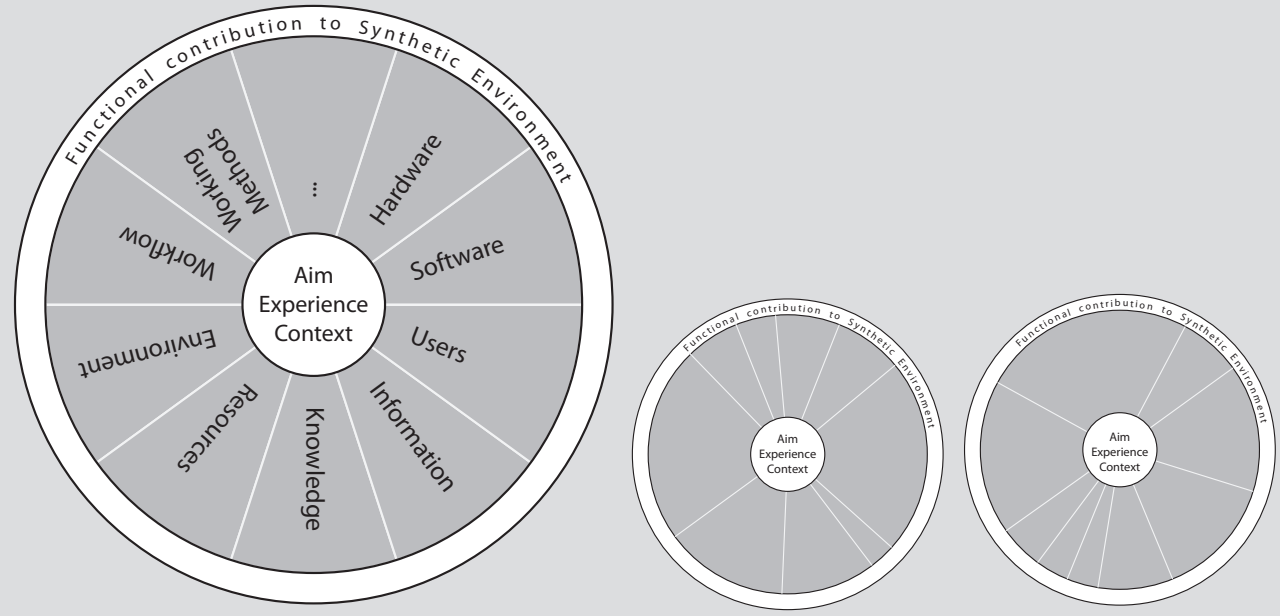

Figure I1.1 | Blueprints

In figure 11.1 the main elements that form a SE are visualised in a circle. The nine elements mentioned in section 4.1.2 are provided as illustrative examples, since the interests of a stakeholder can comprise of more or less than these nine proposals. The main purpose of the SE (as seen from the perspective of one stakeholder) is documented in the core of the blueprint, while the edge express the functional contributions to the overall SE (as conjointly under development by all stakeholders).

For each of the nine elements, requirements can be specified, although this is not mandatory. Obviously, the amount of documentation related to the different elements can vary, according to the interests, priorities and expertise of the stakeholders. Given the character of, and idea behind the blueprint, its elements are foremost ways to cluster the requirements (Lutters, Houten et al., 2014), rather than a prescribed subdivision. The requirements (clustered in terms of the elements) for connecting the main purpose and the functional contributions are instrumental in establishing an adequate and purposeful SE. 
The requirements to the SE are gathered and documented in line with the different types of stakeholders (section 4.2). Whereas the topics these stakeholders consider relevant, are captured by means of the nine elements of the blueprint. The stakeholders (see section 2.4) additionally have dissimilar perspectives on the SE as concerns the level of aggregation. As introduced in section 4.3, these different levels address:

- Strategic level

(e.g. by the company that provides/sells/installs the SE).

- Tactical level

(e.g. by the operator that will configure the SE for a specific context or project).

- Operational level

(e.g. by the user that is exposed to the SE or by the client that envisages to improve a design project).

Most stakeholders can be positioned in one of these perspectives, and therefore the support and facilitation of the SE development will be - at first - based on this.

Since all stakeholders will have different backgrounds, expertise and amounts of information, these stakeholders will also have a different opinion on what the SE should offer (to them), even at dissimilar levels of reliability. Consequently, each stakeholder will state its own requirements. These requirements will be described from the perspective of the stakeholder, where the template is a facilitator rather than a standardised straitjacket. The blueprint should therefore not enforce nor pre-determine the demarcation or scope of the requirements that are formulated. The stakeholders will bring up both functional and technical requirements (section 4.2.1), describing what conditions the SE should meet, instead of precise ways of realisation, implementation details or enablers of these requirement. Given the blueprint approach, it is also not relevant which requirement is documented first; therefore no standard process of use and no fixed starting point needs to be prescribed.

A blueprint can contain all requirements as stated by the stakeholder who initiated the blueprint. In a (later) reviewing stage this information should be filtered accordingly to the perspective of the viewer. This filtering capability is discussed in chapter 8.

The goal of using the blueprints is to determine and explicate the scope in which the knowledge rules for a specific SE exist (section 4.2). Any stakeholder can easier describe the requirements for the SE from a certain viewpoint related to the context in which the SE has to operate, than from the individual element levels that are constituents of the blueprint. These stakeholders' viewpoints provide more meaning as concerns the requirements, because they incorporate the origin and rationale of a requirement, and provide a clustering of information. These viewpoints (which are always described from the perspective of a single level of aggregation at once) on the requirements for a SE can encompass, but are certainly not limited to, the following:

\section{Functional and technical requirements}

The need for a certain support tool in a product development process often originates from the wish to improve the quality of the product or process, or to enhance the efficiency of one or both. This determines the content and the aim of the SE, focussed on anticipated functionality or technology. 


\section{Constraints}

The constraints determine the contours of the SE; they describe the boundaries of resources in which the requirements have to be fulfilled.

\section{Preferences for strategy}

The preferences for strategy allow the stakeholders to communicate their preferences as concerns working methods (or sequences) as well as priorities, but will not stipulate the method for the complete SE. Multiple perspectives can be used to view the impact of a certain strategy, without selecting a leading strategy at first.

\section{Relevant projects}

This provides the context of the SE. It allows for the exploration of conjuring projects, with the stimulus to find an extension of the use situation, or the consideration to extend the SE to cover multiple projects.

\section{Relevant development phases}

Not all stakeholders will be involved in the SE at the same time. The relevant development phases provide an understanding of parallel or serial processes which may have mutual relations or dependencies.

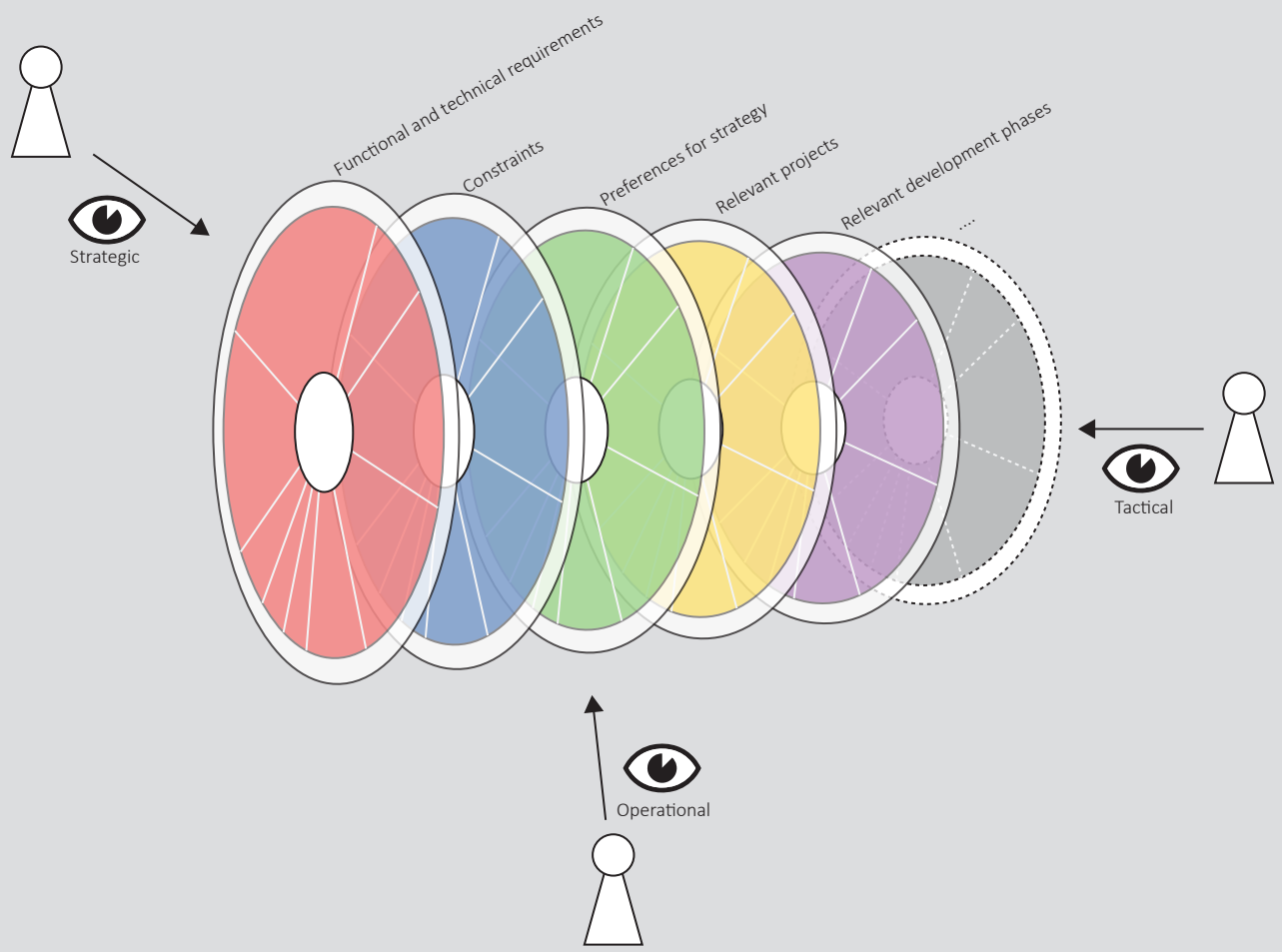

Figure I1.2 | Different perspectives and viewpoints on the blueprint 
Figure I1.2 visualises the different viewpoints and perspectives on the blueprint. They all act as a form of clustering and classification of the information in the blueprint.

The blueprints in themselves will not provide integration, as they - individually - only provide overview over a single perspective. An additional framework is needed to process the blueprints and to determine the most appropriate way of realising the SE. The blueprints will act as a base and trigger for discussion, as they provide stakeholders insight in the different ways of thinking of other stakeholders. The diversity in (and the number of) stakeholders is not limited, and consequently a large number of blueprints can be involved. This results in a situation where all stakeholders can work on setting their individual requirements independent from others.

The combination of several (from two to many) blueprints will form the information basis for the development of a SE. On beforehand, it is not determined what blueprints will compose a SE; based on the content of the blueprint matches between multiple blueprints can be identified. The blueprints have to function as consolidated starting points, subsequently the final SE is not merely the logical consequence of the blueprints. The more information is available on a certain area, the more tailored a solution can become; nonetheless there is no fixed threshold on required information.

Part II of this thesis works towards a support architecture for the integration of blueprints. As such, it describes approaches on how to enhance the development and use of a SE. The three perspectives (strategic, tactical and operational) of the different stakeholders are used as a structured starting point, because the requirements on the flexibility of the blueprints can be traced back to these three categories. Throughout part II, these perspectives will be elaborated to employ them to their fullest extent. There is no hierarchy, starting point or sequence in these chapters, all can be read independently and in every order.

Part II consists of the following chapters:

- Chapter 5: Strategic (e.g. SE providing company perspective)

- Chapter 6: Tactical (e.g. SE operator perspective)

- Chapter 7: Operational (e.g. user and client perspective)

Intermezzo 2 will combine the different perspectives on how to enhance the use of a SE as an enabler, while also addressing how this knowledge can be combined to realise the most appropriate SE. 


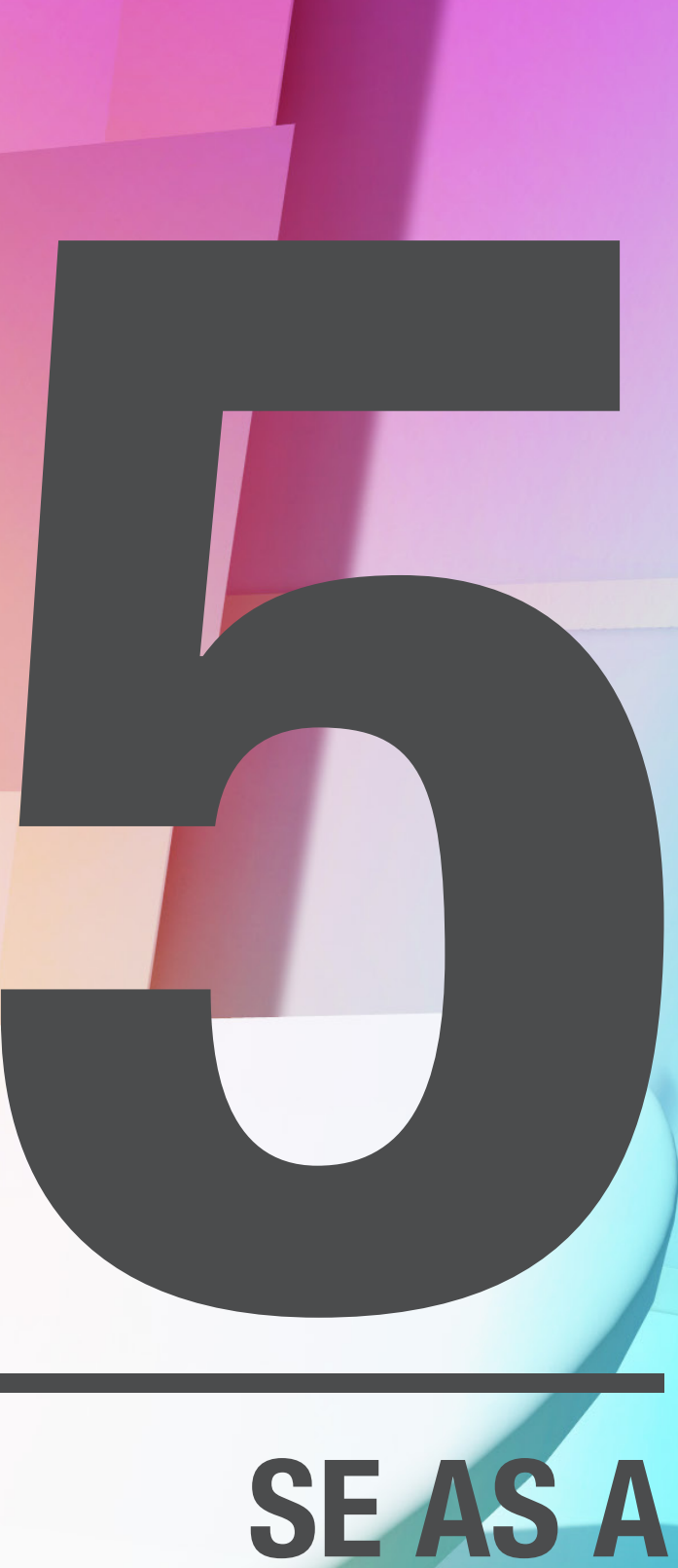

\section{PRODUCT SERVICE} COMBINATION 


\section{Se as a Product Service Combination}

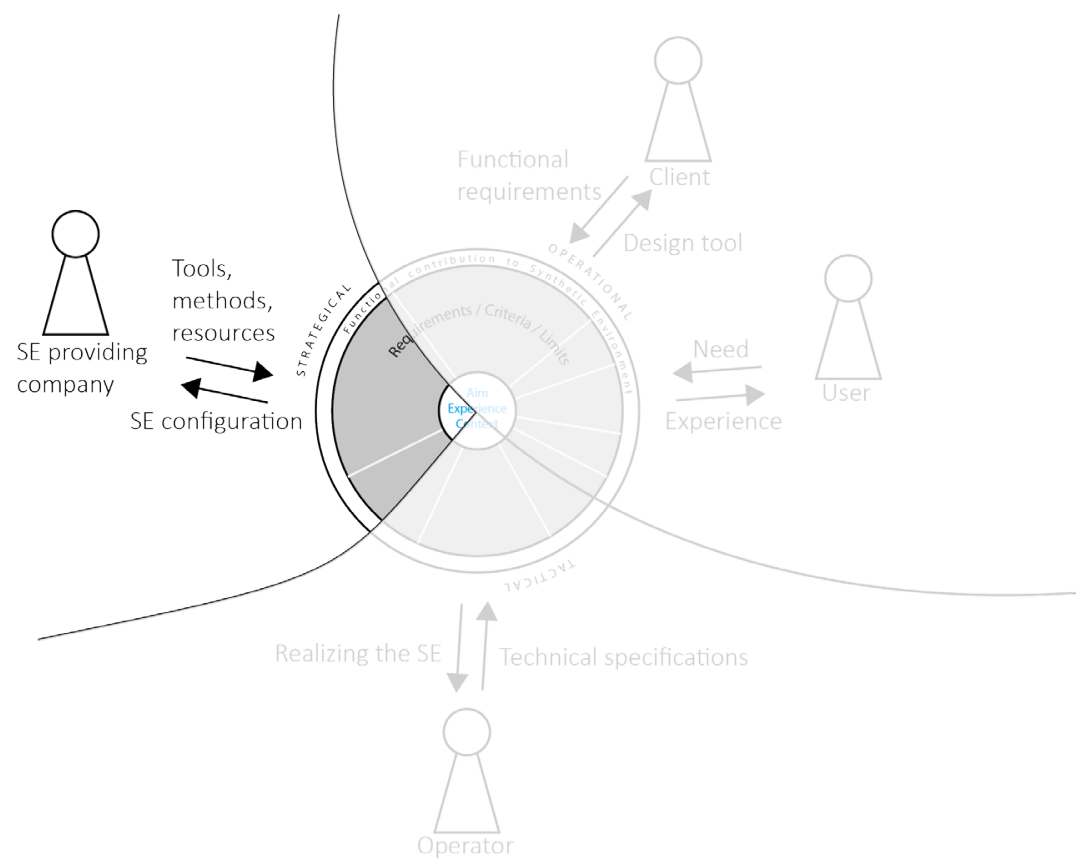

Figure 5.1 | Perspective of this chapter

A Synthetic Environment is not solitary a combination of all the elements mentioned in Intermezzo 1. Only physically and/or digitally combining those elements into one solution will not directly offer something functional to the stakeholders involved. A SE should be used to achieve a certain goal; therefore it rather represents a toolset whereby the tools themselves are subordinate to the results of using the tools. One could say that a SE should facilitate a project phase (by supporting certain activities, enhancing the understanding, improving the experience, enabling the information exchange, etc.) in order to improve the overall process it is a part of. In order to realise a properly working and most appropriate result, all requirements from each viewpoint can first be translated into what will be documented in the blueprint. This information can be used as requirement specifications, and originates from the knowledge rules mentioned in section 4.2.2. To make as a stakeholder the translation from personal requirements, to a shareable and explainable requirement specification, it is desirable to have a feeling on the impact these requirements are going to have on the end result.

For the supplier of a SE the focus is not on building a tool alone, but on providing a particular opportunity for the user, and on enabling a certain experience. This can be seen as a service that is offered to the user, while the SE is only an enabler for the experience (of the service). The added value for the user is not in the use of a SE, but in the consequences of using it. To make the desired experience possible for the user, the SE comes into play. The SE providing company should thus also see the SE as an enabler for a particular experience. The company should realise a (pre-defined) experience, which is during use tailored to (constantly changing) requirements of the stakeholders. In this context the user has no 
direct need for an additional (new) tool or device, but the user wants to pursue a certain goal. The provided service - in the form of a SE - will help the user to realise that goal. With the focus on addressing SE as a product service system, the aim is to use the rationale of PSS to gain more flexibility and robustness in the development and use of SES.

From the SE providing company's perspective, there is a need to maintain an overview over several projects, the same can be said for clients that have multiple projects in which the use of a SE is considered (or already done). Mainly in the construction of a new SE the need to purchase new equipment can occur. In order to make a choice in this, it is relevant to consider the broader capabilities of individual tools than just the use in some projects. By seeing a SE as a combination of tangible and non-tangible elements, the possibility arises to make quicker adjustments to the composition of elements that form the product, while the experienced service for the user has no hindrance from that.

The goal of the company delivering SEs shifts from delivering a physical product, without a promise on what the user can achieve with the product, to delivering certain experience (where their physical product is one of the enablers for the perception of the experience). Consequently, in the field of SEs, a distinction should be visible between tool development that focuses on improving a single asset (e.g. VR hardware, software, information management, ...) and on developments that focus on providing a complete integrated experience by means of a SE.

This chapter describes the possibilities of using the PSS approach on SEs, seen from the perspective of the supplying company. The focus is on controlling the relationship between the various components; as the company wants to steer on the whole SE, not just on individual parts. In addition, the solution should also be adaptable to the future needs, without having to notice major differences in the end use.

\subsection{COMPARISON OF SE AND PSS}

Proper development and use of a SE can benefit from a product-service system approach, but currently available and developed VR solutions and SEs are often rigid and standardised instantiations or reminiscences of the flexibility once intended.

Various classification are developed for PSS, according to (Tukker, 2004), these can be combined into three main categories: product oriented, use oriented and results oriented. Each of these categories contains different types of PSSs with their own characteristics. In figure 5.2 these different characteristics are visualised.

In a product-oriented PSS, ownership of the product remains with the customer, but the provider sells additional services. The business model is still mainly geared towards sales of products, but some extra services are added. In a use-oriented PSS ownership remains with the provider and usage rights are sold to the customer. The traditional product still plays a central role, but the business model is not geared towards selling products. The product stays in ownership with the provider, and is made available in a different form, and sometimes shared by a number of users. In a result-oriented PSS the product's functional results are sold, that directly fulfil customer needs. The client and provider in principle agree on a result, and there is no pre-determined product involved (Ostaeyen, Horenbeek et al., 2013; Tukker, 2004).

(Ostaeyen, Horenbeek et al., 2013) also describe different types of revenue mechanisms that can be applicable to every PSS, ordered according to the level of performance orientation: 
- input-based (IB). Revenue is transferred from the customer to the provider according to the inputs delivered to effectuate the function of a product or service.

- Availability-based (AB). Revenue is transferred from the customer to the provider based on the time period during which the product or service are available for the customer, independent of how much they are actually being used or delivered in that period.

- Usage-based (UB). Revenue is generated only during the actual usage of the product or service.

- Performance-based (PB). Revenue is generated based on the functional performance of the product or service. In this category three different options can occur; solution oriented (PB-SO) PSS, effect oriented (PB-EO) PSS and a demandfulfilment oriented (PB-DO) PSS.

These classifications can help comparing the different types of PSS available, and show the PSS developer the different kinds of demands solvable with a PSS. Currently, the designers of SE address the technical specifications in order to select the right tools, while focusing on the consequential service, to meet the use conditions, can be a better approach. Any SE always offers a (digital) interaction with the service; this can often be seen as the goal of the user in using the solution. The service is the results of using the solution. This shows that the dependencies between the tangible product for enabling interaction, and the intangible service for providing the results, need attention during the development of the SE.

The PSS approach has some remarkable benefits, which could be a welcome addition to the way in which a SE is developed and used. Many SE providing companies have the perspective to offer the customer a solution that allows a long-term relationship, while being flexible in the configuration of the solution. Traditional VR solutions are often developed as a standalone product, while nowadays the adjacent service becomes even as important. These solutions are often pre-defined; deliberately deviating from this (for the product or the service) leads to tailored solutions that require a different approach.

By reviewing the common characteristics between SE and PSS from a high-level perspective, similarities come forward on aspects where developers of VR solutions can use
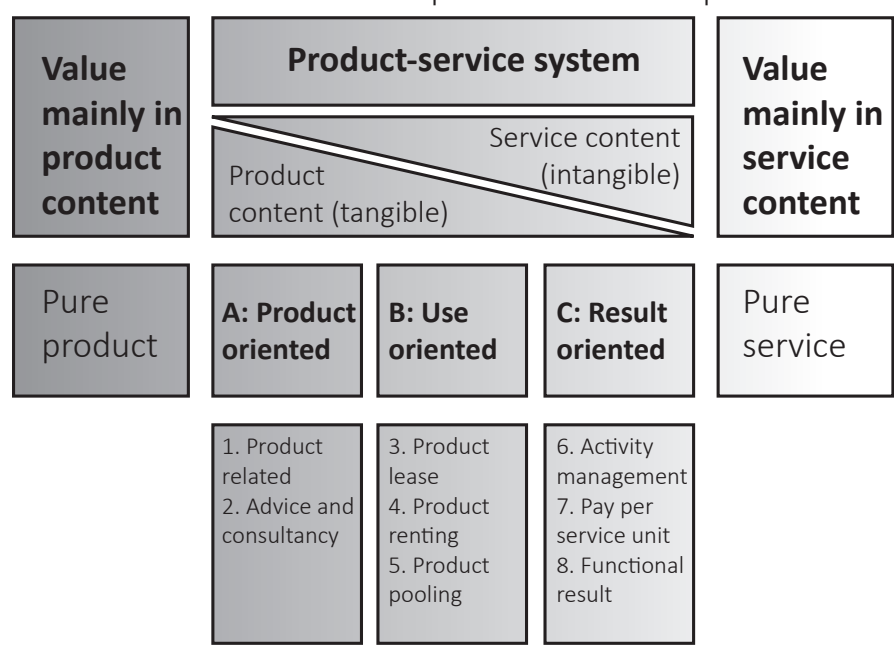

Figure 5.2 | Main and subcategories of PSS (Tukker, 2004) 
the experience and expertise available in the field of PSS ( $H$. N. Nguyen, Exner et al., 2014). There, the interfaces between different physical and non-physical attributes are already seen as one of the main pillars for a successful solution. In a SE these interfaces are also essential for a successful system. Nevertheless, they are typically seen as a necessary evil. Changing this approach requires a different view on how to realise SE configurations. The current focus in the development of SEs is often on selecting the best fitting hardware and software and can be compared to the traditional business of selling complete functional and stand-alone machinery. In a PSS approach, the resulting service (defined by functional specifications) is leading, while the enabling hardware and software are only treated as interfaces or assets to achieve the experience (Nemoto, Uei et al., 2015).

The approach of representing VR solutions as a product-service system is not common, nor is that for a SE. Based on the definition of IPSS (Meier, Roy, \& Seliger, 2010; Meier, 2014) the tangible product should support the intangible service to achieve a successful PSS. Furthermore, (a part of) the product will not function without the service, and (a part of) the service will not function without the product (Boehm \& Thomas, 2013). Every SE consists of tangible and intangible items; the physical devices are substantiating interaction with the intangible aspects of the solution such as behaviour and information. This unavoidable combination of tangible and intangible items shows the inherent dependencies between them, require decent integrations, and is one of the major motives to make use of a PSS approach.

Currently, the development of new (VR) technology or tools is often focused on a predefined set of requirements for a single hardware device or a software solution, while the connecting interface is not part of the development. Being able to integrate new (VR) tools seamlessly in SEs for product development often requires conscious amendments of the system. This results in the demand for tailor-fit solutions, while requiring craftsmanship for development and use.

\subsubsection{IDENTIFYING A SE AS A PSS}

In a PSS the resulting service is always a combination of multiple resources achieving a certain goal by working together and controlled by multiple stakeholders (Moser, Maisenbacher et al., 2015). This also applies for SEs, as already highlighted in Intermezzo 1: for every SE it is an essential aspect to find the most appropriate combination of the provided nine aspects, in order to achieve its goal (Damgrave, Lutters, \& Houten, 2012). These aspects are the baseline for the blueprint from Intermezzo 1. The SE can serve multiple goals by means of the various aspects. The user of a SE has a specific purpose in mind, and in order to achieve that purpose, a particular experience is desirable. This experience takes place in the context of the user. The gap between on the one hand the aim, experience and context of the stakeholder, and on the other hand the final SE, is reconciled with the aspects that are part of the SE. There is always the need to use these aspects in order to achieve the purpose and desired experience in the stated context with use of the SE. Configuring solutions to fill this gap between the expected experience of the user and the provided behaviour is commensurable with the rationale of PSS. This similarity concedes the validity of utilising the knowledge and skills of PSS in the methodology of SE development.

None of the elements that form a SE is leading, but all should be balanced during the development, in order to achieve the best possible service and experience. Therefore, the focus should shift towards the interfaces between them, while maintaining the quality of individual items. The challenge here is to provide the maximum flexibility of the system, 
with a predictable and guaranteed robustness of the service experienced. This approach has the danger of a loss of focus due to the broad expertise needed by the developers. Previously, this was difficult to achieve within the current VR tool developments, because many VR tools required expertise, or even craftsmanship to operate. Due to the improved accessibility and lowered threshold for use, it is now also possible to combine VR tools inside a SE without having to be an expert in each individual field. This creates the possibility to shift the focus to an interface-oriented approach; precisely the area in which PSS excels.

The similar challenges in the approaches for the development of SEs and the PSS approaches lead to the identification of reciprocal relations. The experience and expertise of current and upcoming PSSs give the opportunity to streamline future VR developments (Marilungo, Peruzzini, \& Germani, 2015). Within this chapter, the impetus is also on facilitating and stimulating the use of the PSS rationale for developers of SEs during the complete lifecycle (H. N. Nguyen, Schnürmacher, \& Stark, 2014; Wiesner, Freitag et al., 2015), and not solely for the experience of the end user.

\subsection{ADDRESSING A SE AS A PSS}

To make optimal use of available and new (VR) tools and technology inside SEs in the near and far future, the emphasis of this approach will be to work towards a system of systems. The overall SE can be seen as a fully operational system, while the configuration of the SE can consist of multiple independent systems not noticeable to the end user. Hardware and software can still be developed separately, but a flexible and adjustable interface is necessary for connecting the two. Dependencies between individual parts and between complete systems should be made more visible and understandable. Dependencies should not be handled as boundaries or restrictions, but can be handled as opportunities for reinforcing the system and used to understand the robustness of the solution.

More flexibility is needed in future SEs, due to the constant changing parts of the solution, especially as the developments in VR hardware and software are faster than the lifespan of a SE. Flexibility becomes inherent to future SE if the solutions want to make use of the continuously evolving technology. Furthermore, the data in the system will constantly change and adjacent systems or solutions will also change. Taking this into consideration the only way to provide and guarantee a result is to focus on the interconnecting elements of the system, and the expected experience for the user.

To achieve more robustness in the complete SE, the consequences of new (or changes to the) tools and technologies combinations should be more predictable. This can only be achieved if the effects of changes in the configuration of the complete solution can be made transparent to the underlying interfaces. Thus, it is necessary to define the functional specification of each element of the solution (Damgrave, Lutters, \& Drukker, 2014), and subsequently the relation it has with other elements. These relations can, for example, consist of receiving input, providing output, controlling other elements or acting as an enabler. By being able to predict the experienced behaviour of the solution, it will be easier to optimise it and to increase the resilience of the solution offered.

The demands imposed by the user on the solution should be defined using functional specifications. Especially when the focus is on delivering a complete system, the company or end user should not be concerned with choices on the underlying enabling aspects like hardware and software solutions; the SE provider must take care that they fit the documented requirements. Firstly, the user is no expert in the field of designing and developing a SE, and secondly, the user is not capable of keeping an overview of 
dependencies between elements of the solution. As an example, this can be compared to using a copier: the user does not have to know the composition of the technical parts of the copier, he only has to be able to use it.

In an adequate PSS, the user is not forced to make a distinction between a service and a product. The system is experienced as a whole, and for the user it is not necessary to know if a tangible product or an intangible service is responsible for providing that experience. This perspective is often neglected in the development of a SE, which results in emphasising the relation between a product and a service. Through this, the user loses overview of how the $\mathrm{SE}$ responds to the interaction provided, and can experience the feeling of not being in control.

A PSS offers the customer more compared to product ownership, a PSS is more aimed at providing an experience than on product use. During the configuration of the PSS each element in a SE should therefore been treated as an enabler of possibilities. The challenge is to provide an experience to the user which is, as most as possible, in line with the expectations. While also the management aspects of the PSS should be considered during the appraisal. These aspects aim on optimising the effort needed to ensure the perceived quality of the PSS (Sassanelli, Pezzotta et al., 2015).

\subsection{Resulting ApProach}

The common ground of PSS and the identification of usable aspects described in the previous chapters are converted and translated into an overview model for SE, illustrated in figure 5.3.

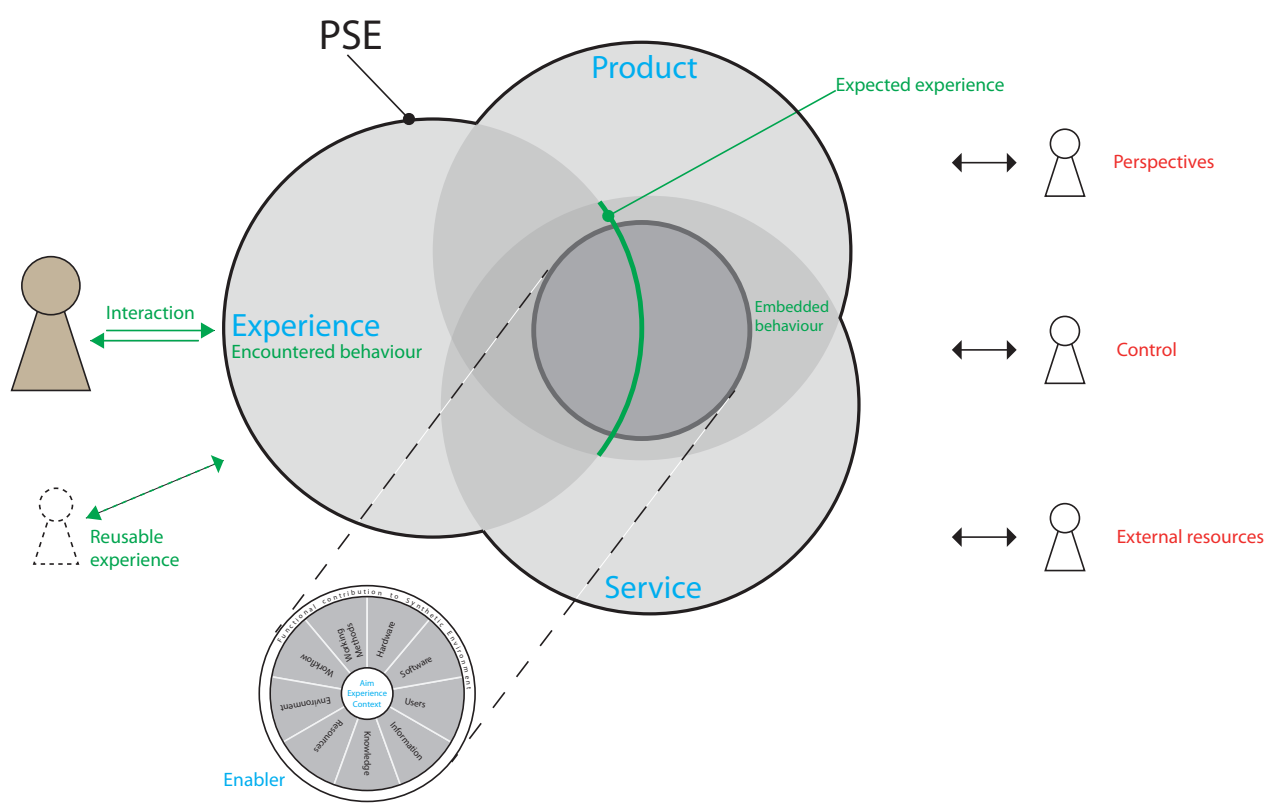

Figure 5.3 | The product service experience (PSE) overview 


\subsubsection{Product SerVICE EXPERIENCE}

The company has to be facilitated and stimulated to use the blueprint for documenting their needs, and for reviewing the status and possibilities. The internal communication between the higher level aspects (functional specifications) and between the multiple lower level elements (enablers) is a system of systems. Besides this internal communication between the different tools and devices that function as an enabler, the PSS needs input from the user in order to provide the service. Communication between the PSS and the user is essential in order to tailor the service to the expectations of the user. This can be seen as external communication.

This internal and external communication of a SE results in two types of behaviour:

- Embedded behaviour

The behaviour of the internal systems, not noticeable to the end user. E.g. the synchronisation of physical devices that act as a whole, such as the visual and aural feedback.

- Encountered behaviour

The behaviour encounterable for the end user, resulting in the experience of the service. E.g. the hearing of the sound and the seeing of the screen.

The use of a SE can become much more effective and purposeful if the user experience is explicitly involved and addressed. After all, the use of SEs in development trajectories is predominantly instigated by a desired experience (chapter 4). As such, the combination of products and services in the field of VR only provides added value when the experience is an inherent part of the system. Therefore, a SE should not be referred to as a PSS but as a product service experience (PSE) in the perspective of the user.

This also allows for a better conversion of the functional specification into an encountered behaviour, where the focus is not on a product, nor on a service or on the combination of both; rather, it is on the desired experience. This experience is directly influenced by the interaction with the user. The encountered experience is the reason why anyone would use a SE in product development trajectories, and should therefore be accentuated. Subsequently, this experience should offer something not possible without having the SE.

All three parts of a PSE have a certain overlap, and influence each other. E.g. every user has his own opinion on how a physical product looks, this is an experience of a tangible item, and thus can influence the encountered behaviour. The same can be said with how a digital service (e.g. digital interface) can influence the quality perception of a tangible item. The experience of the user goes beyond what the SE will offer; there is always a certain interference with the real world. The relevance of the overlap between these areas can differ amongst different PSEs. The overlap of the experience can be focused more on the product part or on the service part. This overlap and borders are not relevant nor important for the user, as the user can access the PSE as a whole. The user is actually an essential constituent of the PSE. After all, without the user, nobody is experiencing the PSE, so it no longer is a PSE. Nevertheless, the overlap can provide more overview and insight for the developers of the PSE. It can also act as a simplified profile of the solution, to make it easier comparable to other solutions, or to find more adjacent solutions based on a similar or comparable overlap.

\subsubsection{EXPECTED EXPERIENCE}

One of the key elements of a PSS is the inevitability of interaction between the individual 
elements that form a SE. The main difference between a service and a product-service system is the need to interact (conscious and unconscious) with the product. This enables the solution to tailor the service, during use, according to the current user. It also enables different users to use the same system but to experience different services. The embedded behaviour of the PSE is the combined result of the product (tangible) and the service (intangible), this embedded behaviour is not experienced by the user; it is the not noticeable collaboration between the different elements that form the solution. Some part of the behaviour will be encountered by the user; this is the combination between the product, service and the user. This encountered behaviour is also the result of the users' interaction with the system. The expected experience is what the designer/developer of the PSE would like to give as an experience to the user. This is the boundary between the behaviour not noticeable to the user, and the actual experience of the user.

In order to realise a better understanding of the consequences and relations between this proposed PSE model and a general VR tool, a metaphor is used throughout the upcoming clarification. As a metaphor we can explain the use of a SE as a visit to a theatre; the user is the audience of the stage play, the actors and stage properties are elements that form the SE, as is the theatre itself (building and location) and the adjacent people involved in realising the play (e.g. director, caterer, light and sound engineer, ...). Tailoring the SE can be compared to visiting a theatre where the performers respond to the reaction of the visitors (PSE) versus watching a movie (static product, experience cannot be adjusted to the viewer during use). One of the most valid reasons to use a SE in product development processes is to gain a certain experience (trigger specific senses) not possible without the SE. These experiences should be described as functional specifications, rather than technical specifications. Based on these specifications, the service can be preconfigured and tailored to the customer. The way to achieve these desired experiences for every individual user is something that requires a SE that can be tailored to the user during use, i.e. the functional specifications will remain the same, but the solution to achieve them can change. To achieve the same expected experience by multiple people, the way the experience is provided to the user can (but does not have to) be different for each user. This is comparable to a theatre performance where the customers individually decide if they want to see a musical or a comedian. Both are not directly prescribing what the actors on stage are going to do, but are describing what kind of experience the customer would like to have.

The user experience is something that will (and must) dissolve after use in order to have added value in a PSE. Because every experience an individual user encountered with a PSE, should be as much as possible tailored to that specific user. Based on his expected experience and the occurred interaction, the encountered behaviour will be experienced differently by each user. This tailored service approach is essential for a PSE, and makes a SE more than just a regular combination of (tangible) products and (intangible) services. Every user has its own personal experience with the SE; the challenge is to anticipate on this encountered behaviour, by alternating the embedded behaviour of the SE. Part of the solution for this is to use the functional specifications as the expected experience, and use that approach to bridge the gap between anticipated experience and the embedded behaviour.

Although the experience will evaporate for each user after use, it can be experienced multiple times. The encountered behaviour can still be the same, while the enabling system has changed. Interaction can be used to tailor the experience, and by capturing the effects of changes in the system to the encountered behaviour, the PSE can give insight in which configuration leads to a best practice situation. This control system checks if the expected 
experience overlaps enough with the encountered experience. This approach can be used to improve the predictability of future solutions. Compared to the theatre, it is like going to the theatre multiple times. This can be to experience the same play, but it can also be another play with in the same genre and even with the same actors. For the user the reason to go to the theatre was to gain a certain experience based on functional specification set during the selection process of selecting the best fitting play, and not based on (technical) requirements a theatre can offer.

\subsection{SE AS AN ENABLER}

As stated in Intermezzo 1, the focus on a PSS approach in a SE lies with the interfaces between the (e.g. nine) different elements of the solution. All these different aspects can also contain multiple elements (e.g. multiple hardware items or multiple software items in one SE). All these elements have to work together in order to make the solution work. This implies communication between elements, but also communication between the different aspects (Damgrave, Lutters, \& Thalen, 2012) of the PSE. The PSE is the representation of the combination of all SE aspects both in the product as well as in the service domain. This helps enabling the interaction, adhering to the expected experience (reference for the user) and constituting embodied or embedded behaviour.

The selected techniques and tools in the SE are the enabler for experiencing the product service combination. The SE allows for a combination of multiple aspects (e.g. devices, data sources, software tools, etc.) needed to realise a supporting virtual environment. The different aspects can communicate with each other inside the SE, without any human interruption. This is the part of the SE on the right side of the expected experience line in figure 5.3. The product and the service can respond to each other without influencing the experience. Nevertheless, a human can also be part of this, not necessarily the end user, but people (instead of devices) responsible for providing parts of the service. This internal communication is an enabler of the embedded behaviour. The power of a PSE lies in the possibility that the way in which the system realises the expected experience (as closely as possible to the functional specification), is possible without it being noticeable to the user how this is exactly realised; the user is not forced to make a distinction between the product and the service, the traditional borders fade. This is also in parallel with a theatre; the way in which a certain event on the stage is achieved is not noticeable to the viewer. For example, a stage property or piece of scenery can be moved over the stage by human power or by an automated system. For the viewer there need not be a noticeable difference between them; but for the organisation each option has its own advantages and disadvantages.

Following from the internal interaction and resulting embedded behaviour, a PSE can also be influenced by external factors that act as an external resource, have a different perspective on the PSS and/or can control (parts of) the SE. These external factors can for example be responsible for the adjustments in the SE to make it more tailored to the user, or for adding products or services from other sources into this SE. The view on the PSE from these external factors gives a different perspective on how the PSE functions; comparable to e.g. a director from a stage play who observes (and experiences) the performance in a different manner than the audience. Also from these perspectives, the PSE should perform according to the specifications from that stakeholder, in order to ensure that there is as little difference as possible between the expected experience and the encountered behaviour. The view from this perspective is focused on the expectations of possibilities, while the focus of the user lies at what is expected to encounter. 


\subsubsection{EXPECTED IMPACT}

In order to develop a SE from the PSE point of view, a different approach is needed. First, the emphasis will be on the relationship between the various elements that will form the $\mathrm{SE}$ (tangible and non-tangible). The focus is on covering the gap between the expectations from user and the functionality of the whole SE instead of on the development of individual elements. In addition, the functional specifications defined by the user will be leading in the development of the SE, and in the underpinning of choices. To be able to steer on this, a consultation model in which the multi-stakeholder decision-making processes are supported and facilitated is needed. A model to keep an overview of the entire PSE is desirable (Exner, Lindow et al., 2014; Exner \& Stark, 2015), since it results in a combination of multiple disciplines and expertise. The communication and dependencies between these different areas of expertise need to be emphasised; similar to the emphasis on the dependence between the different elements within the PSE.

Especially now, exploiting that different approach is interesting. The number of consumeroriented VR tools is tremendously increasing (e.g. due to head mounted devices like Oculus), making the availability of off-the-shelf products larger than ever before. From the company perspective this challenges the company to find the balance in functionality and costs; sometimes it is possible to offer $90 \%$ of the desired experience for $10 \%$ of the costs compared to the best possible experience. Correspondingly, the need to deploy custom made equipment in a SE decreases. Initially, the challenge was to develop the best possible technology to fit the purpose of the solution. Now, it is increasingly relevant to configure the best possible solution from the ever-expanding offer of contributors.

As a consequence, the realisation of a SE will increasingly involve more fields of expertise. As a result, the solutions have the potential to become increasingly flexible in design if all expertise can be utilised to its maximum, but also the risk of misinterpretation and miscommunication increases. This asks for a strong integration of all stakeholders in the design process, and not solely rely on the perspective of the company. A strong relation with the interpretation of the user is essential, as will be discussed in chapter 7 . The benefit of this can also be explained as: "In service engineering customer integration is characterised by a particularly strong customer contact during service delivery". Therefore, the customer is frequently involved in the service design process in order to test and evaluate the service process. In design engineering processes most approaches focus on the improvement of product ideas with customer feedback. An integration in the actual design process is rarely conducted in practice (Exner, Damerau, \& Stark, 2016). The possibility to make use of existing configurations must made more easy. With simple adjustments, the existing solutions can be tailored to fit the new customer or situation. The challenge in this is to know on beforehand what the consequences of those changes will be. Due to changes in the availability of VR tools happening at this moment, reconsidering the approach of the development of a SE is becoming more and more relevant. By focusing on the overall combination of product, service and experience, the quality and predictability of the SE can be increased. The position of a SE in the overlap between these three fields provides developers more predictable results, while the borders fade for the user.

The perspective from the company viewpoint on the blueprint will therefore focus on providing a more predictable SE; which can cope with changes before, during and after use. The information provided in the blueprint will be aimed on determining which resources of the company (tools, methods, people, etc.) contribute to realising a certain aim in a defined context, by realising a functional SE (figure 5.4). 


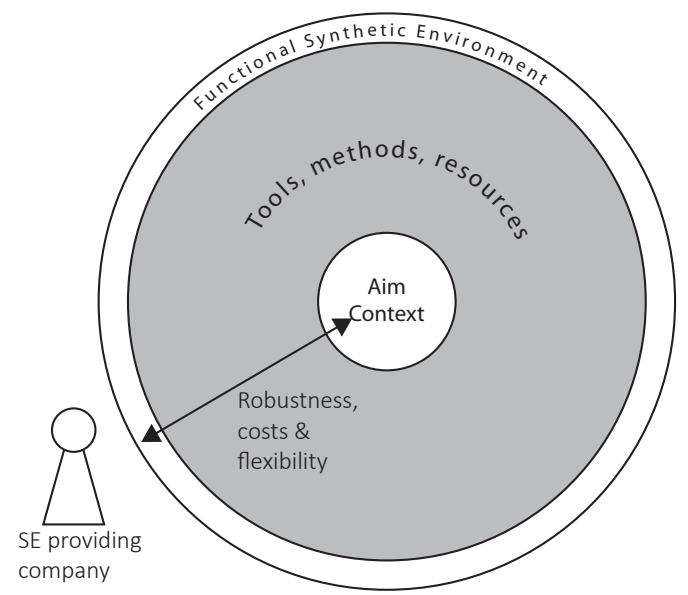

Figure 5.4 | The blueprint as seen from the company perspective

\subsection{ROBUSTNESS AND FLEXIBILITY}

By making use of the previously mentioned model an attempt is made to achieve robustness and flexibility in the development of a SE. This can prevent the development of a SE to enter a problematic status quo, wherein it is not clear what the needs for a SE are, and thus too much functionality is put into the solution. This abundance of functionality often works against the robustness, since it remains unclear to the company owning the SE, which part of the SE will be used and what the consequence of that use will be. This often neglects the flexibility of the SE; to have (the feeling of) more control over the quality of a SE, often is chosen for a unique SE for every situation and stakeholder. Companies end up in the realisation of single-usable solutions that are not reused afterwards.

The main reason to adopt the rationale of PSS in the development of a SE is the need for more understanding of the flexibility and robustness. Increased flexibility can be traced back to core of the approach of VR solutions as a PSE, where each component is defined by the functional specifications, and is part of the embedded behaviour. As a result, a component may be replaced without the user has here notion of. The other way around, a component can serve multiple functional specifications. Furthermore, this triggers developers to realise linkages between systems without having a direct need or application; only for the need of expanding the toolbox of components and connections. As a results the flexibility will keep increasing.

In addition, to improve the robustness of the system and to make it more transparent where the vulnerabilities are, a PSE offers an overview of the dependencies of a system. These dependencies can also be mapped on existing solutions, but with the PSE approach, they are an inherent part of the development. These dependencies can be used to cycle through worst case scenarios, but also to be able to switch quickly to an alternative solution in the event of a fault. An overview of dependencies also provides insight into areas that are more vulnerable than others (e.g. due to more dependencies); this can all be taken into account when realising backup systems. More robustness can be achieved by knowing the position of the dividing line of expected experience between the embedded behaviour and encountered behaviour of a SE. This allows developers to gain more understanding of internal and external relationships of the SE. 


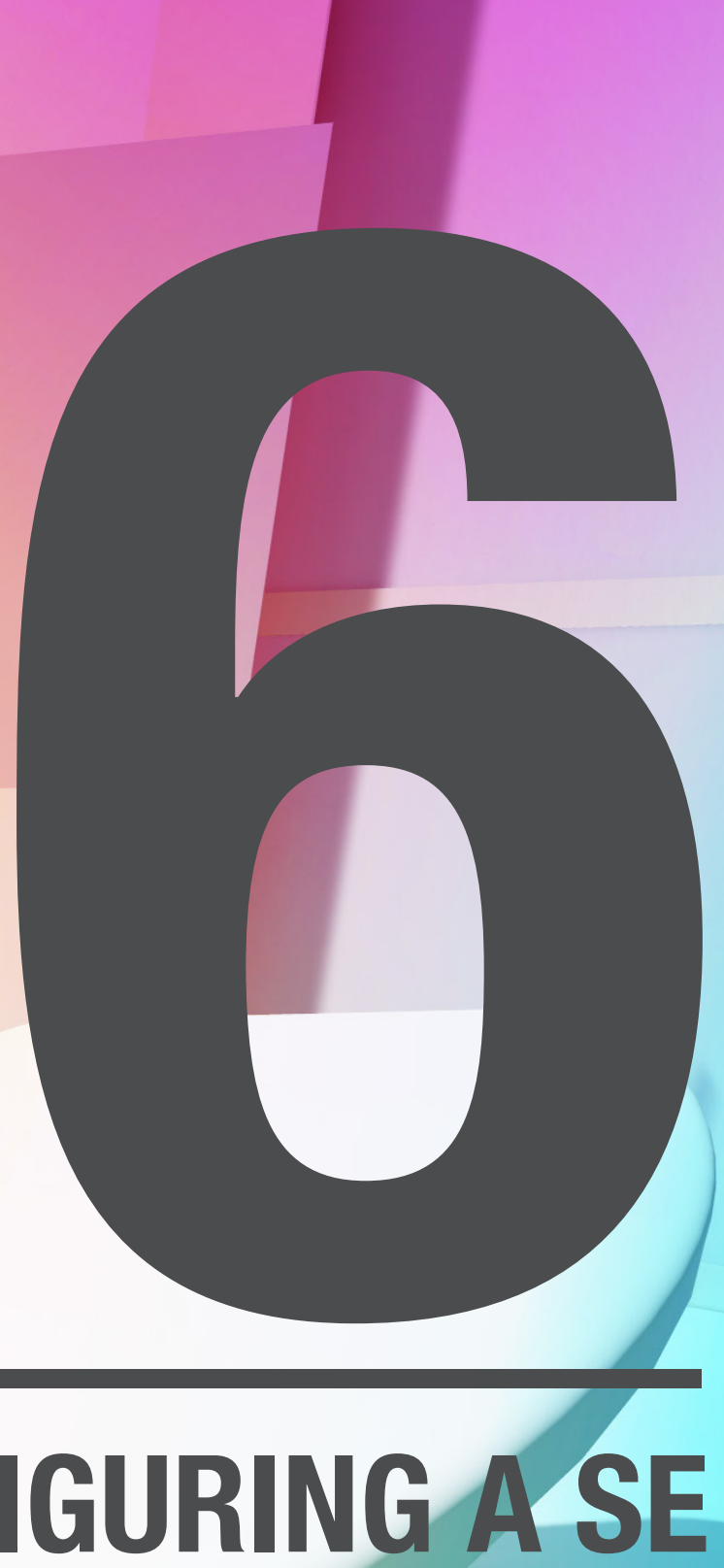




\section{CONFIGURING ASE}

Figure 6.1 | Perspective of this chapter

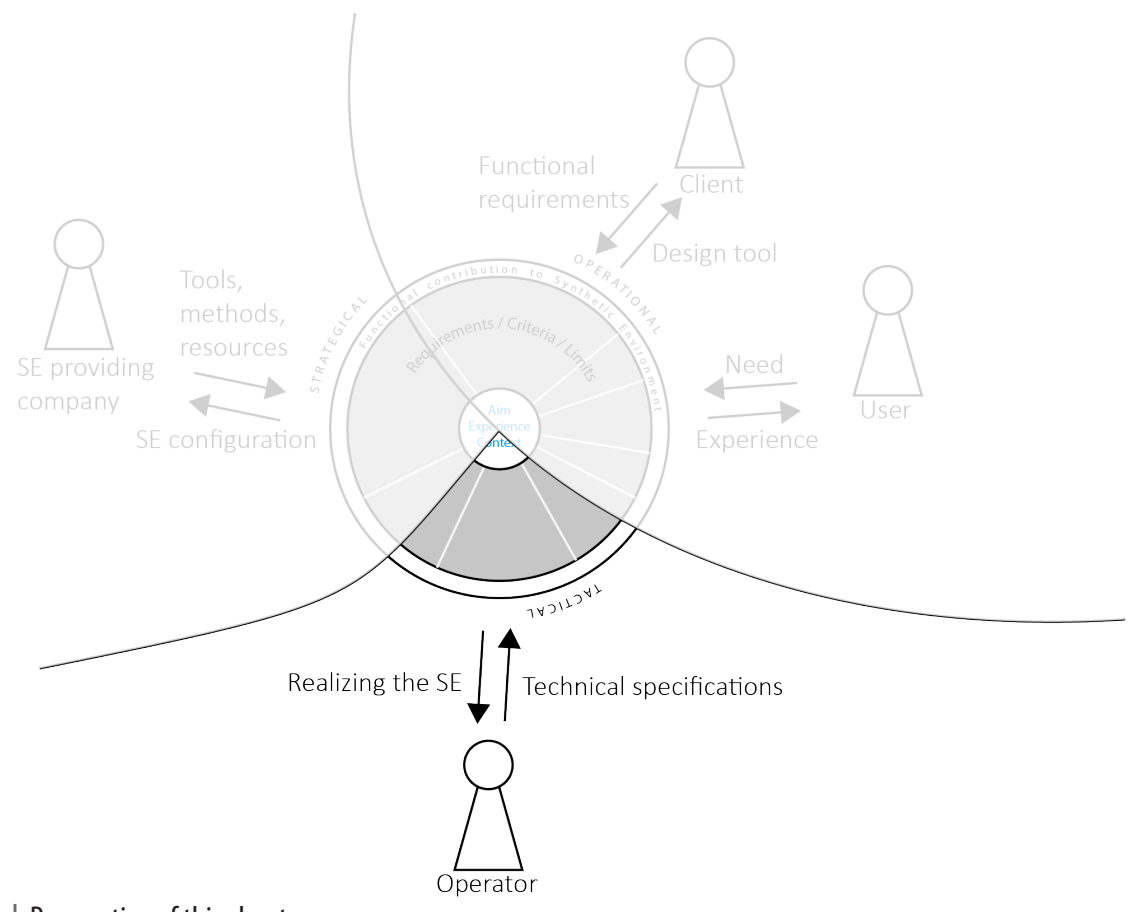

All Synthetic Environments are formed using a combination of multipletangible (e.g.devices) and non-tangible (e.g. software, processes, planning) elements. The process of selecting the right elements to make the most appropriate solution requires some understanding of the possibilities and limitation of the potential configurations; and therefore can be seen as a configuration problem. From a (limited) set of available tools, a thorough selection has to be made, taking into account all the requirements from each stakeholder and consequences of the solution on those stakeholders. This selection procedure constantly balances between making changes to the set of available devices (investment in resources) and changing the characteristics of the SE (modifying the characteristics of the solution). A change in the available devices can directly influence the possibilities of the solution, ranging from less effort to realise the solution, to providing more functionality. Realising a SE is always a compromise between how much resources may be spend to realise a certain solution. It is not possible to make on beforehand the appraisal between the SE characteristics if the resources are unknown, and vice versa. The amount of detail that is required in order to proceed with the execution of a SE largely depends on two factors. This is on the one hand the level of how much of the most ideal and desired solution is achieved, so to what extent should the most ideal solution be pursued. This can be viewed in the light of the requirements that the stakeholders have listed in the blueprints. On the other hand, this also depends very much on the experience of the operator.

To make any (large) investment in new devices, decent argumentation should be available why the current set of tools is not sufficient or optimal. This argumentation should provide enough information to convince other stakeholder iN supporting this decision. And if the 
choice for the purchase of a new tool is made, detailed information should be available regarding the specification of the new tool. With this information a better decision can be made to find the best fitting new tool. The only way to select the best fitting option, is to know what the criteria of all stakeholders are. Changing the characteristics of the SE also requires persuasiveness to convince other stakeholders to review their requirements or performance indicators to currently possible SEs. With increasing possibilities of the available tools, also increasing demands can be required, even though this is not necessary in order to use the SE.

With the focus on making combinations between different devices, it is obvious that combining functions from different devices into one more advanced function is also stimulated. The expertise field of VR solutions and SEs is not the only situation in which these combination are made, especially in production environments, combining multiple functions in one production step is not unusual (Lutters, 2001). In VR solutions and SEs this should also be one of the main objectives to realise an efficient and effective solution, especially since in VR and SE the combination between two devices can actual provide more than treating them as single tools. For example: when combining the (function of) visual representation of a model with the (function of) haptic feeling of the texture and temperature, the whole experience will improve. If the user only perceives a visualisation, or only the haptic feedback, the experience will be of a less quality. Subsequently, this synergy of combined functions makes it more difficult to assess the consequences of different configuration that form the SE. It will be harder to predict how others will interpret the results of the $\mathrm{SE}$, because the perceived experience is partially subjective. While with only physical models (in e.g. a production environment) the results of manufacturing processes can be checked by e.g. performing measurements. The selection of most appropriate tools (and selected functionality) to form a SE is by that means also subjective and disputable.

From the above can be concluded that the process of realising a SE can be considered more as a (shared) configuration problem, than a design problem. The main challenge is to find the right configuration of (often already existing) elements, rather than on designing a complete single new tool. In literature (Ali \& Kidd, 2013; Lafou, Mathieu et al., 2015; Lind kvist, Stasis, \& Whyte, 2013; Müller \& Sebastian, 1997; Schuh, Rudolf, \& Riesener, 2014) many approaches can be found to facilitate or organise (shared) configuration problems (chapter 4.1). Based on the similarities between VR and manufacturing highlighted in chapter 3.5, taking a closer look into the available solutions in that area of expertise can be meaningful. In manufacturing, this activity can be referred to as (computer aided) process planning.

Using the metaphor of process planning for assembling a SE has several goals. In addition to all the benefits and experiences already emerged at the beginning of this chapter, there is a strong relationship with the product service system approach in chapter 5 . This revealed that there are relationships and dependencies between the components that form a SE, and the way they are experienced by the end user. For the operator the challenge is to find these connections and realise the best possible coherence between expected experience and assessment experience. VR and SE has offered more flexibility than job preparation for production. The operator has to use that benefit, but in order to do that he needs to know how to make optimal use of this possibility. For example, VR has an undo function for the data adjustments: the same original and raw material can be simultaneously processed in multiple ways without having the original material affected. This makes it much easier for an operator to quickly test a new or modified processing step, before it is actually applied in the final solution. A thin line exists between the availability of the undo function for data, and the impossible to undo function for experience. Any experience, whether this 


\section{Part II}

is a visualisation or other influence of a human sense, is impossible to undo, and can even influence the perception of the upcoming experience. The way this process is being planned is different from manufacturing; there is a much greater possibility for change and iteration. This is also reflected in the use of the craftsmanship of the operator; there is a need to be able to carry out quickly and without permanent effects tests in order to discover the relationships and dependencies of parts.

\subsection{PROCESS PLANNING}

Process planning in the context of manufacturing can be defined as “... the act of preparing detailed processing documentation for the manufacture of a component or an assembly. Depending on the production environment, the degree of detail may vary." (Houten, 1991), with the goal "to allocate combinations of machine tools, cutting tools and fixtures to every batch of parts which has to be produced". A broader definition is formulated as "the determination of processes and resources needed for completing any of the manufacturing processes required for converting raw materials into a final product to satisfy the design requirements and intent and respect the geometric and technological constraints. Process planning is the link between product design and manufacturing." (Scallan, 2003b). Process planning encompasses the compromises that need to be made during the selection of processes, and in sequencing them against constraints of time, quality and cost. Determining the sequence of operations and the accompanying resources can be seen as the 'macro' level. On the 'micro' level the focus is on defining the parameters of each operation, and the details of each individual step (H. ElMaraghy, 1993). Process planning systematically determines the steps needed to manufacture a part, not only according to the design specification, but also while incorporating the limitations of the available manufacturing resources and their corresponding capabilities (Deb, Ghosh, \& Paul, 2006).

There is a lot of variation in the complexity of process planning. This variation comes from the number of individual production steps necessary for producing the product, the variety in each produced item, the number of products that have to be produced, the variation in the production line (and how often changes occur). For smaller projects with few production steps and a small quantity, there are little considerations in the planning of the production process. Whereas in products with high personalisation options, large quantity and many production steps, the planning of the production process will have a large influence on the success of the project (Scallan, 2003b). The level of flexibility and agility of a production line also influences the process planning, the more flexible and agile the production is, the easier changes can be made. Furthermore the consequences of wrong decisions have a less impact; quick corrections can be made. This entices to try-out different solutions, instead of trying to achieve the best solution at the first attempt.

The required or desired level of detail specified in a process plan largely depends on the type of environment in which the execution of the plan is employed (Rembold, Nnaji, \& Storr, 1993; Salehi \& Tavakkoli-Moghaddam, 2009). The process plan selects the appropriate parameters and processes to convert the initial raw (stock) material to the specified final form, it uses the information on the product to produce work instructions needed for manufacturing the product. The plan should provide the right type of information to the correct user, therefore, making a thorough process plan is a complex activity that requires a multiplicity of knowledge of design and manufacturing (H. Xu, Yuan, \& Li, 2009). As (Lundgren, Hedlind, \& Kjellberg, 2016) explains it: "Process planning is definitely more than the term itself might indicate. It includes both creativity, where ideas or solutions are synthesized, and analysis where decisions must be made by evaluation of proposed ideas.". 
Process planning in a production environment is used as a metaphor in this chapter, the terminology of manufacturing can be used to explain the terminology of Synthetic Environments. Raw materials are the different available digital data, physical devices and reusable and configurable software components. The final product is the completed SE, the requirement specification resembles the requirements following from the blueprints, and the geometric and technological constraints are the constraints in the combinations of items and environment. Semi-finished products can also act as a starting point for a SE process plan, so that bigger parts of existing SE can be reused, or parts of the desired solution can be outsourced.

Both projects based on assemble to order and projects based on engineer to order should be covered with the approach. With assemble to order no new elements need to be produced, so the process is only aimed on selecting the best fitting options from the available pool of items. In projects based on engineer to order the best fitting item needs to be developed at first; but that item can also act as a semi-finished product in future projects.

In the product development phase (chapter 2.1), the detailed requirements of the product are set by the designers and developers, and are handed over to manufacturing to determine the right type of process, as a sequential process (the classical "over the wall approach") (Loch \& Terwiesch, 1998). The detailed work instructions following from that phase seem to be separate from the design phase, but in many models (Arentsen, 1995; Liebers, 1998; McMahon \& Browne, 1993) there is a strong connection between these phases, with process planning (figure 6.2 and figure 6.3) functioning as the interface between the activities.

For developments in SEs, this sequential process has its limitations in finding a balance between when to change the configuration of devices, and when to change the available devices. In this case there is the need to perform the planning tasks in a more flexible way (Giebels, Lutters, \& Kals, 1999). There are multiple ways to provide a certain experience to the user, even without the user being able to assess the differences between the configurations (especially when handling a SE as a product-service experience, see chapter 5). But for the providing company the differences can be enormous in terms of reliability, costs, flexibility and maintainability. Thus, these differences are interpret differently from each stakeholder's perspective, and therefore these different perspectives on changes should be facilitated.

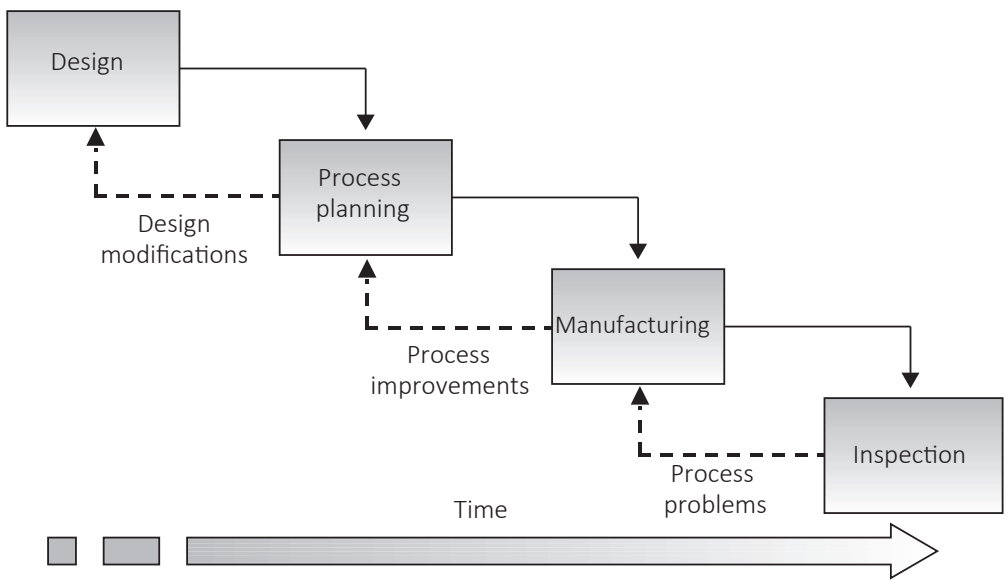

Figure 6.2 | Process planning relations according to (Scallan, 2003b) 


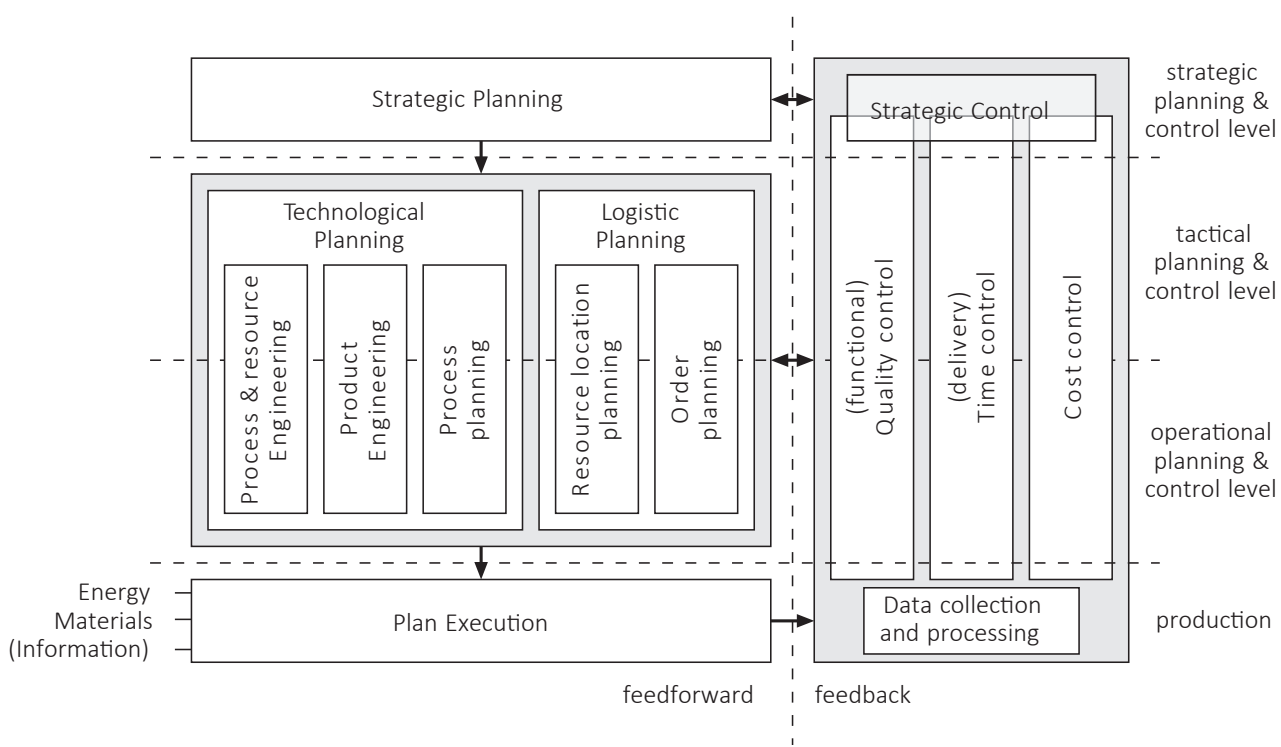

Figure 6.3 | Manufacturing planning \& control reference model (Lutters, 2001)

In process planning the main output is often the routing sheet and the operations sheet. An additional focus is made in this thesis; realising a profile of the Synthetic Environment. This profile should contain the main characteristics of the SE, making it able to store - besides the process plan - the configuration of the SE and to compare this with other existing and future SEs. The focus is on facilitating and documenting the discussion, argumentation and rationale of the configuration process. With this information it is easier to review and predict what the consequences of changes will be.

The time needed between formulating the requirements of the SE and realising the actual SE should be minimised (without quality loss or increase of costs) to enable for fast changes and iterations. Minimizing this time period prevents that the world has changed too much in the meantime, and it allows for more iteration steps to improve the quality. In process planning research many approaches have been developed to compress this time between designing a product and having the product on the market (S. Jiang \& Nee, 2013; X. Xu, Wang, \& Newman, 2011). In many research publications the focus is on changing the organisation in such a way that cooperation between different disciplines is stimulated and facilitated (Mas, Menéndez et al., 2013). In these organisations projects are carried out between people from different departments. These matrix-based organisation structures encourages all departments to contribute to the design of the product, and are often aimed on multidisciplinary teams. This stimulates the use of multiple expertise in each project, and aims on realising a synergy between the team members. This is also known as simultaneous or concurrent engineering (Eversheim, Rozenfeld et al., 1995; Sohlenius, 1992). "The goal of concurrent engineering is to develop a product and the accompanying processes simultaneously, in order to achieve an improved -and possibly faster- product development." (Lutters, 2001). The functions of such cross-functional teams include the assurance that all involved stakeholders understand enough about the project to make well-founded decisions on their expertise, which contributes to the complete design. It should also function as a method to understand the relation between product function and manufacturing methods. 
For an operator of a SE to be effective in the role as a process planner, the operator must possess a wide variety of skills and knowledge. Some of this knowledge can be obtained by literature and study, but the experience over time will certainly be the core of his capabilities. There is also a creative part in process planning. This is subjective, and relies on the experience, creativity and expertise of the process planner. "For the same set of requirements, virtually an infinite number of possible solutions can be created. Since the process planner must be able to abandon or discard bad ideas quickly to enable the creation of new ideas by exploring different possibilities etc., creativity and analysis are interrelated in process design." (Lundgren, Hedlind, \& Kjellberg, 2016). An artisan will be able to make faster decisions, with a better predictability of the final assessed experience. The aim of this process planning for SE is to design a robust SE configuration, capable of realising the most appropriate SE with the right quality at a competitive cost. (Lundgren, Hedlind, \& Kjellberg, 2014) also mention that in manufacturing there is big different in the way an expert acts: "Where the novice calculates, using rules and facts for determining actions (just like a computer following a program) the expert not only sees what needs to be achieved, he or she also sees immediately how to achieve this goal". Since the use of experience and creativity is something often appreciated by novice stakeholders, and it provides more possibilities regarding the flexibility and agility in the development process, the SE configuration process should facilitate and allow for the use of experience and creativity. The knowledge involved with making decisions during process planning is very broad, in the manufacturing process the following compromises have been identified for process planning (Houten, 1991, 1992):

- the interpretation of the product model

- the selection of machine tools

- the selection of tool sets

- the determination of set-ups

- the design of fixtures

- the determination of machining methods

- the selection of tools

- the determination of machining sequences

- the calculation of tool paths

- the calculation of process conditions

- the generation of NC programs

- capacity planning

These compromises are similar to what is needed in the development of a SE. For some of them the resemblance is exactly the same, while with some, e.g. 'the generation of NC programs' a SE can require a broader approach, such as more code generating than only NC programs.

\subsubsection{OPTIMISING THE DEVELOPMENT PROCESS}

Preventing waste throughout the entire process of realising a (physical or non-physical) product, is also an element considered in process planning. According to (Krafcik, 1988; Ohno, 1988) there are seven wastes of production: overproduction, waiting, transporting, inappropriate processing, unnecessary inventory, unnecessary motion and defects.

For SE's some of these seven wastes can be applied directly; 
- Overproduction; e.g. providing too much feedback or information to the user. This is not desirable because it obscures the relevant information. Furthermore it utilised capacity from the system which was not necessary.

- Waiting; e.g. the result of making changes in a virtual environment should be visible as soon as possible, because the results are often the input for the next phase or next decision.

- Transporting; e.g. moving persons or inventory takes up time, in this time the person or inventory cannot be used for its intended purpose. This is often a problem in travel time if multiple persons want to have a meeting.

- Inappropriate processing; e.g. making conversions of data without using the results.

- Unnecessary inventory; e.g. overwhelming and non-understandable data. The SE should offer the most appropriate experience to the user, which not always has to be the experience of the highest possible quality.

- Unnecessary motion; e.g. an interface that requires too much input from the user, in a non-logical sequence.

- Defects; e.g. not functioning elements of a SE.

A lot of steps have to be taken to make the transition between the composition of the SE, and the actual construction of the SE. Alongside with preventing waste, a lot of improvements can be made in this process. This preparation process is the process planning activity for the SE. (Chase, Aquilano, \& Jacobs, 1998) states that the process planning should be a longterm planning activity, strongly related to other planning activities. The process planning is part of the complete development cycle of a product, rather than a stand-alone activity happening after the requirements of the product are determined.

The blueprint introduced in Intermezzo 1 also requires a constant integration of foreseeing the consequences of combining blueprints, rather than setting a baseline of information needed in the blueprint. The more information is added, the more reliable the results can be.

In a process planning activity, the task of the process planner is not to improve the complete product development cycle, but focusses on the manufacturing steps. (Scallan, 2003b) formulates this as: "The focus of the process planner is to determine how a job is to be done and how long it will take. Therefore, the process planner is not concerned with resources of the shopfloor as such. For example, it is neither the responsibility nor the concern of the process planner if certain workstations are over or under-loaded with regards to capacity."

Since the development of a SE is often a sequence of appraisals, an operator for Synthetic Environments can prepare for this discussion. For each SE a review of the technical capabilities of the SE can be made. The same can be done with the capacity of resources. Both are even valid, and can be the starting point for a discussion about what to change: product or process. For example an outcome can be that the desired functionality can be achieved with the technical capabilities, but it will take longer than the available time. If the parameter 'time' cannot be changed; the operator can provide the answer on what is maximal achievable within the limited time. 


\subsubsection{PROCESS PLANNING APPROACH}

The outputs of the process planning are the main inputs for the construction of the SE, together with implementation and gathering of the right data. As such, the resulting information should contain enough to build and understand the SE. The operator must have all the information to know what the functional specifications of the SE should be, but also the conversion into more technical specifications for the software and the physical devices. To actually start the process planning activity, existing methods and approaches described in literature can be used. The next paragraph outlines the main differences in these approaches.

In the early days of manufacturing, before the second industrial revolution (chapter 3 ), the drawings made for the product were consulted as the end result of the development phase (Pahl \& Beitz, 2013; Shigley \& Mischke, 1986). The manufacturing foreman would use this drawings as a fixed element, and determines the best way to manufacture the part, based on the skills and machinery at his disposal (Houtzeel, 1996).

There are two basic methods available for process planning; variant and generative. Both can be applied in manual process planning and computer-aided process planning (CAPP). In the manual process planning the variant approach can be seen as the traditional approach and the generative approach is the workbook approach. The traditional approach is based on the experience of the process planner who decides the best fitting approach, in the scope of the company's available tools. The results are documented in a process planning layout. In the workbook approach, the process planner uses pre-determined sequences of operations to determine the best fitting approach. (Fletcher, Ritchie, \& Lim, 2012) state that "Traditionally process plans were carried out by a senior engineer and by combining their expertise with the part requirements a process plan would be generated that could then be passed to the shop floor for manufacture. The problem with plans generated this way is that they suffer from excessive clerical content, lack consistency and are dependent on the knowledge and experience of the planner."

There are some clear disadvantages of manual process planning (Scallan, 2003b):

- Excessive clerical content - labour intensive due to the excessive paperwork.

- Lack of consistency in planning - there are many ways to manufacture parts, different process planner will select different approaches.

- Late design modifications - manual process planning is not very responsive to late changes.

- Changing technology - new processes, tooling and materials are introduced faster than a single process planner can keep up with.

These disadvantages were the foundation of developing CAPP. A large amount of research has been conducted on CAPP (Duflou, Váncza, \& Aerens, 2005; H. ElMaraghy \& Nassehi, 2014; Houten, 1991; X. Xu, Wang, \& Newman, 2011), and the advantages of this are considered to be (Rembold, Nnaji, \& Storr, 1993; Yusof \& Latif, 2014):

- Less time spent on process planning by reducing throughput time and improving quality.

- Less reliance on the knowledge and experience of the process planner.

- More efficient use of manufacturing resources leading to improvements in costs.

- Improved productivity.

- Improved accuracy and consistency of process plans. 
CAPP consists of the determination of processes and parameters required to convert raw material into a finished part/product (Ham \& Lu, 1988). According to (Chryssolouris, 2013) it includes the interpretation of the design data and the selection and sequencing of the necessary operations to manufacture the part. Furthermore it also integrates the selection of machine and cutting tools, determination of cutting parameters, choice of jigs and fixtures, and the calculation of the machining times and costs. CAPP provides the link between design and manufacturing, it aims on reducing the time and cost while improving the quality of the product (Fletcher, Ritchie, \& Lim, 2012; Yusof \& Latif, 2014).

The CAPP methods can also be categorised as variant CAPP or generative CAPP (Boer, Petitti et al., 1990). The variant CAPP retrieves a standard (already available) plan and modifies it to suit the given part. This is approach uses results from previous designs to generate new or partial plans, through the use of a classification code (Alting \& Zhang, 1989). These plans can then be taken as a base line by the process planner for further refinement into the final plan.

The generative CAPP lets the computer develop a complete new process plan for every part. Feature recognition and design by features plays an important role in the CAPP approach, it allows for understanding standardised elements and steps in parts (Waiyagan \& Bohez, 2009) (Butdee, Noomtong, \& Tichkiewitch, 2009) (Joseph \& Matthew, 2010). Another key part of CAPP which can also be relevant for the development of SEs is knowledge-based technology (H. Xu, Yuan, \& Li, 2009). This allows the capturing of knowledge from experts and is able to simulate the problem-solving skills of a human expert in a particular field (Denkena, Shpitalni et al., 2007).

\subsection{ASSESS TECHNICAL POSSIBILITIES AND LIMITATIONS}

The SE operator is involved in many of the development phases of a SE. To prevent that this single person is responsible for the complete SE, many of the tools described in this thesis are aimed on supporting the collaboration between all involved stakeholders. The operator is often treated as the link between different stakeholders; not as an expert in every field. The major role for the operator is to realise a workable SE, and for this appraisals have to be made, and the rationale behind that must be communicated among all relevant stakeholders. Therefore a common base that functions as a discussion space is desirable.

The operator needs to make decisions on what devices and what data is used in the SE. So in this approach, the operator is the responsible person for making the process planning for a SE. In the area of VR and SE, and therefore in this thesis, the aim is on configuring solutions that are made from not solely newly developed items, but also can use existing items. Rather than to compound an entire factory that holds all the items to configure multiple SEs, the starting point is the development of a single SE. The operator needs to map the possibilities of individual devices. To achieve that, the existing knowledge and approaches of (computer-aided) process planning can be used. Furthermore, not only the possibilities of individual devices are of importance, also the additional gained possibilities when devices are combined is something that needs an overview. New functionality can be achieved if the right devices are used conjointly; this is something not common in manufacturing. E.g. the combination of a drill and a bending machine doesn't offer a whole new function (although it can speed up the process), whereas the combination between e.g. a motion capturing suit and a head mounted device can offer new interaction possibilities not possible with a single one of the tools. Within manufacturing it is common to subdivide the individual production steps needed to manufacture a product; for a SE subdividing 
the steps needed to achieve a certain experience is needed. Knowing the relation of what device is responsible for realising a certain stimuli of a sense, and how that add ups to a complete experience (see chapter 4.2).

To be able to predict how good a SE will eventually function, the selection process has to serve multiple goals at the same time. The process will be a continuous event of decision making, comparable to the process planning in manufacturing (Chryssolouris, Chan, \& Suh, 1985). During these processes compromises have to be made. To come to the best fitting solution, it is important to take strategies and comparative assessments in consideration during the decision making. The task of the operator is not only to determine the configuration of the SE, but also to provide the right information to maintain and operate the SE; and to communicate this information among the other stakeholders. Whereby the operator for a SE has to deal with not only the requirements from the SE providing company and the client, but also with the assessed experience of the actual end user, which is not common in all manufacturing approaches (figure 6.4).
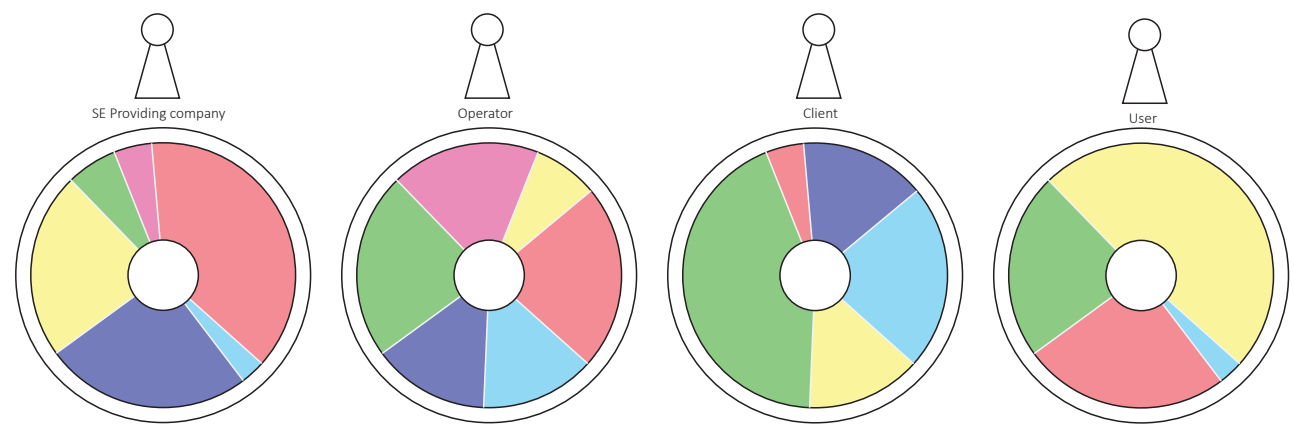

Figure 6.4 | Multiple stakeholders with different segmentations (and focus) of requirements

The blueprints provide a documentation of the desired functionality and conditions as seen from a single stakeholder perspective. The operators can utilise this information as a base to determine what the overlap and boundaries are between different perspectives. The overlap can be discovered by reviewing similar or succession requirements, while the boundaries can be recognised by comparing the stated limitations on each aspect. To prevent over-the-wall engineering, none of the blueprints, nor stakeholders, is the fixed starting point of the development of a SE. Furthermore there is no predetermined sequence in information flow or process steps between the blueprints, and there are no hierarchy possibilities in the blueprints.

The lack of interoperability between different data formats results in information fragmentation, data duplication and potential data inconsistency. If data is shared by multiple stakeholders, this becomes visible in the blueprints, and duplication can be prevented by linking them to each other. By reducing the amount of data duplication, the blueprint increases the direct value adding requirements from each stakeholder, to achieve a more holistic view in interdisciplinary work between different experts. This area in which the SE should take place is the 'discussion space'. This discussion space is the combination of all requirements that represents the maximum freedom in which the SE has to be developed. The process planning approach should reduce this area into a more consolidated space with more potential for the solution: the solution space. In the solution 


\section{Part II}

space more preferences can be made towards the final solution, and it contains all the parameters that eventually define the final SE (figure 6.5).

This solution space should map the possibilities and limitations of each perspective, relevant to the desired solution. The selection of the best fitting solution is an appraisal between the four following items;

- Time

- Quality

- Costs

- Accessibility

Where the first three criteria are common in many selection procedures, incorporating 'accessibility' is not. Due to the constantly changing availability of (VR) tools used in a SE, using the experience of an artisan to understand the possibilities of new technologies can make the threshold for quickly adopting new tools and techniques lower. The operator needs more possibilities to steer on experience; the added value of the craftsman should be higher appreciated. Especially when the relation between tools-techniques-solution (chapter 2) is understandable and the results for the final assessed experience can be easily communicated. Accessibility represents this (subjective) knowledge, and can be taken into consideration during the appraisal, with the same importance as the more objective first three items. Realising a sequential process of decision-making is not desirable in this constantly changing atmosphere. It is less relevant where the knowledge for a decision originates, the results of the decision on the other hand is extremely important, as is the usability of the decision.

Choices have to be made during all phases of a SE development. The goal of a SE is different for each stakeholder; while at the end one single SE should function for all stakeholders. Based on the approaches from (computer-aided) process planning a prediction can be made what the upcoming step should be. Alongside the operator can decide if all the steps between should also have to be taken. The supporting system for realising a SE should therefore provide more of a direction in which the operator must evolve, rather than forcing specific steps to be taken or concrete solutions to be used.

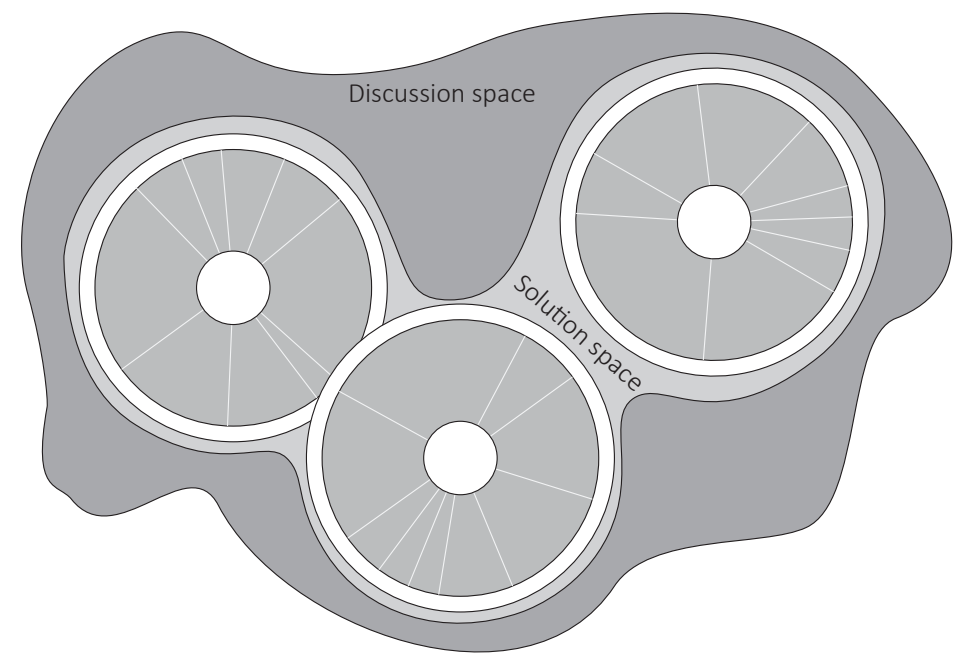

Figure 6.5 | Discussion and solution space 


\subsection{CONSEOUENCES AND PREDICTABILITY OF COMBINING TOOLS}

The role of the operator is not only that of a process planner. He is also a stakeholder in the final solution, and therefore has a personal interest in the solution. For the operator, it is important to know how to judge whether a particular objective, criteria or requirement fits into the whole of the solution. The task is to find the right elements which allow for a certain experience. The alleged experience comes from the blueprints made by different stakeholders and perspectives. The available elements will originate from the tools which are currently available to the operator. In a non-matching criteria, the choice must be made between adjusting the (functional and/or technical) specifications resulting from the blueprints, or adjusting the solution. The last option results in changing the inventory of available tools. In the first option the composition of the SE goes back to the discussion space; changes have to be made in one or more blueprints. In the second case the operator has to have good arguments whether the investment is worthwhile. This requires insight in the probable possibilities of new tools in other SEs. Being able to communicate how the perspective from all stakeholders are taken into account, also on the long term (during preparation of use and actual use), it is essential to realise a supporting base. To facilitate this, the profile of the SE should also be visually communicable.

All the information provided in the blueprints can be stored in a database or folder structure. This information is hard to communicate if it cannot be visualised. There are various aspect that should be taken into account when designing such an interface. There are usability concerns that should be taken into account, and there are constraints to the application of interfaces with certain properties due to human factors. Human information processing capacities through different senses affects the designation of the interaction possibilities of the blueprint. There are several aspects described in literature about the usability of graphical user interfaces (Galitz, 2007). Human perception and processing of information is a complex domain. The desired architecture should support decision making through enabling users to discern critical cues impacting the consideration of design alternatives. The design process should be supported, not hindered. Task performance in virtual environments can be improved when the interface is appropriately designed to avoid conflicts in division of attention, allowing the user to focus on what is important (Jacko, 2012). A few techniques are depicted by (Darken \& Peterson, 2002) to facilitate this navigation process:

- Maps: Enable users to maintain overview of the different elements even when focusing on one task. With this, the current perspective on this map should be clear.

- Landmarks: Offering spatial cues aid navigational tasks.

- Trails or footprints: Review of taken steps can be visualised through so-called trails or footsteps of the development process.

- Directional cues: Directional cues in combination with maps, landmarks or trails provide with positional information.

By having a profile available of every SE that is made - e.g. within the context of a company the possibility occurs to get an insight into tools or compositions that are used more often. By means of this "DNA of the SE" it can be visualised that a specific tool is more often used in various configurations than others. With that information, the decision can be made to invest in that specific tool, with the knowledge that it has a larger potential. In addition, frequently used combinations of tools can be further improved, and perhaps even be merged into a single tool or module in order to save costs and efforts in this way. The decisions to make (large) investments follow the use of resources. This is similar to 


\section{Part II}

the "SE as a factory layout" (chapter 3.4), in which exactly this flexibility of VR is related to the learnings of the past (Marzano, Friel et al., 2015; Menck, Weidig, \& Aurich, 2013; Menck, Yang et al., 2012). This allows solutions to improve over time as they are more commonly used. And the investments are a more effective instrument to enhance the quality of the SE. The operator is supported in answering the question when the threshold is reached to make major investment; since simulations can be made of existing (or past) SEs containing the modified tool. This will show whether the offered experience is actually better (or equivalent) to what is was. Also considering the approach of treating the SE as a PSS (chapter 5 ) the focus will be more on steering towards providing the experience with maximised efficiency. The gap between the expected and assessed experience can be made as small as possible, while the end-user will not need to notice any difference in the way the perception is experienced. Through these simulations of possible future solutions the opportunity arises to view the rationale and effect of decisions from different viewpoints.

This thesis focuses on the realisation of flexible and low-end SEs. This deliberated choice originates from the possible applications of VR in product design, as described in chapter 2.3. In realising SEs which are composed of relatively inexpensive tools a much higher flexibility can potentially be achieved, and the (financial) threshold for (first time) use is much lower. By taking distance from the dedicated and custom-build solutions, already some criteria in the selection process arise: focus on cost-effective solutions that make re-use of components possible. In order to accomplish this the strength of efficient process planning comes into use. It offers - in combination with the SE profiles - insight in which solutions actually offer more than the sum of the individual tools. Even though the emphasis is on more accessible SEs; the operator will always have to take into consideration the turning point between virtual and real. There are always projects available which not benefit by using VR or SE solutions; this tipping point between real and virtual must remain part of the selection process.

The process and operations following from the blueprints will also function as a quality assurance. The solution should be developed in such a way that the quality of the provided experience can be ensured over a longer period of time. Large documentation activities or high workload by managing documents for Process Failure Mode and Effect Analysis (PFMEA), Control plans, Initial process studies and Measurement System Analysis (MSA) (Lundgren, Hedlind, \& Kjellberg, 2015, 2016) should be avoided by integrating the documentation automatically in the blueprint approach. This enables learning from successes and failures of the past, without the large resource investment. The combination of blueprints and available best practices of other SEs will provide the operator with enough information to assure a certain quality, and if needed; allows for the use of the data in different quality assurance approaches.

\subsection{SCHEDULING}

Individual objects that form a SE can also be used to realise other SES. A SE should be seen as a temporary combination of tools, software, models and data. This flexibility is important to achieve a higher efficiency in the use of resources, and more optimisation in the use of existing elements. The (re)use of elements in multiple SEs should be stimulated in order to enable the option to spread costs among multiple projects. Here the operator must find a balance - during the development of a SE profile - between the need for a completely new SE, or to perform modifications and additions to an existing SE to create a new usage option. The balance must be found between the optimal use of complete SE, and the optimal use of parts of SEs. So it can occur that enormously flexible SEs during use always 
unused a big part of the components, making the efficiency of each part actually very low, but the efficiency for the complete SE is very high for all.

Putting together all the elements that form the SE also require a lot of creativity and subjectivity. Here comes experience in handy. The operator will review during the composition of a SE how much time is involved in all the necessary steps towards realisation. As with process planning (Chryssolouris, 2006), within a SE can be looked at standard times for specific activities, which can be used to determine what the cost will be for installation, first time use, normal use and disposal. This will also provide the information needed to decide whether or not to rearrange existing SES, for example in case of new technology or new use situations. Especially in SEs the amount of time needed for preparation can vary enormously. The VR items in SEs can require a very dedicated and accurate order of steps needed to perform the desired task. Often this emanates from converting digital models or calibrating physical and virtual items (J. Kim, Pratt et al., 2008). Preparing the use of for example a high-end CAVE (Cruz-Neira, Sandin et al., 1992) is significant more time-consuming than lower-end devices, e.g. head mounted devices such as the Microsoft Hololens ("Microsoft Hololens", 2016). This is comparable to the difference in preparing the use of a CNC machining centre to a manual lathe. By better predicting this preparation time, more flexible use of individual elements of a SE is possible.

As a metaphor the construction of a SE can be compared to how a plumber uses his van. Everything the plumber may need on a daily basis is available in the van, even though he will not use every tool every day. But the most high-end solutions will not be carried around daily, and require therefore more preparation to use.

The way an operator looks at the blueprints will have the focus on the realisation of the SE. For an operator an easy maintainable SE is important. It has to be a robust, but also flexible solution that fits the expertise and capabilities of the operator. The information in the blueprints will be aimed on the relations and dependencies between how certain actions are implemented in the SE and how they enable the use of the data and resources (figure 6.6).

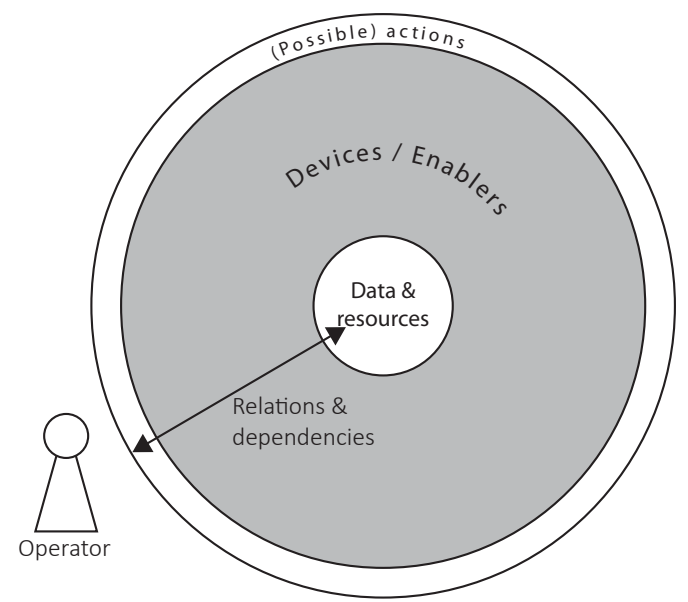

Figure 6.6 | The blueprint as seen from the operator perspective 
Part II

6 


\section{SETUP FOR SE SOLUTION}

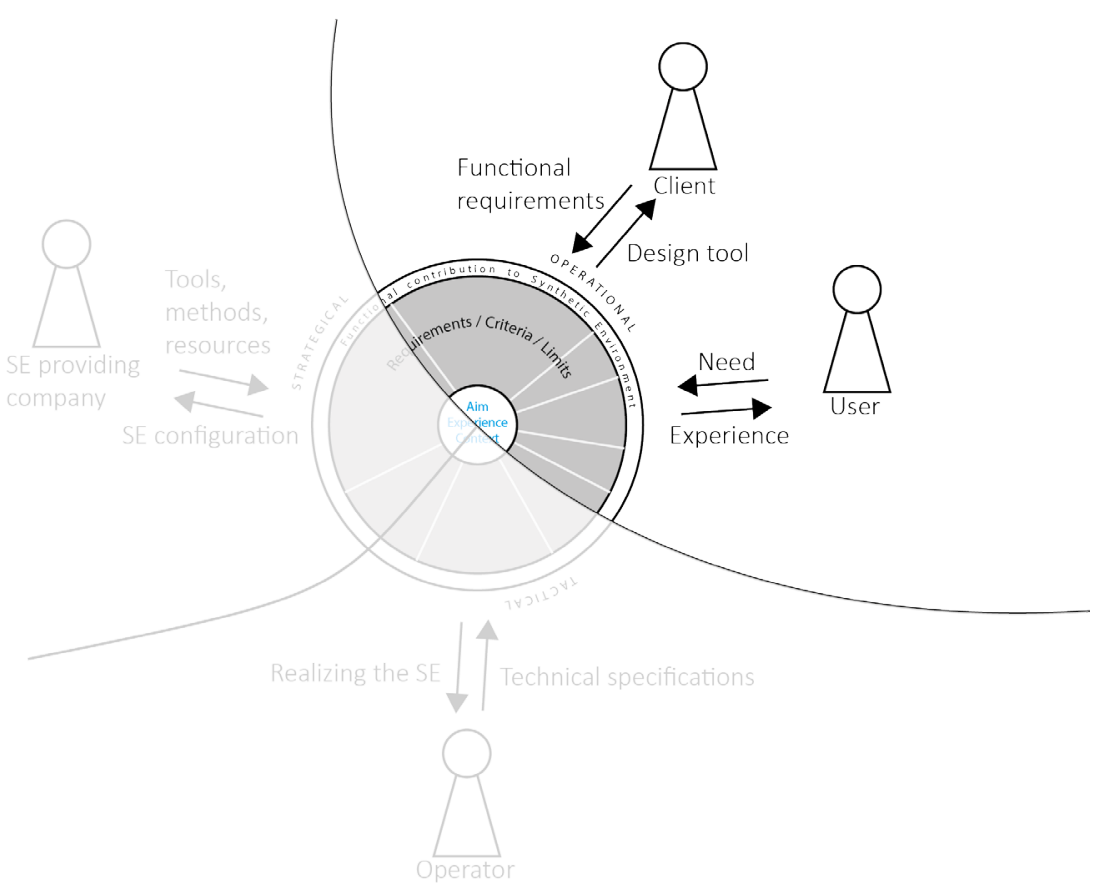

Figure 7.1 | Perspective of this chapter

Within the field of product development, the need for support and facilitation of the various product development phases is obvious. In general, product developers also show enthusiasm for approaches that offer adequate support. Any SE usable within a product development process (PDP) has the aim to optimise that process in terms of quality, efficiency or effectiveness. A SE is not a stand-alone tool that can function without utilising existing data from previous phases of the PDP (chapter 2.3), nor is it an automatic 'solution generator' that works without interaction with a user (Damgrave, Lutters, \& Houten, 2012). The SE is seen as an enabler for the stakeholders involved in the PDP, and should be developed towards the most appropriate tool for the user. In order to realise such a SE, the needs for the user have to be extracted and made communicable with other stakeholders. The blueprint of Intermezzo 1 is the proposed way to communicate and document the requirements for the desired SE as seen from each involved stakeholders' perspective.

Comparable to the developments of other PDP tools, there can be a difference between the client (who orders the tool, and is involved in the selection process) and the user (who actually uses the tool). This potential difference directly visualises that the number of possible and available blueprints should not be predetermined. The approach of acquiring the appropriate information from each stakeholder requires flexibility and adaptability in the process in order to tailor the approach to the stakeholder. This flexibility is inherently connected to the blueprint approach of preventing a hierarchy. Relations and interactions between stakeholders will appear, even though they are not obliged. Therefore facilitating and enabling these interactions is important, but it is not necessary to define exactly the communication and information between each stakeholder. Each relationship can exist, 
and can be filled in depending on where the user is confronted with. Figure 7.2 indicates the existing relations between the stakeholders, but also intentionally does not contain the definition of the communication between them.

\subsection{RECOGNISE THE NEEDS}

For a SE to function properly, the best possible association (according to the criteria set by all stakeholders) with the expected experience (chapter 5) and purpose of the end-user and the client has to be made. To achieve this, the SE providing company and the operator who develops the SE (chapter 6) must know what the expectations from the end-user and the client are.

The essential goal of the desired solution can be documented and communicated as the stated purpose. It contains the predefined, formalised and static reference of that specific goal. It reflects the pre-imposed requirements of a stakeholder (Miedema, Voort, \& Houten, 2009; Miedema, Voort et al., 2007). Based on this stated purpose, the SE providing company and operator can determine the best fitting approach for realising the SE. To come to a stated purpose, the information must first be defined using the blueprint from Intermezzo 1. It is not the intention that the client acts as the designer of the SE, the future potential user is in fact not aware of the possibilities that a not-yet-existing solution can offer. The focus should be on aspects, within the existing PDP, where the stakeholder recognises, in his opinion, a need for possible improvements. The improvement itself is a characteristic of the solution, whereas the goal of what those improvements should offer can be defined as a functional specification. This is, in the perspective of the user-stakeholder, the purpose of using a SE. The focus of the user is on the result of the use of the SE (what possibilities should it make accessible), and less on the specific devices that made it possible. Since the SE will act as a tool within an existing or future PDP, preconditions will have to be made in which the SE will have to operate. Not only technical or environment-dependent conditions

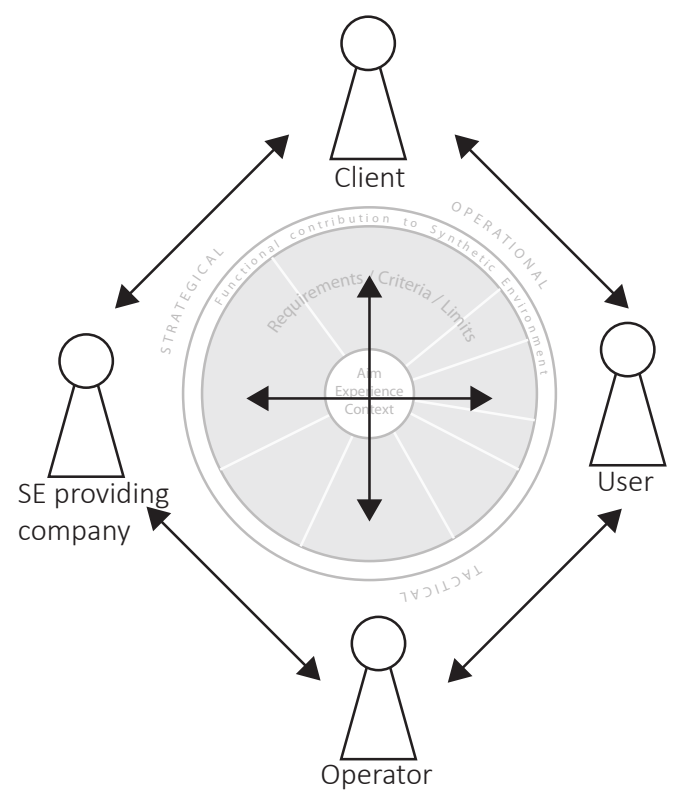

Figure 7.2 | Stakeholder interactions 
are relevant, also the capacity of the user can be set as a precondition. These conditions can also be documented in the blueprint. The blueprint hence facilitates documenting the functional specifications and the aim (stated purpose) of the SE, together with the conditions this SE must meet in order to be useful for the targeted PDP.

To facilitate and stimulate the discovery of these aims and preconditions, the client and the end-user have to be supported in this process. There is a lot of research done on integrating the end-user in the design process (Kaulio, 1998; Kujala, 2003), and a large number of methods and approaches have been developed over time.

The blueprint does not require a pre-defined approach for documenting the requirements of the stakeholder. Several methods are suitable for this, and it will be mainly based on the preferences of the stakeholders which one is preferred. In addition, every stakeholder should also be able to add requirements (based on e.g. strategy or policy) without a supporting method and without a direct assignment or task from others. Any form of hierarchy should be avoided in this stage of the development, to prevent that based on the status of the stakeholder some requirements are considered more important. This is undesirable because argumentation for differences in importance are lacking. The needs that occur during the execution of a PDP, or the vision a stakeholder has independent of a current PDP should also be captured in a blueprint. The user should always be the stakeholder that defines the functional specifications that are relevant in his opinion, often based on an operation perspective. Later, the developer of the SE can translate this information into actual technical specifications (section 4.2). The blueprint should give the possibility and the occasion for discussion on the requirements. Since the user is the not the one who designs and actually realises the SE, the provided and documented information should be understandable and usable in the perspective of other stakeholders, such as the strategic perspective of the company or the tactical perspective of the operator.

Various methods and approaches to acquire needs and functional specifications from users are described in literature. In the approach of this thesis, these existing methods and approaches should be usable as a functional tool to extract this information from the client and the user, and document it in the structure of the blueprint. Therefore the connection between them and the blueprint is essential to lower the threshold for using the blueprint, and increasing the use potential.

A selection of approaches is made to determine and discuss the suitability of them in this research, and will be discussed in the upcoming paragraphs:

1. VR-lab approach

2. Consultancy roadmap

3. Scenario based product design

4. User-centred design \& Participatory design

The selection is made based on the criteria that the approach is already used in combination with the development of VR solutions or SEs. This is done so that the focus of the research can be on the link with the blueprint, rather than reviewing if the approach can be used in the context of VR or SE. Furthermore, the selected approaches all put the user in a different role. In the (1) VR-lab approach the user is facilitated in a decision making process, where all stakeholders can participate in. In the (2) consultancy roadmap an external person (consultant) tries to acquire the information from the user, while in the (3) scenario based product design approach the user is confronted with multiple scenarios to put the information into context. Finally the (4) user-centred design \& participatory design 
approaches treat the user as a designer of the solution. All these different roles of the user should fit in the supporting architecture of this thesis.

\subsection{VR-LAB APPROACH}

Within the VR-lab of the University of Twente ("Virtual Reality Lab, University of Twente", Appendix A), product developers are encouraged to address and optimise the development processes they employ in daily practice. The approach used in the VR-lab of the University of Twente is aimed at developing, realising and using a SE in cooperation with multiple stakeholders. This approach allows for the use of a variety of design tools within the SE development process, and as such will act as the basis for further development of enhancing the use of design tools in SEs (Damgrave, Lutters, \& Van Houten, 2013).

The scope and emphasis of the VR-lab approach is on supporting the decision-making processes that involve multiple stakeholders who aim to understand the implications of the many decisions that have to be made. Within these processes, many choices have to be made that involve multiple stakeholders. This immediately leads to complex dependencies between the choices made and the consequences thereof. These consequences are not always clear for every stakeholder involved. The approach of the VR-lab aims to give insight in the relations between and dependencies of all decisions, and to present them in the most purposeful and adequate manner. Furthermore, for the design process, it is important that such support can be delivered quickly, with minimal adjustment to the development process, the project planning and schedule. This implies that the configuration of support should be flexible and easy to adapt to different situations.

This approach gives designers the ability to rely on support in the design process when it comes to cooperation (figure 7.3). Such support is available from the earliest stages of the development process. In these stages, it is desirable for the various stakeholders to define a common vision and understanding of the (explicit and implicit) problems that together constitute the basis of the development project. During the solution generation phase, the lab offers the possibility to clarify ideas for future scenarios using many types of visualisations and interactions. This also gives direct insight into the consequences of possible choices in areas such as safety, construction, use situation and composition. The lab adds the most added value to a process when a (large) group of stakeholders is interacting with one and the same set of information, and when they approach and
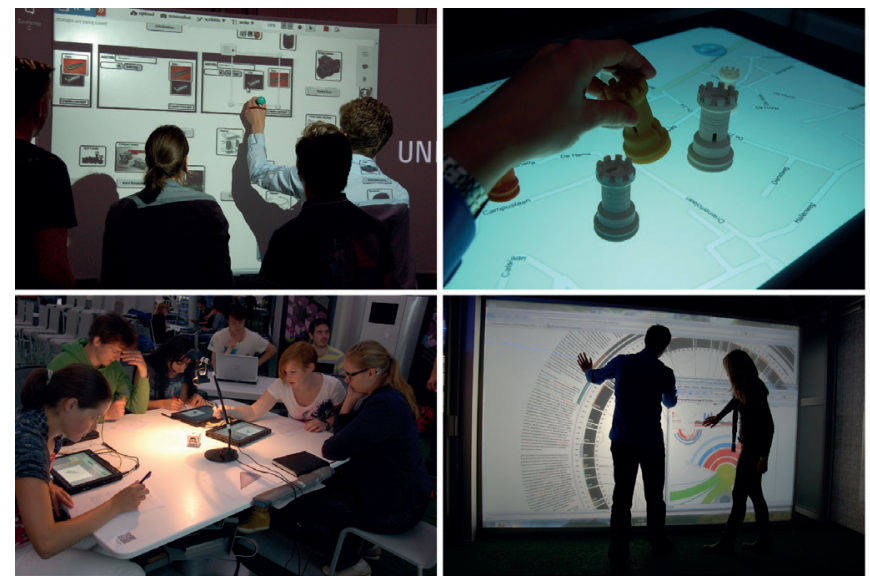

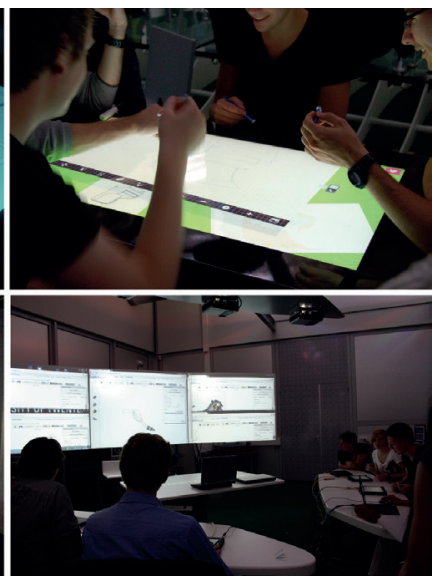

Figure 7.3 | VR-lab cooperation sessions 


\section{Part II}

handle this set in a way that best suits their own personal expertise. In this manner, the interactions and adjustments of other stakeholders to the data are immediately relevant and can be made visible. It is therefore possible to assess the collaboratively composed solution (path) based on individual expertise. In this, it is essential that every stakeholder perceives the information that is meaningful for him; therefore it must be possible to omit redundant information and information that cannot be processed. In other words, the working methods, together with the capabilities of the VR-lab, should enable individual stakeholders in effectively and efficiently addressing information that is relevant for his perspective, in the context of the overall solution (path).

\subsubsection{Methodology}

A product development process can be considered to be a constant trade-off between problems and solutions (Krishnan \& Ulrich, 2001), and the same can be said for SE development processes (Lu, Shpitalni, \& Gadh, 1999). To support and facilitate this tradeoff, it is important that all stakeholders share an aligned vision on both. This starts with the definition of the actual design problem, rendering a shared understanding between the various stakeholders. With this, everyone can assume that the defined problem is interpreted in the same way by all participants. This synchronised start creates a situation where different backgrounds and expertise of the various participants come together and where even end-users can be involved in the process. By providing each stakeholder with the possibility to directly and explicitly communicate in his or her preferred way, the risk of misinterpretations is minimised. Each stakeholder should be involved in the process by

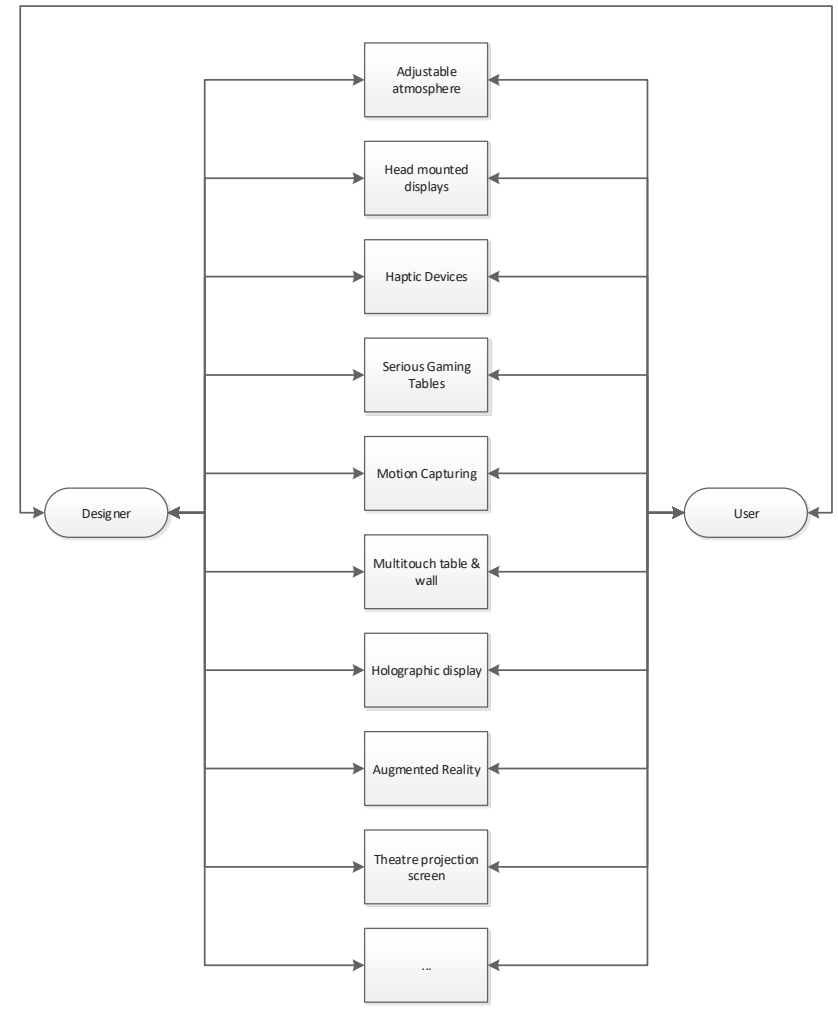

Figure 7.4 | Toolbox approach 
being provided with an optimised method to contribute. Based on the supplied input, the interests and bias of each stakeholder within each stage of the process can be depicted, in which this preference is strongly related to the actual circumstances. Based on all supplied input, purposeful and continuous iteration between problem definition, solution generation and the assessment is feasible.

The methodology and working methods that constitute the basis for the VR-lab allow for structured, transparent and straightforward use of different tools during product development lifecycles. Usage of these tools ranges from scenario development and serious games to what-if design and information management. The VR-lab can be compared to a workshop, in which the available (VR) tools are exposed and can be addressed as utensils in a toolbox (figure 7.4), which requires process planning to use (chapter 6). In order to make optimal use of the VR-lab, all of the aspects from the blueprint should be taken into account, but should not be handled as limitation or obligation.

\subsubsection{THE VR-LAB AS A SE}

As with every workshop, the end result that can be achieved depends on the craftsmanship and expertise of the people using it; therefore, it is essential to adequately align the users' requirements, functional specifications and capabilities with the appropriate configuration of the lab and its tools. In other words, no fixed configuration can cater for all approaches, but a flexible and modular set of equipment can allow for quick creation of new settings.

The basic approach, as mentioned in the previous section, leads to an atmosphere in which initially a conjoint view of the problem, its setting as well as a better understanding of dependencies between all stakeholders is realised. From that systematic beginning, solution paths can be explored effectively and efficiently by employing working methods and tools in the lab. It is without doubt that the development and realisation of a SE requires extensive

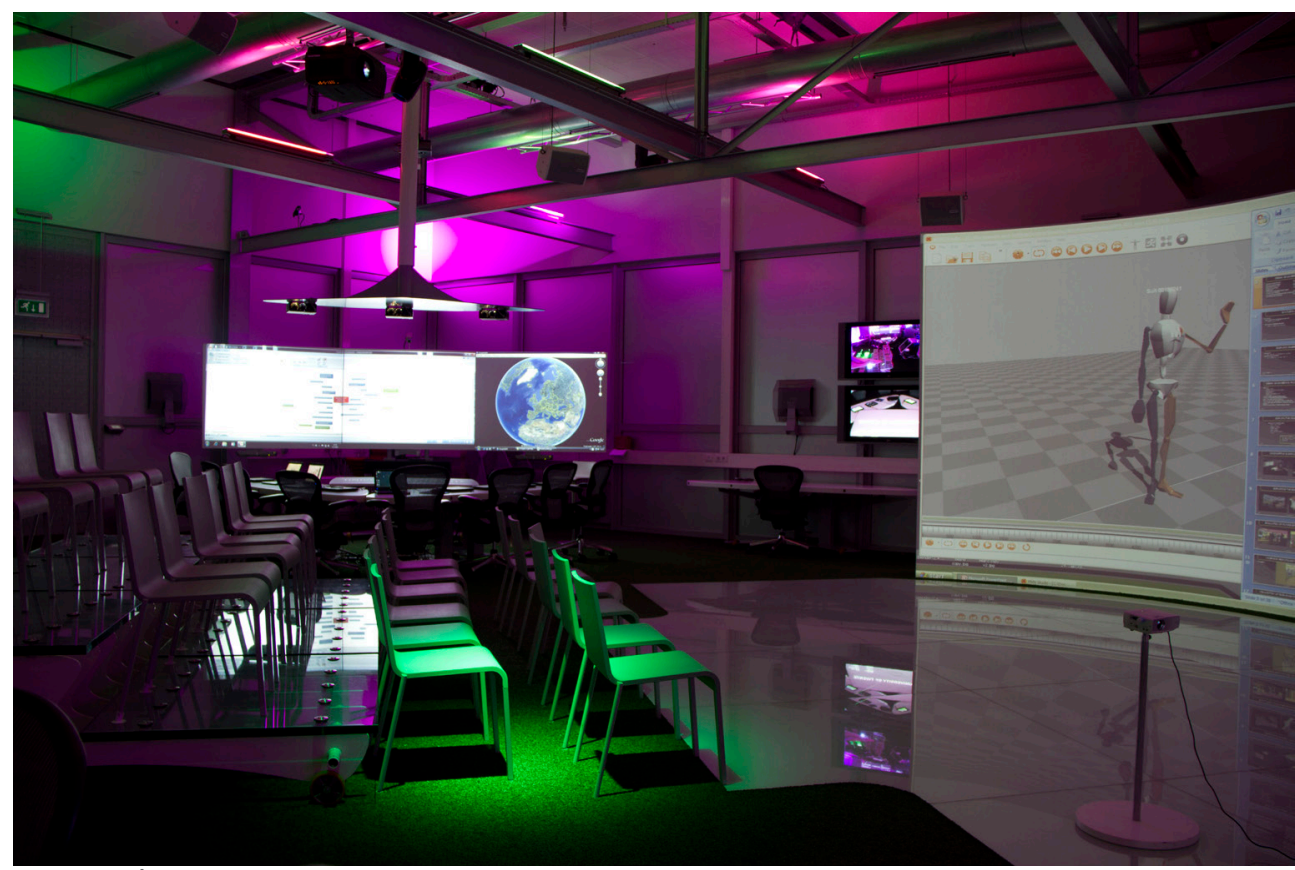

Figure 7.5 | Impression of the VR-lab 
preparation in order to effectively provide substantial and useful results, not only for that specific case, but also for the reuse of the results. This preparation often is a cooperation between the users who want to use a SE, the facility that can provide the environment, the client who orders the session and the host who can organise it. Nevertheless, there is no predetermined method to involve end users in this process, as will be discusses onwards.

The flexible layout and composition of the VR-lab (figure 7.5 and Appendix A) provides capabilities within a wide variety of projects. However, this flexibility of the configuration needs clear principles as concerns the composition of attributes. Given the comparison of the lab with a workshop, it is important to adequately address the preparation in the selection of elements that together will constitute a SE. In itself, the lab is not an automatic solution generator, but it can be a facilitator to make effective and efficient use of the expertise of all attendees. In order to properly prepare for the usage of a SE, it is necessary to determine on beforehand what the conditions are as concerns the desired goal, but also as concerns the technology used. Furthermore, the initiation of the desired use and the dependencies of the different stakeholders should be available on beforehand. In this respect, the VR-lab often uses the subdivision mentioned in chapter 4.1:

- Techniques; embedded techniques like sensors and actuators

- Tools; combination of techniques that form a tool

- Solutions (SE); the combination of multi tools that form a solution, such as a SE

To be able to make optimal use of the VR-lab as a SE, it is essential to communicate the characteristics of such an environment with future users. From the perspective of the operator, it is important to get the right information from the future users, but that information can only be given by those users if they understand what added value a SE can have for them. This preparation should therefore be organised in such a way that the appropriate information is gathered from the prospective users in a structured way so that the data can directly be used by the operator to assemble the environment. This is essential to allow the possibility to make a selection of the right (most appropriate) tools based on the desired goal of the user, client, SE providing company and operator.

\subsubsection{APPROACH}

Even though multiple approaches are possible in the VR-lab, the most commonly used approach is by using a moderator (e.g. a designer, consultant or the operator of the lab) to extract the information from the involved stakeholders (figure 7.6). The problem statement itself does not need to be fully elaborated at the start of use. Often, conjointly determining what the actual problem is, creates more added value during early sessions in the VR-lab than anything else. Often the real problem appears to be hidden behind the articulated problem statement, therefore any session starts from a problem area. This area should challenge all participants to see the common responsibility, while stressing the variety in viewpoints and perspectives involved.

Therefore, the problem area is demarcated, thus avoiding inclusion of too many details or dimensions. Additionally, there should be a clear problem owner, who is capable of assessing the adequacy of the problem statement and its evolution. Moreover, he will need to judge the level of abstraction as well as the desired (level of the) outcome of the project. During the sessions, it is essential that the problem owner does not have ascendancy on the course of the interactions.

While discussing the demarcated problem area as well as the initial ideas for solution 


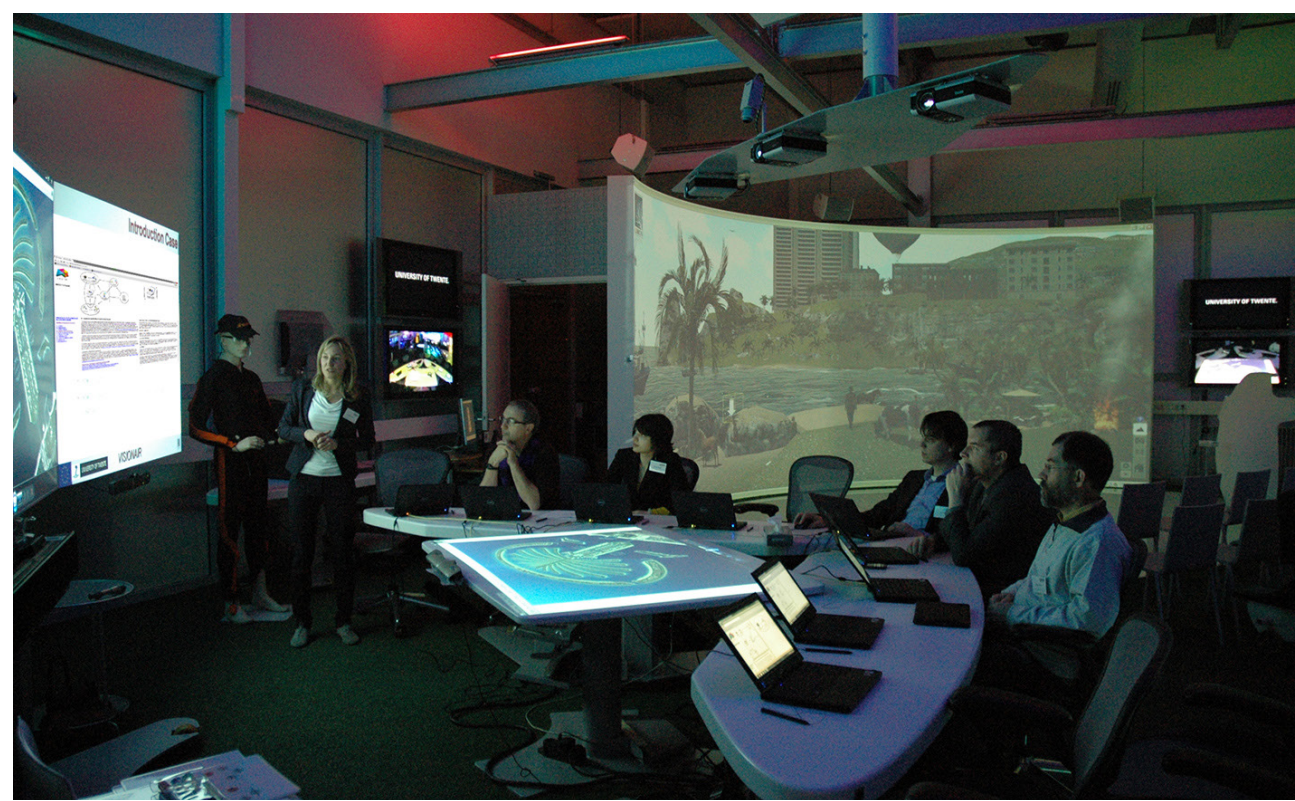

Figure 7.6 | Moderated session in the VR-lab

paths, the scope of the project is set. This involves preparing for example 3D models, environments, animations, but also simulation/probability models and a controllable set of premises that underlie the interactions in the SE. The translations that convert ideas into environments that allow for purposeful interaction are performed by the researchers working in the VR-lab.

In preparing for a session, quite some effort is spend in preparing the lab in an adequate manner. Often, creating, converting and assembling 3D models are important, as can be the realisation of libraries of $3 \mathrm{D}$ models that have a dynamic role in the session. The hardand software can be tailored in such a way as to exhibit the behaviour that actualises the environment in which all stakeholders can realistically investigate different perspectives on the problem area. Even more, the course of a session is planned, based on scenarios, simulation models and serious gaming approaches.

\subsubsection{PROJECTS}

Over the years, the VR-Iab has served as facilitator of SEs for a large variety of projects in several phases of development. It is in the diversity of the projects that the flexibility of the use of the lab is evident. The diversification includes the number of stakeholders involved, the phase of the project, the equipment and the time required. But especially the content and objective of such projects is never the same, and does not allow for a one-to-one copy to other projects. Although the focus of the VR-lab is mainly on product development processes, it often shows that the methodology and approach is also applicable to decision-making processes in general. The core value mainly lies in the support of multiple stakeholders in creating and balancing multiple choices/decisions.

The researchers of the VR-lab perceive clear similarities in the way of approach for the different projects. Because different devices and techniques are used in multiple ways, the VR-lab is a good example of a facilitator for SEs. Since the lab contains a selection 


\section{Part II}

of commercially available and custom made hardware and software, combinations of hardware and software that are frequently used together gradually emerge as a kind of higher-level building blocks. Every combination of VR-lab equipment and intended use in a SE allows the researchers to assess how successful the combination is or if the combination proposes any challenges. In any case, the gained experience provides input for use in future projects. In addition, during project execution, demands for adjustments and additions to the SE can be addressed. For example, additional support may be necessary in the process, which provides directions for new equipment or methods that need to be developed or purchased in the near future.

\subsection{CONSULTANCY FRAMEWORK}

In order to facilitate the development of a SE, and to communicate and explain the possibilities of it to potential future users a consultancy approach can be used. This approach consists of a roadmap that guides the consultant in the process of acquiring and documenting the right information (Miedema, 2010; Schutte \& Du Preez, 2010). Additionally a framework is provided that can be used as communication and library tool. Roadmaps use descriptions of processes and process steps to access and structure information. At the same time, individually provided information gives guidance in understanding the suitability of the involved steps in the overall process.

The roadmap is a guideline for the consultant during the consulting process between the facilitator of the SE and the potential user of the SE; it guides both in determining what information is needed to execute the process and defines how the information is, or should be, interrelated (figure 7.7). It functions as a common framework for multiple stakeholders. Furthermore, the roadmap provides an overview on how to structure all the information generated in the start-up phase, the roadmap concept can provide a flexible way of supporting stakeholders during their collaboration. Additionally, it provides an overview of the current state of preparation (Dankers \& Lutters, 2013).

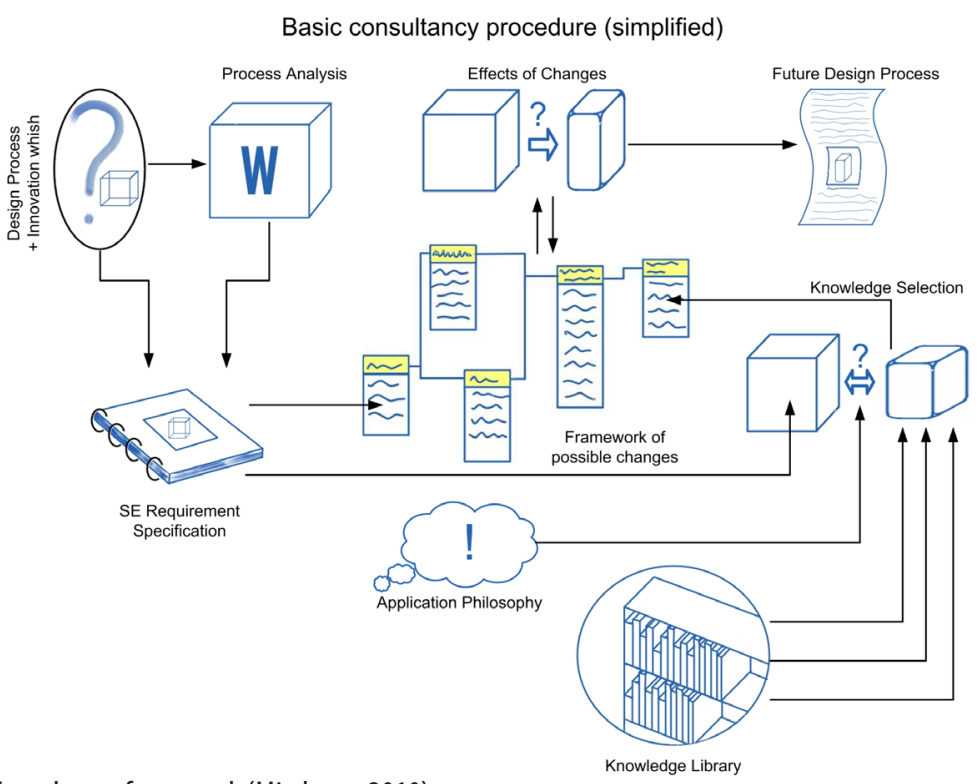

Figure 7.7 | Consultancy framework (Miedema, 2010) 
To utilise the roadmap, an appropriate information structure needs to be identified. The consultancy framework for SE development of Miedema maps three types of information:

- Information about the client's design process

- Benchmark knowledge about known applications of SE

- Desired and plausible effects of introducing a SE in the client's design process

The framework captures the information content that is used for the development of a SE. It is able to adequately subdivide the entire information storage into sub-repositories. This allows other stakeholders to easily retrieve information relevant to them. The framework has been used for multiple projects related to the VR-lab, and an adapted version is developed by (Dankers \& Lutters, 2013) for use in the preparation of utilising the lab in the European infrastructure project "VISIONAIR" (“VISIONAIR", 2017) (figure 7.8 \& section 9.3.2).

The different items in the roadmap are stored and retrieved like a library. The information in the roadmap can be used to understand, interpret and exploit the rationale behind decisions made during the development of a SE. In addition, the considerations on whether or not to use a SE in the process are included. As often more than one approach can be used to generate the same (type of) information, stakeholders are free to choose any approach that appears useful; they are definitely not restricted to using approaches offered by the roadmap. As such, each element of the roadmap also contains the description of interest in acquiring that information, rather than on the way it is collected.

The consultancy roadmap, and the framework are available through a website, this allows all stakeholders to use the roadmap on the device, location and time they prefer. This digital overview of decisions and documented information can be used throughout all phases of the construction of a SE. With this approach most of the interpretation of the perspective of different stakeholders is done by a consultant. This person has an important role; and, even

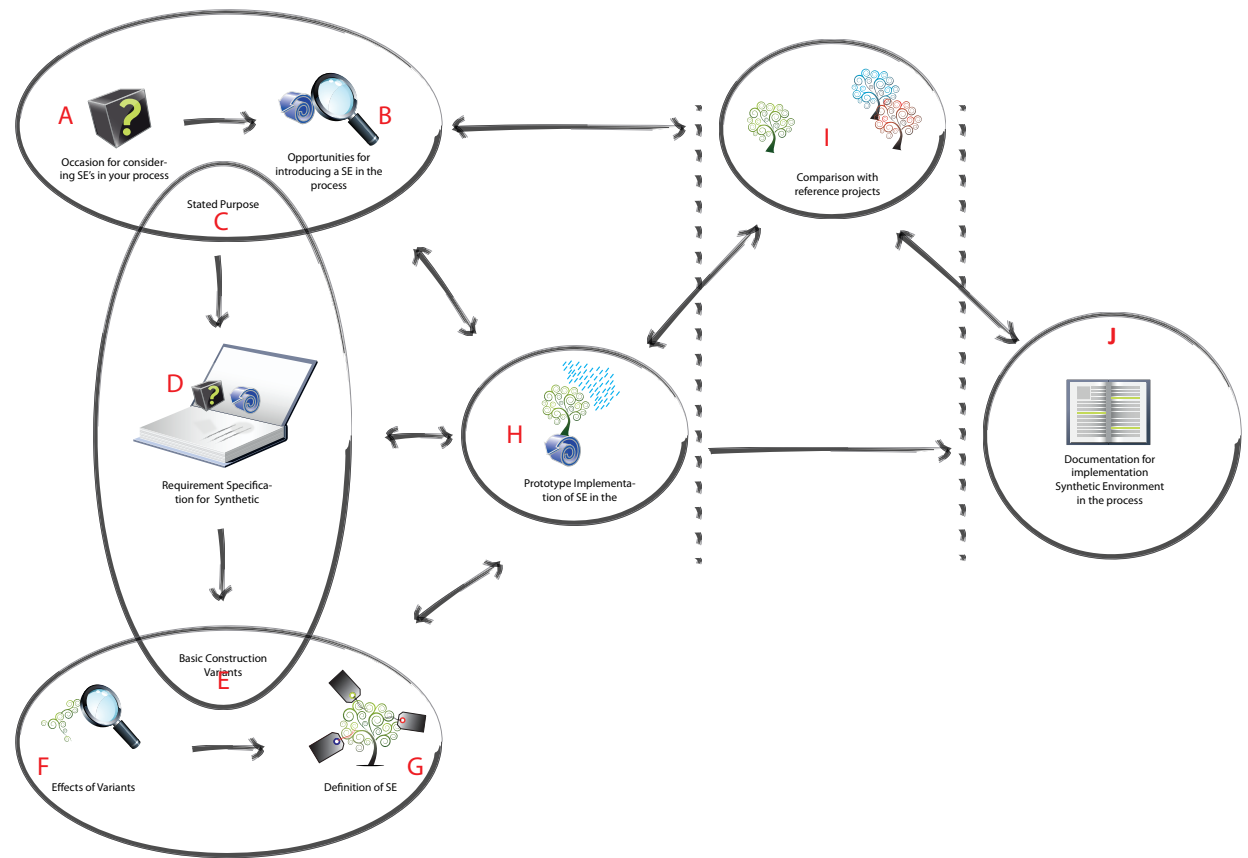

Figure 7.8 | Framework used in VISIONAIR (Dankers \& Lutters, 2013) 


\section{Part II}

with the supporting tools, needs to be an expert in multiple fields, such as the technical field of VR, business strategy and human-machine interaction. The architecture developed in this thesis therefore needs the flexibility to allow for changes (or selections) in the responsibilities of information collection. An external person should be able to determine the requirements for all other stakeholders.

\subsection{SCENARIO BASED PRODUCT DESIGN}

To better understand how a product will function in its (future) environment and context, scenarios can be used to explicit describe hypothetical events the product can encounter during use. These events can be both intentional and unintentional by de user. Scenario based product design is in this case the common denominator for methods and approaches that apply scenarios to realise a harmony between product, environment and interaction (Anggreeni \& Voort, 2007; Carroll, 2001).

The use of scenarios is not limited to the description of current situations, also at this moment impossible situations can already be described. These future scenarios can help explaining potential functional specifications. Scenarios can be used to explore and communicate the desired user experience in an early stage of the PDP, it not only focusses on the future possibilities of the product itself, but also on the integration of it in different situations. Since the use of the blueprints starts in the most early development phases of a $\mathrm{SE}$, the design process of the SE is also still very dynamic. The scenarios can help providing concrete descriptions of the goal of the future SE, making it easier to communicate the consequences of design decisions in terms of scenarios. The scenarios allow to have multiple views on the use and consequences of the SE; enhancing the understanding of the relationship between the different stakeholders and the accompanying perspectives (Fulton Suri \& Marsh, 2000). Figure 7.9 shows the essential elements needed in describing a scenario (Anggreeni, 2010; Rosson \& Carroll, 2002).

The way scenarios are written can be in terms of behaviour or in terms of specific actions. When the scenario is written in terms of behaviour, the function the user would like to achieve is explained with the accompanying enablers. For example: 'View the other side of the virtual model'. In specific actions the same activity can be written down as more specific action, for example: 'Rotate the virtual model by pressing the right mouse button and move the mouse upwards'. Both contain the same goal, but offer different insight

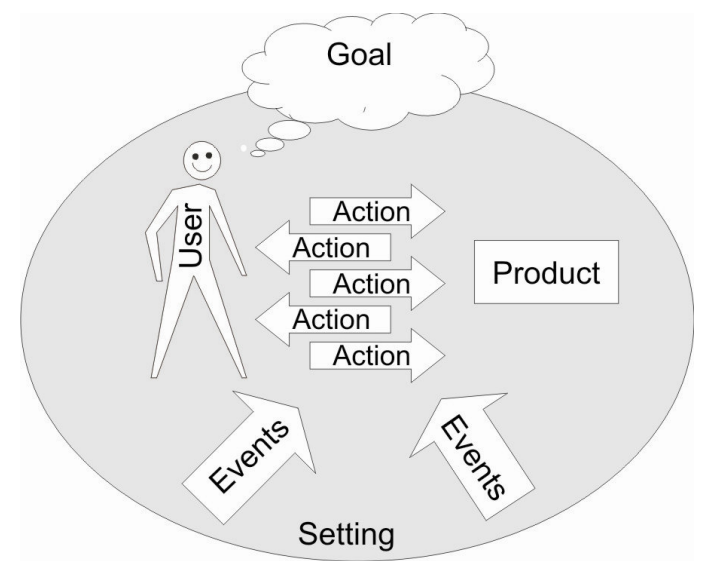

Figure 7.9 | Scenario construction (Anggreeni, 2010) 
into how the goal can be achieved. The difference is in the level of description, often the need for explaining specific actions is not desirable in the early stages of SE development. Describing the goal, with the potential behaviour of achieving it allows more creativity and opportunities during the development of the SE. The high abstraction level prevents focussing too much on the design details, while the overall experience is not defined yet.

The stated functionality in the scenarios has to be converted into a conceptual design. (Tideman, 2008) explains two approaches for this. The first option is to find a single solution for every function, and combine all those functions into one concept. The second approach is to "reformulate the set of functions so that they all concern the same aspect of the solution, and then find one concept that covers all reformulated functions together". After this a solution can be searched (in e.g. the previous and current SEs) that covers the entire set of functions. As any SE consists of multiple elements that form the complete solution, also the search for those elements can be based on finding existing elements or tools that cover as much functions as desirable. This approach is comparable to the subdivision in techniques, tools and solutions as described in chapter 4.1. By finding a tool that combines several techniques, a more efficient final solution can be realised. (Tideman, 2008) proposes a simulation model that functions as a backbone. This model consists of two databases; an environment database and a technology database. The environment database contains the set of elements that represent the world relevant to the product. The technology database contains the set of technology that might be relevant to the product. Both databases are created and maintained by the designer.

The stakeholders are allowed to alter the information in both databases, and can extract information from it. Scenarios are realised by combing elements from the environment database with a task description. The scenarios can be experienced by performing the task in a simulated environment. Incorporating multiple iterations allows the stakeholder to experience what his needs are, and by combining elements from the technology database a preliminary solution can be generated that fulfils his needs and requirements.

This model allows the end user to self-configure the scenario and the corresponding solution. The user is facilitated in exploring his expectations of the solution, and checking whether the assumptions were right. The same scenarios can be applied to different

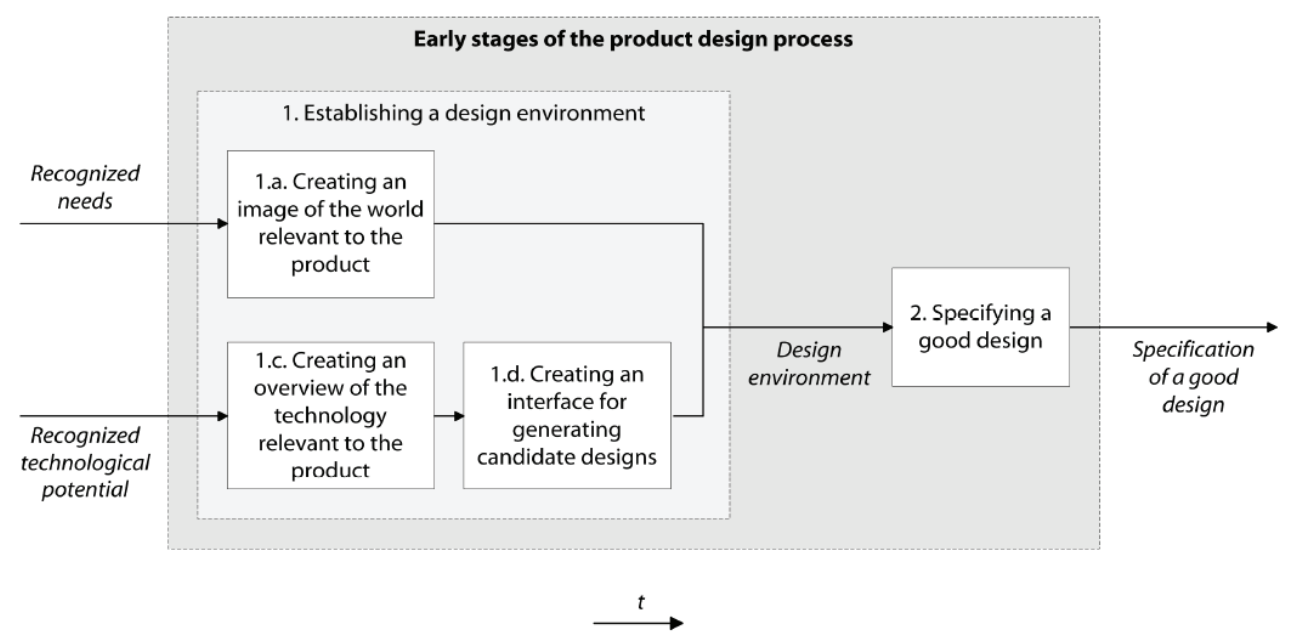

Figure 7.10 | The higher-level processes during the application of the method by (Tideman, 2008) 


\section{Part II}

settings, allowing the user to experience if the functions also perform as expected under different circumstances, or to review what the consequences of changes to the available resources are. The stakeholder can always make adjustments to the scenario and the functions, this is not limited to a predetermined period.

This model is split two separate phases. The first phase aims on developing the design environment into a valid representation of the world relevant to the product and the technology that may be usefully applied to the product. During the second phase, this is used to specify a good design. An infinite number of redesign cycles can be organised, which will eventually end with a solution in which the stakeholder can confirm the completeness and correctness of the design environment. At that moment the design environment has become saturated, and will contain the "problem-solution space". At that moment the focus changes to improving the quality of the proposed solution, rather than improving the quality of the design environment (figure 7.10).

To capture the subjective information, Tideman suggests to create a "personal report" for every involved stakeholder. "This personal report contains both objective information (i.e. personal information and a specification of the "most attractive design") and subjective information (i.e. reasons for why the specified design is so attractive and why other product features are less desirable)" (Tideman, 2008).

Scenarios can hereby be used for several stakeholders to communicate the environment, context and interaction possibilities with the potential user. The scenarios show strong relationships and interdependencies between these different elements. It is not about how to define the scenario, but that the scenario is defined. An important questions often arises during the use of scenarios; what part the scenario can be visualised or simulated, and what part should be physically present within the design environment. This consideration can take a fair a mount of time, and can also have a large impact in the quality of the results, therefore the designer has to make these considerations carefully.

To utilise the benefits of scenarios in the architecture of this thesis, best practices of previous SE and examples of a future SE, should be experience throughout the development of the SE. This means that even if the information collection is not complete; a potential scenario of use could be experienced. This allows for direct feedback on the interpretation of the outcome, which should be directly used to make an iteration step. Therefore the architecture should allow for taking a step back in the decision process to make a new step forward.

\subsection{USER-CENTRED DESIGN \& PARTICIPATORY DESIGN}

According to the user centred design philosophy, the potential end users should have a central role in the design processes. The main purpose of integrating the user in this process is to understand better what (future) use situations can be. With this information the design can better meet the requirements and needs of the user. Iteration throughout the design process and multidisciplinary product development are used to understand the user and the task requirements (Hoolhorst, 2012). Gould (Gould \& Lewis, 1985) mentions three principles to produce a useful and easy to use product:

- Early focus on users and tasks; understand who the user is by studying their cognitive, behavioural, anthropometric, and attitudinal characteristics.

- Empirical measurement; intended users should use simulations and prototypes to observe, analyse and record their real work. 
- Iterative design; there must be a cycle of design, test and measure, and redesign, repeated as often as necessary

The numerous available approaches for user centred design differ in the way they involve the user; the user can be put into the role as a designer, or the user is a concept tester (Garde, 2013). Also the design phase in which the user is involved differs among the approaches. Figure 7.11 illustrates the different user involved design methods on the axis of level of user involvement and project phase. This figure represents the classification of the methods, not clustering them, the exact definition of these methods is not relevant at this moment. These methods has to gain benefit by using the architecture from this thesis, or the other way around: the construction of a SE has to benefit of using these method. These methods can be seen as already predefined communication lines between the stakeholders, as represented in figure 7.2. Using one of these methods in facts determines some of the preconditions for communication and collaboration.

Participatory design aims at the participation of end users (and other stakeholders) in the design process, using a set of principles to support that, rather than on providing a prescriptive method. Nevertheless a large collection of design tools, techniques and methods are developed in order to facilitate and stimulate the involvement of other stakeholders (Robertson \& Simonsen, 2013). By letting the stakeholders participate in two roles, that of the user and that of the designer, more information about the functional specifications and encountered experience of the SE can be gathered. While the user strives to communicate their desired functionality and encounter the appropriate technology to achieve them, the designer strives to acquire the rationale behind the needs of the user. The use of user centred design should aim on emphasising the mutual learning between designers and stakeholders, and as a side effect it allows all participants (even the introvert, and the ones with low communicating skills) to express themselves. For the development of a SE the most important benefits of using participatory design are the commitment and better acceptation of the new SE, incorporating multiple perspectives during the development and developing a more tailored solution.

The blueprints of intermezzo 1 already support the direct integration of the requirements for every single stakeholder, and allow therefore to give the user a role in the design process. The architecture can support this even further if the user is incorporated in the whole process, and not only in the determination of requirements.

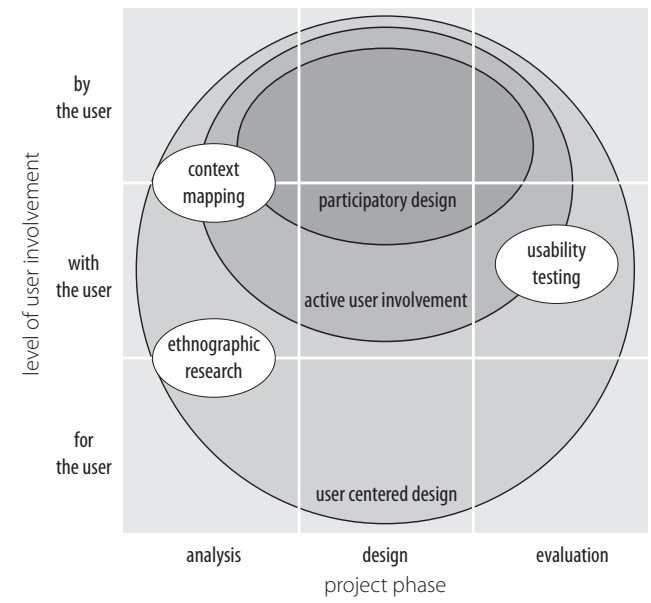

Figure 7.11 | Different user-involved design method, redrawn after (Thalen \& Garde, 2013) 


\subsection{MAP USE POSSIBILITIES}

Allthe previous mentioned approaches (ortools) can be a useful starting point to facilitate the process of complementing the blueprints. They all focus on determining the requirements and expectations from the user. For the client and the end-user, the functional specifications and conditions listed in the blueprint act as starting point to come to a definition of the desired and expected experience. What the user wants as the final experience, has to be effectively translated to other stakeholders by processing the information available in the blueprint. From the blueprint it will be translated to the demands and needs that are most important for the realisation of the SE. This recognition of requirements, elimination of possibilities, ranking of importance, etc. requires a certain structure and guidance. This can be initiated by an operator by means of the methodologies that result from process planning metaphor of chapter 6 . To encourage this approach as much as possible, a fixed starting point (for any perspective) may not be a precondition during the developed of the SE. This prevents bias due to already eliminating options without clear argumentation.

On the basis of these needs the possibilities of use can be mapped; this is the actual translation of what should be able in the SE into a true composition of elements that form the SE. This translation is made in cooperation with the operator. The operator must be able to explain to all involved stakeholders (e.g. the customer, user and company) what the solution will offer and to what extent value can be added to the existing process. With the use of AR and VR tools the user can be triggered to provide better feedback, due to reviewing the consequences of a future $S E$ in an existing context. Especially the use of $A R$ tools show a great potential to communicate decisions better among all stakeholders (Nee, Ong et al., 2012). The user is most capable of reviewing the possibilities of the SE in terms of added value. Adding value to a process, and being useful as a tool is the most important aspect of a SE, and that will also be the most logical form of his review.

For the user this is hugely multifaceted, the user is not able to determine what the best solution will be for him. Scenarios can help him to put the consequences and effects of a solution in context. But only when the user is actually involved in (working with) the solution, it becomes clear what the solution should offer. That does not specify directly about whether there might be another (completely different) better solution available. Therefore the knowledge from the user defining the stated problems that the SE has to solve is more usable than his opinion on the resulting SE. The operator will hereby also have to take into account the context of the use because the solution is always connected with the existing environment. The importance of context elicitation (and modelling) while working with the documented requirements in the blueprint is also highlighted in the research of (Dhuieb, Laroche, \& Bernard, 2016). In the approach introduces by Dhuieb, the multi-scale based approach structures the (manufacturing) knowledge according to different completeness levels. The approach reduces information overflow by giving the exact needed information in an appropriate format. Maintaining the connection with the existing environment, while offering a new solution, with a low threshold for use, is the most important vision for the SE. This is comparable to a well-known industrial design approach of Raymond Loewy: "most advanced yet acceptable".

The documented information in the blueprint has to be usable to other stakeholders, in multiple phases of the (SE) development process. This knowledge is captured on different moments of time, and by different stakeholders. To utilise this to the upmost extend, the management and usage (visualisation) of this knowledge should be supported. Existing industrial knowledge management tools offer a system suitable for reproducible cases (Hervy, Laroche et al., 2013; Hervy, Laroche et al., 2014). But the user is taken more into 
consideration in new ways of knowledge management (Laroche, Bernard, \& Cotte, 2008; Laroche, Bernard, \& Hervy, 2015). In these approaches the focus is to understand and to model one idea under different points of view. Supporting these different perspectives on the same set of data encourages the communication and collaboration between different stakeholders.

There is no common denominator for the final result, the number of possible solutions is as diverse as the products you can realise with the available resources. Because the potential of the process planning is correspondingly constantly changing, there is also in this way no fixed boundary of possibilities. Steering on the functional specifications is therefore the only guidance for the user. The requirement specifications provide insight in the criteria of decisions and can be influential in future decisions. Consequently, requirement specifications need flexibility and elaboration as concerns the level of aggregation. The requirement specifications can form a constraints if they are set too early in the process. But they also act as an indispensable way to communicate with multiple stakeholders throughout a project. At some moment they are fixed, but also should remain flexible (Lutters, Dankers et al., 2014).

It is precisely this design process of a SE that entails no requirement specifications being fixed at the beginning of the process. By recording too much details in an early phase, the likelihood of frustration against these details is significant; achieving the details becomes more important than the question of why these details were needed. The more information that becomes available during the completion of the blueprint, the more information is available of the desirable solution. Gradually the specifications may be more specific and more focused on this solution. The specifications will grow with the project (Chandrasegaran, Ramani et al., 2013). And various stakeholders will deal with the information in different ways; this ranges from very specific details to generic information.

Lutters (Lutters, Dankers et al., 2014) provides a cohesion of requirement specification types to facilitate the different interpretation and usage goals based on the different level of aggregation (figure 7.12).

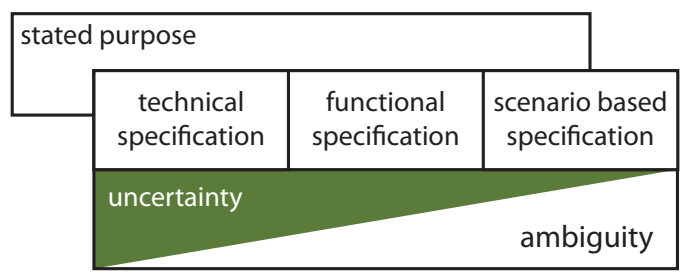

Figure 7.12 | Cohesion of requirement specification types (Lutters, Dankers et al., 2014)

Based on the (formalised and static) stated purpose, the other mentioned three types of specifications can be established. The technical specifications are unequivocal specifications of the solution. These are more interesting for the operator and the company responsible for building the SE. The functional specification describe the desired functionality of the solution, this can be seen as the main goal of what the future user of the SE should provide in the blueprint. The scenario based specifications place the solution in the future context, and determine how the user will work with the solution.

For the desired SE support in this thesis, the cohesion provided by Lutters can be slightly adjusted to fit the VR-lab approach. The four different approaches that are described in 


\section{Part II}

this section can help to fill in parts of the blueprint. The image in figure 7.13 addresses the mentioned approaches, and positions them in the general overview of the VR-lab approach. A ranking can be given to these approaches, ranging from very specific (qualitative and objective) specifications, to abstract (quantitative and subjective) specifications. Roughly it can be said that the operator view (chapter 6) is standing on the concrete side of the spectrum, and the user is positioned at the abstract end of the spectrum. The company supplying the SE (chapter 5 ) is positioned in between.

Based on the above, the note can be made that this approach shows a convex hull of all the encapsulated tools used in the process. All possible approaches fit within the overall VR-lab approach, but based on the different perspectives, blank spaces between the tools may appear. The aim is to use as little of these unnecessary elements as possible. The non-relevant tools or approaches for that time, are not part of the set of tools. For each SE development trajectory (at the start, and also during executing) a new convex hull will be generated. Topics can be crossed out, or can be outside the scope of the research. The aim to make as little preparations as possible for activities that will not be performed, similar to assembly-to-order. This allows each solution to have its own convex hull, which can help identifying and comparing the different solutions. A roadmap approach is essential in this to prevent ending up in developing an infinite number of predefined workflows. The roadmap can provide all the possibilities, and allows for high flexibility, as long as it contributes to the final result.

Throughout the process each stakeholder has to handle with uncertainties, and the collaboration with multiple stakeholders introduces perspective dependent uncertainties. Not all uncertainties are experienced the same for each stakeholder, and not all uncertainties are even valid for each stakeholder. The ambiguity of this is that incompleteness is an inherent part of the development (Lange, Oude Luttikhuis, \& Lutters, 2016). The only certainty that can be given to the stakeholders is that there is some uncertainty from other

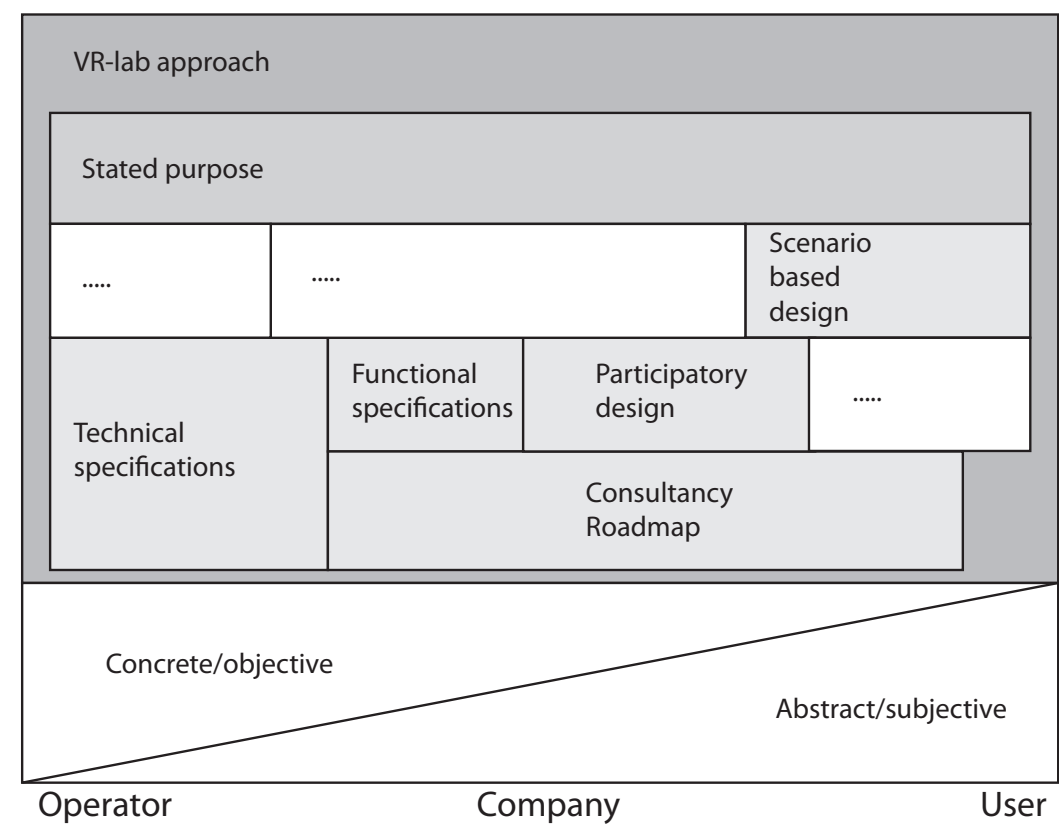

Figure 7.13 | General overview VR-lab approach 
perspectives. This also corroborates the impossibility of a fixed starting point; this point is never interpreted the same for other perspectives.

In some cases it will not be possible to define the entire composition of tools and approaches without restraints; the convex hull will not be entirely optimal, some not used elements are within the convex hull. This applies, for example if there is made use of equipment which has been developed in the basis to support a wide variety of processes, such as a CAVE (Cruz-Neira, Sandin et al., 1992) that forms a rigid solution composed from multiple tools, not able to be separated. It is unlikely that for each application the maximum of the tool is requested. A CAVE offers many possibilities, but in a limited area. For example, the different development domains in which it can be used is broad, but the way in which it is used is severely limited. These limitations follow from the high requirements of preparation for use, and e.g. the physical dimensions of the CAVE which cannot be adjusted for each solution. This implicates that its users will have to adapt to some of the requirements of the CAVE. Nevertheless, a CAVE may provide an appropriate or suitable solution in a specific scenario, but this is not a leading fact (the same as with every tool) if considered for all stakeholders. The conditions for use of tools that form a SE are not fixed, so within the same VR-lab approach, on a certain moment the use of the more abstract scenario based design approach can be desirable, while for another process the choice can be made for the more concrete approach of a CAVE (Stark, Israel, \& Wöhler, 2010). Both fit the VR-lab approach, but their characteristics and implementation cannot directly be transferred between different projects, because the functional specifications of those projects do not match. The proposed VR-lab approach does some concessions to the transferability of solutions.

As seen from the blueprint perspective, the focus of the user is to achieve a certain experience. In order to achieve this experience, some interaction elements are needed that allow for human-machine interaction. There is a certain need occurring at the user (or the need is created by external factors), and based on that need, a design tool (the SE) can help realising that goal by providing an experience. This experience can only be achieved if the right sense is stimulated at the right moment; directly indicating that the solution is tailored for a specific purpose. The mentioned overview of figure 7.13 can help determining the user needs and the requirements the interaction elements should fulfil. The results can be documented in the blueprint (figure 7.14).
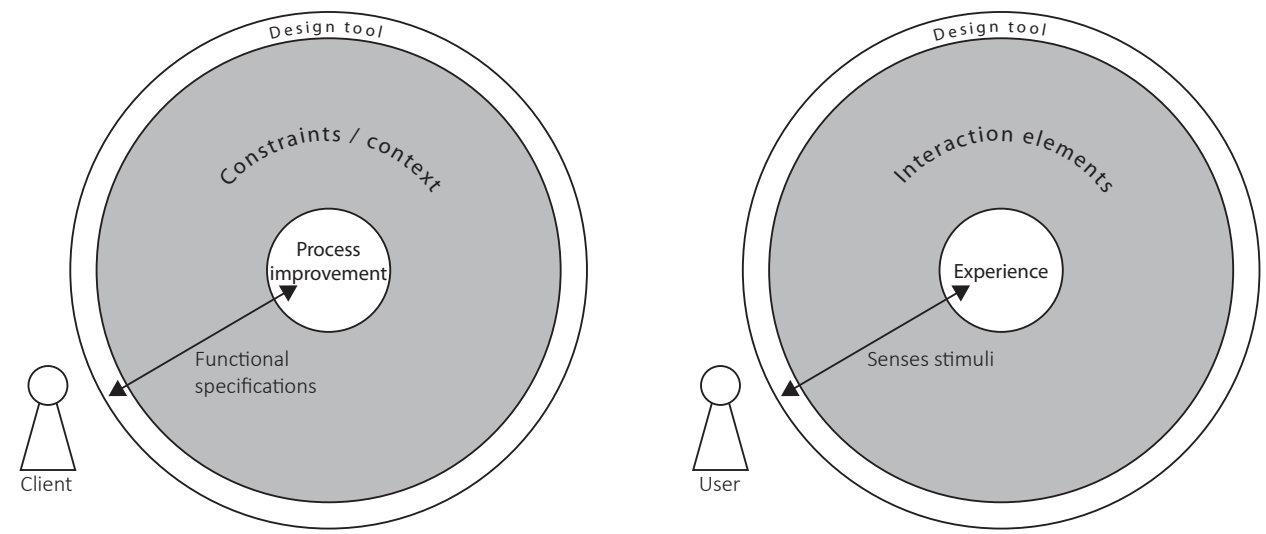

Figure 7.14 | The blueprint as seen from the user and client perspective 
Part II

7 


\section{INTERMEZZO 2}

Following from the previous chapters, one can conclude that there are multiple approaches on how to enhance the use of a SE as design tool. Enhancing can be done in the field of use possibilities, opportunities, predictability of the results, threshold for use etc. From the product-service approach a SE can be improved by focussing on delivering a certain goal, not on the tools that enable this. The process planning methods show that a SE can benefit by steering more on predictability and optimisation. This also requires insight in dependencies and relations between elements of a SE. Involving all the stakeholders throughout the development process shows the benefit of visualising the consequences of decisions, and translates data into usable information for any individual stakeholder.

The different approaches are related to the needs of the different perspectives introduced in intermezzo 1:

- Strategic (e.g. SE providing company perspective): Product service experience approach which has more potential to lead to a long-term relationship with the customer, and easier to tailor solutions.

- Tactical (e.g. operator perspective): More insight and understanding in how each element of the SE contributes to realising benefit for each stakeholder.

- Operational (e.g. user and client perspective): Communicate the expectations of the SE in terms of desired additional value to the development process.

The blueprint introduced in Intermezzo 1 facilitates documenting all elements that are in any way relevant or important for each stakeholder. From every viewpoint a documented expectations of the solution is made in the blueprints, but they do not offer a direct integration of viewpoints, they are a repository of information. Furthermore the blueprints are used for storing and documenting the information, but are not responsible for gathering the information. There is a need to combine the (possible) endless numbers of blueprint to form a working SE. Additional support is needed for stimulating the transition from different blueprints into one SE. An architecture should offer (support for) integration of these individual items, and offer guidance in how to combine those views into one SE.

In the previous chapters different viewpoints on the information of a SE are discussed. These are all different views on the same information. They are used to filter out information, or categorise the data, in order to make it understandable. All these viewpoints are a way of filtering, clustering or tagging information from the requirement repository (figure 12.1). These requirements are already limiting the discussion space, since they determine boundaries in which the SE has to function. The perspectives show differences between the (interpretation of) requirements of each stakeholder, those differences are the most common issues to solve. But even more interesting for the development of a SE are the similarities between the stakeholders; they provide the common ground to start on, and are originated from the different perspectives. This requirement repository has contradictions in it (visualised with warning signs or darker colours), those are needed to understand the ambiguity and uncertainty of the information (Lange, Oude Luttikhuis, \& Lutters, 2016; Lutters \& Houten, 2013). The uncertainties and ambiguities arise by combining the perspectives; a view from perspective "Strategic" is valid for that perspective. The same can be said for the perspective of "Operational"; but that does not mean that both perspectives are true at the same time. Those events function as a starting point for collaboration and discussion. The white spaces in the requirement repository will be used to form the convex hull. 
The blueprints contain a (desired) result of activities - possibly with requirements and conditions -, not the activities themselves. That will be the same for the architecture; a profile of the possible solution will be realised. The detailed execution or realisation of the $\mathrm{SE}$ is not part of this. All consequences of the SE can be examined and reviewed based on the perspective and expertise from each stakeholder. This profile combines as much information (e.g. conditions, functions, requirements, goals, etc) as possible from all stakeholders. It acts as a map that contains all the information; the type of map (e.g. technique, interaction, environment, etc.) can be decided during use, and will filter the information. As a metaphor this can be compared to the map of a country; all information is present but based on your type of transport (e.g. bike, car, train, boat, etc.) some information is more relevant than other.

The architecture should not define a starting point; starting the development of a SE is a coordinated action of all involved stakeholders. Every stakeholder can be the initiator for this, but needs the support from other stakeholders to continue. An existing solution
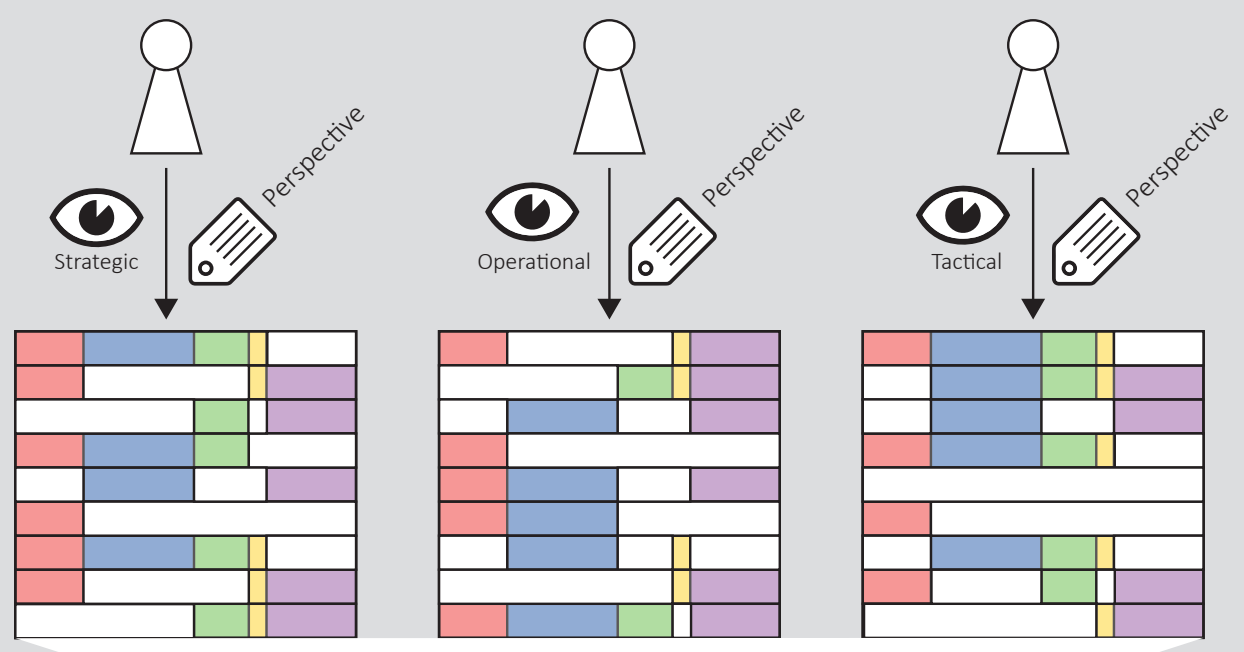

Figure I2.1| Requirements repository

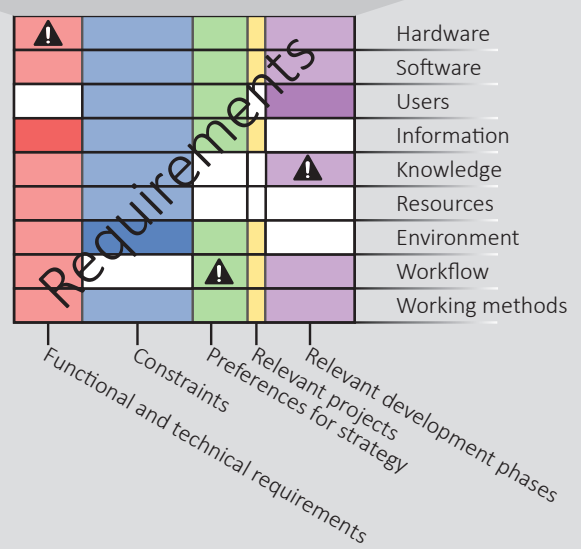


can also be the starting point for further development. All stakeholders have to uphold their perspective on the potential solution, multiple goals must be pursued at the same time. The operator can take the initiative to steer in this polytheism process, by showing best practices and by visualising which (aspect of) a perspective is influenced by a certain decision. This is not only a discussion, but a series of iterations. All taken actions and decisions need a response from others. This in combination with the blueprints enable a structured approach, since all information is categorised and (inter)dependencies are known. To have a certain control in this process, the nine aspects of the blueprints can be used for some guidance and steering.

The architecture of the SE is the combined area of blueprints. Each one of the selected blueprints act as a parcel in the architecture. The area forms a convex hull around the different blueprints, and acts as the common ground and communication layer. This area can be defined as the 'scouting space' of the SE (figure 12.2).

This scouting space is the most rudimentary form of the architecture. This fundament will not change during use, and therefore acts as the ground layer of the SE. On top of this map additional overlay maps can be added to visualise and understand connections between different elements (e.g. information domains) (figure 12.3). This is comparable to a street map: the cities will not move, but the different connections (roads, canals, and railway) between the cities can change. This creates a deterministic setting in which iteration is possible, and the system will be more complete after each step. The different overlays also function as a filter; unnecessary information will be filtered out. This is not only based on the subject of the overlay map, but also based on the expertise of the different stakeholders.

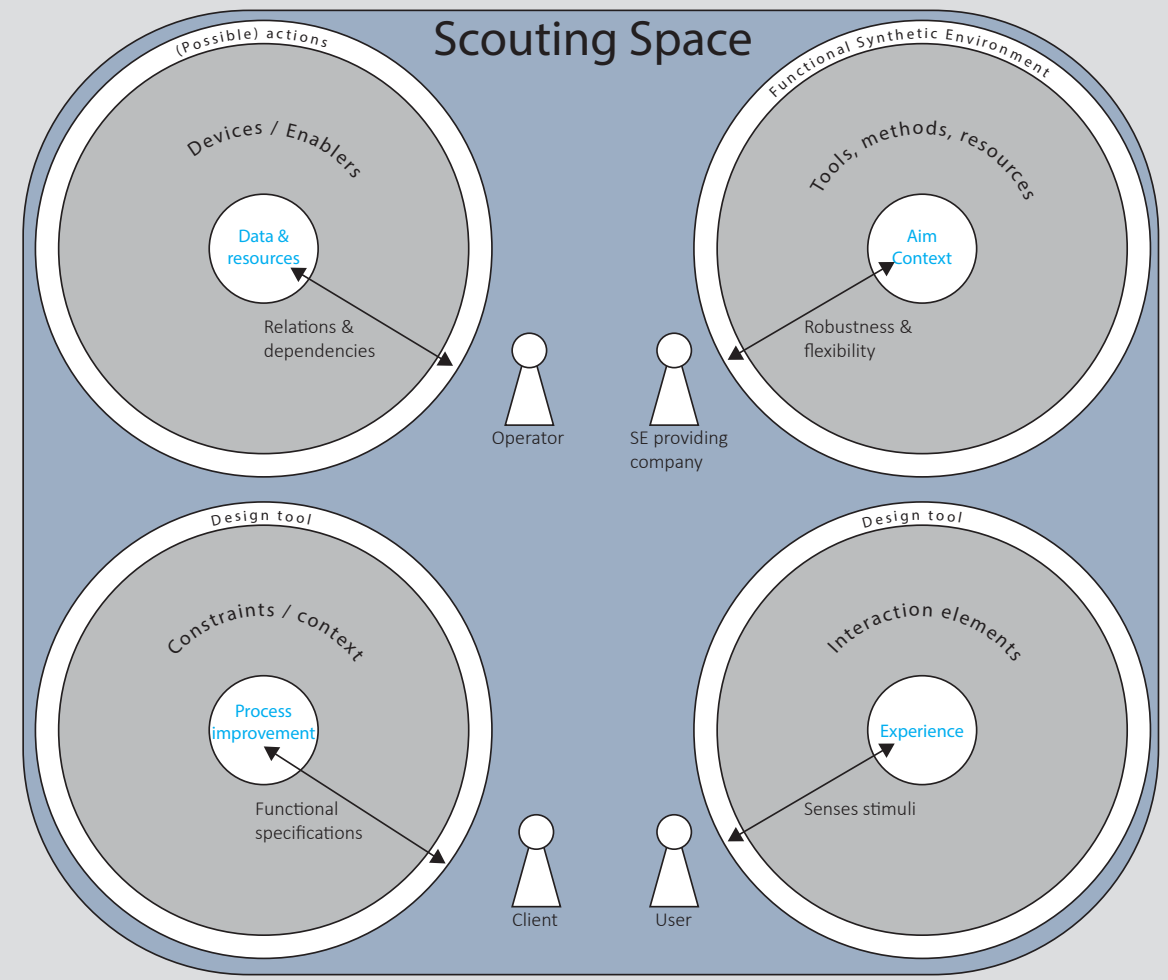

Figure I2.2 | Convex hull around blueprints, forming the Scouting Space 
The different perspectives on the SE remain present in the scouting space, but with use of the overlay maps they will transform into 'aspect perspectives'. On each aspect of the SE, the perspective of all the different stakeholders can be projected. This forms a system of systems; the first system is the combination of the different blueprints in the scouting space, the second system are the different overlays on top of this, which visualises the connection between individual items. The architecture allows all the different configurations possible to realise a SE, the architecture only functions as a tool for working with these configuration problems.

This resulting profile of the SE allows comparison of the SE with other (existing or previous) $\mathrm{SE}$. The best practices and experiences can thereby be reused, and the SEs can influence each other, and even improve each other. Based on this profile the SE can be constructed, the approach for realisation is not determined in this profile, and allows the constructor to use their preferred approach.

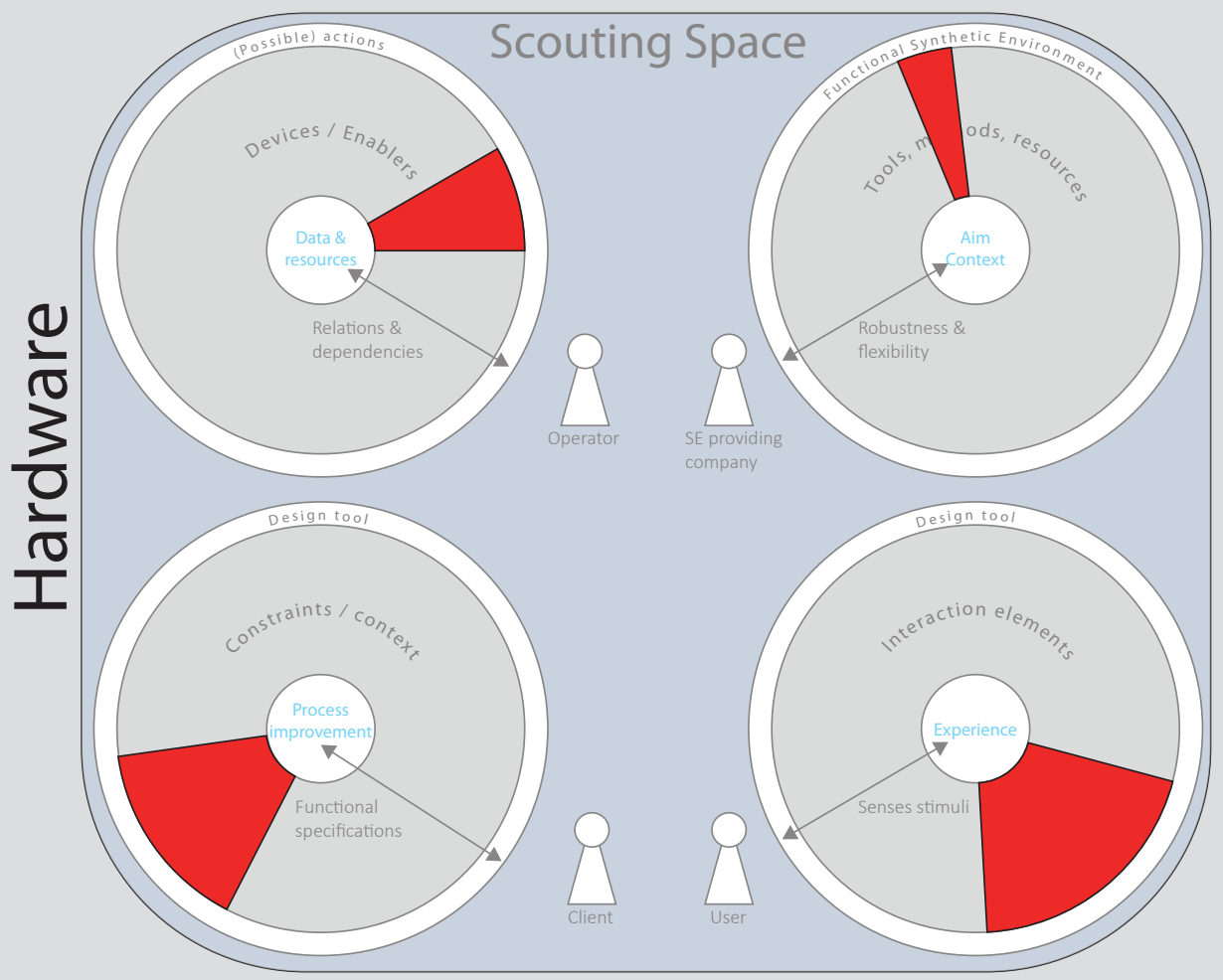

Figure I2.3| Information filtered for one element 

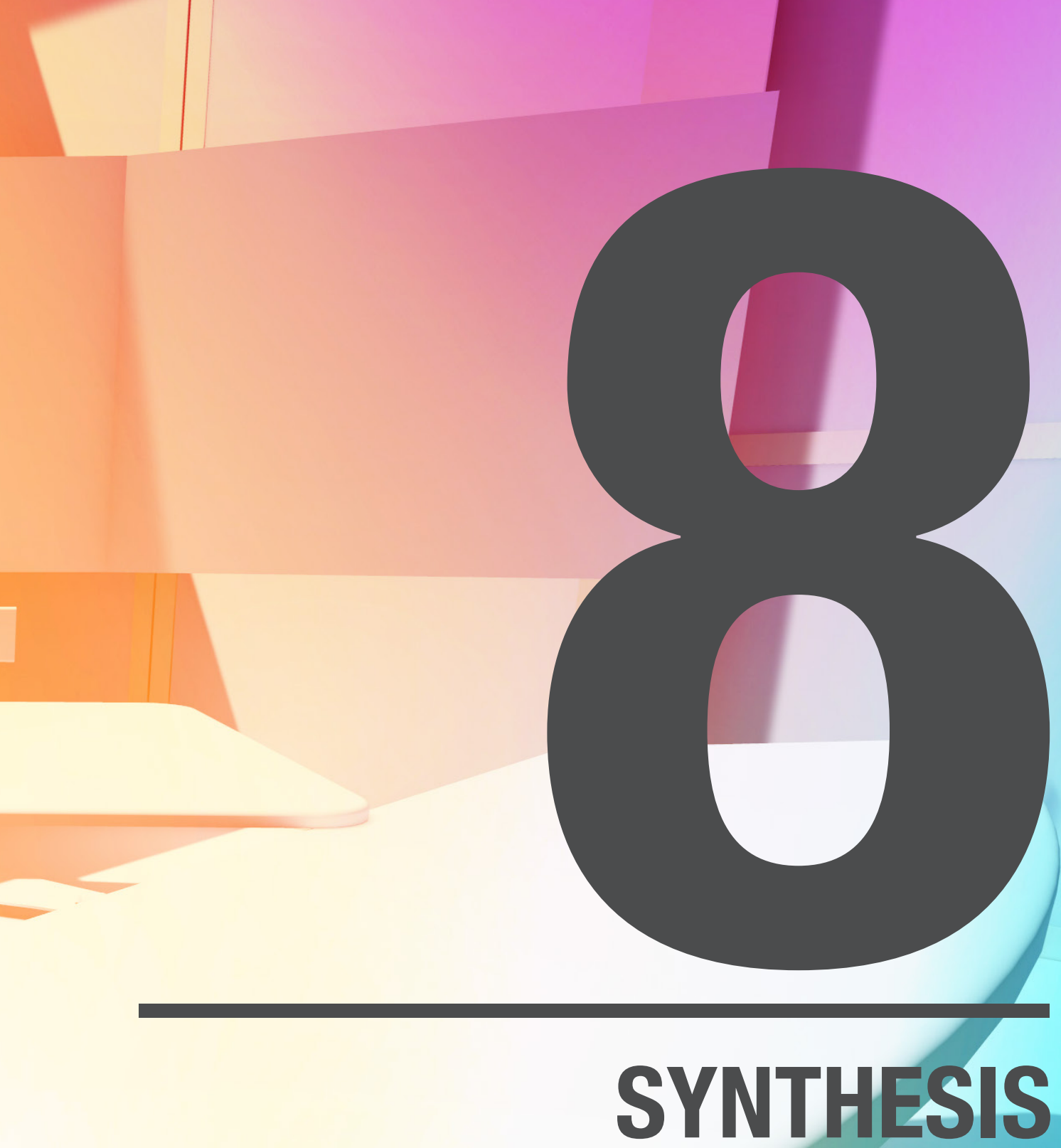


\section{SYNTHESIS}

The knowledge from the different types of stakeholders gathered in the blueprints needs to be processed to a comprehensive whole. This fundament is based on flexibility and agility, consequently a process flow can be sketched to visualise the most probable way of working with the fundament. Important is that the use is integrated in everyday work, and that users are familiar with the adaptability to different stakeholders. The goal of the fundament of the architecture is not to determine the complete process of working towards a SE; it acts as a code of conduct on how to work collaboratively towards a solution. The proposed architecture following from this chapter describes the preconditions on how to handle the gathering, documenting and utilising of information in order to support the decision making process of working towards a SE. The knowledge in the architecture is aimed at the use of different tools in the development process, rather than on focussing on potential application issues. There is no need to know in an early phase of the process what the outcome will be; as long as the stakeholders are able to use the available tools. This synthesis aims at knowing the generic potential of different elements, rather than on defining specific applications. The inclination is on approaching the set of available tools as a pool mechanism; review the potential of available tools and align them to fit the use scenarios, instead of requiring to alter the use scenarios.

\subsection{EVOLVEMENT IN SE DEVELOPMENT}

The blueprints introduced in Intermezzo 1 provide a structure to categorise the information necessary in a SE. The blueprints are meant to stimulate all stakeholders to use the same terminology to document their requirements for a desired solution. The categorisation and the different perspectives contribute to the mutual understanding of each other's insights and opinions. To facilitate and encourage the collection of the relevant information discussed in part II of this thesis, different available approaches and tools are described. These tools are existing solutions that are already used in other processes, and therefore do not directly provide support in the categorisation of the acquired information. It is necessary to set boundary conditions to make sure that the categorisation is done according to the desirable manner. For the usefulness of the collected information, it is important that the right information is stored in the right way. It is relevant for stakeholders to know when the information meets the preconditions. This process can be referred to as the metaprocess of the realisation of the blueprint, the goal is not so much to support the collection of information, but to indicate which specifications the information must meet. Hence describing how the information can be documented in the right and proper way. To make the blueprints functional, a structural representation, description and overview, which defines a specified flow of activities in the realisation of a blueprint is developed.

Figure 8.1 shows the scope of the blueprints. The perspectives from the different stakeholders are made explicit, and act as different dimensions by documenting them. The requirements (gathered with the use of the methods described in chapter 5, 6 and 7) are collected in the middle ring of the circle. They are tagged with the viewpoint and the relevant elements. Later they can be grouped and filtered as needed. Each requirement can belong to multiple groups and multiple filters can be added at the same time. The stated purpose is originated directly from the stakeholder (and his perspective), and is put in the centre of the circle. It determines the freedom to act in relation to the desired goal, and highlights that every stakeholder can make their own decisions and statements on what the solution should offer. Every stakeholder can determine its own stated purpose, and the documenting is not effected by translation or interpretation errors by others. 


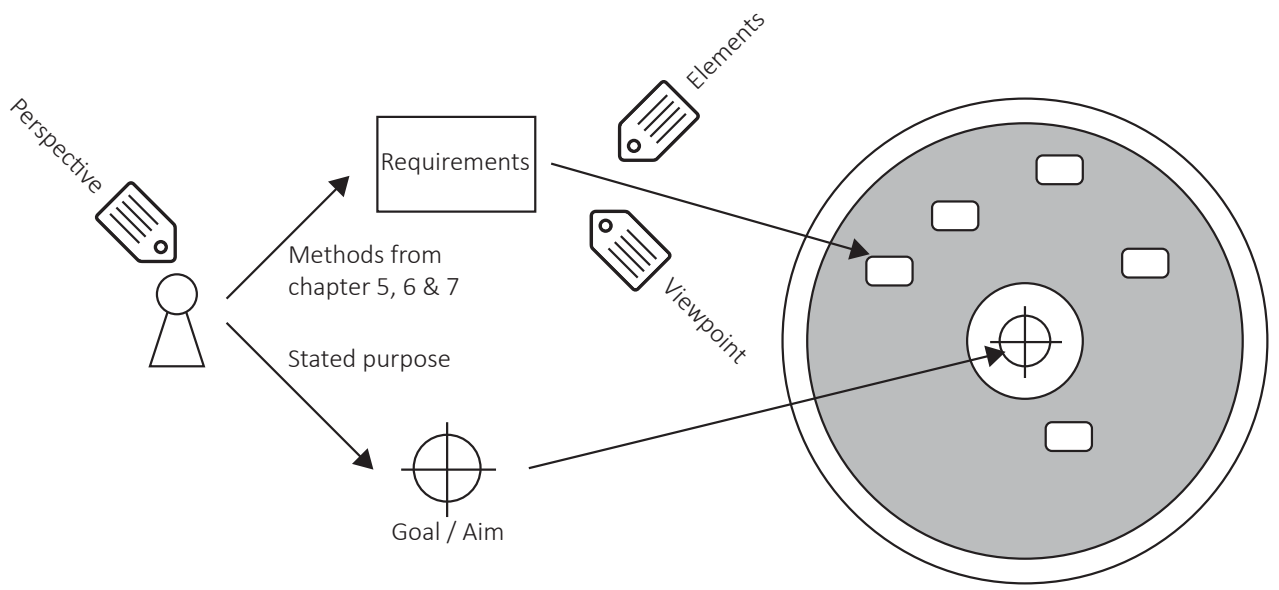

Figure 8.1 | Scope of the blueprint

The scope contains the different dimensions (e.g. hardware, software, behaviour) on how the environment is build. These are the perspectives that form the basis for implementation. Since blueprints can be realised independent of a running development project, organisation or subject, the exact way of how the information has to be filtered is not known on beforehand. The relevant elements chosen by the stakeholder, the viewpoint in which this requirement will function, and the perspective of the stakeholder are considered metadata linked to the requirement. By adding this metadata to the requirements, they can be more easily filtered in various ways later in time. This filtering of information prevents an information overload if similarities between different blueprints is searched, or if the impact of requirements on a specific viewpoint or element should be communicated with other stakeholders. This also provides a starting point for the categorisation. Some control in the process of establishing the blueprint is needed in order to get the required information efficiently and effectively from the various stakeholders. The control is hereby focused on supporting the creation of the blueprint, not to impose making a blueprint. The assessment of the content is hereby separated from the creation of the content.

For stakeholders the biggest interest is that their opinion is formulated and stored in a decent way, according to their requirements, in the blueprint. The blueprints avoid that by hierarchy or personality attention biases towards the opinion of a certain person/ perspective. Anyone can add information independently of each other, and all information is initially equally important. The support is only given in the determination of the threshold to what requirements the information should fulfil. These requirements are focused on contextualising criteria. Each requirement should be using the metadata to indicate the relationships it has with one or more of the (9 suggested) elements that shape a SE, with one or more of the five classifications, and with one or more of the three perspectives. These "tags" make it possible to filter information and relate them to each other. An example of a filled blueprint is visible in figure 8.2. A visible blueprint is always a perspective on the information, because the view originates from the desired information retrieval from the viewer. For the use of the blueprints it is irrelevant how the blueprint looks like; therefore this chapter is not aimed on providing the visualisation of the blueprint, but on what can be done with it. 


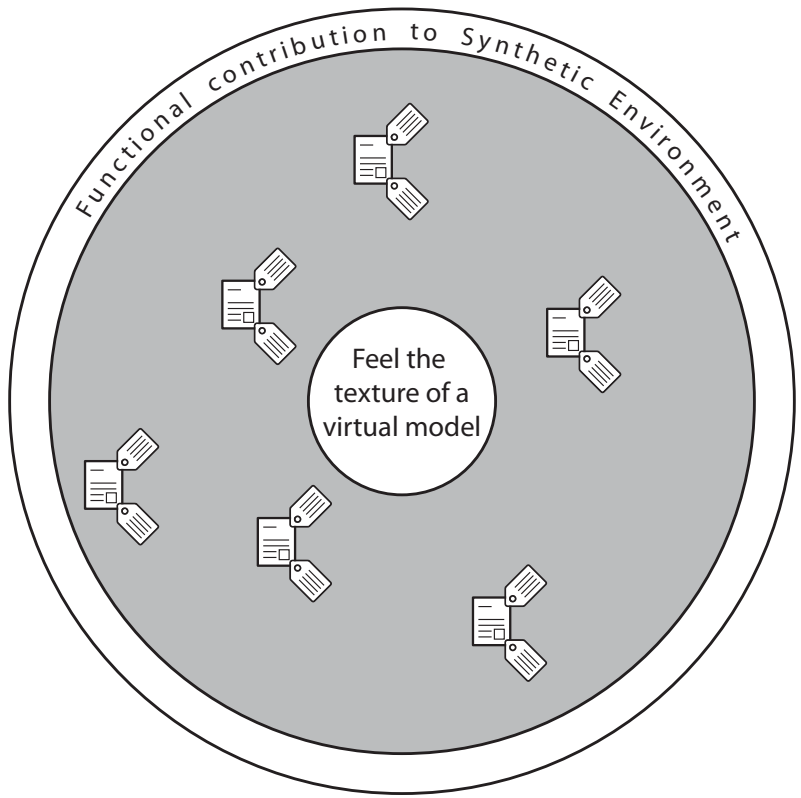

Figure 8.2 | Example of a blueprint visualisation

\subsubsection{SUPPORT IN MAPPING EFFORTS}

Since this thesis aims on improving the realisation of a SE in collaboration with multiple stakeholders, a SE needs multiple blueprints to be realised. To realise a SE based on the combined information of multiple blueprints, these different blueprints should be placed in an area (map) introduced in intermezzo 2. This process can be initiated by any stakeholder, or can be triggered by an external person. This external person is not a stakeholder of the SE, but can act as a problem-solving consultant, rather than a process-guiding consultant. Based on the available metadata compositions of blueprints can be generated. This selection procedure can be automated based on similarities in the blueprints, or it can be performed by a stakeholder. This demarcation (convex hull) arises only when a configuration or composition of blueprints is selected, the map functions as the area in which the selected blueprints are visualised. This means there is no starting point in building a SE, any choices made that force a specific application to be used, are delayed in this way.

Forming a collection of blueprints is a deliberate decision needed to make a next step in the developed of a SE, and thereby forming a demarcation is an expected effect. Making a decision is a means to achieve something, it prevents remaining in a phase without adding more information because the fear to not be complete or the fear for the unknown blocks the progress. These decisions offer the opportunity to make an own interpretation on preconditions of supporting the decision making process of working towards a SE.

To understand how (the implementation of) a SE is interpret by multiple stakeholders, the different perspectives have to be distinguished. Each perspective is a way to add information to the common base of the SE, and can therefore benefit by placing that in a layer. To visualise a single perspective, not hindered by irrelevant information, different layers can be placed (at the same time) on top of the map. These layers display specific information or relationships. The metadata in the blueprint will also act as different layers.

The layers that can be visualised are legion, and mainly depend on what connections exist. 
These connections follow from similarities in the provided information, or from suggested connections based on previous experiences. Examples include resemblances on goals to achieve, constraints in use or opportunities in comparable data formats. By visualising the similarities between different blueprints, or by merely indicating that there is a connection between these blueprints, opportunities can be recognised. This process is comparable to making a geographic map; by documenting and visualising observations, a particular pattern or relationship is made visible. A stakeholder who wants to extract information out of the whole information repository can create a map at any given time: as an informationpull approach. This map is dynamic, and will update every time it is created. Furthermore the map is perspective dependent, and aligned with what that specific stakeholder would like to visualise on the map.

The person making the visualisation of the map will not interfere with the visible pattern (e.g. road infrastructure); the only activity is to describe the information in the correct (settled) way, so that this information can be used as good as possible in the other stages. In the mapping of SE all the information is already categorised and available in the blueprints. This mapping process requires a tool to map the area of interest for specific layers. For that, it is necessary to know what needs to be mapped, and what is usable for the stakeholders. This can be argued from the information that is available in the blueprints.

All of this is comparable to a map of a country, thereby also the environment can be mapped (visualised) in several ways. Based on what the user wants to know, multiple views on reality can be provided to achieve the best possible understanding. There are layers available that give information about connections between geographic locations (road maps, water maps, data connections maps) or consistency between locations (countries, provinces, municipalities). But there are also layers that are not so much based on the geographical location, but rather put less tangible information in context, such as land use, disposable income or political affiliation. And even information based on activities (types of industry, employment) can be used as an overlay. In this way an infinite number of layers can act as an overlay on the scouting space (figure 8.3 - the geographic location is hereby elected as a basis). It is impossible to give all the information at once; there will always be the need to make a selection to what should be made visible. In addition, multiple layers can be put over on top of each other, and even these layers can contain dynamic information (e.g. display of the amount of usage of a connection between two objects by means of colour difference).
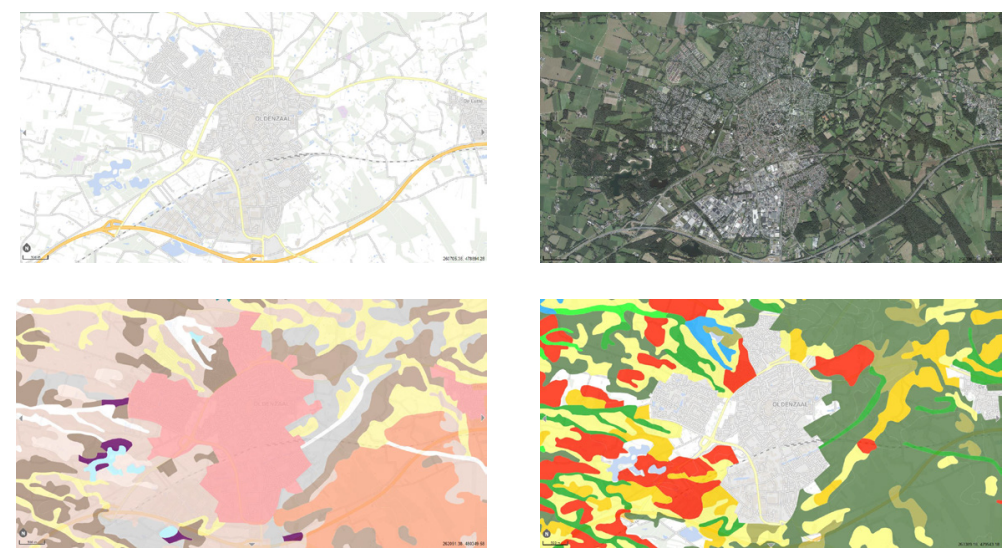

Figure 8.3 | Example of different layers on the same map

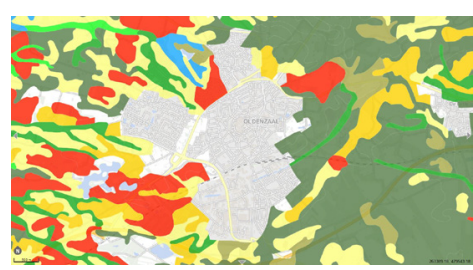




\section{Part III}

There is no single layer responsible to function as the basis; all layers have a shared coordination system that allows every layer to be set as the foundation layer. With use of the layers the dependencies and similarities between blueprints can be visualised, and this could serve as a basis to get visible where conflicting interests between stakeholders are, where the connections are, and what still needs development. The blueprints develop individually, and are not affected by the layers. The map is the navigator to get an overview of the blueprints. Based on their own criteria, the view on the blueprints may change. The different criteria are dependent on the available metadata. This ranges from technical and functional specification to involved or responsible stakeholders (figure 8.4). This figure shows similarities with figure 12.3, but instead of only providing an overview of the spread of requirements, this visualisation shows the content of the requirements.

Initially a SE will be developed on the basis of needs that have been communicated by one or more stakeholders. A map is created based on what the stakeholders would like to visualise in order to achieve a certain understanding. This map is handled as one of the possible views on the information, and can be reused as often as needed. The information provided by the map can be used by the stakeholders to streamline this process of realising a SE. If there are a greater quantity of blueprints available at a given moment, an existing SE can be used to review if the SE can be useful for more applications. At that time a collection of 'push' (supply) and 'pull' (demand) blueprints arise, which could be combined on several ways, and could benefit from each other. The value of each blueprint is dependent on the perspective of the stakeholder. Each stakeholder can add a blueprint on the demand-side, with a description of the criteria that a solution must meet. On the other hand, a builder of SEs can offer existing SEs as a solution. Such a repository or warehouse (figure 8.5) will serve as inspiration for developers; not only for offering solutions, as well as an overview of the elements which are mainly used of the blueprints. The repository of blueprints does not determine what is possible with current and future SEs, it only communicates the rules and preconditions governing the blueprints to serve as a blueprint. In addition, in the outcome of this thesis the rules of the repository are the main deliverable; not a template for what exactly a blueprints should be.

The repository shows a collection of the blueprints with on top the different available scouting spaces. Since these convex hulls are automatic and dynamic derivatives of the layers/blueprints; a scouting space cannot exist without those layers/blueprints. A scouting space is thereby also based on the position in time. The parts that stretch the convex hull together have to correspond with the scope; the scouting space is a way to visualise that. It
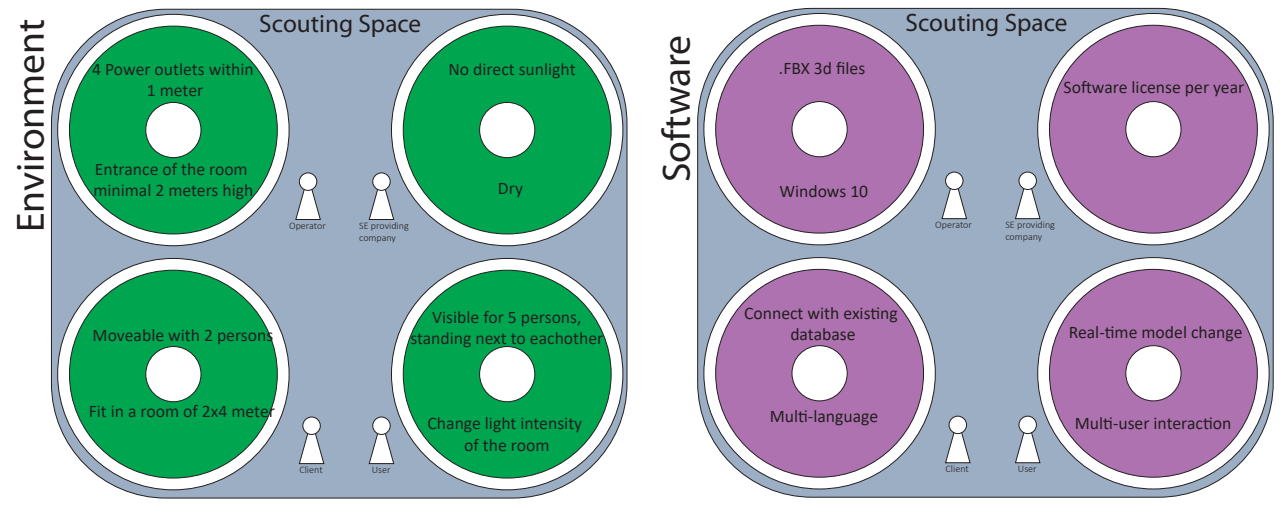

Figure 8.4 | Example of different layers on the same scouting space 
is the potential of the solution; and needs a concordance between the supply and demand. In case the convex hull is smaller than the scope it is an indication that with those criteria no fitting solution can be offered. This means that there is the need for an increase in the flexibility of the available tools, or that the expectations have to be altered. This can also be reviewed over multiple projects at the same time; if a certain area is missing in multiple scouting spaces the need to work on the missing link is higher and more attention and resources can be paid to develop this missing piece. There is the likelihood that solutions will occur more often at the junctions of common infrastructure, as that increases the potential use scenarios. The scouting space helps in providing information on what is possible with the capacity and capability, and when these need to change.

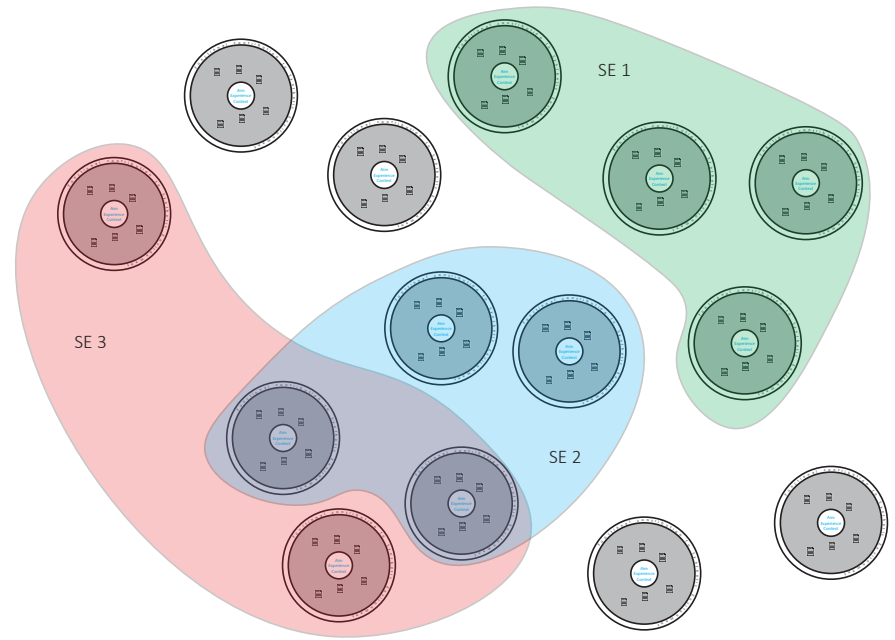

Figure 8.5 | Blueprint warehouse

\subsection{SE PROFILE}

An important element throughout this thesis is stimulating and facilitating the collaboration between the different stakeholders. To make optimal use of the expertise from each stakeholder, it is essential to maintain the perspective of each stakeholder. One the key characteristics of the proposed approach, and one that distinguishes it from the innumerable other available approaches, is the ability to allow each stakeholder to use the shared information repository on different levels of aggregation at the same time. There is no predetermined level of aggregation in this approach, and stakeholders are even allowed to change their level during use. The perspective of the stakeholder is the level of aggregation on which the information is provided. A level of aggregation is a relative notion, and consequently it is not possible to position the different levels of aggregation on a simple linear scale. Naturally, this makes the comparison between information provided from different perspectives not plainly possible. Therefore no value judgement can be made on the information on beforehand. For the development of a SE this is a big advantage, since during a significant part of the development process the details of the solution are impossible to distinct from the main elements. The relation between cause and effects of requirements are not clear while setting those requirements; changing the level of aggregation during use provides more understanding of these relations.

Since the scouting space is the potential of the solution, it needs additional steps to come to an instantiation of a solution. This convex hull delineates the discussion space 


\section{Part III}

for the SE that forms the combination of all requirements that represent the maximum freedom in which the SE can be developed, it is the depiction of context and environment. The discussion space forms the base on which the SE has to be developed, it defines the outer-boundaries of the area in which the SE has to be developed. This discussion space contains all the blueprints from the involved stakeholders, and can be visualised as a graph. This base graph contains all information following from the blueprints. The nodes in the graph originate from the requirements documented in the blueprints, and arise from all the involved stakeholders. The lines between the nodes represent the metadata which was added to the requirements with use of the tags. Consequently, none of these lines will have by definition the same meaning; which results in a conceptual graph (Sowa, 1983). The graph theory is used widely among all kinds of project, and has shown its benefit throughout multiple research fields (Acosta-Mendoza, Gago-Alonso, \& Medina-Pagola, 2012; Gago-Alonso, Muñoz-Briseño, \& Acosta-Mendoza, 2013; X. Jiang, Xiong et al., 2009; Lange, Oude Luttikhuis, \& Lutters, 2014; Lutters, 2001).

The information from the blueprints can be related back to the origin perspective, since the stakeholder is one of the tags in the metadata. The blueprints provide a taxonomy of elements which are most common to expect in the discussion space. Based on how current and future SEs will be constructed, new elements will occur, some existing elements will occur more often and some of them will disappear. The nine throughout this thesis mentioned elements are examples based on experience from previous projects, if other elements are introduced in future projects, these will be added to the list. This forms an information base for a self-organising system; based on activities from the past, discussion will be triggered in future projects by highlighting often-used elements from previous projects. The blueprint is thereby responsible for providing a kick-start, by showing the elements that where relevant in previous projects, stakeholders are triggered to think about the relevance of that element in their current perspective. It also allows to review the completeness of the information collection by comparing the used elements to the elements used in previous (comparable) projects. If a stakeholder has the most influence on a certain aspect of the project, it is expected that this stakeholder provided some requirements in that area. If not, relevant questions can be asked to a stakeholder (from stakeholder to stakeholder), which are directly related to the expected missing information. The taxonomy is in this the language in which the SE is formulated.

From this discussion space, a more consolidated space occurs, which contains the minimum information necessary to proceed with the construction of the SE. This can be referred to as the solution space (section 6.2). The solution space is a converging evolution of the discussion space. During the development process decisions are made with regards to, or triggered by, the discussion space that lead to the boundaries of the solution space, therefore the solution space is subjective by definition. In the solution space more preferences can be made towards the final solution, and it contains all the parameters that eventually define the final SE (chapter 6). This solution space will also change during the development and implementation phase if more or less information is required than previously thought.

This solution space is a sub-graph of the base graph that forms the discussion space. In this sub-graph no new elements are added, only decisions are made to converge the area. The sub-graph is a consolidated version of the base graph. If during this decision making process new requirements arise, these can be added to the base graph.

The size of the solution space also depends on criteria not one-on-one originating from the blueprints. This criteria is based on strategic decisions. Every stakeholder can provide 
criteria that define a specific instantiation of the SE. This information is not available in the blueprints, since it is related and based on the combination of blueprints. Therefore this information can only be provided at the moment the stakeholders know which blueprints (and therefore stakeholders) are combined. This criteria can for example be based on the business strategy of the SE providing company, or long-term vision of the client. Consequently the two roles of the blueprints are first leading to the discussion space; secondly it triggers making the decisions towards the solution space. All stakeholder can provide these subjective criteria, and this includes among others the following criteria:

- Preferences for use

- Capacity available at the moment, or for this purpose

- Capability at the moment, or for this purpose

- Long-term company strategy

- The policy of the company

- Financial criteria

- Logistics

- Interest in stakeholders

$\cdot \ldots$

These (interpretations of the) criteria are subjective, as is the solution space since it is liable to strategic decisions. So not only technical or functional requirements will narrow down the solution space, also non deterministic preferences from stakeholders have influence on the area. The converging process from discussion space to solution space is therefore steered by the decisions and strategies. The resulting sub-graph still has differences in interpretation based on the perspective of the viewer. This is desirable since it allows to give a constructive opinion on the sub-graph without the risk of translation errors.

This combination of discussion space, blueprints and solution space is called the SE profile (figure 8.6). In the SE profile the potential of the SE is embedded, the use of the SE profile is therefore aimed on unlocking this potential.

The discussion space is in essence bigger than the solution space. By limiting the possibilities based on the made decisions, the decisions become explicit and the consequences visible. Each decision made during the process will limit the possibilities. This is essential to happen to realise the converging from discussion space to solution space, otherwise no progress towards the best fitting solution can be made. This establishes the rationale of the solution. Consequently, the set of decisions is the backbone that enables the stakeholders to initiate, substantiate and assess the evolvement of the SE development against the context and requirement specification. Decision making should therefore be understood as a value adding activity. It also allows a roll-back option where a single or multiple steps back in the process can be made to correct an error or to try another possible approach. Since the solution space provides the parameters that define the solution, and not the solution itself, the SE has to function within these boundaries. Multiple instantiations of the solution can fit the solution space, and therefore the solution most in line with the requirements of each stakeholder is visualised in the third layer, positioned above the solution space.

There are no direct lines of communication drawn between different blueprints, but the discussion space functions as the base layer and facilitates the decision-making and communication process. Because there is no mandatory or pre-defined decision-making process all stakeholders can make best use of their experience. If a developer has already 


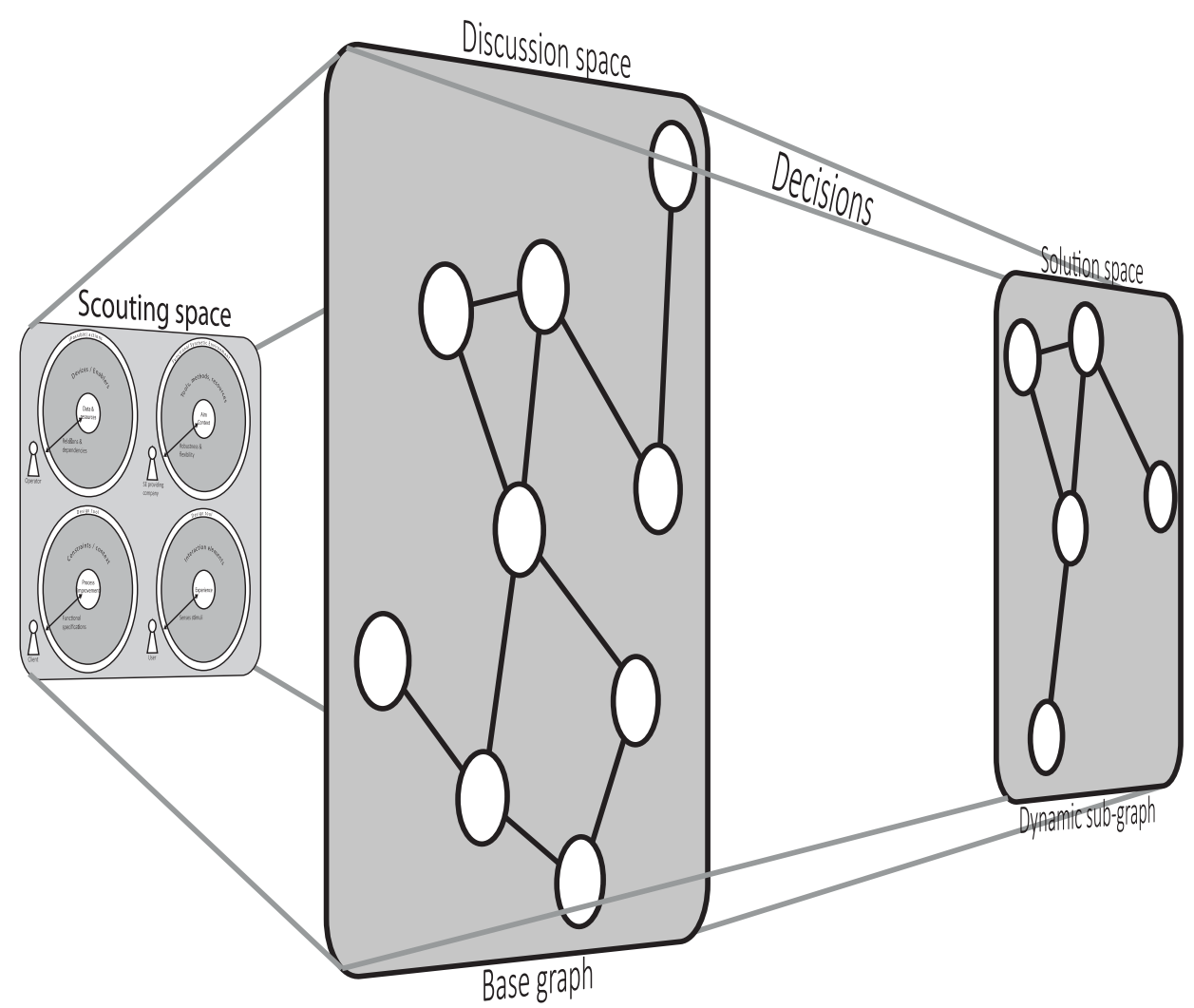

Figure 8.6 | SE profile

a lot of experience with SEs, it is often not necessary to make all considerations by means of a fixed pattern, but can be made much quicker by utilising his experience. The SE profile supports multiple scenarios for use. Since each solution is an instantiation of the SE profile, the approach of realising this solutions depends on the chosen scenario. These scenarios are interpretations of the approach, they can range from e.g. using a consultant that guides the process and interpret the rules (Miedema, 2010), dictating the solution due to lack of expertise and experience of the end user, or already providing predefined selection of solution variants where the user may select from (Thalen, 2013).

The SE profile allows, and stimulates, argumentation for decisions to be made on different levels; strategical, tactical or operational. The assumption of a SE profile is that there is no starting point, this is explicitly dependent of the chosen strategy and scenario; and therefore subjective by design. This is considered essential to provide a flexible and agile support for the development of a SE. In some cases or projects this starting point can already be made at the beginning of the process. This fixed point can arise from, for example, already available equipment, or desired environment of use. If for example the use of a CAVE is already set as a hard criterion (because the client already has such a device), the other blueprints may have to adapt more to this. With the use of low-cost devices this will be a far less obstruction, these devices has become 'potentials' for the solution. And at a later moment of time some elements can be chosen as anchor points to stimulate the further development. 


\section{Metaphor:}

To understand the philosophy of the SE profile better, a metaphor is used. In this metaphor the development of a SE is described in terms of the construction of a building.

The blueprints acts as the wishes and demands from all stakeholders. The user has for example demands on the number of bedrooms, or the size of the living room. The building contractor of the house has constraints and preferences for the used tools and the costs. The work foreman want to use his workforce efficiently, and has requirements for the planning. And the architect has requirements on the used materials and quality of the result. All of these blueprints are combined in a shared environment; the scouting space.

This scouting space determines the discussion space in which the building has to be build; comparable to how a parcel defines the area on which a building may be build. The parcel is the discussion space; and already contains the potential of the building by all the available tools, materials, foundation, etc, that follow from the blueprints. Relations and dependencies among these items and stakeholders are represented in the graph. The potential of the solution is also limited by constrains that raise at the moment the combination of stakeholders and parcel is made; e.g. regulations, view, neighbours, etc. This realises the solutions space; a narrowed down area on the parcel where the building may arise. At that moment still multiple types of buildings can be realised that all will satisfy the stakeholders. As long as it fits the specifications.

At that moment an instantiation of a solution (building) can be made; the exact position of the building on the parcel, the boundaries of the building and the drawings of the final construction. This results in one solution that satisfies all the stakeholders. But all stakeholders know that there were more different buildings possible. The SE profile allows for the virtual creation of multiple of those solution instantiations, even before constructing it. The SE profile contains all the information that forms the rationale of the solution.

This approach of giving insight in the potential of a solution is applicable to multiple metaphors (already used throughout this thesis). In the metaphor of the theatre, used in chapter 5.3, the potential of the play is already encapsulated in the combination of theatre, stage-properties, actors, director and audience. Multiple plays are still possible, but they are limited by the combination of elements, and each stakeholder will also have its own preferred play based on the determined combination of elements. The sub-graph for a specific play is the result of converging all available possibilities to a setting most appropriate for that genre.

In chapter 6 the metaphor of process planning and factory layout is used. Compared to the SE profile, the potential of a machine factory is already determined by the available machines, the capabilities of the employees, capacity of the company and the results of the process planner. Based on these elements, a statement can be made what the limitations of possible to produce products/machines are. Especially in this metaphor the opportunities of realising a better fit to the demanded requirements is easy to explain; it is a decision on whether to change the composition of elements that form the machine factory or to change the requirements of the solution.

To complete this list of metaphors: building a SE is like realising a Lego model. The potential of the solutions is made by the selection of building blocks. The resulting solution is mainly realised by creativity, preferences and trial-and-error. 


\subsection{REOUIREMENTS AND ARCHITECTURE FOR IMPLEMENTATION}

All involved stakeholders have their own perspective on the same information, which should be facilitated and stimulated throughout all phases. These perspectives offer relevant information from different expertise during discussion and decision making activities, mainly because the stakeholder can select the desired visible information themselves. Unwanted information can be filtered out. The feedback of a stakeholder on the information or requirement defined by another stakeholder indicate how they interpret that information in their context. To understand the relations and dependencies of criteria, each stakeholder can review the SE from his own perspective, or using the graph to understand what the perspective of the other stakeholders is. Reviewing this profile from a process planning perspective (chapter 6 ) highlights the importance of being able to make planning and design decisions in parallel. The information available in the profile must be bi-directional, dynamic, concurrent and automatic (Lutters, 2001). However, the most important aspect is that the information must be understood by both the dispatching stakeholders, and the receiving stakeholders. Since the SE profile functions as a navigator and filter on the available information, the chosen data structure needs to be dynamic.

Figure 8.7 shows the different phases of use of the same information. It visualises the multiple views and approaches on the same information set. This not a flow of activities, but multiple use scenarios of the fundaments described in intermezzo 1, intermezzo 2 and this chapter. These different views can occur at the same time; and do not have a standard sequence of use. The processes might be based on presupposed steps, but might as well
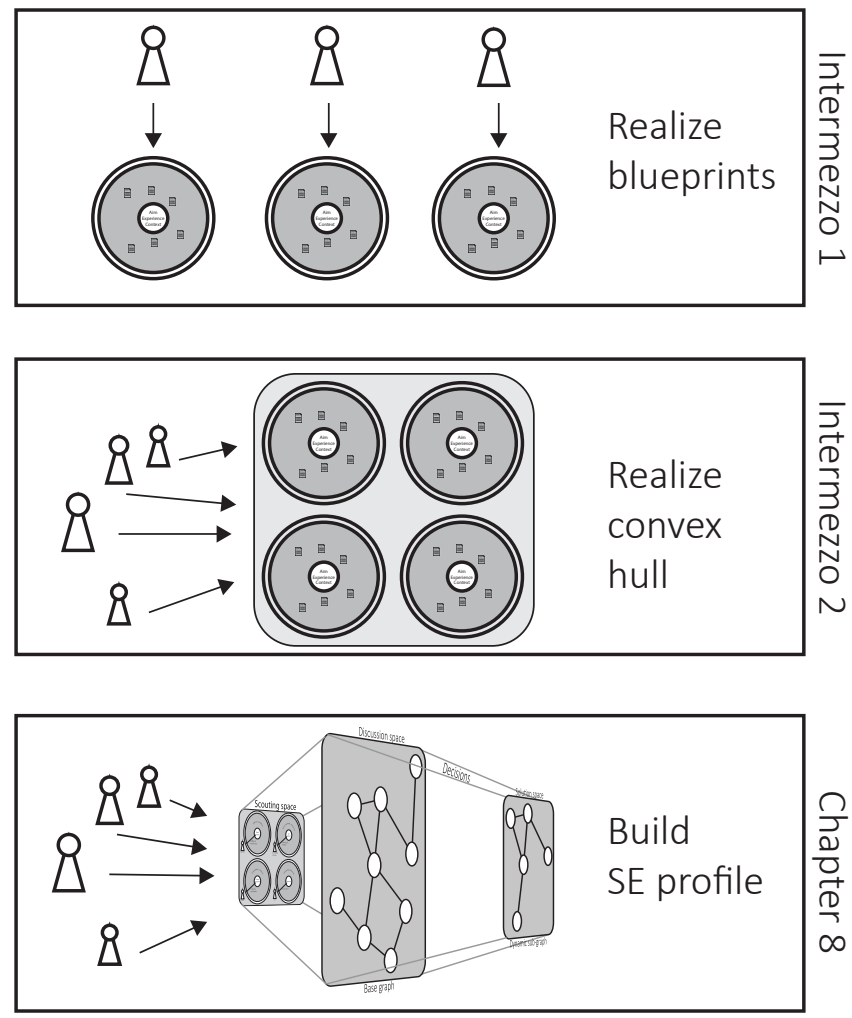

Figure 8.7 | Different views on the use of blueprints 
follow a completely different route. Moreover, the views on the blueprint are no fixed procedures, nor is their sequential execution self-evident.

The different perspectives on the information allow stakeholders to focus more on what is unknown in the information repository, rather than only focussing on what is known. For the developers of a SE the consequences and aftereffects of decisions are often unclear, and a false sense of correctness can occur if the stakeholder only rely on decisions. Decision making is the activity that determines the preferred course of action (Lange, Oude Luttikhuis, \& Lutters, 2016). In the SE profile, there is a relation between decision making, and the content of the information repository. The focus of the SE profile is not on prescribing a course of actions, but on creating information; decision making is the elementary activity in establishing that information content. The stakeholders already have tacit knowledge and implicit decision criteria. In order to make the information from the SE profile useful in decision making, the use and representation of that information should be tailored to its context and purpose. This approach is in line with the statement of (Lange, Oude Luttikhuis, \& Lutters, 2016): "Similar to tangible objects under construction, where the status is evidently visible, the information content (i.e. the product definition) should be seen as a workpiece."

To build as a SE providing company and a SE operator the most appropriate SE for a specific purpose, knowledge must be available about how the proposed experience is actually experienced (chapter 5), and how the SE meets the other demands set by all involved stakeholders. The encountered behaviour must be measured throughout the use of the SE, and even better, must be able to be simulated on beforehand. The needs and wishes of the stakeholders must be clear in order to make this measurement. The approaches of chapter 7 can help in that. These provide the functional specifications desired by the stakeholders, related to the capability of these stakeholders. The final setup is aimed on providing an experience, but for the operator it is also 'just a working machine', and for the providing company it is just the product and service they want to offer. So also other criteria like time and costs can be a measurement to review the solution. The result of the SE must be measured constantly to the expectations from each stakeholder, and if needed adjustments have to be made. With use of feedback loops and iteration possibilities, a SE profile allows the stakeholders to make adjustments without having to completely start over again. By documenting the history of changes made to the SE it is easier to take a step back, or to see what changes are responsible for what causes. These discussions and changes can be documented in the discussion space; the consequences for the solution are visible in the solution space.

Figure 8.8 illustrates the complete architecture. The three stadia of evolution of a SE are clearly visible; the most left is the scouting space and is aimed on gathering the requirements from all stakeholders. The middle stadium is the discussion space and contains the base graph, and the dynamic sub-graph that forms the solution space. The right side provides an instantiation of a SE, based on configured resources. The SE can be approached from each stadium, there is no predetermined process for this. 
Part III
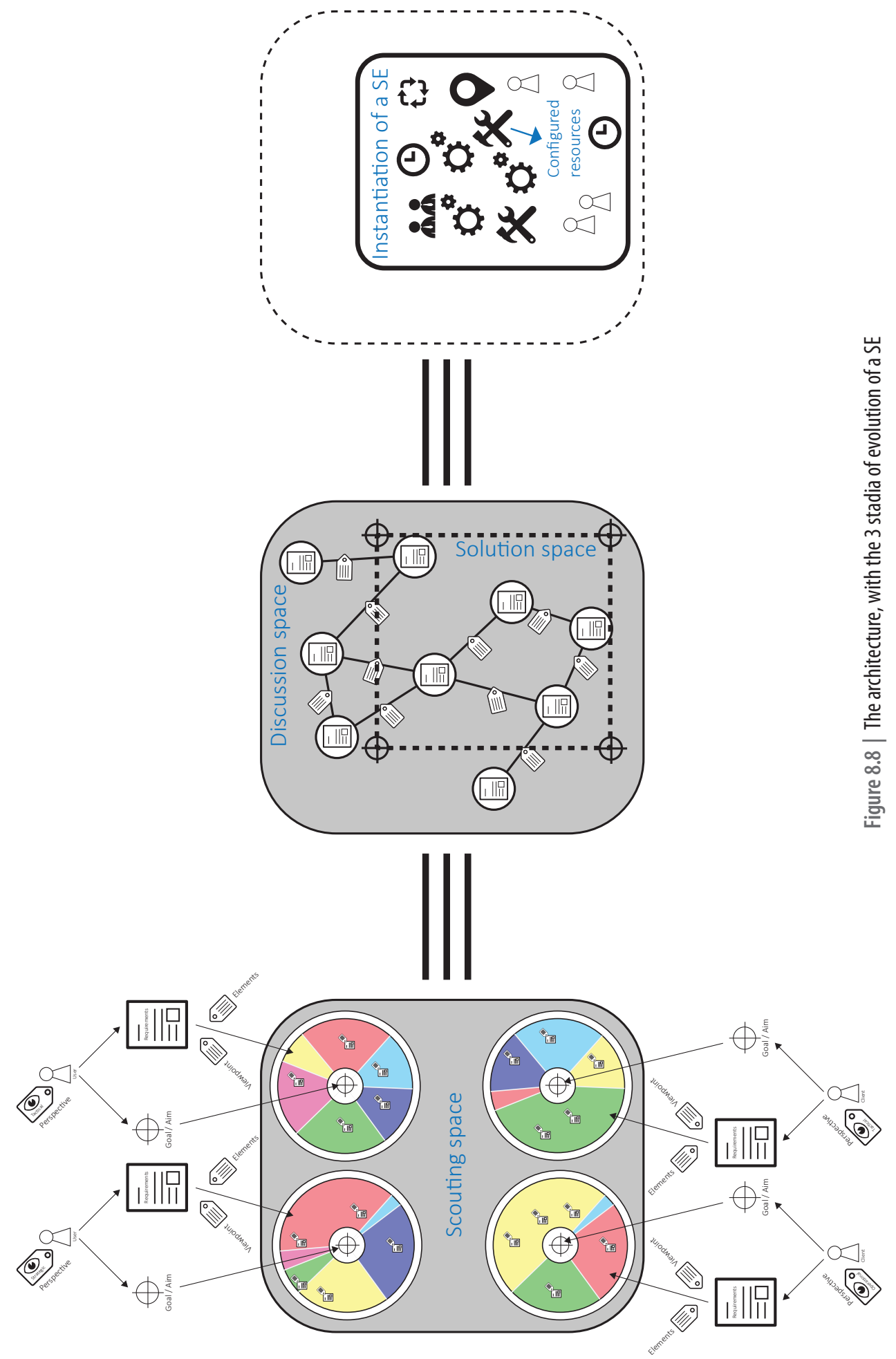


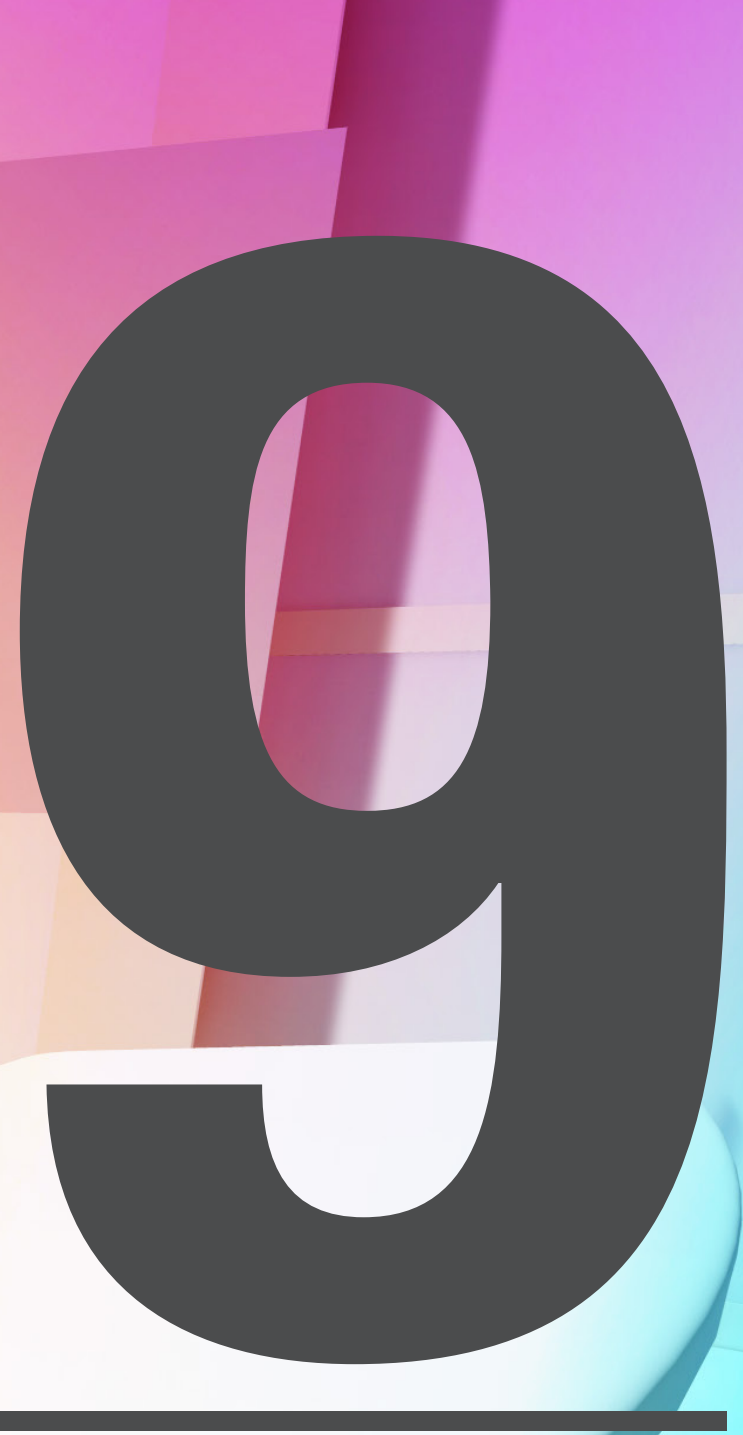

\section{IMPLEMENTATION}

AND CASE STUDIES 
Part III

\section{IMPLEMENTATION AND CASE STUDIES}

The SE profile introduced in chapter 8 provides a theory on how information gathering and decision making can be supported and facilitated in a SE development process. To use this approach in a practical environment some additional insights and understandings are required for lowering the threshold for implementation, and to achieve the most benefits. To utilise the fundaments described in Intermezzo 1 and 2, and the SE profile of chapter 8 , to their utmost extent, support in the implementation and integration process is desirable, and the scope of the implementation needs to be clear. This chapter will first elaborate on the relation between the research from this thesis and previous research in the same research group. This is followed by a more profound explanation of the consequences of implementation, related to three case studies. Based on the experience from this case studies an evaluation and future scenario is provided.

\subsection{VALIDATION IN RESEARCH IN THE DEPARTMENT OF DPM}

In the department of Design, Production and Management (DPM) at the University of Twente multiple research projects have already been performed in the context of utilising VR and SEs in product development processes. This design engineering research aims to improve product development processes, approached from multiple perspectives. Since the architecture (see section 8.3) allows for the use of different scenarios, different interpretations of the preconditions should be possible in the use of the SE profile. It should be possible to rephrase the approaches from previous research in terms of the architecture described in this thesis. Firstly, this validates the structure and applicability of this architecture, moreover improvements of the architecture can be deduced from the comparison.

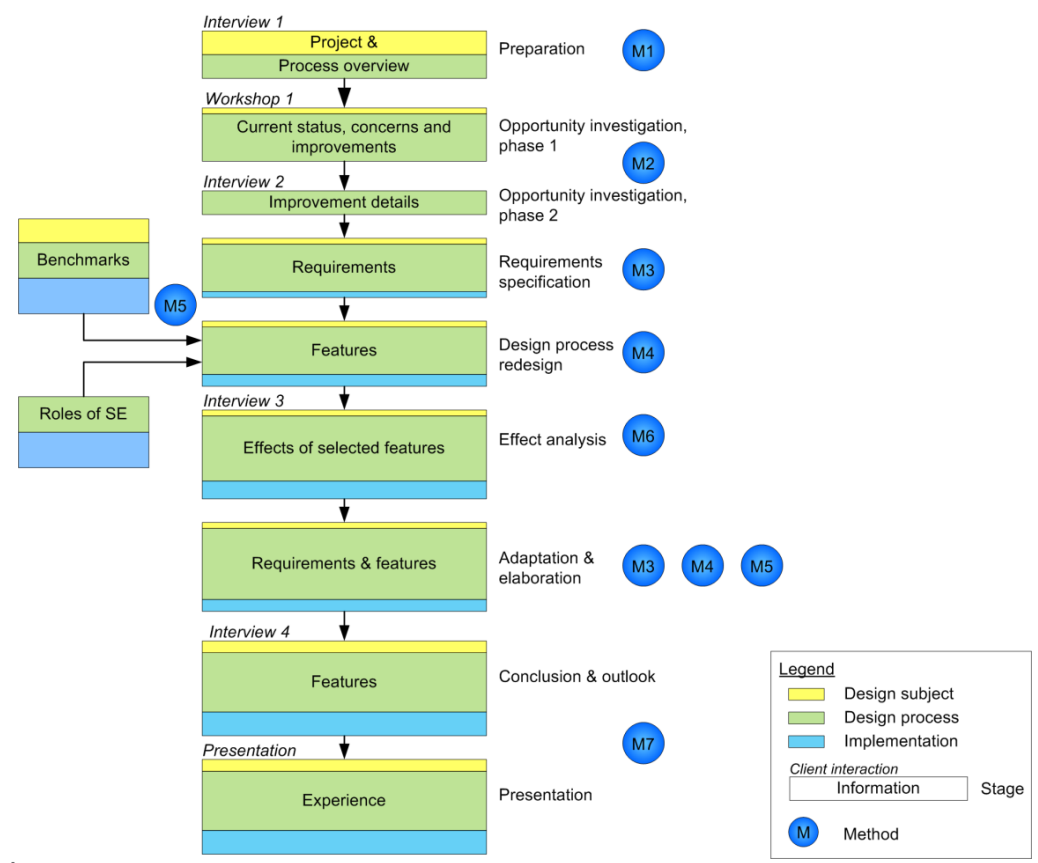

Figure 9.1 | Flow of activities by (Miedema, 2010) 
The research of Miedema (Miedema, 2010) focused on the use of Synthetic Environments in design processes. In the proposed method from that research, the presence of a consultant is leading. This consultant is a person who is responsible for collecting all the necessary information to define the requirements of a SE; the consultant is also involved in the final configuration of the SE. In this approach, the assumption is made that the scouting space is always bigger than the solution space, even more: that there is slack between the two; the consultant will only provide solution options that are possible within the recognised requirements. Based on a flow of activities (figure 9.1) seven methods are presented that can support the consultant in this process. Each of these methods describe a proposed approach to acquire the right information. The resulting information following from these methods can be used as SE requirements in the blueprints. Miedema proposes a consultancy framework (figure 9.2) that summarises which information transitions are plausible based on the method definitions. The information flows indicate the dependencies of the information content. This consultancy framework is comparable to a filtered view on all gathered information. This approach can be used in the SE profile, for example the steps described in 'requirements specifications' can be performed as a tool for filling in the blueprints, while the 'SE definition' and 'Knowledge selection' steps are useful tools to determining the scouting space and discussion space that will form the solution space.

The approach of Miedema is comparable to a scenario that aims to collect information from the end users; this fits as an approach to achieve the goal of the blueprints. The consultancy framework makes less distinction between different stakeholders, which is a strategic decision that will not hamper the use of the SE profile. An issue can occur in the process of combining multiple blueprints to a functional SE, in this phase often decisions have to be made which influence the requirements. In such an occasion, it is more difficult to find the person responsible for setting the requirement, since it is more or less translated

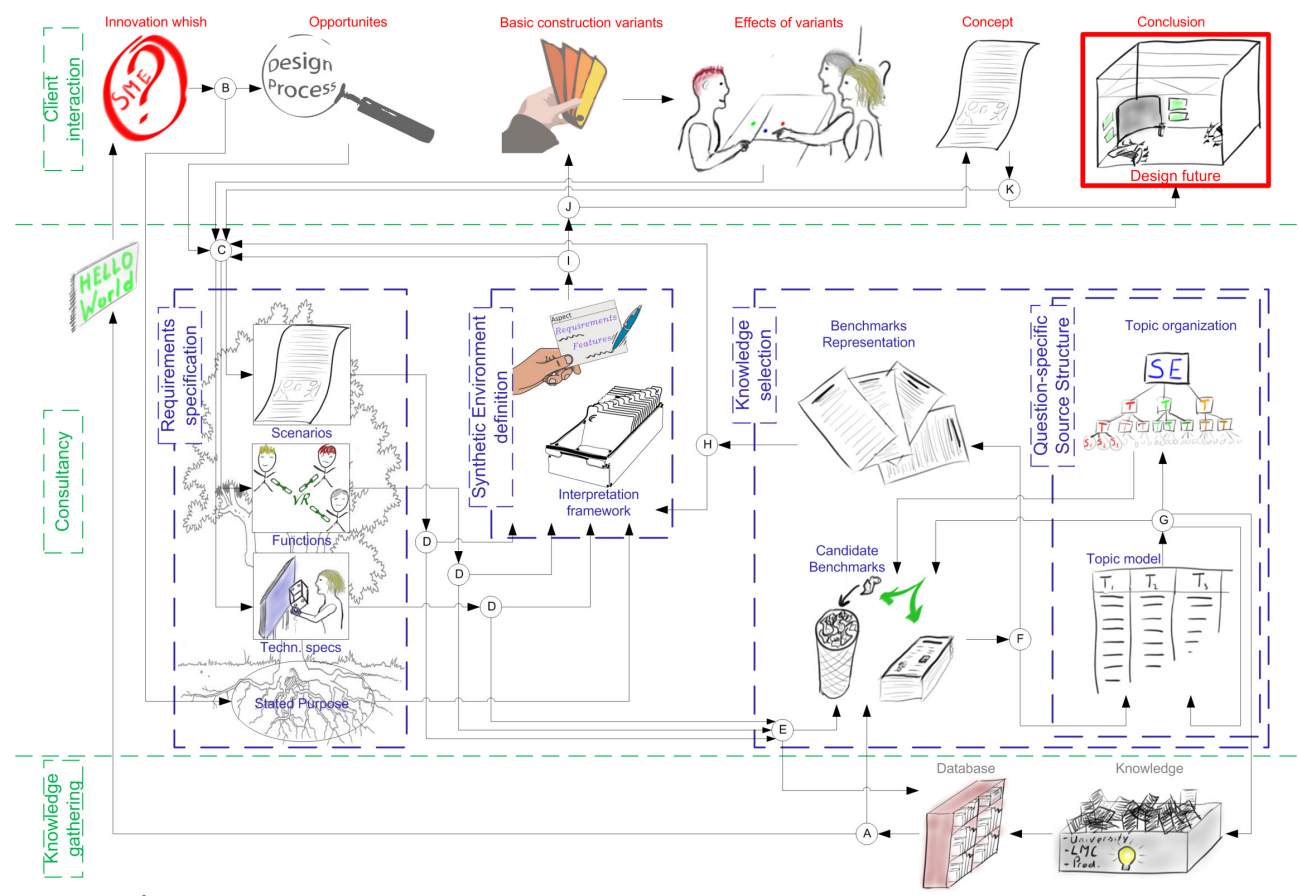

Figure 9.2 | Consultancy framework by (Miedema, 2010) 
Part III

by the consultant, who has little insight in the consequences for every stakeholder.

The research of Thalen (Thalen, 2013) focuses on facilitating user centred design supported by Virtual Reality. This approach aims on first exploring the possible VR applications within a certain design context, and requires an application definition. This process develops the discussion space and the solution space separately. It starts with the realisation of a set of solution spaces developed based on discussions with the client, which could possibly solve the challenges or problems of the user. The selection of most appropriate options is based on a close cooperation between the different designers with their own expertise (figure 9.3). The users are highly involved in the further realisation and demarcation of the VR application. Based on a provided (and predefined) solution space, the designer and the users conjointly work towards the best possible instantiation of a VR solution. This is a process of multiple updates on and iterations of the solution, which make it more tailored to the expectations of the user.

This process starts with a technology push approach, and allows for modification and adaptation of the solution space to make it better fit to the needs. This SE profile will contain a fixed solution space, which also determines the maximum area of the discussion space. Some of the requirements in the blueprint of the SE providing company will be treated as a fixed point in the further development, and can also be seen as the starting point for further development. The approach of Thalen stretches the interpretation of the boundaries of the SE profile to an extreme that opposes the starting point of Miedema, even though both the approaches can use the SE profile.

Both research projects operate in the same field of expertise, and have a common denominator, but neither of them can be handled as a general solution for each SE development project. This is one of the reasons why the proposed architecture should allow for the use of different approaches. New approaches will be developed (in- and outside the DPM department), and the architecture should be the foundation for this. More insight into the consequences of implementation are provided in the next paragraph, and the utilisation of the different approaches is visualised in the upcoming case studies.

Other DPM research projects which also can be related to this research is the participatory design approach of (Garde, 2013) and the scenario based design approach of (Anggreeni, 2010). Both approaches are already discussed in chapter 7, and both contribute to the set of available approaches to acquire the right requirements from the different stakeholders.
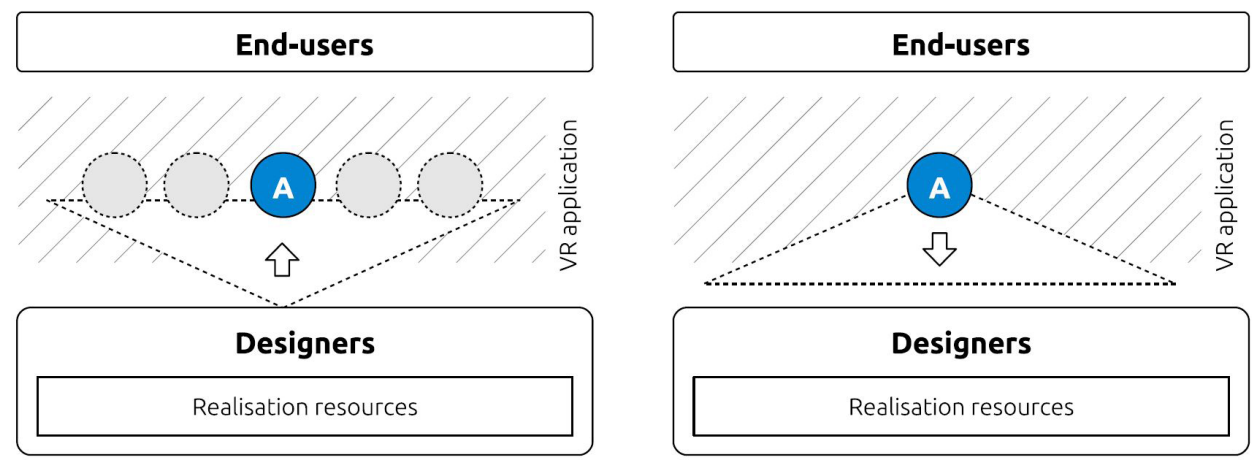

Figure 9.3 | Realisation of a VR application according to (Thalen, 2013) 


\subsection{IMPLEMENTATION}

The main purpose of the architecture, with its SE profile, is to facilitate discussions between different stakeholders. In these discussions the foundations and well-considered decisions come to light. To achieve these results, the stakeholders of the discussion need explicit information during the decision making process, to document the argumentation of decisions. The discussion space (see section 8.2) is aimed at providing that explicit information. Even without the SE profile approach, a discussion space will implicitly exist during the development of a SE, but the stakeholders are often unaware of this because it is mainly based on tacit knowledge and experience. This causes the decisions that are made based on this information to be not explicit, and difficult to communicate and document, while reusability becomes impossible altogether.

In using the SE profile approach, the blueprint functions as a trigger for this discussion (see intermezzo 1), but also provides grip by providing relevant aspects. By documenting the information with the use of the blueprint, the information becomes explicit and can also be used by others. Since the blueprints function as a trigger for discussion, the discussion space is a logical outcome of this collection of blueprints in the scouting space.

The first priority of the SE profile is facilitating the convergence process from discussion space to solution space. Providing a constructive approach to realise a SE is the main purpose of this research, as is elaborated in the previous chapter. The second priority is to optimise the process of developing a SE.

Every build and usage of a SE should contribute to the knowledge and experience of the stakeholders. All encountered pitfalls, disappointments and best practices add up to the tacit knowledge of the stakeholder, allowing a better starting point to be chosen for future SE development. It will still be possible to deviate from this starting point, but it can be expected that the starting point will be closer to the goal than without the experience. Based on tacit knowledge more probable paths between blueprints and solution space can be made, since not every decision is a rational one, and often information is lacking, resulting in uncertainty (section 4.2.3). More experienced stakeholders are more likely to make decisions while handling uncertainty.

The base-graph (see section 8.2) and the sub-graph of the SE profile allow for the recognition of patterns. Such patterns are combinations of elements and relations often used in multiple projects. These patterns can be explained as VR features; a specific feature that can be recognised as an enabler in a project. Similar to design or process planning features, they are assignable entities that carry a specific importance from a specific perspective. These features are not necessarily pre-conceived, but can be detected during the development of a SE, or afterwards by reviewing similarities between different SES. Recognising VR features is based on clustering the information from the SE profile, rather than classifying it on a predefined set of rules. This allows for the recognition of clusters not being thought of during the development. These VR features can change over time, with the development of new technology and insights, the added value of a VR feature can change. Each VR feature will include parameters that tailor the use to the specified SE (with an engineering meaning). This also indicates that the focus is more on the provided goal of the feature, than on the way that goal is achieved. With this, VR features can become meaningful building blocks that allow for effective and efficient configuration of feasible SEs. Based on these recognised VR features, new tools can be developed that enhance the quality of the features. It allows for more dedicated and focussed development of "building blocks" that can contribute in many SE. 


\section{Part III}

The VR features indirectly shows that realising a SE can be a configuration problem or a design problem. On the one hand it will be a configuration problem if multiple comparable VR features that provide overlapping functionality are available for integration in the final solution. In this case, a selection has to be made which VR features will be integrated, and the stakeholders are indeed facing a configuration problem. If there are no (combinations of) VR features available to resolve a specific problem within the requirements, the realisation of the SE requires the development or identification of a new VR feature. This results in a design problem.

Determining if the configuration of a specific SE is a configuration problem or a design problem is driven by the factors like time, quality, costs, feasibility and accessibility of the resources needed to construct the SE. Here, the comparison to process planning (as depicted in chapter 6.2) is obvious. Each of the factors can contribute to determine if it is desirable to make use of available VR features, if new features have to be developed, or if the requirements to the SE have to be altered.

During the development of a SE, it is not only useful to recognise combinations of elements or tools that are (often) employed in other SEs to allow for efficient reuse. Not only constructive VR features can be recognised in the base-graph and in the sub-graph, but also anti-features are very important to recognise. Based on failures or disappointments from previous projects, specific combinations of elements can be identified as unfavourable, infeasible, ineffective, inefficient or even counterproductive. By detecting these combination in an early phase of the development, other approaches can be favoured as soon as possible. This prevents setbacks, disillusions or frustrations in later stages of the development or use of the SE, thus increasing the predictability and robustness of the SE.

Comparing different SE profiles will prevent developing the same configuration twice. Since the SE profile is the combined result of decisions made throughout the process, and provides the potential of the solution in the solution space, it also allows the possibility to compare SE profiles. To enable the (partial) reuse of VR features, modules in a SE or even an entire SE in different projects, the stakeholders need to get insight in the scope of the application. Since the level of aggregation and the perspective will be different for each stakeholder, a VR feature is not limited to be reused on only the level of aggregation at which it was developed. All visualisations of a SE profile are based on the information from the blueprints plus the discussion space and the solution space. In this way, also the gap between stakeholders who are more image-based and those that are more text-based is covered.

If the number of available SE profiles increases, the benefit of using the architecture also increases. More similarities can be found between different SE, development phases, projects and stakeholders. Not only during the development of a new SE a profile for the solution can be made, but also for existing SEs it is possible (and desirable) to make a SE profile. This profile will primarily be a description of the composition and use situation of the existing SE. Not all argumentation from each stakeholder can be deduced, but it is often possible to make a statement about the value of a particular SE in a certain stage of the product development process. There is also the possibility to use the perspective of a design phase to look at the existing solutions which are already widely implemented in that specific phase, and therefore may be of interest to examine the usability. This information can be used to recognise VR features in already existing SE, which can act as a starting point to develop new tools. 


\subsubsection{APPROACH}

All the information and approaches described in this chapter relate to different perspectives. Each stakeholder has a different view on the approach, but also the expertise and experience from a stakeholder will influence the utilisation of this architecture. Some of the stakeholders (e.g. the operator and the SE providing company) have more experience in developing a SE, and will be continuously involved in SE development projects. It will be a recurring event for them. In contrast; the user is likely to encounter the SE development process only ones. The first time the user is involved in a SE development process will also be the first encounter of the architecture provided in this thesis. Those stakeholders require a different approach on how to be involved in the process.

When a stakeholder is involved in a SE development process for the first time, it is undesirable to confront them directly with the (potential) graph of the SE profile, since that stakeholder is not aware of, nor can grasp the complexity of the process at that time. Immediately providing him with that information will not improve the quality of the provided information, since the SE profile is too abstract at that moment and is hard to relate to a context. A novice stakeholder should be introduced to the SE profile at moments of discussion and collaborative decision making. The blueprints have a lower threshold for use, but emphasis should be on that the fact that the use of the blueprints is based on providing preconditions. The preconditions provide guidance in what has to be done to create a successful SE, but not on prescribing the exact executing of tasks. The preconditions can be tuned between all stakeholders; this still allows for personal preferences on execution of the tasks. The provided architecture emphasises on how a certain approach can lead a certain results (and how that result is achieved), instead of prescribing what should be achieved, and how that should be done.

First the blueprints, and later on the graphs, provide the stakeholder with potential interesting items commonly used in previous SE. The stakeholder can interpret these as trigger for determining if they have certain requirements on that area. The stakeholders are free to choose how they determine the requirements, as long as it fulfils the preconditions of the blueprint. Without predetermining each process, the architecture is not vulnerable to become outdated if new tools, methods or approaches appear. The architecture is thereby the reference point to which each stakeholder returns to combine all the gathered information.

The SE profile supports the process of realising a SE by offering the stakeholders a blueprint to determine their own requirements based on their own perspective, a discussion space that acts a foundation for making decisions, and a solution space that functions as the boundaries in which the SE can be realised. All these different supporting, stimulating and facilitating tools increase the insight and understanding of the development of a SE, since they can be encountered on each level of aggregation. The rationale of each decision is made more visible, and the information about the project is made explicit by documenting it. The SE profile allows for multiple scenarios of use and provides grip and guidance on how to document the decision making process.

\subsection{CASE STUDIES}

To review the fit of the architecture to the suggested working environment, a selection of case studies is described. Over the past years a large number of Synthetic Environments have been built in the context of the VR-lab at the University of Twente, showing a considerable variety in scope, reach, as well as in complexity. The scenarios used in these 


\section{Part III}

projects are mapped on the facilitating possibilities of the SE profile, to review if the proposed architecture is generic enough to cover the wide variety of the case studies. The architecture should be flexible and agile enough, without hindering or (inadvertently) steering the process. Furthermore, the proposed architecture should realise a noticeably better structure in previously executed projects. With the architecture, the decisions made in the process, and the selected perspectives in it, could be considered more adequately throughout the process.

In the case studies, the structure of the architecture is also reviewed, since the development of a SE requires a combination of multiple factors that are all equally important, e.g. different stakeholders, elements, insights, perspectives and level of aggregation. To have an overview of this development process one cannot rely solely on tacit information. The architecture makes the structure explicit, which is necessary to understand the relations and dependencies between all items. Furthermore, the case studies are used to examine if, and how, items are being reused between multiple SE.

In the previous chapters the most relevant characteristics of the development process of a SE are elucidated. To highlight how the proposed architecture can support facilitating these characteristics, three case studies are described. These case studies are used to indicate how the different characteristics occur in different SE development processes. The purpose of this section is therefore to indicate that these characteristics are likely to occur in a SE development setting, and that they are not a consequence of the SE profile since the proposed architecture of this research was not available at the time of this case studies. For this research, an important aspect is to validate that it is plausible that these characteristics are likely to occur in every SE development cycle. For the SE profile, the assumption is made that by facilitating each one of them individually, while being part of a constructive whole, the SE development process will improve.

The characteristics that emerge in SEs are:

1. Structure

Provide the required structure to underpin the required steps in the process.

2. Different perspectives and levels of aggregation

Understand which stakeholders are involved in the SE, and what the difference in perspective and level of aggregation is. Make the decision if all stakeholders involved are known, or that new perspectives should be added.

3. From tacit to explicit

The use of tacit information in decision making processes allows better use of experience, and can speed up the process. For exchanging viewpoints and documenting the design rationale this information needs to be made explicit.

4. Reuse of elements

Realising a SE often results in a configuration problem; understanding if and how elements can be reused can be made beneficial to the overall process.

5. Understand the complexity

Complexity will occur in the development of a SE, being able to assign this complexity to different elements of a SE makes this complexity manageable.

In the upcoming description of the case studies, the occurrence of these characteristics are indicated in the text using the numbers from the above list (indicated with $\langle \#\rangle)$. All these characteristics are visible in all the case studies, even though the case studies were executed without the explicit knowledge of this list. Furthermore, the genericness of the 
architecture is assessed by reviewing the different approaches of the above mentioned characteristics in different case studies. This will not proof that no SE development process exists without these characteristics, nor that this list of characteristics is complete, but it will make it plausible that by supporting these characteristics the development of a SE is also supported.

\subsubsection{BRoAdREACH HeALthCARE}

The aim of this project was to develop a 'Health Command Centre' (HCC) for BroadReach Healthcare (BRHC) BRHC supports decision making and policy development in the field of public healthcare. The HCC should provide both the data integration IT solutions while simultaneously providing problem solving/decision making approaches all presented in a highly interactive, highly visual environment. Eventually the HCC in itself will also function as a SE. This case study was executed between March and May 2014.

In the preliminaries of the start of the project, the operator of the VR-lab and BRHC frequently interacted via e-mail and videoconferencing to prepare a reference guideline for the project. These preparations consist of a weekly one hour videoconferencing meeting. In the last week of April four employees of BRHC visited the VR-lab to execute a two-day SE development session.

Based on a listing of available data (types) provided by BRHC and conjoint formulations of the goal, the outline of the project was assembled. In the subsequent phases, all stakeholders conjointly worked on a comprehensive overview in a kind of pressure-cooker setting, using one of the 'gaming tables' (figure 9.4) in the VR-lab. The next step in the process consisted of determining the requirements of every stakeholder in healthcare analytics $\langle 3\rangle$. The goal of this phase was to extract and recognise the problems the solution should aim at. Moreover, significant effort was spent on identifying all relevant (prospective) stakeholders $\leq 1\rangle$. Here, the focus was on the exploration of the problems currently experienced by every stakeholder, expressed from their own perspective and in their own words, while avoiding to think in terms of possible solutions $\leq 2\rangle$. The aim of this phase was to come up with a clear depiction of the 'problem space'.

Figure 9.4 | 'Gaming table' in the VR-lab

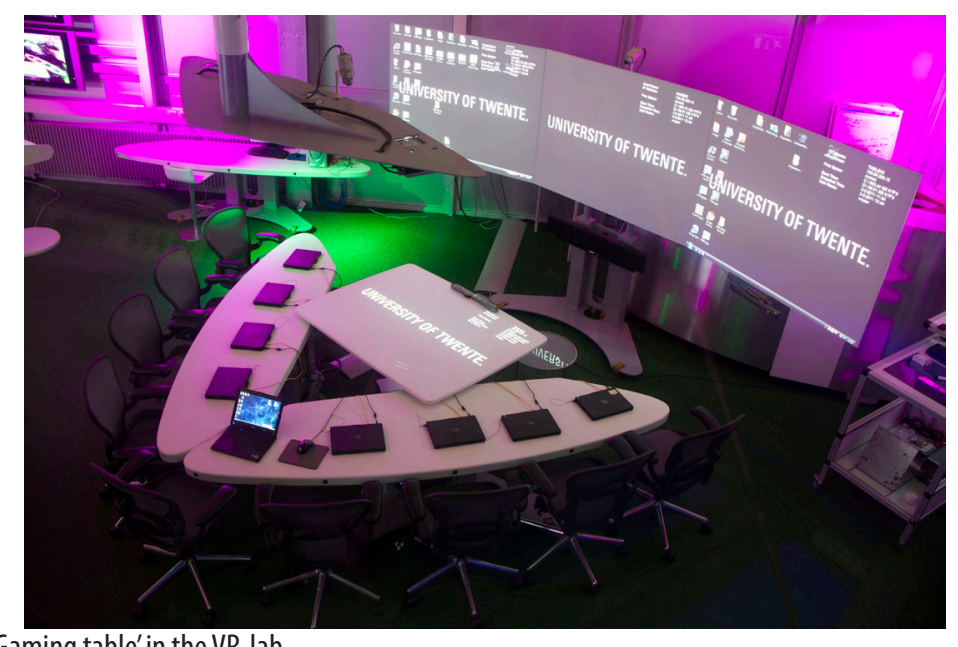




\section{Part III}

The second phase was to create an outline of available data within the project. This overview should only provide the currently available data, preferably in the original raw format $\langle 1\rangle$. A moderator from the University of Twente was present to guide the participants, based on the initial outline, by questioning them to formulate their individual problems using keywords, sketches and images collected on a personal tablet computer running a dedicated interface. All these individual items were visible for the entire group on one of the larger screens $\langle 1\rangle$.

Harvesting all individual items resulted in the central overview, while being discussed by the entire group $\langle 1\rangle$. Each participant should understand the problems experienced by other participants before an item could be added to the central overview of problems $\langle 2\rangle$. This is achieved by allowing every individual to elucidate problems during discussions. This information was stored in structured mind maps $\langle 1\rangle$; the repository of mind maps was visualised on the larger screens $\langle 5\rangle$. All changes or additions made to blueprints of other stakeholders are visible in that overview, and would inspire others.

This phase ended with representations of the current problems and of the data that can currently be provided by the participants. This result is used as the starting point for defining the requirements of the solution. The approach for determining the requirements is comparable to the process of the first phase. Together with all participants each problem was discussed and possible relations with the available data were made $\langle 1\rangle\langle 5\rangle$. This was done by putting the mind map of "available data" and "current problems" simultaneously on large screens. Virtual lines were drawn between available data that can provide enough information to solve a specific problem $\langle 3\rangle$.

After the 'problem space' has a dequately been charted $\langle 1\rangle\langle 2\rangle$, the aim shifts to establishing an appropriate SE that does justice to the needs and requirements stemming from the overview generated earlier.

Setting the requirements and functional specifications imposed on the VR solution have been leading in this, as that provided the combination of tools and techniques that offer the desired functionality to the end users. Based on these requirements for the HCC, possible types of visualisation technologies have been compared using solutions and best practices from previous projects $\langle 4\rangle$. The operator made a purposeful selection $\langle 5\rangle$ of previously performed projects that share similarities on one or more of the following topics based on the provided data from the client):

- Desired type of interaction

- Available type and amount of data

- Number of active participants working with the solution conjointly

- Size, accessibility and visibility of the visualisation

Taking into account considerations on intellectual property and non-disclosure, the filtered projects were (partially) combined in a set of best-practices and examples of what the combination of different tools might offer.

To assess what data visualisation techniques are optimal, it is essential to take into consideration each stakeholders' requirements with respect to data and visual representation of that data $\langle 2\rangle$. This is non-trivial, given the different fields of expertise and different levels of aggregation of the stakeholders. Therefore, the functional requirements set in the overview are reviewed and compared to the functionality of the existing solutions.

The project resulted in a delineation of the prototype of the HCC, in the form of mind maps 
(figure 9.5). These mind maps provide information about the hardware, software, data and functionality required to establish the prototype $\langle 3\rangle$. In the hardware section, the required tools are specified in terms of their functionality (e.g. touch table), complemented with a list of possibly interesting equipment to implement that functionality (e.g. Microsoft PixelSense).

The request for a HCC by BRHC was aimed on a solution which could be realised within a year, in their own facility in South Africa. This provided some limitations in the resources, these limitation were known by the stakeholders from the company. For the approach of this TNA these limitations are normal and expected, since the SE is configured by the stakeholders (and only facilitated in the process), the stakeholder of the VR-lab don't have to know every detail about all limitations on beforehand (in contrast to the approach of (Miedema, 2010) and (Thalen, 2013)). The HCC has been well-received in its initial rollout in South Africa in 2014. Current users are stakeholders from the South African government, international donors and BroadReach staff. They access the HCC in two ways - either via desktop computers using a software as a service model (SaaS) or in a physical HCC data lab in BroadReach's Cape Town and Johannesburg offices. The data lab allows for real-time, multi-stakeholder meetings and problem solving while the SaaS assists users in their daily and weekly work.

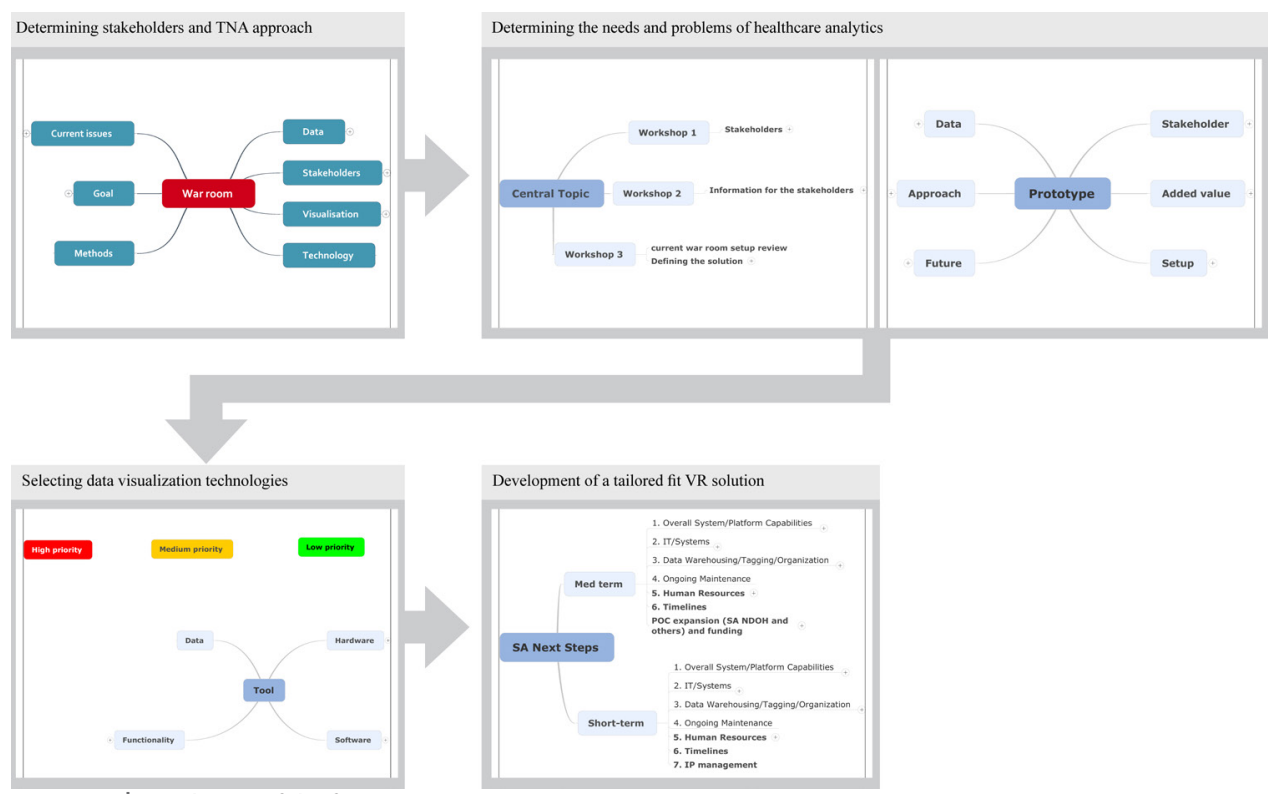

Figure 9.5 | Mindmaps of the future HCC

\subsubsection{VISIONAIR ROADMAP}

VISIONAIR is a European infrastructure that grants selected researchers trans-national access (TNA) to high-level visualisation facilities and resources across Europe. A TNA, however, can only be efficient and effective for both the researchers and the facility, if it is preceded by adequate preparation. Aligning requirements and assessing resource usage and working methods are essential here $\langle 1\rangle\langle 5\rangle$. Providing a static preparation processes is not sensible, as the stakeholders are geographically scattered all over Eu rope and have their own backgrounds and interests $\leq 2\rangle$. Therefore, supporting the underlying deliberations can yield huge benefits in preparing a TNA. Eventually the TNA will result in a SE. In the 


\section{Part III}

context of the VISONAIR projects and the VR-lab of the University of Twente an approach has been developed that provides a working method to fit the preparation of a SE to meet the requirements specified in the context of TNAs. This a pproach is provided in the shape of a roadmap; the usage of the roadmap is initiated by the operator of the facility.

In essence, the structure of the roadmap for a SE in VISIONAIR consists of 'checklist' items that guide users in their process of developing and establishing a SE:

$\begin{array}{ll}\text { A } & \text { Occasion for considering SEs in the process }\langle 2\rangle \\ \text { B } & \text { Opportunities for introducing a SE in the process } \underline{\langle 1\rangle\langle 5\rangle} \\ \text { C } & \text { Stated Purpose }\langle 1\rangle\langle 2\rangle\langle 3\rangle \\ \text { D } & \text { Requirement Specification for } \mathrm{SE}\langle 1\rangle\langle 2\rangle\langle 3\rangle \\ \text { E } & \text { Basic Construction Variants }\langle 3\rangle\langle 4\rangle \\ \text { F } & \text { Effects of Variants }\langle 2\rangle\langle 5\rangle \\ \text { G } & \text { Definition of SE }\langle 1\rangle\langle 2\rangle\langle 3\rangle \\ \text { H } & \text { Prototype Implementation of SE in the process }\langle 3\rangle \\ \text { I } & \text { Comparison with reference projects }\langle 1\rangle\langle 4\rangle\langle 5\rangle \\ \text { J } & \text { Documentation for implementation } \mathrm{SE}\langle 3\rangle\langle 5\rangle\end{array}$

The different items in the roadmap indicate the information that is required to underpin the decisions that are made during the construction of a $\mathrm{SE}\langle 3\rangle$. Also the considerations on whether or not to use a SE in the PDP are included. The list of items is also based on, and inspired by, the consultancy roadmap of chapter 7.3. Each element of the roadmap is provided with a description of the rationale of acquiring the information. Moreover, approaches to generate that information are suggested $\langle 1\rangle\langle 4\rangle$. As often more than one approach can be used to generate the same (type of) information, stakeholders are encouraged to choose any approach that appears useful $\langle 2\rangle$; they are definitely not restricted to using approaches suggested by the roadmap. In fact, the roadmap is never finished, nor complete;

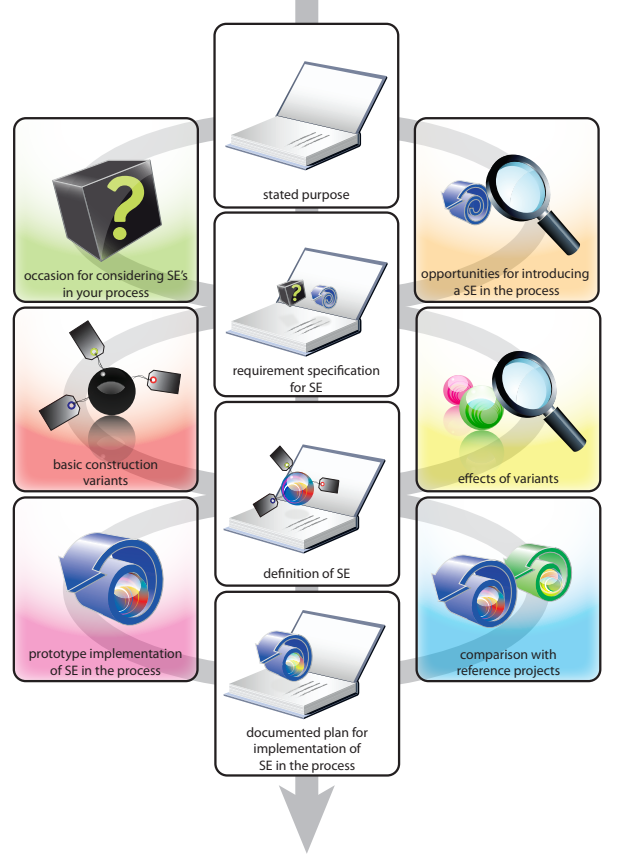

Figure 9.6 | TNA Roadmap 
the roadmap benefits from regular updating to allow new approaches (not only limited to the VISIONAIR project) to become part of the content.

In the structure of the roadmap the documentation steps are made explicit $\langle 3\rangle$. This is done by placing these steps in the centre of the visualisation and by consequently re-using the book-icon in these steps (figure 9.6). The different blocks in the roadmap give indications on the information that is required to meticulously underpin the decisions that are made during the construction of a Synthetic Environment. In the different blocks, users can find a description of the information that is required in that specific block. Moreover, the roadmap will suggest approaches by means of which this information can be generated. The final block of this documentation 'backbone' represents the summary of documentation that is done $\langle 1\rangle$. The evolving character of the documentation is made more explicit by this visualisation. The other steps are placed in reference to the evolving documentation 'backbone'. By this, a visual roadmap structure is created that is easier to survey.

When using the roadmap to structure the considerations and decisions during the establishment of a SE, it is helpful to employ the roadmap structure to capture the information content as well. To support users in this documentation effort, a mind-map is provided that acts as a digital 'workbook' $\langle 1\rangle$. By attaching rationale and decisions, e.g. in documents, to this mind-map, users are able to efficiently capture their work $\langle 1\rangle\langle 5\rangle$.

In order to make the roadmap easily accessible for all VISIONAIR partners as well as (prospective) visitors to the VISIONIAR facilities, the roadmap is published on a website. A depiction of the proof-of concept of the website is shown in figure 9.7.

An example of a case study that has been performed is the test that was conducted during the VISIONAIR General Assembly 2012 at the University of Twente. The test with VISIONAIR partners was arranged in the VR-lab of the University of Twente. Aim of the test was, first of all, to familiarise the various partners with the proposed roadmap approach. This was done by allowing them to use the roadmap in a small case study in which they created a plan for implementation of a SE in a research process.

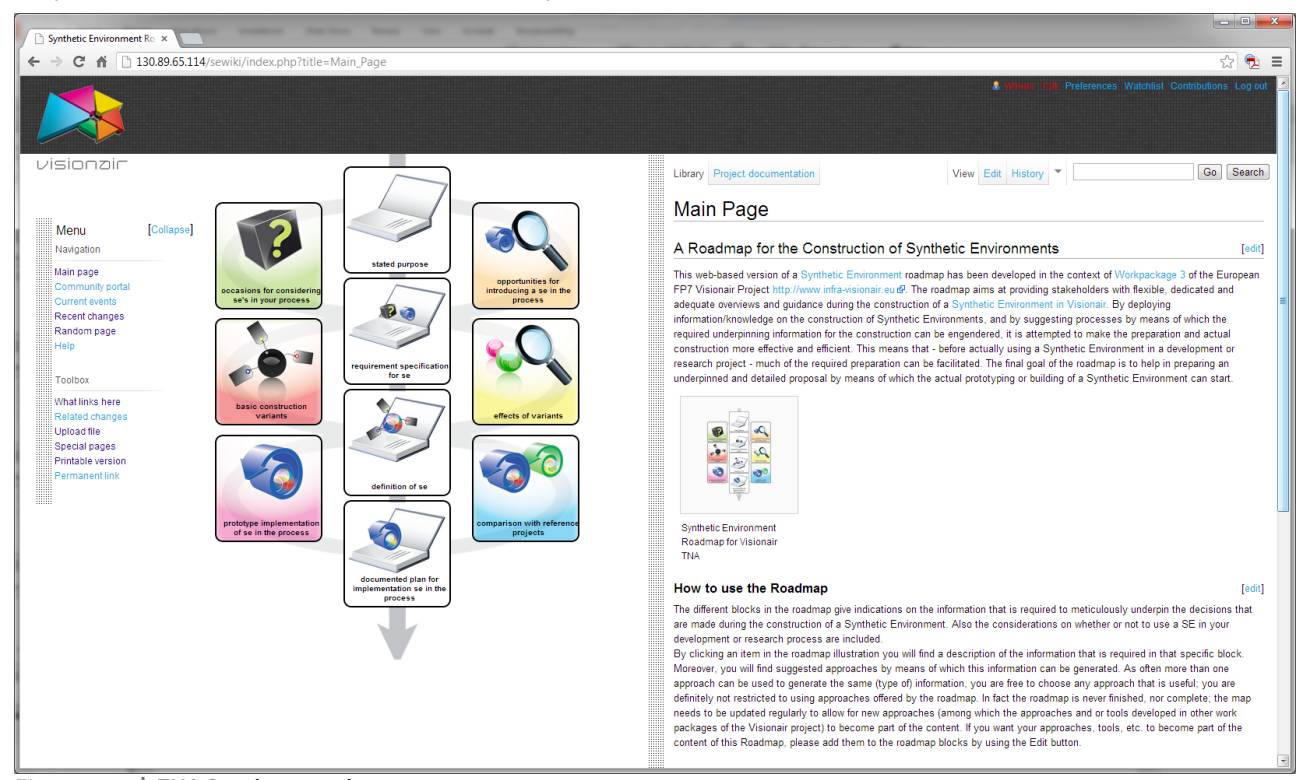

Figure 9.7 | TNA Roadmap website 


\section{Part III}

During the workshop, the partners had to take into account both the customer and supplier of the facility. Therefore, the group was split up in two smaller groups, each representing one of the two roles. The groups had to collaborate on how a SE could be implemented in an effective manner, and what the SE should look like. The roadmap was used by both groups to support the collaboration and to help both groups to conjointly prepare a proposal. The information that was gathered during the workshop was documented in the mindmap that was provided with the roadmap. This document could - after gathering enough information - be used as the final proposal for the requirements of a SE. In some parts of the roadmap, it would be helpful to have a number of 'example' projects that illustrate the usage of the roadmap (capturing best practices in the roadmap itself). It is expected that such examples (captured in block I of the roadmap) will enable applicants to reduce the time required for learning to use the roadmap.

In the VISIONAIR project, the roadmap has been applied multiple times, underpinning a number of (TNA) research projects. Over time, more best practices have been captured and made available in the roadmap. At the time, the architecture was not yet explicitly available, but much of the functionality in the architecture was - in one way or the other covered by the roadmap.

\subsubsection{VR MASTER COURSE IDE}

In the Industrial Design Engineering master course 'Virtual Reality', students are challenged to design and strategically position a Synthetic Environment to support a specific phase or circumstance for one or more stakeholders.

The students are taken out of their 'comfort zone', by confronting them with the assignment to develop a SE for an extreme stakeholder that has little or no knowledge and experience (and perhaps even no interest) in VR $\langle 2\rangle$. The stakeholders involved can be from industry or have a research background. To mention just two examples: one year an academic research group focusing on positive psychology provided a case, the next year the client was the airline company KLM. Based on extremely short introductions by the clients (maximal one hour), the context and environment of the client are provided. The client only explains what the advantages, challenges and disadvantages are of the current situation. On purpose, there is no suggestion for improvement or solution provided $\langle 3\rangle$. The students themselves single out what specific area of this expertise they would like to focus on, and what (combination of) stakeholder the solution would be aimed at.

The course aims at exploring the possibilities of Virtual Reality tools by integrating theoretical knowledge and background and practical application. The focus is on the integration and combination of available techniques, rather than developing new ones $\langle 4\rangle$. These techniques include different possibilities to stimulate the visual, aural and haptic human senses. During the course the students must find the best fitting virtual support tool. The main challenge is the conversion of a theory into a workable situation using virtual tools of a.o. the VR-lab of the University of Twente, while keeping in mind that the virtual tools should support, and not obstruct, the users. The term 'Virtual Reality` includes all kinds of digital tools varying from a simple display to a full-blown 3D environment. The students will have the opportunity to try to find new applications for technologies available inside and outside the VR-lab, and to create new tools for product development projects. Based on (guest) lectures, workshops and consultancy meetings the students work on a thorough description of the envisaged virtual tool, while taking into account aspects like product life cycle, information management, multi-user environments and interaction possibilities $\langle 5\rangle$. 
The students work in groups of five students on the assignment. The SE should be described as an achievable and feasible solution within a time horizon of two years. The students also have the freedom to select or develop their own approaches and methods. Furthermore, a workable demonstrator has to be established, tested and evaluated in co-operation with the client and with another group of students during test sessions (figure 9.8).

Nearly all groups first start to find literature that focuses on the specific fields of expertise that characterise the client. All groups made contact with the client (e.g. via e-mail, but also via visits), to ask questions aimed at finding confirmation of the problems as recognised, identified and specified $\langle 1\rangle\langle 2\rangle$. A remarkable difference in the interpretation of stakeholders can be noticed between the two different projects depicted here. With the first client (psychology research group) the results of the students were aimed on providing the best SE experience for the practitioner and the patient. In the second year (KLM), the students were much more focussed on how the SE can be utilised in a commercial environment. It goes without saying that this demonstrates how influential a stakeholder is in the decision making; at the same time, however, the underlying approaches and working methods appear to be insensitive to such differences.

Since no structured way of documenting the information is prescribed or provided, each group selected an approach al ready experienced in other projects focusing on development processes. The students had no prior knowledge about what information might be useful in the upcoming processes, nor does the client have that knowledge $\langle 5\rangle$. Most groups worked towards a list of requirements following from the communication with the client, seen from the perspective of the client and the user. They made lists of requirements and criteria based on researching the perspective of multiple stakeholders involved in the envisaged SE $\langle 1\rangle\langle 2\rangle$. Simultaneously, the groups experienced the requirements of VR tools by trial-anderror and literature study. This lists of requirements functioned for the vast majority of the groups as the starting point for the construction of a $S E\langle 1\rangle\langle 5\rangle$.

A minority of the groups took a different approach; they first selected a (for them) interesting VR tool (in these cases a head mounted display), and attempted to identify a problem they could solve with this technology push 'solution'. The requirements they set
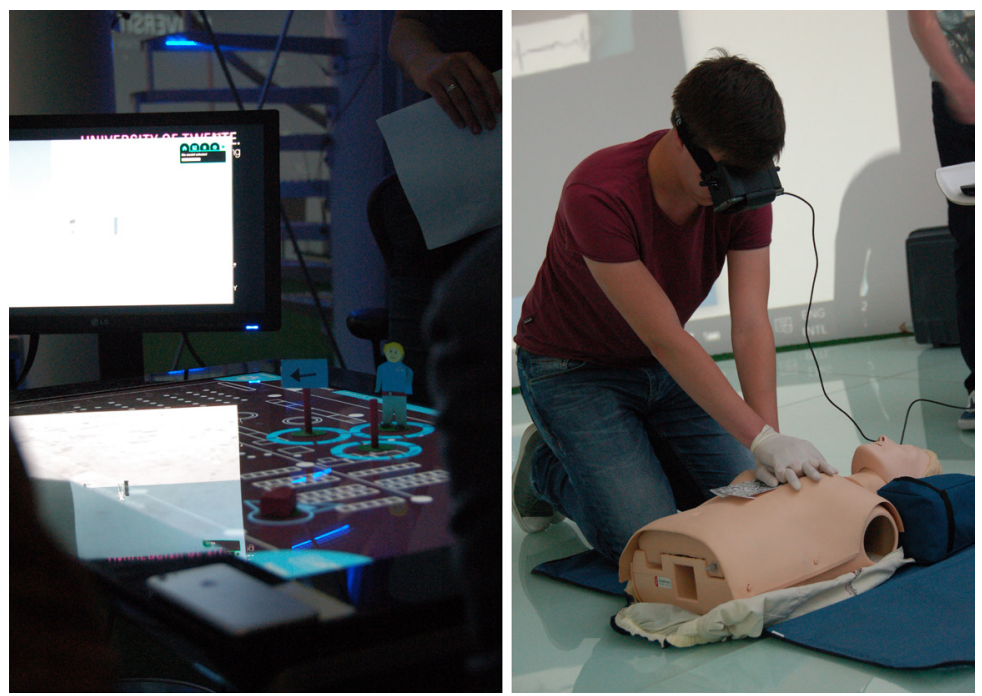

Figure 9.8 | VR Master course test session 


\section{Part III}

at the beginning of the process were merely technical limitations of the VR tool, without taking into account any functional specifications as the other groups did. These groups discussed two times with the client, and worked towards a design brief for an external developer $\langle 3\rangle$. This design brief contained all the information required to realise the SE, and could be handed over to an external company for actual realisation of the SE. This specific approach left little room for iteration and discussion.

The students used their list of requirements to determine the best fitting selection and combination of items to realise the SE. This description of the selected/established process of most groups left to be desired, foremost because they had no clear methodology to start this process. Especially communicating about the design rationale $\langle 4\rangle\langle 5\rangle$ appeared to be cumbersome. Many of the groups directly started sketching solutions (without taking the available VR tools in consideration), and went into a trial-and-error process of finding the suitable tools. Some tried to give some structure to this configuration by using schematic overviews of what VR tool is responsible for what interaction element, but lacked providing insight in future consequences of changes. Again, the architecture was not explicitly available to the students; in the coming years, the architecture (containing and addressing experience gained in the previous years) will be an additional underpinning of the course. With this, it is expected that not only the outcomes of the projects will show an even higher quality, but especially that the processes will be more elaborate, mature and better underpinned.

Every year approximately 60 students participated in this course ( 55 students for the psychology case, 65 for the KLM case). This master course has a study load of 140 hours, and is executed in a time period of 10 weeks. In every week the students have 8 hours access to the VR-lab and all its equipment, additionally four lectures of each four hours are provided in the first weeks of the course. The students worked in a group towards the results, and could contact the academic staff at every moment. There was no direct tutoring of a teacher appointed to a group, the initiative for feedback must come from the students. The closure of the course consists of a test session, where each group should perform a halfhour test with their own developed SE. The client was asked to act as the test person for the SE. The feedback of the client on this test should be incorporated in the final description of the SE. In both years, the client was present at the first day of the course, one day on week 5 , and during the closure of the course in week 10. In the meantime the client was willing to answer questions by e-mail.

Both years the clients encountered interesting SEs in the results of the groups. In the case of psychology, five project groups were asked to present their result on a symposium about "Monitoring \& Coaching". One those groups continued their project in a second course in which they worked towards a project proposal for granting a subsidy. Another group decided to make a commercial variant of their solution, and started their own company. Based on the results of the KLM case two students are currently graduating at KLM. Both of them work on the topics that formed the base of the assignment. The clients of both the subjects were satisfied, and in some cases even surprised, with the result. For them it only took them a relative low effort to achieve a large collection of ideas and suggestions. Even though both the clients, and the students, were no expert in the field of SE development, for both clients SEs were presented that could benefit for the company. For the upcoming years already multiple companies showed interest in participation in this course, the media company 'RTL' will provide the case for the next year. 


\subsection{EVALUATION AND FUTURE SCENARIOS}

Reviewing the previously performed projects in the area of Synthetic Environments in the context of the VR-lab, of which a small selection are discussed in this chapter, allows for the evaluation of the use potential of the proposed architecture. The previous discussed case studies describe the SE profile from multiple perspectives: the VR-lab as a SE providing company, the researchers and students of DPM as operators, and the customers as clients and users. From these different perspectives, different evaluations can be made, and also a future perspective can be sketched.

The main characteristics as mentioned in chapter 9.3 can be compared to the metaphor of making a map, used in chapter 8; in that case all the five characteristics can be associated to road signs in this mapping process. The architecture should provide structure, facilitate different perspectives and levels of aggregation, stimulate the conversion from tacit to explicit, enable the reuse of elements, and eventually making the complexity of the development understandable. The road signs indicate these different, most common, routes the stakeholders could/should take or should be aware of. These signs help the stakeholders to navigate in the development process; and are always available to show what main characteristics are (often oblivious) part of a SE, and should be taken into account. They help the stakeholders to understand the advantages of using the architecture, and provide direction on what to expect during use.

\subsubsection{Evaluation}

The case studies provide insight in how the boundaries of interpretation and the preconditions of the supporting architecture can be stretched for the width variety of stakeholders. The architecture demonstrates to be generic enough to provide a certain benefit to the variety of case studies. A lot of similarities are visible between the different projects executed in the VR-lab. All these projects were executed independent from each other, without a clear agreed upon or pre-structured approach. Most decisions about the process were taken with tacit knowledge, and without making this explicit. Nevertheless, the observed steps towards stabling the different SEs are comparable. There is a lot of variation in the users of the VR-Iab and the SEs, with the direct consequence that the need for collaboration between these stakeholders is one of the main challenges in realising a $\mathrm{SE}$. The need to be able to make fast switches between the different perspectives on the solution is a weighty functionality in each project.

Many of the decisions made in the projects are based on experience or intuition. Both of them should not be hampered, and sometimes should even be stimulated. In the case studies, it is visible that many decisions are made based on tacit information; even though the results or quality of the decisions are not questioned, making the information explicit will improve the communication of the rationale among all stakeholders. Because of a lack of (structured) documentation on the rationale of a SE, it becomes even more challenging to reuse existing elements or parts of solutions between projects. At the same time, all case studies demonstrated that stakeholders explicitly and willingly are interested in solutions that have previously been developed in comparable circumstances or addressed similar aspects of development cycles.

With the SE profile architecture the view on the documentation is improved, even though there is no fixed method of documentation. This lack of a predefined documentation system allows for project-dependent implementation and usage of a documentation system, while the overall architecture is generic enough to cover a wide variety of projects. 


\section{Part III}

Even though the VISIONAIR roadmap was not developed in the context of this thesis, a lot of inherent similarities come to light. Nearly each element of the roadmap can be concerted to the criteria of a SE as stated in this thesis. The same can be observed in the other case studies; the five main characteristics of the SE profile can be highlighted in all case studies. What is often envisaged in the case studies, and is especially visible in the VR master course, is the reuse of existing parts of a SE. This is not easy to achieve, since up to now, no SE is documented in such a way that single elements can be identified and found. An example of the benefit and advantage of developing parts of a SE as separate reusable tools is visible in the use of a 'ranking tool'. This tool, which has been used in multiple case studies, allows stakeholders to rank virtual objects on two axes simultaneously (but actually capturing many interdependent axes in the underlying model), using a table with build-in touch-screen. This tool was developed based on experiences of several SE, where in hindsight the solution could have greatly benefited from a tool like this. The ranking tool was developed separately because in no single project the explicit requirement was expressed strong enough to justify its development. Nevertheless, in looking to multiple projects in an integrated manner, the applicability of such a tool could be substantiated. After developing the tool, it was provided to all users of the VR-lab. Since then, the tool has been used in multiple education projects, and also in research projects such as (Hoolhorst, van Rompay et al., 2014). Providing insight in the need for such an activity of developing new tools based on previous projects is something that could be made more structured and faster with the SE profile architecture.

The case studies substantiated that there is a benefit of not incorporating specific processes or process descriptions in the SE profile architecture, since this allows for a perspective-driven interpretations of support, and therefore can influence the acceptance of it. It is possible to realise a SE without the support of the architecture, which is in line with the purpose of the architecture: it should facilitate the development of a SE, not being responsible for the development of a SE. Providing an essentially generic architecture is essential in this. By indicating the characteristics in previous performed SE development projects, the most common structure of case studies can be identified. This information is useful to predict the (sequence of) characteristics in upcoming projects. This allows for better preparation of the process, and provides the stakeholders with a better overview of possible upcoming events or activities.

\subsubsection{FUTURE SCENARIO}

The development of the SE profile and architecture will bea constant process, which will never be finished completely. In the near future, a digital support environment is to be developed, which also includes a functionality to navigate through all the available information, and to dynamically set filters. The development of new SE, and thereby also the use of the VRlab, can benefit from an architecture that facilitates this process of navigating through information. This makes the threshold for usage lower, and enables more stakeholders to employ the tools. Facilities like the VR-lab will become more self-supporting since all information can easily be re-used by others. This allows the VR-lab to make a pool of existing (parts of) solutions, and a selection of best practices, even exchangeable with other labs or facilities. This overview allows for insight in the missing links between solutions, or a view on the most used elements. Both of these aspects (missing elements and most used elements) can function as a starting point for new research. These research project can be linked to the research of the department of DPM, in combination with companies and students, and will work towards a long-term vision on the desired research. 


\section{SE as a learning factory}

As mentioned often throughout this thesis, the market conditions for VR tools, and thus SE possibilities, are changing at a constantly increasing speed. Companies need to be able to quickly adapt their methods of work, and their products, to these new market conditions in order to survive. The SE profile is aimed at coping with these changes, but to maximize the use of it, the integration of the SE profile in a learning factory is advised. The VR-lab of the University of Twente is an example of an environment that can function as a learning factory for SEs. Learning factories provide a reality-conform environment as provider of learning experiences; they consists of physical didactic and digital environments to realistically simulate real-life, simulated or even envisaged processes. Physical and digital environments should be integrated to support adaptation and improvement of the digital solutions (Wagner, AlGeddawy et al., 2015). These environments have a strong relation with industry, contain a combination of hardware, software, application and models, and are therefore also well-suited for a SE. Learning factories challenge users from all hierarchical levels to find creative solutions in unknown situations (Abele, Metternich et al., 2015; Wagner, AlGeddawy et al., 2012).

In a (SE) learning factory, the emphasis is on 'learning' as opposed to 'teaching'. This emphasises the importance of experiential learning, where cause-and-effect as well as trial-and-error are used to understand and investigate the relations and dependencies of elements. Especially in the development of a SE this approach has advantages, since the synergy that can occur between different individual elements are not always obvious or predictable (see chapter 6). Besides a greenfield approach (start from scratch), also the improvement of existing SE can be part of a learning factory.

TheVR-lab hosted and hosts many projects and approaches, and has a basis collection of (VR) tools to enable and facilitate this. The learning factory can be used to completely virtually simulate the effects of a SE configuration. Since the complete SE is virtually represented, it is possible to review and simulate it from all different perspectives. All different approaches of using the potential solution can be tried out using scenarios (chapter 7) or simulations, and allow for training of the future solution in realistic situations. Furthermore, it brings the learning process and ability closer to the industrial practice, since the threshold for implementation can be lowered if (many of the) consequences are already known. This also allows for reviewing existing or previous used SEs in the current context. The architecture described in this thesis can stimulate and facilitate the use of - at first - this VR-lab as a SE learning factory. The knowledge and experience gained in this use, can be utilised to further enhance and improve the architecture. Since the research of the VR-lab is strongly related to research performed in other (international) laboratories, the threshold for making the transition to use this architecture in other SE development settings is not consequential.

Due to the constant emergence of new tools, not all effects of a decision can be predicted or calculated on beforehand. Often there still is an uncertainty in the configuration of a SE. A learning factory can be used to prevent that this uncertainty results in guestimates during the selection process. Even if there is no clear argumentation for making a decision, the experience and trial-and-error approach of a learning factory can support in making more educated and underpinned appraisals.

\section{Black Swan}

No established SE will ever function entirely as predicted. This is due to the fact that the system will exhibit unintended states. Some results, effects or occurrences are not easy to 


\section{Part III}

predict based on knowledge of the past. However, beyond such types of influences, also completely unforeseen effects can appear; such effects can be referred to as black swans (Taleb, 2007). Black swans represent events that are very improbable, have an extreme impact and are often retrospectively explicable. They cannot be taken into consideration with risk analysis, since they stretch the boundaries of the system too much. At the same time, "in product development, addressing risks is inherent to the activities of the designer. In general, such risks are assumed to be argumentative consequences of cause-effect relationships". (Kennon, Schutte, \& Lutters, 2015). To cope with them, a company has to be able to better handle extreme events, by reducing the fragility of the system. Through being exposed to extreme stressors, a system should learn and adapt (Kennon, Schutte, \& Lutters, 2015). This demands a flexible and agile SE development a pproach that exceeds robustness.

It cannot be stated that the suggested SE profile architecture is able to facilitate each and every SE development process in a robust, resilient or antifragile (Taleb, 2012) manner. Without a doubt, there will always be exceptions and counterexamples in which the architecture will fail to deliver the required support. Furthermore, it is not possible to actually proof that any architecture like this will function, foremost because the area of SEs is constantly changing. Even with hundreds of examples in which the architecture did work, this still is not enough to proof that no exceptions are possible. The only thing demonstrable from the experiences is that it will support and facilitate different processes in different circumstances.

\section{Embedding}

In this thesis, the tools used for realising a SE are deduced from their context and described from an overview perspective. The different characteristics and issues are treated individually and made explicit, but eventually will become obvious in everyday use. The architecture is agile enough not to hinder the process, but allows for tailored integration and utilisation. Currently ongoing projects in the department of DPM demonstrate how (unconsciously) the architecture approach is used throughout different projects. The projects don't need to be large or long-lasting in order to use the architecture, also for smaller projects the reasoning is certainly useful and usable within hours and without experience or prior knowledge. Stakeholders with different levels of aggregation work with the architecture, without the need to know their exact position in the greater whole.

\section{Collaborative robots}

One of the ongoing projects is expanding the use conditions of a collaborative robot. The ABB YuMi (figure 9.9) is a collaborative robot developed to perform accurate and sensitive tasks, in close cooperation with a human. To enhance the collaborative possibilities of the robot, and to increase the flexibility of the robot several (student) research projects are started on this subject.

In these projects the combination between the robot and a virtual environment is realised. In this combination the actual position, and the future movements, are visualised using VR and AR tools. This provides the opportunity to use the robot as an interaction device or as an output devices in future SEs. As an interaction device the position of the arm is changed by external factors (e.g. the user), and this action is an in put for the virtual environment. As an output devices, the robot can provide haptic feedback based on changes in the virtual environment (e.g. it can move physical objects, or touch the hands of the user).

Furthermore new programming approaches are researched. Programming of robots is generally done in two ways. The first method is teaching, this is done by moving the 
robot by hand or pendant to the required positions, and then logging these positions into memory. Besides teaching, the robot can be programmed offline without interrupting the machine. Offline programming is done in simulation software and afterwards translated into machine movements. The research project aims on a different approaches; imitating the operator. The operator performs a specific action, where after the machine imitates the shown action.

All these research projects don't run aligned to each other, but all work with the same technology. The researchers work on specific use cases of the robot, without enforced cooperation or tuning, and develop reusable elements that will become available for other projects. All projects are aimed at developing the connection between this device and other devices, the focus is not on improve the robot technology itself but on realising synergy with multiple other VR and AR devices.

In these projects the researchers are trying to capture the future aims of a SE, and translate those into requirements of the tools. Understanding the dependencies and relations between the different devices is the main aim for the researchers. If that is known, a 'building block' can be realised that allows the use of this technology in future SE.

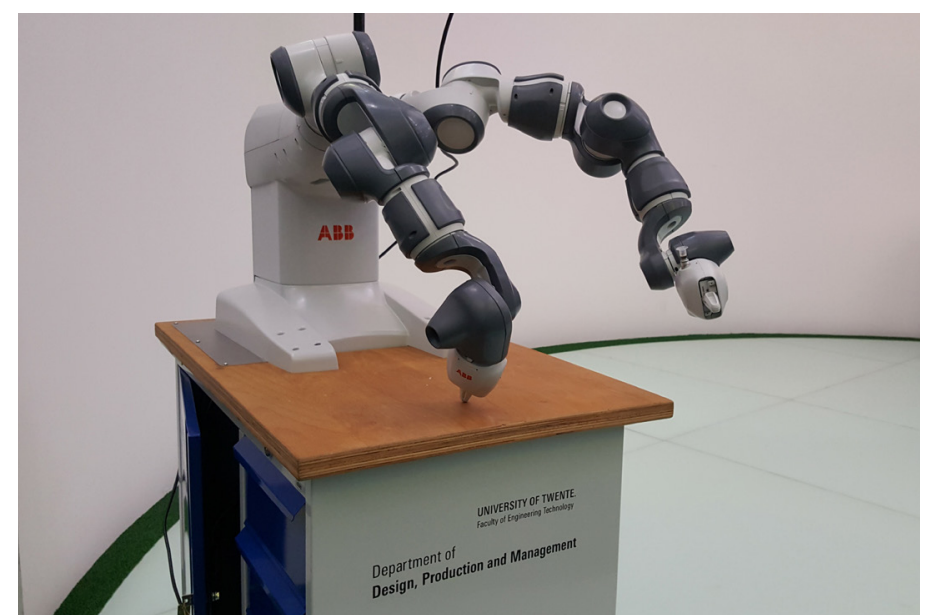

Figure 9.9 | ABB YuMi collaborative robot

\section{Tactile 3D environment configurator}

An ongoing research project in the VR-lab is the development of an interactive tactile VR configurator. This configurator makes it possible to change the composition of a virtual $3 \mathrm{D}$ environment by moving physical objects on a touch-screen table.

This configurator tool is currently simultaneously in development and in use for a project that works towards the realisation of a SE that supports the design of the reconstruction of a university building. During the start-up phase of this reconstruction project multiple stakeholders were confronted with a previous SE that contained elements of the configurator. These best practices functioned as a trigger for showing the possibilities of a SE for their project. Based on this experience the requirements for the new SE were set by the stakeholders in cooperation with researchers of the VR-lab. The standard functionality of the configurator is adjusted to the need of these stakeholders. 


\section{Part III}

The basis of the solution enables users to arrange physical scale models on a table and simultaneously generate a real-time 3D environment. These physical scale models can be used to arrange the setting of objects on all kinds of locations, for example inside buildings, like hospital interior, but can also be used for arranging buildings or objects in a city. With this application the screen inside the touch-table is used as a top view map of the area where the objects in real life will be placed, the physical scale models can be placed and arranged on the surface of the table. Multiple people can arrange the models by simply picking them up and placing them on a new location; the computer detects the location and orientation of the objects.

This enables the users to review the setting in an interactive virtual world presented on multiple visualisation devices. The solution facilitates reviewing the virtual world, simultaneously, on the following types of display:

-2D screens, without size limitations (figure 9.10)

-3D head mounted displays (e.g. Oculus Rift, HTC Vive)

- Holographic displays (e.g. Microsoft HoloLens)

Each visualisation can provide different information to the user, depending on the interest of the viewer. This can for example include information like the resources needed, the underground infrastructure, the predicted costs for installation and maintenance, the expected problem areas and whether or not the setup fulfils are the legal demands. It is possible to walk around in the virtual environment to get an impression of what it will look like in reality. Changing the camera position can be done by means of the interaction possibilities of the chosen visualisation technology, or by using a scale model of a character which is placed on the multi-touch table, in which the viewport of the virtual camera is the viewport of the physical scale model of the character.

Since the solution is not limited to a single visualisation system, the reliability and

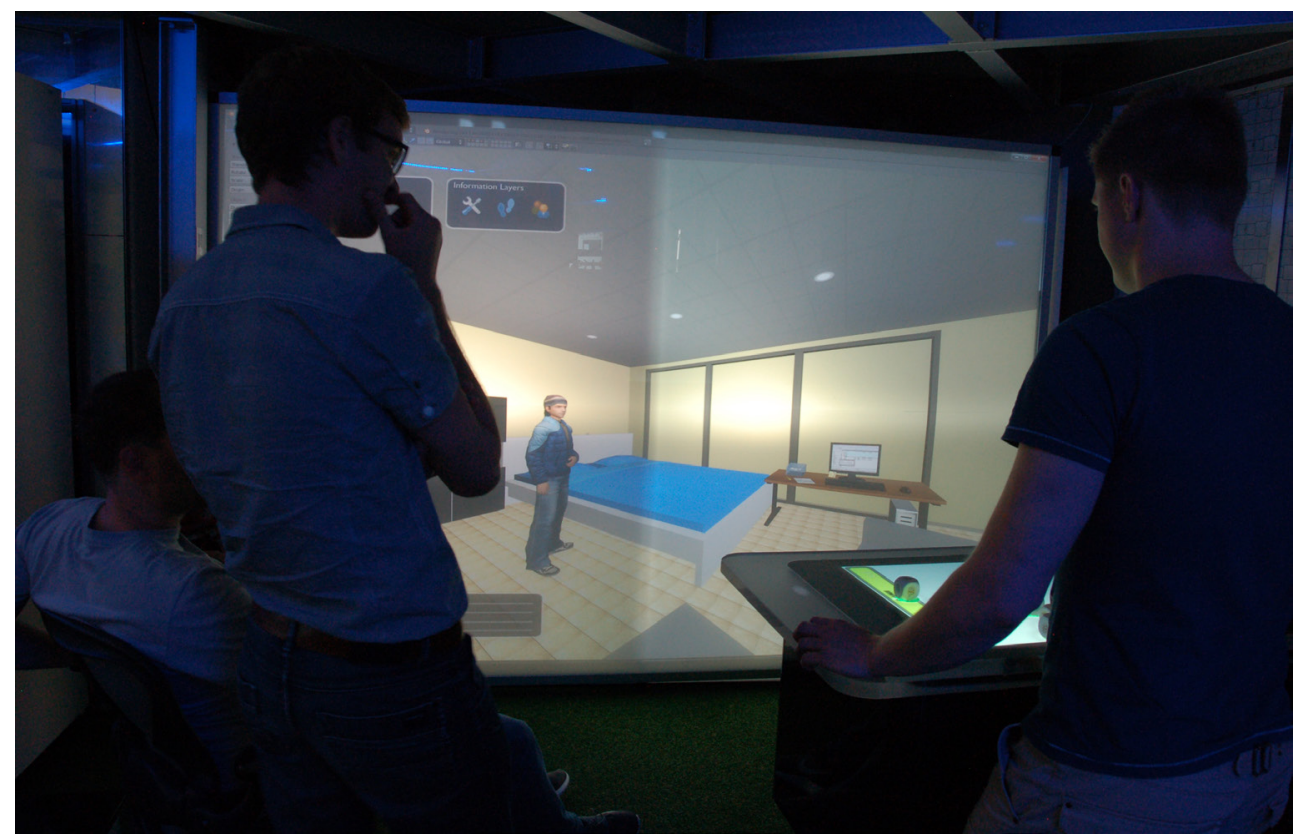

Figure 9.10 | Using the 3D environment configurator 
robustness of the solution is high. In case a selected visualisation technology fails during use (e.g. a hardware issue, or a mismatch in expectations), with little effort a different visualisation technique can be used within minutes.

\subsubsection{FEASIBILITY OF THE ARCHITECTURE}

The first goal of the implementation of the architecture in the case studies has been to test if the suggested facilitation and support provided by the architecture covers the issues occurring in current SE development trajectories. Five characteristics are determined to cover the most occurring issues in the development of a SE. For this chapter, an important aspect was to validate that it is plausible that these characteristics are likely to occur in every SE development cycle, and that the developed SE architecture will support and facilitate these characteristics. In the case studies is indicated that the characteristics are likely to occur in a SE development setting, and that they are not a consequence of the SE architecture. Although the number of case studies used to put the architecture to trial is rather limited, it appeared that the reasoning of the architecture is quite capable of efficiently supporting a broad scope of projects. For the SE architecture, the assumption is made that by facilitating each one of them individually, while being part of a constructive whole, the SE development process will improve. Based on the case studies there is no reason to doubt on that assumption.

Another goal of the implementation is to proof that it is likely that SE development can benefit from this; not that it will enhance every project without any exceptions. This requires a certain form of flexibility in use, which is done justice by the architecture. But the risk of this is that the use of the architecture will be too noncommittal, since it will not force a certain activity of process. This can be considered not to be a problem if experience and intuition can take over; but having the confidence to do that requires persuasiveness. The drawback is that at that moment often decision are made again on tacit knowledge, and that the rationale of a decision is hard to communicate and document. It is likely that the architecture invites stakeholders to think about requirements; if the communication between stakeholders is done with the blueprints as starting point, stakeholders will be provoked to have an opinion on the suggested elements.

The architecture establishes a distinct link between the different ways a stakeholder can interpret the requirements. Based on providing a view on the requirements in terms of elements, perspectives and viewpoints the complexity of a SE development is made visible, and made it more manageable. Eventually the decisions in the development (based on these requirements) are visualised with a dynamic graph. This implies that changes in the requirements directly influence the graph and can be noticed immediately by the other stakeholders (which functions as a trigger for communication, discussion or collaboration).

In the case studies the desirability to reuse VR features is acknowledged. In the case studies the architecture is reviewed as a single use architecture; in future SE development the repository of blueprints and a repository of VR features should be shared among multiple projects. How this will influence the development process is not tested in these case studies, but is already experienced in the research described in the future scenario (section 9.4.2).

Presuming that the requirements and decisions for a SE are made more explicit with the architecture, it is expected that the architecture offers guidance in how requirements and decisions are made and used throughout a SE development process, and that the architecture can provide an enhancement in the use of design tools in the development of future SE. 


\section{Part III}

\subsubsection{IMPACT FOR SME}

From a SME perspective, the use of this architecture can have significant impact on the approach for realising a SE in a PDP. The predictability and seamless integration of a (tailored) SE in a PDP will improve, and therefore the accessibility of a SE will increase while the threshold for use of the SE will be lowered considerably. The development of a SE will change to a configuration problem, instead of a design problem.

The role of the SME in the development and use of a SE will change, for example; there is for a SME no longer the need to be the owner of the SE. Several stakeholders are involved in the development of the SE, with a clear distinction being made between who owns (which part of) the SE. As it becomes easier to reuse (parts of) a SE in other SEs, it is also easier to use different financial models for the use of the SE (e.g., only paying for the use of the SE, not for owning it, which is comparable to a PSS approach as introduced in chapter 5).

The company providing the SE can realise and build its SEs based on modular elements, with less parts specifically designed for a single user, while remaining the flexibility and tailored solution, by having a large collection of interchangeable elements. A resulting SE can therefore also be a temporary solution, which can lower the initial needed investment. The modularity of the SE will also enable the SME to make a decision on what quality level of experience should be achieved; not in all SEs the best possible equipment or experience is needed, if e.g. $80 \%$ of the quality can be achieved with $10 \%$ of the costs compared to a $100 \%$ quality, a SME can consider this appraisal based on financial aspects.

The architecture can help communicate the potential of the SE to the involved (or related) stakeholders. Maintaining an overview by using the architecture can improve the efficiency and effectiveness of the collaboration with academic and industrial partners. Since the relations between different elements of the SE are known, and thus can be visualised, this can be used to communicate where possibilities for collaboration exist; and how these collaborations are related to other elements.

Documenting and sharing the configuration of the SE with stakeholders inside and outside the company, provides more insight in necessary additional research steps to overcome bottlenecks. This information can also be used to indicate where the most advantage of developing a new design tool can be achieved (low hanging fruit). Having more insight in the relations and dependencies of the different tools used inside a SE, also allow for easier modification to the SE. This results in more possible tools that can support the PDP. Easier access to the configuration of existing SEs, will also give more insight in what is needed to change to tailor an existing SE to fit in another context. 

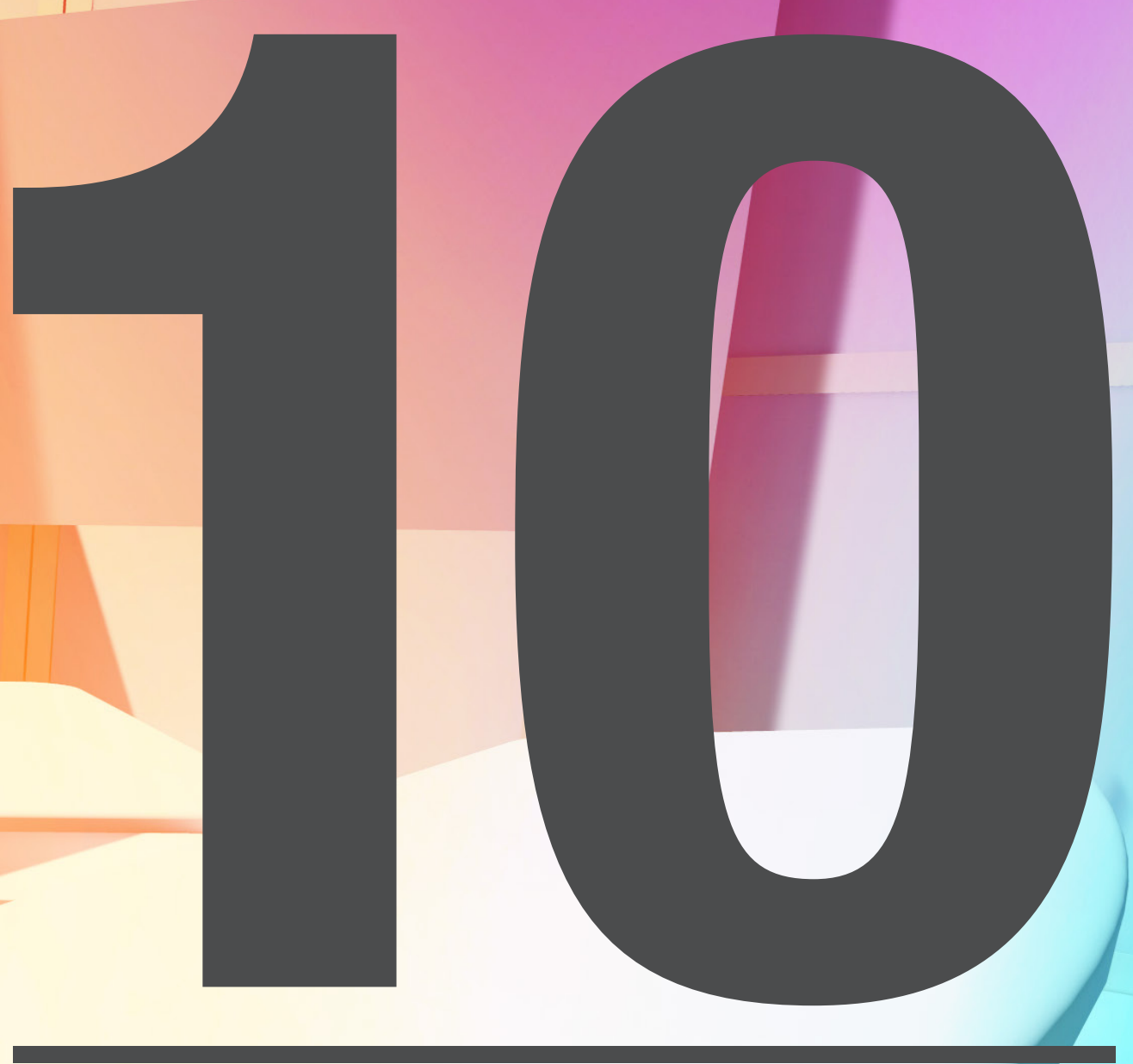

CONCLUSIONS \&

\section{RECOMMENDATIONS}




\section{CONCLUSIONS \& RECOMMENDATIONS}

\subsection{CONCLUSIONS}

The use of virtual tools during product development processes has already widely been accepted in many industries for over multiple decades. Especially in large enterprises, custom-made VR solutions are already integrated in demarcated development phases to support designers. Often, these SEs are inflexible and expensive. For SMEs, it is often still quite unclear what added value the use of a SE could have. Not only the outcome of using a SE is hard to predict, also the consequences and implications of implementation are indefinite. Consequentially, industry has a need for more predictable, future-proof, robust, affordable, flexible and acceptable SEs.

With this, also the need for better control of the effectiveness of a SE during product development process emerges. Especially while formulating the composition of elements that form a SE, a more structured approach will increase the quality of the result. The relations and interdependencies between different elements of the SE are more imperative than individual tools in predicting the effectiveness of a (new) SE in a specific development phase. With a better understanding of (the consequences of) any SE, the likelihood of useful application will increase, while the threshold will lower, and the appreciation will improve.

One of the key elements of a SE is the set of used VR tools that act as interaction or feedback device. Currently, proper use of VR tools during development processes often requires artisanship to utilise the tools to their fullest extent, leading to a dichotomy between new technology and traditional skills. To ensure a certain quality of the outcome of any tool, its manufacturer needs a formalised set of inputs, options and requirements. Both the already available (digital) content - from e.g. previous or concurrent projects - and interaction possibilities are limited by the manufacturer to a certain degree, with the intent to eliminate unexpected behaviour. This can only function if the environment in which the tool is used is highly controllable and predictable: two characteristics not common to a product development process. Consequently, VR tools are mostly available as speciality tools; tailored to intended use at specific moments, but heavily relying on expertise to adjust/ tailor the possibilities. Interesting enough, the availability of VR equipment is constantly increasing, due to the decreasing prices and higher acceptance (and experience) by the users. Encouraging the use of low-tech equipment can make a SE easier to use. Besides, it will increase the flexibility of the solution because there is less need for high investments (and consequently shorter depreciation periods). Additionally, testing new configurations becomes easier and cheaper; nevertheless it will not alter the condition that tools will only function properly if used with pre-defined activities.

Even though the application of SEs is broader than the field of product development, this thesis maintains the focus on the use of a SE during product development. In this, many similarities emerge and prove to be instrumental in comparing the preparation of a SE to the preparation of machining physical products. In process planning and factory layout planning, an enormous amount of knowledge is available on the preparation and optimisation of effective and efficient processes. By identifying relevant decision moments in the applications of VR and SE while reflecting on historical developments in manufacturing (e.g. industrial revolutions), consequences of such decisions can better be predicted and also steps in evolvements of SEs can be made more tangible. This will increase the robustness of the SE, on the condition that the relations and interdependencies between individual elements are known. 
To achieve the most appropriate SE solution, the solutions applied need to be based on the tools that are available and accessible at the time of implementation. At any given moment, new tools and techniques do come to the market, which may influence the composition of the solution. This should not be a surprise or threat, but an opportunity to constantly improve the solution. In case new options appear, the complete setting should be reviewed to see if any of such new option potentially adds value. Before applying any changes, a prediction can be given about the expected impact of the change. This will lead to configuration problems and 'what-if' questions, which may need simulation or visualisation to understand and assess the consequences. No tool will perfectly fit the desired goal, therefore adaptability on micro level (individual tools) and macro level (complete solution) is necessary. The goal is to achieve synthesis between the configuration of the setting (technology) and configuration of the functions (functional specifications). Neither is leading in this process; both should be adapted until they adequately match. Knowing the boundaries and flexibility of the stated requirements, and the influence the configuration has on that, is a key element in the realised SE development supporting architecture. Formulating knowledge rules for the desired solutions are essential, although this remains very difficult and requires a hierarchy or ontology. The fewer rules a solution needs, the more robust it is.

The more flexible and easy to use the SE is, the higher the probability becomes that realising the solution adds another dimension to the configuration problem: the reuse of the equipment/setting in other projects.

There are always multiple stakeholders involved in the decision making process of a SE. All of them have their own goals, criteria, ideas and requirements. While setting the requirements for a SE, the stakeholders must steer on the causes and deal with the effects - just as in product development. The goal is the realisation of the complete experience; definitions of this solution can be made on an individual level. Thus, only if a SE meets the expectations, a user can give a constructive opinion. Therefore, the result should be assessed and made assessable, instead of relying on prescriptions of the process. However, reflecting on the course of previous processes can prevent pitfalls in the future. The provided architecture enables that the design rationale is the main reason to select a certain approach. Here, the reason for not doing things is at least equally important as reasons for doing things.

An important aspect in all activities involved in developing a SE is to prevent (or postpone) fixed starting points in this process, as this may lead to unintentional, undesirable and non-correctable outcomes. In addition, it is important to disregard any (implicit or explicit) hierarchy amongst the stakeholders on beforehand; all opinions are basically equally important. It is always challenging to understand dissimilar perspectives or viewpoints, and no hierarchy should bias such challenges. The architecture facilitates the communication, collaboration and the discussion between stakeholders. It does not impose a certain process, it rather envisages to act as a means for flexible support of all activities related to the development of a SE. It also provides insight in the different perspectives of the solution, as well as a documentation approach.

Since every stakeholder has its own perspective on the requirements of the solution, no single method or approach can be selected that facilitates the extraction of predominant requirements. A SE providing company usually aims for a long-term relation with the client, Therefore the SE is rather seen as a product-service experience than an individual design tool. This SE providing company also benefits from supplying SEs that are structured and predictable, yet agile. For an operator, optimisation of a SE while having an overview of 


\section{Part III}

the composition is most important. The client and the user want to steer on the desired experience, and would like to communicate in terms of functional specifications or functions.

Providing multiple views with different levels of aggregation on the same envisaged solution, is desirable during the development of a SE. The added value of providing a single perspective on the stated requirements, based on a certain expertise, is essential to realise synergy between the different stakeholders. Facilitating those different perspectives, without expecting - or enforcing - any individual to have the complete overview, allows for making optimal use of all fields of expertise available and involved. There is no need for anyone to translate the thoughts and consequences of others to their field of expertise, with the risk of translation or interpretation errors. These individual perspectives are employed to allow collaboration on a higher level in the development of a SE, as it is not possible to indicate which perspective should be leading - or is of higher value - if the main purpose of the process is to balance all requirements. It is not realistic to have the illusion that a single person can have a complete overview of the rationale behind each requirement. The aim is to make optimal use of the craftsmanship of each individual stakeholder

With the use of personal blueprints, the perspective of each stakeholder involved leads to a collection of requirements. The combination of multiple stakeholders, and thus multiple blueprints, constitute a scouting space that results in a discussion space. The option of working in a discussion space allows to enable a discussion setting that contains all the desired options. Stakeholders can work together towards a solution space by reaching (and documenting) decisions. This solution space encompasses any possible final solution. Moreover, this solution space is subjective; it is influenced by e.g. a company strategy or policy. The combination of blueprints, scouting space, discussion space and solutions space forms a SE profile, which is visualised in a graph. This is the collection of all information, decisions (and rationale) on what the requirements of the SE are, while simultaneously determining the potential of the solution.

Comparing solutions is possible based on the SE profile; even if the techniques change, the underpinning of a solution can be reused in other projects. The rationale of a decision process towards a SE is for the SE developer more important than the actual realised SE. A SE is only an instantiation of a potential solution based on the (sub-)graph of the SE profile. Reusing the best practices from a previous SE, in the form of VR features, is one of the opportunities that allow for easier and faster implementation. With the use of what-if scenarios, the step from best practices to educated guess can be made.

Working with preconditions makes the stakeholders aware of the large variety of possible scenarios in using the architecture. Since this research does not aim to provide a completely predetermined method, every SE development process can generate its own interpretation of these preconditions, and allows for multiple use scenarios.

The resulting architecture is generic; it will steer the process as little as possible, but offers the stakeholders more insight in and grip on the most influential characteristics of a SE development process. It supports realising an overview by facilitating a structure, while providing more insight in the complexity of the process. This also helps the stakeholder to learn from previous projects, and to reuse elements from it. Furthermore, it creates stakeholder awareness as concerns the different perspectives and levels of aggregation of the other stakeholders involved, and indicates the necessity of making tacit information explicit. Eventually, this will lead to a more predictable situation, which is flexible in the use, but at the same time robust. 
There is only one certainty throughout the whole development; everything will change. Fixed items are only a deliberate choice, and are a means to achieve a next step. It remains important that the stakeholders do not rely on things that are merely decisions.

\subsection{RECOMMENDATIONS}

The research described in this thesis aims to provide a flexible support architecture for SE development. To discover the limitations of this flexibility, the architecture has to be integrated in multiple projects (also in co-operation with industry) and in different laboratories. Since it functions as an enabler for multiple use scenarios, it will be of the utmost importance that the architecture is used repeatedly and that it is made available to other stakeholders.

The explorations and implementations described in this thesis depict the current insights in an ongoing process of development towards a robust, transparent and flexible development approach for SEs, supported by an adequate architecture. The modular architecture needs to be elaborated upon, to become the more profound basis for the application of Synthetic Environments in product development. The architecture is to be under continuous development, in projects connected in international networks, with continual implementation. The first step should be to formally establish it as the standard documentation and facilitation support in VR-lab of the University of Twente.

Additionally, the architecture should be extended with new theoretical and practical knowledge on techniques, tools, and working methods. Important in the elaboration of the architecture is that it does remain flexible, yet structured, predictable and transparent. Multiple researchers can use the tool for various projects, simultaneously complementing the pool of blueprints and best practices. Another recommended next step is to connect with other research into supporting the different stakeholders in facilitating the requirements from their perspective; also new approaches should be able to use the blueprints and the SE profile. The architecture should remain generic, so that it will continue to be usable for a wide variety of projects. This allows for knowledge transfer between different fields of expertise, since any successful SE can be projected on another context.

Further research is required into optimising the implementation, and thereby realising a strong connection with the research on information and knowledge management. Managing the requirements is one of the fundaments of the SE profile, and should therefore be robust and future proof. To make the provided information as (re-)usable as possible, a real-time visualisation of the progress of SE development is desirable. Essentially, this means that the best way to develop a new SE based on the architecture presented here, would be to develop and use a SE for that purpose. 
Part III

10 


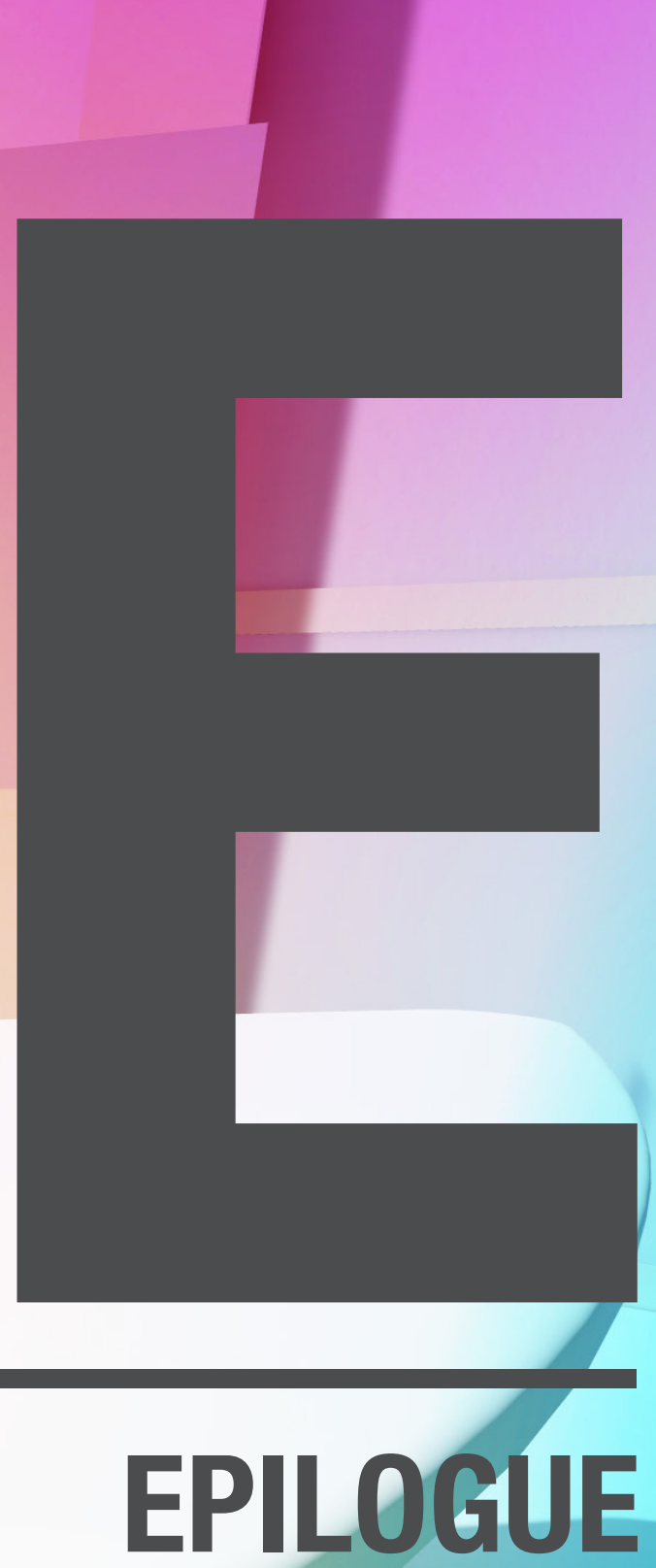




\section{EpILOGUe}

The research described in this thesis will lower the threshold for considering the use (and eventually using) a Synthetic Environment, especially for small and medium sized enterprises. Due to the indistinctness of the added value that new technology (especially VR and AR) can offer for a SME, the threshold for using this is traditionally high. A SE (and especially the VR component thereof) is often seen as a gadget or gimmick, and not as serious tool or enabler that can purposefully be usable in a development process. At the same time, best practices - both from academia and from industry - show that SEs are indeed reliable and useful additions to the toolset of a developer.

The development time of the individual (VR) tools that form a SE decreases continually, and the amount of potential interesting tools is increasing every day; nevertheless, this not necessarily results in faster available SEs. The configuration and composition of these different tools into a workable SE still requires a large amount of time. Realising the cooperation between different tools is often a complex process influenced by multiple external factors (e.g. available data, desired environment, etc.), and susceptible to changes.

With the current developments and integration of 'internet of things', even more devices will be connected (indirectly) to each other. This results in even more influence (-possibilities) between different systems. Keeping an overview of all these relations and the effects of the dependencies will become more difficult, and thus requires more support and facilitation in reviewing the current situation, but also in predicting the effects of changes.

The integration of virtual and augmented reality in everyday situations will become imperceptible over time. Enriching the real world with virtual elements will become the standard; nearly all environments will contain synthetic parts. The impression that a SE is a high-end and expensive solution, which requires the users to perform a deliberate action on a dedicated location with many preparations, will be obsolete. The boundaries of what belongs to the SE (and what is part of the real world) will be unwitnessed by users.

To enrich the real world with virtual elements, requires better understanding of the needs of the user. Filtering information becomes essential; there is too much information available that could supplement the real world, especially if data sources are combined. Clear decisions need to be made on what information should be presented, in which way, at what moment, to which user. This results in tailored solutions for each user, the information and selected techniques will have a close fit with the user.

Until now, the experience of VR and AR is often focused on a single user experience; however many SEs will especially benefit from (or even require) collaborative and conjointly working with multiple stakeholders in the same virtual environment. A SE is often a trigger for discussion, since a SE often represents the envisaged reality, which is still in development at that moment. Feedback and vision from different disciplines are welcome sources to improve this. This requires that the stakeholders undergo the same experience at the same time, and that the provided content is topical and preferably generated in real-time from the available data sources. This allows for fast and purposeful iterations and direct insight into the consequences of changes. 
The (VR/AR) elements that form a SE should be accessible and available as individual tools in a workshop environment. This challenges the users to gain experience with different tools, based on their own preferences of use, without being forced to use the tools in a predefined way. This highlights the different use-possibilities of individual items, and emphasises the flexibility. It also encourages being creative in achieving the best possible result with the resources available. By knowing and understanding which part of a SE contributes to achieving a certain goal in which way, it becomes more insightful for users what the consequences of changes in this configuration will be. A flexible workshop approach can be beneficially for this. Having a large warehouse of blueprints, and in addition a good overview of the blueprints and elements that have led to a SE, stakeholders (SME / researchers / users) have access to a low-threshold toolbox of boundless possibilities. 


\section{REFERENCES}

Abele, E., Metternich, J., Tisch, M., Chryssolouris, G., Sihn, W., ElMaraghy, H., Ranz, F. (2015). Learning Factories for Research, Education, and Training. Procedia CIRP, 32, 1-6. doi:http://dx.doi.org/10.1016/j.procir.2015.02.187

Abidi, M. H., Ahmad, A., Darmoul, S., \& Al-Ahmari, A. M. (2015). Haptics Assisted Virtual Assembly. IFAC-PapersOnLine, 48(3), 100-105. doi:http://dx.doi.org/10.1016/j. ifacol.2015.06.065

Abramovici, M., \& Lindner, A. (2013). Knowledge-based decision support for the improvement of standard products. CIRP Annals - Manufacturing Technology, 62(1), 159-162. doi:http://dx.doi.org/10.1016/j.cirp.2013.03.076

Acosta-Mendoza, N., Gago-Alonso, A., \& Medina-Pagola, J. E. (2012). Frequent approximate subgraphs as features for graph-based image classification. Knowledge-Based Systems, 27, 381-392. doi:http://dx.doi.org/10.1016/j.knosys.2011.12.002

Akao, Y. (2004). Quality Function Deployment: Productivity Press.

Ali, U., \& Kidd, C. (2013). Configuration Management Process Capabilities. Procedia CIRP, 11, 169-172. doi:http://dx.doi.org/10.1016/j.procir.2013.07.043

Alting, L. E. O., \& Zhang, H. (1989). Computer Aided Process Planning: the state-ofthe-art survey. International Journal of Production Research, 27(4), 553-585. doi:10.1080/00207548908942569

Amditis, A. (2004). On balancing costs and benefits in applying VR/VE tools in the intelligent transportation systems sector. Research in Transportation Economics, 8, 483-504. doi:http://dx.doi.org/10.1016/S0739-8859(04)o8021-7

Amditis, A., Karaseitanidis, I., Bimpas, M., \& Blach, R. (2008). Future scenarios of mixed reality: the INTUITION roadmap scenarios. The Visual Computer, 24(11), 935-940. doi:10.1007/ s00371-008-0293-1

Anderson, A. H., McEwan, R., Bal, J., \& Carletta, J. (2007). Virtual team meetings: An analysis of communication and context. Computers in Human Behavior, 23(5), 2558-2580.

Andreasen, M. M., \& Hein, L. (1987). Integrated product development. New York: Springer Verlag Ltd.

Anggreeni, I. (2010). Making use of scenarios : supporting scenario use in product design. Enschede. Retrieved from http://doc.utwente.nl/74438/

Anggreeni, I., \& Voort, M. C. v. d. (2007). Tracing the Scenarios in Scenario-Based Product Design: a study to support scenario generation. Retrieved from WorldCat.org database. Centre for Telematics and Information Technology, University of Twente.

Arentsen, A. L. (1995). A generic architecture for factory activity control. Arentsen, [S.I.].

Aronoff, M., \& Messinaa, J. (2007). Collaborative Augmented Reality for Better Standards. In G. Loureiro \& R. Curran (Eds.), Complex Systems Concurrent Engineering (pp.479-486): Springer London.

Avramenko Y, K. A. (2008). Decision Support in Design. Case Based Design (Vol. 87, pp. 25-48): Springer Berlin Heidelberg.

Azuma, R. (1997). A Survey of Augmented Reality. Teleoperators and Virtual Environments, 6(4), 355-385.

Becker, M. C., Salvatore, P., \& Zirpoli, F. (2005). The impact of virtual simulation tools on problem-solving and new product development organization. Research Policy, 34(9), 1305-1321. doi:http://dx.doi.org/10.1016/j.respol.2005.03.016

Bernard, A. (2005). Virtual engineering: Methods and tools. Proceedings of the Institution of Mechanical Engineers, Part B: Journal of Engineering Manufacture, 219(5), 413-421.

Blach, R. (2008). Virtual Reality Technology - An Overview. In D. Talaba \& A. Amditis (Eds.), Product Engineering (pp. 21-64): Springer Netherlands. 
Boehm, M., \& Thomas, O. (2013). Looking beyond the rim of one's teacup: a multidisciplinary literature review of Product-Service Systems in Information Systems, Business Management, and Engineering \&amp; Design. Journal of Cleaner Production, 51, 245260. doi:http://dx.doi.org/10.1016/j.jclepro.2013.01.019

Boer, C. R., Petitti, M., Lombardi, F., \& Simon, J.-P. (1990). A CAPP/CAM expert system for a high productivity, high flexibility CNC turning center. CIRP Annals-Manufacturing Technology, 39(1), 481-483.

Boogert, R. M. (1994). Tool management in computer aided process planning, [S.I. : WorldCat. org database.

Bowman, D. A., \& McMahan, R. P. (2007). Virtual Reality: How Much Immersion Is Enough? Computer, 4O(7), 36-43.

Brinke, E. T., Lutters, D., Streppel, T., \& Kals, H. J. J. (2000). Variant-based cost estimation based on Information Management. International Journal of Production Research, 38(17), 4467-4479. doi:10.1080/00207540050205235

Broek, E. L. v. d., Meijer, F., Miedema, J., Wang, H., Voort, M. C. v. d., \& Vergeest, J. S. M. (2008). Synthetic Environments for Cooperative Product Design. Lecture Notes in Computer Science, Volume 5220/2008, 1-10. doi:10.1007/978-3-540-88011-0_1

Bruno, F., Caruso, F., nDe Napoli, L., \& Muzzupappa, M. (2006). Visualization of industrial engineering data in Augmented Reality. Journal of Visualization, 9(3), 319-329. doi:10.1007/bfo3181679

Buchert, T., Neugebauer, S., Schenker, S., Lindow, K., \& Stark, R. (2015). Multi-criteria Decision Making as a Tool for Sustainable Product Development - Benefits and Obstacles. Procedia CIRP, 26, 70-75. doi:http://dx.doi.org/10.1016/j.procir.2014.07.110

Buisine, S., Besacier, G., Aoussat, A., \& Vernier, F. (2012). How do interactive tabletop systems influence collaboration? Computers in Human Behavior, 28(1), 49-59. doi:10.1016/j. chb.2011.08.010

Butdee, S., Noomtong, C., \& Tichkiewitch, S. (2009). A process planning system with feature based neural network search strategy for aluminum extrusion die manufacturing. CORR, abs/og07.0611.

Card, S. (2003). Information visualization. In A. J. Julie \& S. Andrew (Eds.), The humancomputer interaction handbook (pp. 544-582): L. Erlbaum Associates Inc.

Carpanzano, E., \& Jovane, F. (2007). Advanced Automation Solutions for Future Adaptive Factories. CIRP Annals - Manufacturing Technology, 56(1), 435-438. doi:http://dx.doi. org/10.1016/j.cirp.2007.05.104

Carroll, J. M. (2001). Chapter 11 - Scenario-Based Design: A Brief History and Rationale. Design Knowing and Learning: Cognition in Design Education (pp. 241-268). Oxford: Elsevier Science.

Cecil, J., \& Kanchanapiboon, A. (2006). Virtual engineering approaches in product and process design. The International Journal of Advanced Manufacturing Technology, 31(9-10), 846-856. doi:10.1007/s00170-005-0267-7

Chandrasegaran, S. K., Ramani, K., Sriram, R. D., Horváth, I., Bernard, A., Harik, R. F., \& Gao, W. (2013). The evolution, challenges, and future of knowledge representation in product design systems. Computer-Aided Design, 45(2), 204-228. doi:http://dx.doi. org/10.1016/j.cad.2012.08.006

Chase, R. B., Aquilano, N. J., \& Jacobs, F. R. (1998). Production and operations management: Irwin/McGraw-Hill.

Chisholm, A. W. J. (1990). Nomenclature and definitions for manufacturing systems. Annals of the CIRP, 39(2), 735-742.

Chou, Y., Lin, Y., \& Chun, K. (2014). A construction of knowledge rules for reactive planning of 
References

job-mix assignment to homogeneous serial batch machines. International Journal of Production Economics, 151, 56-66. doi:http://dx.doi.org/10.1016/j.ijpe.2014.01.020

Chryssolouris, G. (2006). Process Planning. Manufacturing Systems: Theory and Practice (pp. 281-328). New York, NY: Springer New York.

Chryssolouris, G. (2013). Manufacturing systems: theory and practice: Springer Science \& Business Media.

Chryssolouris, G., Chan, S., \& Suh, N. P. (1985). An Integrated Approach to Process Planning and Scheduling. CIRP Annals - Manufacturing Technology, 34(1), 413-417. doi:http:// dx.doi.org/10.1016/S0007-8506(07)61801-0

Chryssolouris, G., Pappas, M., Karabatsou, V., Mavrikios, D., \& Alexopoulos, K. (2007). A Shared VE for Collaborative Product Development in Manufacturing Enterprises. In W. D. Li, C. McMahon, S. K. Ong, \& A. Y. C. Nee (Eds.), Collaborative Product Design and Manufacturing Methodologies and Applications (pp. 59-70): Springer London.

Citera, M., McNeese, M. D., Brown, C. E., \& Selvaraj, J. A. (1995). Fitting information systems to collaborating design teams. Journal of the American Society for Information Science (1986-1998), 46(7), 551.

Cobb, S. V. G., \& Sharkey, P. M. (2007). A Decade of Research and Development in Disability, Virtual Reality and Associated Technologies: Review of ICDVRAT 1996-2006. IJVR, 6(2), 51-68.

Credé, M., \& Sniezek, J. A. (2003). Group judgment processes and outcomes in videoconferencing versus face-to-face groups. International Journal of Human-Computer Studies, 59(6), 875-897. doi:10.1016/j.ijhcs.2003.07.001

Cruz-Neira, C., Sandin, D. J., DeFanti, T. A., Kenyon, R. V., \& Hart, J. C. (1992). The CAVE: audio visual experience automatic virtual environment. Commun. ACM, 35(6), 64-72. doi:10.1145/129888.129892

Damgrave, R. G. J. (2014a). Augmented Reality. In L. Laperrière \& G. Reinhart (Eds.), CIRP Encyclopedia of Production Engineering (pp. 66-67). Berlin, Heidelberg: Springer Berlin Heidelberg.

Damgrave, R. G. J. (2014b). Virtual Reality. In L. Laperrière \& G. Reinhart (Eds.), CIRP Encyclopedia of Production Engineering (pp. 1294-1296). Berlin, Heidelberg: Springer Berlin Heidelberg.

Damgrave, R. G. J., \& Lutters, D. (2011). Multi-user Collaborative Design Tools for Use in Product Development. In A. Bernard (Ed.), Global Product Development: Proceedings of the 2oth CIRP Design Conference, Ecole Centrale de Nantes, Nantes, France, 19th-21st April 2010 (pp. 227-235). Berlin, Heidelberg: Springer Berlin Heidelberg.

Damgrave, R. G. J., \& Lutters, D. (2013). Distance Collaboration Support Environment. In M. Abramovici \& R. Stark (Eds.), Smart Product Engineering: Proceedings of the 23rd CIRP Design Conference, Bochum, Germany, March 11th - 13th, 2013 (pp. 653-662). Berlin, Heidelberg: Springer Berlin Heidelberg.

Damgrave, R. G. J., Lutters, D., \& Drukker, J. W. (2014). Rationalizing Virtual Reality based on Manufacturing Paradigms. Procedia CIRP, 21, 264-269. doi:10.1016/j.procir.2014.03.132

Damgrave, R. G. J., Lutters, D., \& Houten, F. J. A. M. v. (2012). The Virtual Reality Lab as a Synthetic Environment: from strategic approach to practical implement. In $M$. Abramovici \& R. Stark (Eds.), Smart Product Engineering: Proceedings of the 23rd CIRP Design Conference, Bochum, Germany, March 11th - 13th, 2013 (pp. 787-794). Berlin, Heidelberg: Springer Berlin Heidelberg.

Damgrave, R. G.J., Lutters, D., \& Thalen,J.P. (2012). SelectingVirtual RealityTools in relation with their use context. In H. A. ElMaraghy (Ed.), Enabling Manufacturing Competitiveness and Economic Sustainability (pp. 269-274): Springer Berlin Heidelberg. 
Damgrave, R. G. J., Lutters, D., \& Houten, F. J. A. M. v. (2013). The Virtual Reality Lab as a Synthetic Environment: From Strategic Approach to Practical Implement. In $M$. Abramovici \& R. Stark (Eds.), Smart Product Engineering: Proceedings of the 23rd CIRP Design Conference, Bochum, Germany, March 11th - 13th, 2013 (pp. 787-794). Berlin, Heidelberg: Springer Berlin Heidelberg.

Dankers, W. (2013). Decision Making CIRP Encyclopedia of Production Engineering. SpringerReference (www.springerreference.com): Springer.

Dankers, W., \& Lutters, D. (2013). A Tool for Preparing Trans-National Access to High Level Visualisation Facilities. Paper presented at the COMA '13, Stellenbosch, Soth Africa. http://doc.utwente.nl/89745/

Darken, R. P., \& Peterson, B. (2002). Spatial orientation, wayfinding, and representation. Handbook of virtual environments, 493-518.

Deb, S., Ghosh, K., \& Paul, S. (2006). A neural network based methodology for machining operations selection in Computer-Aided Process Planning for rotationally symmetrical parts. Journal of Intelligent Manufacturing, 17(5), 557-569. doi:10.1007/ s10845-006-0026-0

Denkena, B., Shpitalni, M., Kowalski, P., Molcho, G., \& Zipori, Y. (2007). Knowledge Management in Process Planning. CIRP Annals - Manufacturing Technology, 56(1), 175-180. doi:10.1016/j.cirp.2007.05.042

Dhuieb, M. A., Laroche, F., \& Bernard, A. (2016). Context-awareness: A Key Enabler for Ubiquitous Access to Manufacturing Knowledge. Procedia CIRP, 41, 484-489. doi:http://dx.doi.org/10.1016/j.procir.2015.12.027

Drukker, J.W. (2009). Things to come : een economisch-historische visie op de toekomst van het industrieel ontwerpen: University of Twente.

du Preez, N., Lutters, D., \& Nieberding, H. (2009). Tailoring the development process according to the context of the project. CIRP Journal of Manufacturing Science and Technology, 1(3), 191-198. doi:10.1016/j.cirpj.2008.10.003

Duflou, J. R., Váncza, J., \& Aerens, R. (2005). Computer aided process planning for sheet metal bending: A state of the art. Computers in Industry, 56(7), 747-771. doi:http://dx.doi. org/10.1016/j.compind.2005.04.001

EIMaraghy, H. (1993). Evolution and Future Perspectives of CAPP. CIRPAnnals - Manufacturing Technology, 42(2), 739-751. doi:http://dx.doi.org/10.1016/Sooo7-8506(07)62537-2

ElMaraghy, H., \& Nassehi, A. (2014). Computer-Aided Process Planning. In L. Laperrière \& G. Reinhart (Eds.), CIRP Encyclopedia of Production Engineering (pp. 266-271). Berlin, Heidelberg: Springer Berlin Heidelberg.

ElMaraghy, W., ElMaraghy, H., Tomiyama, T., \& Monostori, L. (2012). Complexity in engineering design and manufacturing. CIRP Annals - Manufacturing Technology, 61(2), 793-814. doi:http://dx.doi.org/10.1016/j.cirp.2012.05.001

Erve, A. H.v. t. (1988). Generative computer aided process planning for part manufacturing: an expert system approach. [S.I]. WorldCat.org database.

Eversheim, W., Rozenfeld, H., Bochtler, W., \& Graessler, R. (1995). A Methodology for an Integrated Design and Process Planning Based on a Concurrent Engineering Reference Model. CIRP Annals - Manufacturing Technology, 44(1), 403-406. doi:http:// dx.doi.org/10.1016/S0007-8506(07)62351-8

Exner, K., Damerau, T., \& Stark, R. (2016). Innovation in Product-Service System Engineering Based on Early Customer Integration and Prototyping. Procedia CIRP, 47, 30-35. doi:http://dx.doi.org/10.1016/j.procir.2016.03.084

Exner, K., Lindow, K., Buchholz, C., \& Stark, R. (2014). Validation of Product-Service Systems - A Prototyping Approach. Procedia CIRP, 16, 68-73. doi:http://dx.doi.org/10.1016/j. 
References

procir.2014.03.004

Exner, K., \& Stark, R. (2015). Validation of Product-service Systems in Virtual Reality. Procedia CIRP, 30, 96-101. doi:http://dx.doi.org/10.1016/j.procir.2015.02.092

Falk, B., \& Schmitt, R. (2014). Sensory OFD: Matching Sensation with Measurement. Procedia CIRP, 17, 248-253. doi:http://dx.doi.org/10.1016/j.procir.2014.01.136

Fechter, M., Damgrave, R. G. J., \& Wartzack, S. (2015). Interactive immersive engineering system for distant collaboration. Paper presented at the DS 80-6 Proceedings of the 20th International Conference on Engineering Design (ICED 15) Vol 6: Design Methods and Tools-Part 2 Milan, Italy, 27-30.07. 15.

Fletcher, C., Ritchie, J. M., \& Lim, T. (2012). A Haptic approach to computer aided process planning. Paper presented at the Proceedings of the 37th International MATADOR Conference.

Fulton Suri, J., \& Marsh, M. (2000). Scenario building as an ergonomics method in consumer product design. Applied Ergonomics, 31(2), 151-157.

Gago-Alonso, A., Muñoz-Briseño, A., \& Acosta-Mendoza, N. (2013). A new proposal for graph classification using frequent geometric subgraphs. Data \& Knowledge Engineering, 87, 243-257. doi:http://dx.doi.org/10.1016/j.datak.2013.04.001

Galitz, W. O. (2007). The essential guide to user interface design: an introduction to GUI design principles and techniques: John Wiley \& Sons.

Garcia, A., Kunz, J., Ekstrom, M., \& Kiviniemi, A. (2004). Building a project ontology with extreme collaboration and virtual design and construction. Advanced Engineering Informatics, 18(2), 71-83. doi:10.1016/j.aei.2004.09.001

Garde, J. A. (2013). Everyone has a part to play: games and participatory design in healthcare. Enschede. (PhD Thesis), University of Twente, Enschede.

Germani, M., Mengoni, M., \& Peruzzini, M. (2012). An approach to assessing virtual environmentsfor synchronousand remotecollaborativedesign.Advanced Engineering Informatics, 26(4), 793-813. doi:http://dx.doi.org/10.1016/j.aei.2012.06.003

Gerwin, D., \& Barrowman, N. J. (2002). An evaluation of research on integrated product development. Management Science, 48(7), 938-953.

Gould, J.D. \& Lewis, C. (1985). Designing for usability: key principles and what designers think. Commun. ACM, 28(3), 300-311. doi:10.1145/3166.3170

Giebels, M. M. T., Lutters, D., \& Kals, H. J. J. (1999). Order information structure in integrated manufacturing planning. Proceedings of the 32nd CIRP International Seminar on Manufacturing Systems, Leuven, Belgium.

Grigore, C. B., \& Philippe, C. (2003). Virtual Reality Technology: John Wiley \& Sons, Inc.

Gu, P., Hashemian, M., \& Nee, A. Y. C. (2004). Adaptable Design. CIRP Annals - Manufacturing Technology, 53(2), 539-557. doi:http://dx.doi.org/10.1016/S0007-8506(07)60028-6

Gustafsson, G., Raudberget, D., \& Ström, M. (2016). Unveiling Fundamental Relationships in Industrial Product Development. Procedia CIRP, 50, 204-209. doi:http://dx.doi. org/10.1016/j.procir.2016.05.092

Ham, I., \& Lu, S. C. Y. (1988). Computer-Aided Process Planning: The Present and the Future. CIRPAnnals - Manufacturing Technology,37(2), 591-601. doi:http://dx.doi.org/10.1016/ S0007-8506(07)60756-2

Hanafy, M., \& EIMaraghy, H. (2014). Co-design of Products and Systems Using a Bayesian Network. Procedia CIRP, 17, 284-289. doi:http://dx.doi.org/10.1016/j.procir.2014.01.129

Hervy, B., Laroche, F., Bernard, A., \& Kerouanton, J. (2013). Co-working for Knowledge Management in Cultural Heritage: Towards a PLM for Museum. In A. Bernard, L. Rivest, \& D. Dutta (Eds.), Product Lifecycle Management for Society: 10th IFIP WG 5.1 International Conference, PLM 2013, Nantes, France, July 6-10, 2013, Proceedings (pp. 
317-325). Berlin, Heidelberg: Springer Berlin Heidelberg.

Hervy, B., Laroche, F., Kerouanton, J., Bernard, A., Courtin, C., D'haene, L., Waels, A. (2014). Augmented historical scale model for museums: from curation to multi-modal promotion. Paper presented at the Proceedings of the 2014 Virtual Reality International Conference, Laval, France.

Holston, D. (2011). The Strategic Designer: Tools \& techniques for managing the design process: Simon and Schuster.

Hoolhorst, F. W. B. (2012). Structuring user-centred product development processes. Enschede. (PhD Thesis), University of Twente, Enschede.

Hoolhorst, F. W. B., van Rompay, T. J. L., ten Klooster, R., \& Roukema, M. (2014). Evaluating Shelfready Packaging Designs in a VR Environment. Paper presented at the EuroVR 2014 - Conference and Exhibition of the European Association of Virtual and Augmented Reality.

Horváth, I. (2014). What the Design Theory of Social-Cyber-Physical Systems Must Describe, Explain and Predict? In A. Chakrabarti \& L. T. M. Blessing (Eds.), An Anthology of Theories and Models of Design: Philosophy, Approaches and Empirical Explorations (pp. 99-120). London: Springer London.

Horváth, I., \& Vroom, R. W. (2015). Ubiquitous computer aided design: A broken promise or a Sleeping Beauty? Computer-Aided Design, 59, 161-175. doi:http://dx.doi.org/10.1016/j. cad.2014.10.006

Houten, F. J. A. M. v. (1991). PART: a computer aided process planning system. (PhD Thesis), University of Twente, Enschede.

Houten, F. J. A. M. v. (1992). Manufacturing Interfaces. CIRP Annals, 41(2), 699-710.

Houten, F. J. A. M. v., Damgrave, R. G. J., Dankers, W., Lutters, D., \& Wendrich, R. E. (2013). Virtual Reality Lab (J.W. Drukker Ed.). Enschede.

Houten, F. J. A. M. v., \& Kimura, F. (2000). The Virtual Maintenance System: A ComputerBased Support Tool for Robust Design, Product Monitoring, Fault Diagnosis and Maintenance Planning. CIRP Annals - Manufacturing Technology, 49(1), 91-94. doi:http://dx.doi.org/10.1016/S0007-8506(07)62903-5

Houtzeel, A. (1996). Computer-aided process planning. Manufacturing engineering and materials processing, 48, 461-480.

Jacko, J. A. (2012). Human computer interaction handbook: Fundamentals, evolving technologies, and emerging applications: CRC press.

Jenkins, D. P., Stanton, N. A., Salmon, P. M., \& Walker, G. H. (2011). A formative approach to developing synthetic environment fidelity requirements for decision-making training. Applied Ergonomics, 42(5), 757-769. doi:10.1016/j.apergo.2010.12.003

Jiang, S., \& Nee, A.Y.C. (2013). A novel facility layout planning and optimization methodology. CIRP Annals - Manufacturing Technology, 62(1), 483-486. doi:http://dx.doi. org/10.1016/j.cirp.2013.03.133

Jiang, X., Xiong, H., Wang, C., \& Tan, A. (2009). Mining globally distributed frequent subgraphs in a single labeled graph. Data \& Knowledge Engineering, 68(10), 1034-1058.

Jimeno, A., \& Puerta, A. (2007). State of the art of the virtual reality applied to design and manufacturing processes. The International Journal of Advanced Manufacturing Technology, 33(9), 866-874. doi:10.1007/s00170-006-0534-2

Joseph,E.P.,\&Matthew,C.F.(2010).Advanced process planningforsubtractiverapid prototyping. Rapid Prototyping Journal, 16(3), 216-224. doi:doi:10.1108/13552541011034898

Kauff, P., \& Schreer, O. (2002). An immersive 3D video-conferencing system using shared virtual team user environments. Paper presented at the Proceedings of the 4 th international conference on Collaborative virtual environments, Bonn, Germany. 
Kaulio, M. A. (1998). Customer, consumer and user involvement in product development: A framework and a review of selected methods. Total Quality Management, 9(1), 141149. doi:10.1080/0954412989333

Kennon, D., Schutte, C. S. L., \& Lutters, D. (2015). An alternative view to assessing a ntifragility in an organisation: A case study in a manufacturing SME. CIRP Annals - Manufacturing Technology, 64(1), 177-180. doi:http://dx.doi.org/10.1016/j.cirp.2015.04.024

Kim, G. (2005). Introduction: Virtual Reality in a Nutshell Designing Virtual Reality Systems The Structured Approach (pp. 3-13): Springer London.

Kim, J., Pratt, J. J., Iyer, R. G., \& Sriram, R. D. (2008). Standardized data exchange of CAD models with design intent. Computer-Aided Design, 40(7), 760-777. doi:http://dx.doi. org/10.1016/j.cad.2007.06.014

Koleva, B., Benford, S., \& Greenhalgh, C. (2002). The Properties of Mixed Reality Boundaries. In S. Bødker, M. Kyng, \& K. Schmidt (Eds.), ECSCW'99 (pp. 119-137): Springer Netherlands.

Koren, Y., Heisel, U., Jovane, F., Moriwaki, T., Pritschow, G., Ulsoy, G., \& Van Brussel, H. (1999). Reconfigurable Manufacturing Systems. CIRP Annals - Manufacturing Technology, 48(2), 527-540. doi:http://dx.doi.org/10.1016/S0007-8506(07)63232-6

Krafcik, J. F. (1988). Triumph of the lean production system. MIT Sloan Management Review, 30(1), 41.

Krishnan, V., \& Ulrich, K.T. (2001). Product Development Decisions: A Review of the Literature. Manage. Sci., 47(1), 1-21. doi:10.1287/mnsc.47.1.1.10668

Kujala, S. (2003). User involvement: A review of the benefits and challenges. Behaviour \& Information Technology, 22(1), 1-16. doi:10.1080/01449290301782

Lafou, M., Mathieu, L., Pois, S., \& Alochet, M. (2015). Manufacturing System Configuration: Flexibility Analysis For a utomotive Mixed-Model Assembly Lines. IFAC-PapersOnLine, 48(3), 94-99. doi:http://dx.doi.org/10.1016/j.ifacol.2015.06.064

Lange, J.d., Oude Luttikhuis, E. J., \& Lutters, D. (2014). Networked Design Decisions in Balanced Life Cycles. Procedia CIRP, 21, $230-235$.

Lange, J. d., Oude Luttikhuis, E. J., \& Lutters, D. (2016). Incertitudes in design decisions impediments or instruments? Paper presented at the International Conference on Competitive Manufacturing.

Laroche, F., Bernard, A., \& Cotte, M. (2008). Advanced industrial archaeology: A new reverseengineering process for contextualising and digitising ancient technical objects. Virtual and Physical Prototyping, 3(2), 105-122. doi:10.1080/17452750802045028

Laroche, F., Bernard, A., \& Hervy, B. (2015). DHRM: A new model for PLM dedicated to product design heritage. CIRP Annals - Manufacturing Technology, 64(1), 161-164. doi:http:// dx.doi.org/10.1016/j.cirp.2015.04.027

Lau, H. Y. K., Chan, L. K. Y., \& Wong, R. H. K. (2008, 25-27 May 2008). A VR-based visualization framework for effective information perception and cognition. Paper presented at the 2008 Conference on Human System Interactions.

Lee, J. C. (2008). Hacking the Nintendo Wii Remote. IEEE Pervasive Computing, 7(3), 39-45. doi:10.1109/MPRV.2008.53

Li, H., Huang, T., Kong, C., Guo, H., Baldwin, A., Chan, N., \& Wong, J. (2008). Integrating design and construction through virtual prototyping. Automation in Construction, 17(8), 915-922. doi:10.1016/j.autcon.2008.02.016

Liebers, A. (1998). An architecture for cost control in manufacturing; the use of cost information in order-related decisions.

Lindkvist,C., Stasis, A., \&Whyte,J.(2013).Configuration Management in Complex Engineering Projects. Procedia CIRP, 11, 173-176. doi:http://dx.doi.org/10.1016/j.procir.2013.07.046

Loch, C. H., \& Terwiesch, C. (1998). Communication and uncertainty in concurrent 
engineering. Management Science, 44(8), 1032-1048.

Lorenz, M., Spranger, M., Riedel, T., Pürzel, F., Wittstock, V., \& Klimant, P. (2016). CAD to VR - A Methodology for the Automated Conversion of Kinematic CAD Models to Virtual Reality. Procedia CIRP, 41, 358-363. doi:http://dx.doi.org/10.1016/j.procir.2015.12.115

Lu, S. C. Y., Shpitalni, M., \& Gadh, R. (1999). Virtual and Augmented Reality Technologies for Product Realization. CIRP Annals - Manufacturing Technology, 48(2), 471-495. doi:http://dx.doi.org/10.1016/S0007-8506(07)63229-6

Lundgren, M., Hedlind, M., \& Kjellberg, T. (2014). Process planning methodology guide for interactive learning. Paper presented at the SPS2014 The sixth Swedish Production Symposium.

Lundgren, M., Hedlind, M., \& Kjellberg, T. (2015). Model-driven Process Planning and Quality Assurance. Procedia CIRP, 33, 209-214. doi:http://dx.doi.org/10.1016/j. procir.2015.06.038

Lundgren, M., Hedlind, M., \& Kjellberg,T.(2016). Model Driven Manufacturing Process Design and Managing Quality. Procedia CIRP, 50, 299-304. doi:http://dx.doi.org/10.1016/j. procir.2016.07.032

Lutters, D. (2001). Manufacturing integration based on information management. University of Twente, Enschede. WorldCat.org database.

Lutters, D., Dankers, W., Oude Luttikhuis, E. J., \& Lange, J.d. (2014). Network based requirement specification. CIRP Annals - Manufacturing Technology, 63(1), 133-136. doi:http:// dx.doi.org/10.1016/j.cirp.2014.03.095

Lutters, D., \& Houten, F. J. A. M. v. (2013). Ambiguity and uncertainty of Requirements in Product Development. Paper presented at the COMA'13.

Lutters, D., Houten, F. J. A. M. v., Bernard, A., Mermoz, E., \& Schutte, C. S. L. (2014). Tools and techniques for product design. CIRP Annals - Manufacturing Technology, 63(2), 607630. doi:http://dx.doi.org/10.1016/j.cirp.2014.05.010

Lutters, D., \& Klooster, R. t. (2008). Functional requirement specification in the packaging development chain. CIRPAnnals - Manufacturing Technology, 57(1), 145-148. doi:http:// dx.doi.org/10.1016/j.cirp.2008.03.052

Marilungo, E., Peruzzini, M., \& Germani, M. (2015). An Integrated Method to Support PSS Designwithin the Virtual Enterprise. Procedia CIRP, 30, 54-59. doi:http://dx.doi. org/10.1016/j.procir.2015.02.021

Marzano, A., Friel, I., Erkoyuncu, J. A., \& Court, S. (2015). Design of a Virtual Reality Framework for Maintainability and Assemblability Test of Complex Systems. Procedia CIRP, 37, 242-247. doi:http://dx.doi.org/10.1016/j.procir.2015.08.067

Mas, F., Menéndez, J. L., Oliva, M., \& Ríos, J. (2013). Collaborative Engineering: An Airbus Case Study. Procedia Engineering, 63, 336-345. doi:http://dx.doi.org/10.1016/j. proeng.2013.08.180

Masood, T., Erkoyuncu, J. A., Roy, R., \& Harrison, A. (2014). Integrating design attributes, knowledge and uncertainty in aerospace sector. CIRP Journal of Manufacturing Science and Technology, 7(2), 83-96. doi:http://dx.doi.org/10.1016/j.cirpj.2014.02.001

McMahon, C., \& Browne, J. J. (1993). CADCAM: From Principles to Practice: Addison-Wesley Longman Publishing Co., Inc.

Mehrabi, M. G., Ulsoy, A. G., \& Koren, Y. (2000). Reconfigurable manufacturing systems: key to future manufacturing. Journal of Intelligent Manufacturing, 11(4), 403-419.

Meier, H. (2014). Industrial Product-Service System. In L. Laperrière \& G. Reinhart (Eds.), CIRP Encyclopedia of Production Engineering (pp. 696-700): Springer Berlin Heidelberg.

Meier, H., Roy, R., \& Seliger, G. (2010). Industrial Product-Service Systems-IPS2. CIRP Annals - Manufacturing Technology, 59(2), 607-627. doi:http://dx.doi.org/10.1016/j. 
References

cirp.2010.05.004

Meijer, F., van den Broek, E. L., Schouten, T. E., Damgrave, R. G. J., \& de Ridder, H. (2010). Synthetic Environments as visualization method for product design. Human Vision and Electronic Imaging XV, 7527, 752712-752712-752710. doi:10.1117/12.843691

Menck, N., Weidig, C., \& Aurich, J. C. (2013). Virtual Reality as a Collaboration Tool for Factory Planning based on Scenario Technique. Procedia CIRP, 7(0), 133-138. doi:http://dx.doi. org/10.1016/j.procir.2013.05.023

Menck, N., Yang, X., Weidig, C., Winkes, P., Lauer, C., Hagen, H.,. Aurich, J. C. (2012). Collaborative Factory Planning in Virtual Reality. Procedia CIRP, 3(0), 317-322. doi:http://dx.doi. org/10.1016/j.procir.2012.07.055

Microsoft Hololens. (2016), Retrieved from https://www.microsoft.com/microsofthololens/en-us

Miedema, J. (2010). Synthetic environments in design processes. (PhD Thesis), University of Twente, Enschede.

Miedema, J., Voort, M. C. v. d., \& Houten, F. J. A. M. v. (2009). Advantageous application of Synthetic Environments in product design. CIRP Journal of Manufacturing Science and Technology, 1(3), 159-164. doi:http://dx.doi.org/10.1016/j.cirpj.2008.09.015

Miedema, J., Voort, M. C. v. d., Lutters, D., \& Houten, F. J. A. M. v. (2007). Synergy of technical specifications, functional specifications and scenarios in requirements specifications. Paper presented at the 17th CIRP Design Conference, Berlin, Germany. http://doc. utwente.nl/101605/

Milgram, P., \& Kishino, F. (1994).A taxonomy of mixed reality visual displays. IEICE Transactions on Information Systems, E77-D(12), 1321-1329.

Milgram, P., Takemura, H., Utsumi, A., \& Kishino, F. (1995). Augmented reality: a class of displays on the reality-virtuality continuum.

Moser, U., Maisenbacher, S., Kasperek, D., \& Maurer, M. (2015). Definition of an Approach for the Development of Product-Service Systems. Procedia CIRP, 30, 18-23. doi:http:// dx.doi.org/10.1016/j.procir.2015.02.130

Moubachir, Y., \& Bouami, D. (2015). A New Approach for the Transition between OFD Phases. Procedia CIRP, 26, 82-86. doi:http://dx.doi.org/10.1016/j.procir.2014.07.172

Müller, K., \& Sebastian, H. J. (1997). Intelligent systems for engineering design and configuration problems. European Journal of Operational Research, 100(2), 315-326. doi:http://dx.doi.org/10.1016/S0377-2217(96)oo292-5

National Research Council. (2001). Theoretical Foundations for Decision Making in Engineering Design. Washington, DC: The National Academies Press.

Natyavidushi, J. (2011). Importance of body language in effective multicultural communication. Analele Universitatii din Craiova. Seria Geografie, XIV, 102-127.

Nee, A.Y.C., \& Ong, S. K. (2013).Virtual and Augmented Reality Applications in Manufacturing. IFAC Proceedings Volumes, 46(9), 15-26. doi:http://dx.doi.org/10.3182/20130619-3RU-3018.00637

Nee, A. Y. C., Ong, S. K., Chryssolouris, G., \& Mourtzis, D. (2012). Augmented reality applications in design and manufacturing. CIRP Annals - Manufacturing Technology, 61(2), 657679. doi:http://dx.doi.org/10.1016/j.cirp.2012.05.010

Nemoto, Y., Uei, K., Sato, K., \& Shimomura, Y. (2015). A Context-based Requirements Analysis Method for PSS Design. Procedia CIRP, 30, 42-47. doi:http://dx.doi.org/10.1016/j. procir.2015.02.095

Nguyen, D., \& Canny, J. (2005). MultiView: spatially faithful group video conferencing. Paper presented at the Proceedings of the SIGCHI Conference on Human Factors in Computing Systems, Portland, Oregon, USA. 
Nguyen, H. N., Exner, K., Schnürmacher, C., \& Stark, R. (2014). Operationalizing IPS2 Development Process: A method for Realizing IPS2 Developments based on Processbased Project Planning. Procedia CIRP, 16, 217-222. doi:http://dx.doi.org/10.1016/j. procir.2014.01.024

Nguyen, H. N., Schnürmacher, C., \& Stark, R. (2014). Research on How to Introduce the PSS Engineering into Industry. Procedia CIRP, 16, 74-79. doi:http://dx.doi.org/10.1016/j. procir.2014.01.010

Nonaka, I., \& Takeuchi, H. (1995). The knowledge-creating company: How Japanese companies create the dynamics of innovation: Oxford university press.

North, C. (2012). Information Visualization Handbook of Human Factors and Ergonomics (pp. 1209-1236): John Wiley \& Sons, Inc.

Ohno, T. (1988). Toyota production system: beyond large-scale production: crc Press.

Ostaeyen, J. v., Horenbeek, A. v., Pintelon, L., \& Duflou, J. R. (2013). A refined typology of product-service systems based on functional hierarchy modeling. Journal of Cleaner Production, 51, 261-276. doi:http://dx.doi.org/10.1016/j.jclepro.2013.01.036

Oude Luttikhuis, E. J., Lange, J. d., Lutters, D., \& Klooster, R. t. (2015). Evolving Product Information in Aligning Product Development Decisions across Disciplines. Procedia CIRP, 29, 573-578. doi:http://dx.doi.org/10.1016/j.procir.2015.02.049

Pahl, G., \& Beitz, W. (2013). Engineering design: a systematic approach: Springer Science \& Business Media.

Peltonen, P., Kurvinen, E., Salovaara, A., Jacucci, G., Ilmonen, T., Evans, J., ... Saarikko, P. (2008). "It's Mine, Don't Touch!": Interactions at a Large Multi-Touch Display in a City Centre. CHI 2008 Proceedings - Multitouch and Surface Computing.

Philippe, F., Guillaume, M., \& Pascal, G. (2011). Virtual Reality: Concepts and Technologies: CRC Press, Inc.

Qin, J., Liu, Y., \& Grosvenor, R. (2016). A Categorical Framework of Manufacturing for Industry 4.0 and Beyond. Procedia CIRP, 52, 173-178. doi:http://dx.doi.org/10.1016/j. procir.2016.08.005

Rachuri, S., Subrahmanian, E., Bouras, A., Fenves, S. J., Foufou, S., \& Sriram, R. D. (2008). Information sharing and exchange in the context of product lifecycle management: Role of standards. Computer-Aided Design, 40(7), 789-800. doi:http://dx.doi. org/10.1016/j.cad.2007.06.012

Rembold, U., Nnaji, B. O., \& Storr, A. (1993). Computer integrated manufacturing and engineering: Addison-Wesley Longman Publishing Co., Inc.

Ren, Z., Yang, F., Bouchlaghem, N. M., \& Anumba, C. J. (2011). Multi-disciplinary collaborative building design-A comparative study between multi-agent systems and multidisciplinary optimisation approaches. Automation in Construction, 20(5), 537-549. doi:http://dx.doi.org/10.1016/j.autcon.2010.11.020

Robertson, T. J., \& Simonsen, J. (2013). Participatory Design: an introduction Routledge International Handbook of Participatory Design (Vol. 1, pp. 1-17). USA: Routledge.

Rosson, M. B., \& Carroll, J. M. (2002). Usability engineering: scenario-based development of human-computer interaction: Morgan Kaufmann.

Sabaei, D., Erkoyuncu, J. A., \& Roy, R. (2015). A Review of Multi-criteria Decision Making Methods for Enhanced Maintenance Delivery. Procedia CIRP, 37, 30-35. doi:http:// dx.doi.org/10.1016/j.procir.2015.08.086

Salehi, M., \& Tavakkoli-Moghaddam, R. (2009). Application of genetic algorithm to computer-aided process planning in preliminary and detailed planning. Engineering Applications of Artificial Intelligence, 22(8), 1179-1187. doi:http://dx.doi.org/10.1016/j. engappai.2009.04.005 
Sanders, A. J. B., Luursema, J. M., Warntjes, P., Mastboom, W. J. B., Geelkerken, R. H., Klaase, J. M., . Verwey, W. B. (2006). Validation of open-surgery VR trainer. Stud Health Technol Inform, 119, 473-476.

SangSu, C., Kiwook, J., \& Sang, D. N. (2015). Virtual reality applications in manufacturing industries: Past research, present findings, and future directions. Concurrent Engineering, 23(1), 40-63. doi:doi:10.1177/1063293X14568814

Sassanelli, C., Pezzotta, G., Rossi, M., Terzi, S., \& Cavalieri, S. (2015). Towards a Lean Product Service Systems (PSS) Design: State of the Art, Opportunities and Challenges. Procedia CIRP, 30, 191-196. doi:http://dx.doi.org/10.1016/j.procir.2015.02.123

Scallan, P. (2003a). 1 - Introduction to manufacturing Process Planning (pp. 1-34). Oxford: Butterworth-Heinemann.

Scallan, P. (2003b). 2 - What is process planning? Process Planning (pp. 35-62). Oxford: Butterworth-Heinemann.

Schuh, G., Rudolf, S., \& Riesener, M. (2014). Similarity-based Product Configuration. Procedia CIRP, 17, 290-295. doi:http://dx.doi.org/10.1016/j.procir.2014.01.056

Schutte, C. S. L., \& Du Preez, N. (2010). A comparative study about the formal design life cycle of the Integrated Knowledge Network to support Innovation.

Segreto, T., \& Teti, R. (2016). Manufacturing. In P. The International Academy for, L. Laperrière, \& G. Reinhart (Eds.), CIRP Encyclopedia of Production Engineering (pp. 1-5). Berlin, Heidelberg: Springer Berlin Heidelberg.

Seidel, R. H. A., \& Arndt, G. (1988). Productivity Improvement in Job Shop Production. CIRP Annals - Manufacturing Technology, 37(1), 421-424. doi:http://dx.doi.org/10.1016/ So007-8506(07)61668-0

Sherman, W. R., \& Craig, A. B. (2003). Understanding Virtual Reality Understanding Virtual Reality. San Francisco: Morgan Kaufmann.

Shigley, J. E., \& Mischke, C. R. (1986). Standard handbook of machine design.

Silverstein, D., Samuel, P., \& DeCarlo, N. (2013). The innovator's toolkit: $50+$ techniques for predictable and sustainable organic growth: John Wiley \& Sons.

Sohlenius, G. (1992). Concurrent Engineering. CIRP Annals - Manufacturing Technology, 41(2), 645-655. doi:http://dx.doi.org/10.1016/So007-8506(07)63251-X

Sowa, J. F. (1983). Conceptual structures: Information processing in mind and machine: Addison-Wesley Pub.,Reading, MA; None.

Ståhl, O. (1999). Meetings for real - Experiences from a series of VR-based project meetings. Paper presented at the Proceedings of the ACM symposium on Virtual reality software and technology, London, United Kingdom.

Stark, R., Israel, J. H., \& Wöhler, T. (2010). Towards hybrid modelling environmentsMerging desktop-CAD and virtual reality-technologies. CIRP Annals - Manufacturing Technology, 59(1), 179-182. doi:http://dx.doi.org/10.1016/j.cirp.2010.03.102

Stechert, C., \& Franke, H. J. (2009). Managing requirements as the core of multi-disciplinary product development. CIRP Journal of Manufacturing Science and Technology, 1(3), 153-158. doi:http://dx.doi.org/10.1016/j.cirpj.2008.09.008

Stevenson, A. (2010). Oxford dictionary of English: Oxford University Press, USA.

Stowers, J., Hayes, M., \& Bainbridge-Smith, A. (2011, 13-15 April 2011). Altitude control of a quadrotor helicopter using depth map from Microsoft Kinect sensor. Paper presented at the 2011 IEEE International Conference on Mechatronics.

Suh, N. P. (1990). The principles of design (Vol. 990): Oxford University Press New York.

Synthesis, (2017) Merriam-Webster Collegiate Dictionary - Encyclopædia Brittanica. Retrieved from https://www.merriam-webster.com/dictionary/

Taleb, N. N. (2007). The black swan : the impact of the highly improbable. New York: Random 
House.

Taleb, N. N. (2012). Antifragile : things that gain from disorder. New York: Random House.

Tang, W., Lee, J., Song, B., Islam, M., Na, S., \& Huh, E. (2011). Multi-Platform Mobile Thin Client Architecture in Cloud Environment. Procedia Environmental Sciences, 11, Part A(o), 499-504. doi:http://dx.doi.org/10.1016/j.proenv.2011.12.079

Thalen, J. P. (2013). Facilitating user centred design through virtual reality. (PhD Thesis), University of Twente, Enschede.

Thalen, J. P., \& Garde, J. A. (2013). Capturing use: user involvement and participatory design.

Tideman, M. (2008). Scenario based product design. (PhD Thesis), University of Twente, Enschede.

Tolio, T., Sacco, M., Terkaj, W., \& Urgo, M. (2013). Virtual Factory: An Integrated Framework for Manufacturing Systems Design and Analysis. Procedia CIRP, 7(0), 25-30. doi:http:// dx.doi.org/10.1016/j.procir.2013.05.005

Tomiyama, T. (1994). From general design theory to knowledge-intensive engineering. Artificial Intelligence for Engineering, Design, Analysis and Manufacturing, 8(04), 319333.

Tomiyama, T., D'Amelio, V., Urbanic, J., \& Eimaraghy, W. (2007). Complexity of multidisciplinary design. CIRP Annals - Manufacturing Technology, 56(1), 185-188. doi:10.1016/j.cirp.2007.05.044

Tomiyama, T., Gu, P., Jin, Y., Lutters, D., Kind, C., \& Kimura, F. (2009). Design methodologies: Industrial and educational applications. CIRP Annals - Manufacturing Technology, 58(2), 543-565. doi:http://dx.doi.org/10.1016/j.cirp.2009.09.003

Tukker, A. (2004). Eight types of product-service system: eight ways to sustainability? Experiences from SusProNet. Business Strategy and the Environment, 13(4), 246-260. doi:10.1002/bse.414

Ullman, D. G. (1992). The mechanical design process (Vol. 2): McGraw-Hill New York.

Ulrich, K. T., \& Eppinger, S. D. (2012). Product design and development. New York: McGrawHill/Irwin.

Uncertainty, (2017) Merriam-Webster Collegiate Dictionary - Encyclopædia Brittanica. Retrieved from https://www.merriam-webster.com/dictionary/

Unger, D., \& Eppinger, S. (2011). Improving product development process design: a method for managing information flows, risks, and iterations. Journal of Engineering Design, 22(10), 689-699. doi:10.1080/09544828.2010.524886

Váncza, J., Monostori, L., Lutters, D., Kumara, S. R., Tseng, M., Valckenaers, P., \& Van Brussel, H. (2011). Cooperative and responsive manufacturing enterprises. CIRP Annals - Manufacturing Technology, 6o(2), 797-820. doi:http://dx.doi.org/10.1016/j. cirp.2011.05.009

Virtual Reality Lab, University of Twente. Retrieved from http://vrlab.ctw.utwente.nl/

VISIONAIR. 2017, Retrieved from http://www.infra-visionair.eu/

Wagner, U., AlGeddawy, T., ElMaraghy, H., \& Müller, E. (2012). The State-of-the-Art and Prospects of Learning Factories. Procedia CIRP, 3(0), 109-114. doi:http://dx.doi. org/10.1016/j.procir.2012.07.020

Wagner, U., AlGeddawy, T., ElMaraghy, H., \& Müller, E. (2015). Developing products for changeable learning factories. CIRP Journal of Manufacturing Science and Technology, 9, 146-158. doi:http://dx.doi.org/10.1016/j.cirpj.2014.11.001

Waiyagan, K., \& Bohez, E. L. J. (2009). Intelligent feature based process planning for five-axis mill-turn parts. Computers in Industry, 60(5), 296-316. doi:http://dx.doi.org/10.1016/j. compind.2008.09.009

Wang, L., Shen, W., Xie, H., Neelamkavil, J., \& Pardasani, A. (2002). Collaborative conceptual 
References

design—state of the art and future trends. Computer-Aided Design, 34(13), 981-996.

Wiederhold, B. K. (2016). Lessons Learned as We Begin the Third Decade of Virtual Reality: Mary Ann Liebert, Inc. 140 Huguenot Street, 3rd Floor New Rochelle, NY 10801 USA.

Wiendahl, H. P., ElMaraghy, H. A., Nyhuis, P., Zäh, M. F., Wiendahl, H. H., Duffie, N., \& Brieke, M. (2007). Changeable Manufacturing - Classification, Design and Operation. CIRP Annals - Manufacturing Technology, 56(2), 783-809. doi:http://dx.doi.org/10.1016/j. cirp.2007.10.003

Wiesner, S., Freitag, M., Westphal, I., \& Thoben, K. (2015). Interactions between Service and Product Lifecycle Management. Procedia CIRP, 30, 36-41. doi:http://dx.doi. org/10.1016/j.procir.2015.02.018

Wigdor, D., Penn, G., Ryall, K., Esenther, A., \& Shen, C. (2007). Living with a Tabletop: Analysis and Observations of Long Term Office Use of a Multi-Touch Table. 60-67. doi:10.1109/ tabletop.2007.33

Wilson, J., \& Dcruz, M. (2005). Virtual and interactive environments for work of the future. International Journal of Human-Computer Studies. doi:10.1016/j.ijhcs.2005.08.007

Womack, J. P., Jones, D. T., \& Roos, D. (1990). The Machine That Changed the World: The Story of Lean Production: How Japan's Secret Weapon in the Global Auto Wars Will Revolutionize Western Industry. New York, NY: Rawson Associates.

$\mathrm{Xu}$, H., Yuan, M., \& Li, D. (2009). A novel process planning schema based on process knowledge customization. The International Journal of Advanced Manufacturing Technology, 44(1), 161-172. doi:10.1007/s00170-008-1804-y

Xu, X., Wang, L., \& Newman, S. T. (2011). Computer-aided process planning-A critical review of recent developments and future trends. International Journal of Computer Integrated Manufacturing, 24(1), 1-31.

Yusof, Y., \& Latif, K. (2014). Survey on computer-aided process planning. The International Journal of Advanced Manufacturing Technology, 75(1), 77-89. doi:10.1007/so0170-0146073-3

Zhang, H., \& Merchant, M. E. (1993). IPPM - A Prototype to Integrate Process Planning and Job Shop Scheduling Functions. CIRP Annals - Manufacturing Technology, 42(1), 513518. doi:http://dx.doi.org/10.1016/Soo07-8506(07)62498-6

Zhou, R., Hu, Y., Xiao, S., \& Wen, J. (2016). A Multi-agent Based Decision-Making Approach for Field Service Delivery of IPS2.Procedia CIRP,47, 228-233. doi:http://dx.doi.org/10.1016/j. procir.2016.03.070

Ziout, A., Azab, A., Altarazi, S., \& ElMaraghy, W. H. (2013). Multi-criteria decision support for sustainability assessment of manufacturing system reuse. CIRP Journal of Manufacturing Science and Technology, 6(1), 59-69. doi:http://dx.doi.org/10.1016/j. cirpj.2012.10.006 


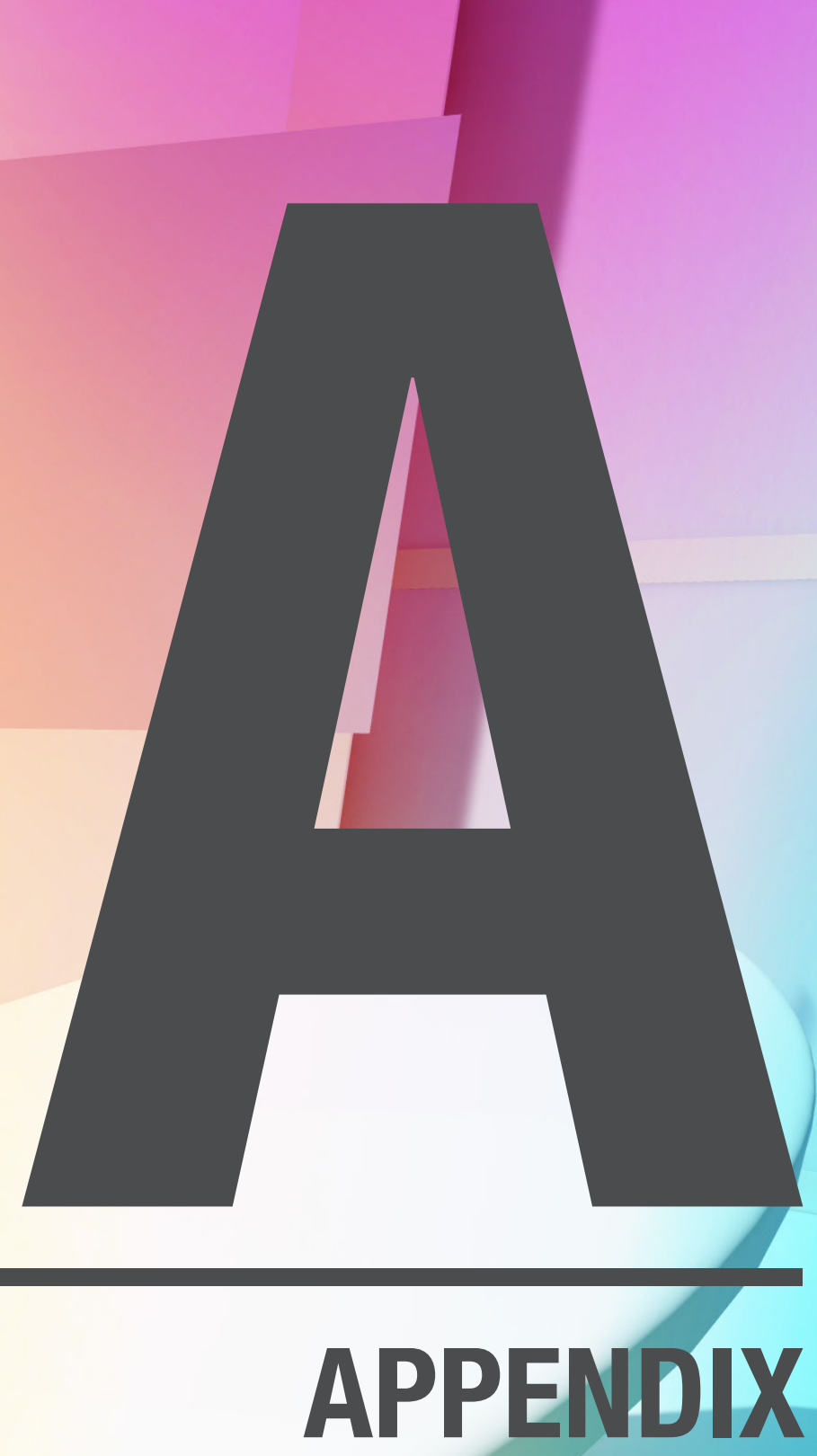




\section{APPENDIX A}

\section{The VR-Lab of the University of Twente (abstract of (Houten, Damgrave et al., 2013))}

\section{REALISATION}

In 1978 the research group Production Technology started its research on Computer Aided Process Planning (CAPP). In 1987 the PART system (Planning of Actions, Resources and Technology) was developed by a team of ten people over a period of four years, and the prototype was finished in 1991. PART could interpret CAD models and extract manufacturing features for which it could allocate manufacturing methods and tools. It could then calculate cutting conditions and tool paths based on geometric configurations and manufacturing tolerances.

PART was based on 3D solid modelling and the group had gained ample experience in this field. Later, when Feature based solid modelling was entering the mainstream CAD world, the group developed feature based applications on commercial platforms like Catia and Unigraphics. Parametric modelling became the trend in CAD for the early nineties and the group performed research and developments in this field.

Product design gradually became a more prominent research area of the group and in 1998 a separate chair in Design Engineering was established. This chair received a starting grant of the equivalent of $€ 150.000$, which facilitated the investment in new computer graphics equipment and haptic devices. In the same year the foundation VR-Valley Twente was established, with the mission to make industry in the region aware of the existence and potential of Virtual Reality technology. The initiative was taken by Dick Arnold, the technical director of Thales Netherlands (the former Thomson-CSF/HSA), together with Ton Beune of the Development Agency East. One of the first projects the group was involved in together with Thales was MERTaC, an approach to improve the speed and efficiency of product development by early visualisation of design concepts in combination with customer feedback. The first VR dedicated equipment entered the laboratory in the form of a stereoscopic display, some head mounted devices and a tracking system.

In 2000, the group was asked to investigate the possibility to start an educational programme in Industrial Design Engineering, which had to start in august 2001. A venue was found in the tower of the Horst building and there the first dedicated VR-Lab was established. Because of lack of lab space, a temporary solution was found in a shared VRLab facility together with the biomechanics group. In the meantime the renovation of the rest of the Horst building was on the brink of execution and it became clear that there was an opportunity to create substantially more floor space.

The idea of creating a substantial VR-Lab was born and the target was to open the lab in 2005. A grant application was submitted under VR-Valley II to the Innovation Impulse Overijssel and the applicants received $€$ 500.000,-. Additionally the University donated $€$ 300.000,- and after the remodelling of the building finished in April 2005, construction of the lab's interior could start.

The look and feel should be spectacular. The Thales Effect Based Solutions method for multi-stake-holder decision making required an environment that stimulates creativity: a high-tech state-of-the-art synthetic workspace that could flexibly be adapted to any kind of required or specified design environment. The envisioned VR-space had to become highly accessible by design, transcend a futuristic vision on technology, evoke surprise in styling and enhance the visual spectrum through a hybrid combination of real-world artefacts and 
virtual content systems.

The team that worked on the genesis of the initial plans was formed by Martijn Tideman, Ralph Klerkx, Wouter Eggink and directed by Robert Wendrich. The lighting and audio design was a cooperation between Fred van Houten en Robert Wendrich. The space of $245 \mathrm{~m} 2$ in potential floor surface and $14700 \mathrm{~m} 3$ in volume for the prospective VR-Lab was analysed, measured and planned for a complete makeover, using traditional and high-tech tools. Thales and the University signed a three year agreement to exploit the lab under the name T-Xchange (Technology Exchange) in a commercial way, acquiring orders from industry, government and organisations like Rijkswaterstaat, Deltares, Dutch railways, etc.

The official opening was on 25 November 2005. The official opening was performed by Arno Peels, the CEO of Thales Netherlands, Henk Zijm, the Rector of the University, Carry Abbenhues, Deputee of the province of Overijssel, and Fred van Houten, professor of Design Engineering. The opening act consisted of pouring a glass of champagne with four people each pulling on one of four strings. Some things which can easily be done alone may become quite complicated for a team!
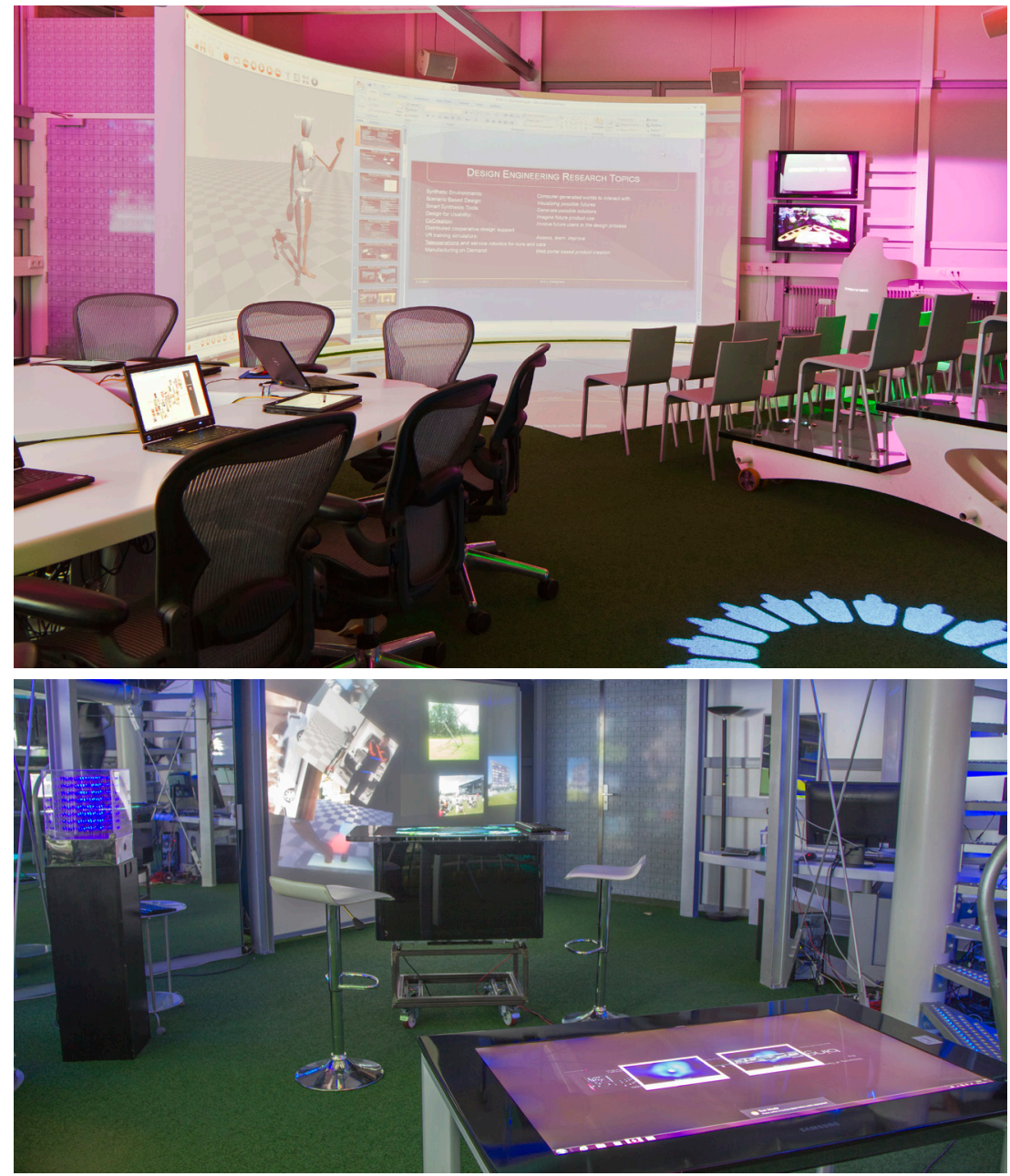

Figure A1.1| Impression of the VR-Lab 
Appendix A

\section{LAYOUT}

The ultimate design of the VR-Lab consisted of a projection area with a radius of 8.8 meters located in the South-East corner, equipped with a 3.5 meter high curved screen. The tiered theatre seating arrangement is modular and mobile to enhance flexibility and adaptation of the laboratory lay-out to different settings. A total of 30 conference chairs are implemented for seating with 12 fixed chairs on the podium. The floor between the curved screen and the podium is made from layered float glass to create visually appealing space and distance. In addition a custom designed lectern has been added to complete the presentation area.

Diagonally in the opposite North-West corner of the laboratory the Director's Room is located, containing all necessary control instruments and mixing panels for the Matrix computer system, the DMX lighting system and audio-visual equipment. In the North-East and South-West corners of the VR-Lab two semi-fixed Gaming Station areas are situated. Each Gaming Station is configured out of two mobile gaming tables, one horizontal projection table and eight office chairs, styled to specification. Above this set-up, a projector wing is fixed to the ceiling of the hall, supplied with three projectors, which allow for threechannel projection on three screen panels. The gaming tables come equipped with eight Tablet-PC's, individual audio headsets and network ports.

Furthermore, three custom designed Mobile Work-stations are part of the VR-Lab lay-out, that can be arranged in any configuration to fit every possible required scenario.

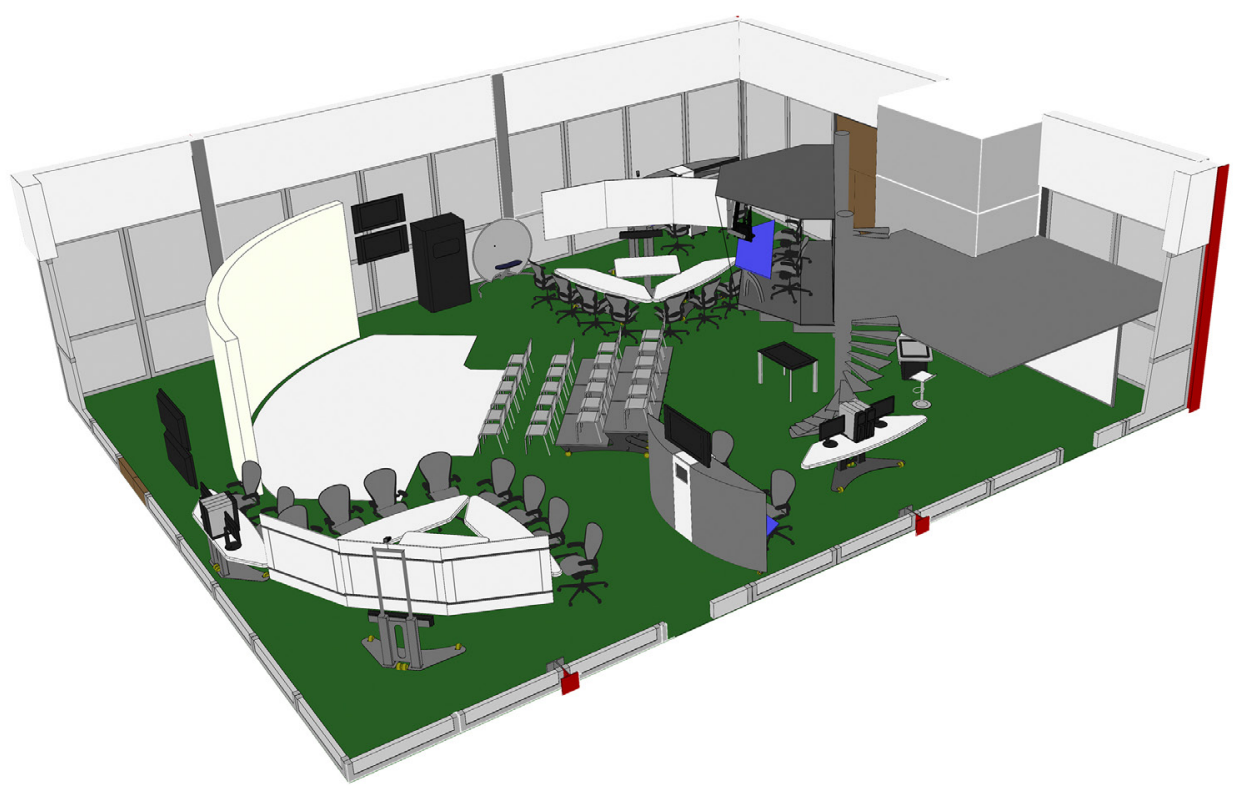

Figure A1.2| Layout of the VR-Lab 


\section{WORKING METHODS}

The experts that employ the Lab are people that think in terms of the project as brought along by the prospective user of the Lab. Whether a project definition is correct and complete is initially not even relevant; it is the structure and breadth of a problem statement that appeals to the possibilities of the Lab and the feasibility to use it. It is the proficiency of the creative expert that identifies the way in which a preliminary problem statement can be connected to the way in which the hardware in the lab can come to life. Resembling a sculptor who already sees the statue in a block of marble, the expert is trained to recognise the basics of a solution in the initial problem itself.

For an experienced user, the Lab encompasses a wealth of opportunities, captured in its hard-and software, in the evoked possible futures and mainly in the determination of the combination of resources and approaches that will render a maximum of added value for the client in the most flexible and efficient manner. Here, the Lab becomes a versatile toolbox, providing many tools with great potential. Yet, it takes knowledge and expertise to select the appropriate tools for any specific job and quite some craftsmanship in applying them in a purposeful manner.

\section{SyNTHETIC ENVIRONment}

Consequently, it's all about establishing a synthetic environment that is able to create an alternative reality in which - through simulation - imaginary worlds, objects and characters can be experienced that are impossible to realise and experience in non-virtual reality. Virtual reality allows the creation of new objects, spaces, interactions without the need for their actual construction, thereby providing the possibility to experience products even in the very early stages of the design process.

By employing high-end simulation techniques, design information is made explicit and verifiable. Through a personalised interface, all actors can be enabled to directly influence design information and directly assess the consequences of their decisions. By allowing stakeholders to experience products in the very early stages of the design process, insight in stakeholder requirements and communication within the design team as well as with stakeholders is improved and design quality is enhanced.

Overall, synthetic environments support product design processes by offering a demonstrative environment that facilitates the experience of future products by stakeholders in a wide range of (use) scenarios, enabling an identification of the needs and wishes of stakeholders with regard to the product design.

\section{PLAN}

Understanding a problem is the major prerequisite for obtaining a good solution. Before moulding a synthetic environment, there is a considerable challenge for the prospective user of the lab to make the problem field where the Lab will be employed transparent. The problem statement itself does not need to be fully elaborated. Often, conjointly determining what the actual problem is, creates more added value during early sessions in the Lab than anything else. Besides, more often than not, the real problem appears to be hidden behind the articulated problem statement. Even worse, with an explicit, yet improper problem statement, the wrong problem will be solved.

In other words, any session should rather focus on starting from a problem area. This area 


\section{Appendix A}

should challenge all participants to see the common responsibility, while stressing the variety in viewpoints and perspectives involved. Therefore, the problem area should be demarcated, thus avoiding inclusion of too many details or dimensions. Additionally, there should be a clear problem owner, who is capable of assessing the adequacy of the problem statement and its evolution, of being instrumental in selecting the right stakeholders and of evaluating the outcome of the sessions. Moreover, he will need to judge the level of abstraction as well as the desired (level of) the outcome of the project. During sessions, it is essential that the problem owner does not have ascendancy on the course of the interactions.

\section{Prepare}

While discussing the demarcated problem area as well as the initial ideas for solution paths, the scope of the project is set. This scope is instrumental in delimiting the 'wanderings' of participants in meetings. This involves preparing for example 3D models, environments, animations, but also simulation/probability models and a controllable set of premises that underlie the interactions in the synthetic environment. It goes without saying that the translations that convert ideas into environments that allow for purposeful interaction are at the heart of the craftsmanship of the researchers working in the Lab.

Moreover, there is quite some expertise involved in integrating the environment with its setting and a well-balanced combination of the hard-and software with the working methods to be used. For researchers, the challenge is to support and facilitate the process as functional and effective as possible, avoiding at the same time to implicitly hide a solution in the approach.

In preparing for a session, or an entire trajectory, quite some effort is spend in bringing the

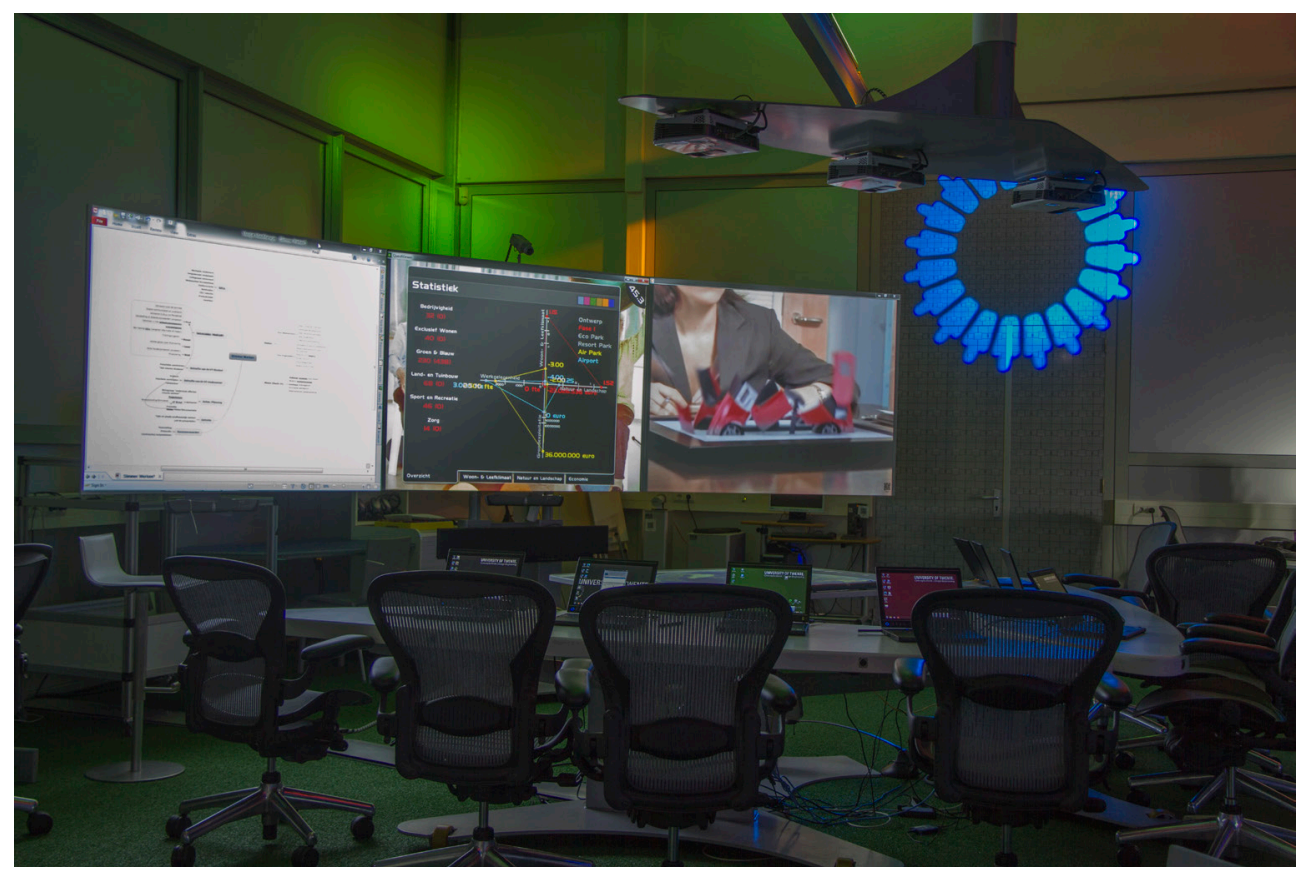

Figure A1.3| Gaming Table at the VR-Lab 
Lab to life in an adequate manner. Often, creating, converting and assembling 3D models are important, as can be the realisation of libraries of 3D models that have a dynamic role in the session. All other resources used might require programming, data sets or training. With the employment of such resources, the hard-and software can be tailored in such a way as to exhibit the behaviour that actualises the environment in which clients, users and all other stakeholders can realistically investigate different perspectives on the problem area, which is supposed to bring forward the various alternative solutions. Even more, the course of a session is planned, based on scenarios, simulation models and serious gaming approaches. All in all, having a session in the Lab can resemble an iceberg: the part that is visible floats on all the preparatory efforts involved in a session, which are hidden from sight during the session itself.

\section{INTERACT \& MODERATE}

After a sound preparation, the Lab has changed from a rather gloomy room to an environment that appeals to the commitment and creativity of all stakeholders involved in a project. When the participants enter the Lab for a session, they are immediately brought in the synthetic environment dedicated to 'their' context and 'their' problem. With the help of skilled moderators, the stakeholders are introduced to the abstract reality that will help them to better get to the core of the problem.

The skill in moderating a project is to foresee adequately what tools and methods will contribute the most to the successful execution of a project. This includes an assessment of the type and amount of preparation that is required. While employing the prepared scenarios and gaming approaches, the stakeholders start to explore the problem and its context. Usually, ampletime is spent on adequate phrasing of the problem; more often than not, participants are actually prevented from jumping to possible solutions too early. The reason for this is that every suggested solution brings along its own details, particularities and consequences, all concealing the essence of the actual problem.

With many different techniques, ranging from mind-mapping, via collages to classification, the participants conjointly formulate a basis from which the search for an optimal solution can start. The solidity of this basis justifies the efforts spent on it; it allows the participants to focus on developing solutions, without having to revisit the starting points.

While developing different concepts for a solution, the participants are supported by the prepared simulations and gaming approaches. Obviously, such interactions only buttress the activities of the participants, without influencing them. When a session is in full swing, the stakeholders, the moderators and all technology involved in the process and the controls of the Lab environment are inextricably bound up with each other. The atmosphere in the Lab is a factor that should not be underrated. It can allow people to focus, to shift attention, and even to - cautiously - pull people out of their comfort zone.

\section{Act \& EVALUATE}

As with almost all projects, a session or complete trajectory in the Lab suffers from a considerable risk: achieving a great solution is one, but adequately capturing its specific characteristics before the project is over, is a different matter. In other words, not only in the early phase of a session it is essential to record evolvements in - for example - a mindmap; it is especially in the conclusion that the added value of a session can be fathomed and secured. 


\section{Appendix A}

It is important to allow all participants to maintain the conjoint understanding and the resulting solutions paths that have been established. Here, the moderator has a great responsibility in making sure that the participants address the focal points that have been essential in the session. Realising an effective summary while doing justice to all perspectives involved is a shared responsibility that will usually require quite some effort and attention - to say the least. Experience has indicated that there is another essential reason for adequately capturing the result of a session: after the end of a session, its result has to be separated from the environment in which it came into being. Towards the end of the session, all participants have to retreat more or less from the synthetic environment with all its possibilities for interaction and simulation. After the session, the solution should have been formalised in such a way that it can inherently and autonomously survive, without the aid of the environment.

In other words, the Lab purposefully disintegrates again into a set of independent tools with individual capabilities that no longer belong to that temporary and goal-oriented synthetic environment that - in the hands of the craftsmen - could engender the required added value. That is, if the problem owner has achieved a breakthrough in the project. Only then, the lights in the Lab turn to cold pale-blue again; to allow the stakeholders to step back into the 'real world', but also to allow for the preparations for a new session or project to start.

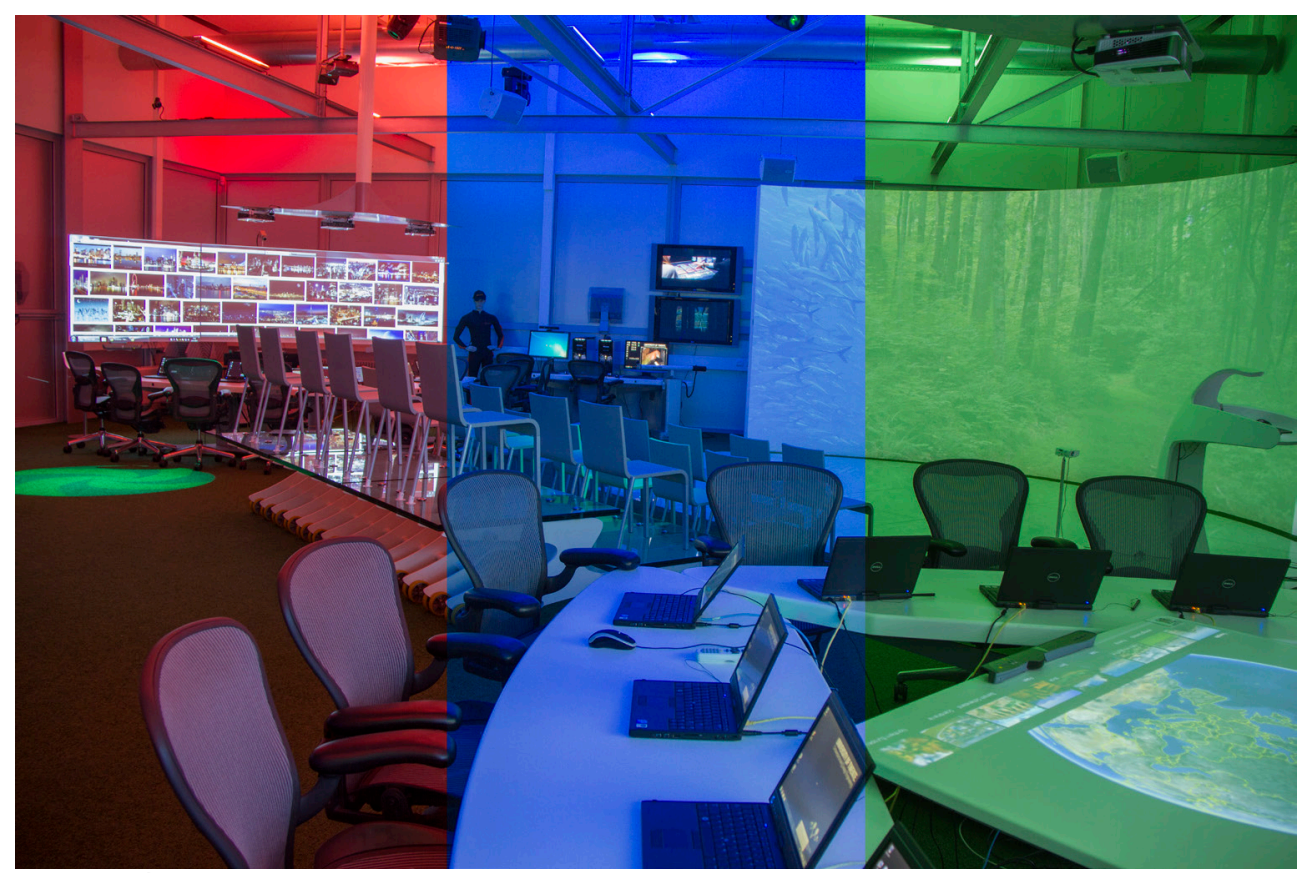

Figure A1.4| VR-Lab atmosphere 


\section{LAB EMPLOYMENT}

\section{INDUSTRY}

A visit to the Lab is a great experience, even for experts in the field. It, however, is obvious that the time and resources invested in this visit and the preparations for it, should be repaid somehow. The aims for using the Lab are various, even when merely simple industry visits are considered.

The synchronisation of stakeholder perception (inside or across the borders of an organisation), the visualisation of possible future scenarios, complex multiple stakeholders decision making, collective idea generation or impressing/overawing clients, are among the targets.

In relatively simple scenarios it is possible to reach the goals by em ploying the functionalities of individual tools and techniques. The targets of uncomplicated mind-mapping or brainstorm sessions usually benefit from the availability of multiple large screens and the possibility to apply multi-user data input on the spot.

Sometimes, however, a more overall experience is required to extricate stakeholders from their daily situation, to make them think beyond their usual boundaries or to make them realise the complexity of a situation. By pulling attendant stakeholders out of their comfort zones, their stress levels can be slightly raised, resulting in enhanced levels of concentration, focus and alertness. This high state of preparedness makes it possible to get the best out of a scenario and to make real progress towards the targets that are set.

So-called 'Serious Games' are potent means to create settings in which existing roles and conditions are not taken for granted anymore. As serious games entertain stakeholders, while at the same time having been designed for the investigation of difficult situations, they provide an inspiring mix of seriousness and fun. Serious games are ideal to discuss complex topics and issues, while simultaneously they actively involve, challenge, motivate and reward the player-participants with game elements.

As people usually imitate each other when they are largely free to act as they please, individual assignment are great means to prevent unintended 'group thinking'. Although the realisation of group thinking can be the goal of a visit, the desire for harmony in a group might also override a realistic appraisal of alternatives or lead to serious blockades in a creative process. This is problematic when for example the development of new product ideas is pursued. By using role playing elements in a serious game it is possible to explicitly confront players with the aberrant feelings of other stakeholders and to make them consider effects of decisions from different perspectives.

Additionally, serious games can focus attention on formerly underexposed aspects by filtering out some of the more obvious aspects. Players can experiment with the situation and discover new relations without being restrained by constantly seeing trouble ahead. In this way serious games help visitors to achieve the understanding, awareness and behavioural changes that are often desired.

\section{RESEARCH}

The location and the nature of the Virtual Reality Lab makes it a real hot-spot for researchers. The Lab not only offers a perfect opportunity for use in many different research projects; the techniques, tools and methods that are available are also a source of research themselves. 


\section{Appendix A}

Researchers employed at the University of Twente as well as scientists from Europe and the rest of the world apply not only to use but also to investigate the possibilities of the Lab. As the Lab is part of a European funded infrastructure that grants researchers access to high level visualisation facilities, emphasis can be put on the excellence of proposals instead of the research budget available. The research for which the Lab is employed is related to a wide area of fields including - but not limited to - engineering, medical science, nanotechnology, chemistry, physics, behavioural sciences and biology.

By testing ideas or findings in truly immersive environments, researchers can employ the lab to gain results without the need to prematurely invest in real - not virtual - test environments. Early stage visualisation of solutions benefits research on the interiors of ante-, peri-, and neo-natal care departments, on crime prevention through environmental design or the design of in-car lane-change systems. By virtually representing an interior or environment in (close to) real size, initial tests can be done without the need to actually build physical prototypes. Changes in e.g. colours or shapes can be realised real-time, and their effects can be discussed immediately.

The equipment of the Lab helps researchers to identify and analyse aspects that are difficult to study with the naked eye in the physical world. For example, by using motion capturing techniques in combination with sensor data and visualisation techniques, (human)movements can be captured and analysed. Based on the findings, work situations can be adapted to become more safe and healthy, the ergonomics of a packaging can be improved or equipment for training surgeons can be developed.

The examples mentioned above, only describe a few of the large amount of research purposes the Lab is employed for. The available technology is updated regularly and new combinations of technology can support almost any sort of research one can think of. This, however, is at the same time one of the major traps to avoid. Sometimes the attractiveness of the Lab, and the desire to spend some time in there, inclines to distract from actual research questions; apart from that some research questions might not always really need a synthetic environment to be solved.

Some researchers however are the lucky ones. Research on the Lab, it's technology and suitable working methods, requires frequent visitation, and is therefore mainly done by researchers of the faculty of Engineering Technology. These researchers among others concentrate on the development of computer generated worlds to interact with, the visualisation of possible futures, the involvement of future users in design processes, distributed cooperative design support, the use of virtual reality in training simulators, and the future technology of future technology of minimal invasive surgery. It is obvious that their results can be used for implementation in other scenarios for employment almost immediately.

\section{EDUCATION}

In the curriculum of Industrial Design Engineering (IDE) many of the functionalities of the Lab are used in beneficial ways as well. In the BSc.-programme, the visualisation possibilities of the Lab not only allow for clear explanation of difficult topics during lectures; the available technology is a welcome source of support in project based teaching too.

During project based teaching at IDE, students work on realistic engineering problems in group-based projects. In these, students groups act as design teams, independently shaping their own product development processes. User investigation, on the spot virtual 
representation of products, evaluation of ergonomics in product use, and user tests are examples of steps that are often required in such processes. In these the techniques and tools available in the VR-Lab have proven to be a great help for students.

The MSc.-traject of Industrial Design Engineering goes one step further than merely using the available equipment, as it introduces students to lab-related research topics. In one of the courses on virtual reality, students work on finding a suitable virtual support tool for a chosen phase or activity in a product development process. The term 'virtual reality' includes all kinds of digital tools varying from a simple display to a full-blown 3D environment. Students are allowed to use or develop any virtual support they can think of and are even not limited to the equipment that is available in the VR-Lab. The requirement that the virtual tools should support, and not obstruct its users is one of the main challenges for students. Covering users with heavy head mounted devices or other equipment, and telling them to 'act normally' is not considered to be a very realistic scenario. Making students realise and test their solution, prevents them from developing solutions that are not really suitable in practice. The open-minded approach of students towards the development of virtual reality tools, makes their results very much refreshing and useful for further development and use in one of the other scenarios of lab employment.

\section{FUTURE REALITY}

As the employment of the VR-Lab relies on flexible, modular and interchangeable combinations of hard and software, new technology can easily be included in the toolbox of the Lab. This not only directly allows the quality of virtual experiences to improve with new developments, it also widens the scope of solutions that can be created.

In the everlasting race to keep up with new developments it is important not to become too greedy; the most incredible tools are often dedicated to the most specific problems. Next to the fact that the relevance of these dedicated solutions is low in a lab that has a wide range of stakeholders, the life cycle of such tools is often relatively short. Additionally, when they become outdated, this often means that the entire set of software and hardware constituting a tool is written off and that the substitutes cannot be dedicated to other purposes. Consequently it is the aim to focus on the acquisition of relatively small, standardised and general sub-modules that can be employed to tackle any dedicated demand.

Obviously the acquisition is guided by some trends/topics that can be seen internally and externally, including distance collaboration \& virtual presence, information sharing, holographic visualisations, unconscious user input, and of course the faster execution of old logic.

\section{Distance COLLABORATION AND VIRTUAL PRESENCE}

Communication and collaboration between people will be facilitated and supported by continually improving technologies. Imagine having a conversation together with a few discussion partners that are actually present at several different locations, as if they are in the same room. In the future this will become part of daily life, allowing people to work together across the globe, whenever needed or wanted, without any travelling issues, planning problems or high costs.

The future scenario of distance collaboration goes far beyond the abilities of current 


\section{Appendix A}

video conferencing systems, which only partly display participants on a framed monitor, in a different size, in a different environment. Where the size of a virtual representation is currently not always matched with its size in reality, future collaboration systems will visualise your virtual discussion partners as if they are actually sitting around the same table. By only projecting the real-size person him- or herself, without his/her 'real' environment, distraction from other surroundings is limited and the person will perfectly be placed into the shared environment. As the arms and hands of your partners are also visualised, even the smallest gesticulation can be received. Using a large touch screen as a conference table, which can be operated from every location, participants will have the opportunity to discuss any 'item' that comes to table. And, maybe, one day it even becomes possible to touch each other.

\section{INFORMATION SHARING}

The processing of complex information in a simple and especially easy way, is a topic that remains important, and continuously needs upgrading. A situation in which it does not matter anymore with what device and on what location what type of information is gathered or shared, is not that far away. We are rapidly heading a situation in which the user isn't bothered anymore with the technical details and organisational factors of (re) using and sharing information.

The future work space, for example, has a giant touch screen (possibly concealed as a discussion table) that recognises the information devices you bring, like your mobile phone, tablet pc, or memory stick. It allows you to wireless push the information from your device to the table and to share it with the other people that are present (in person or virtually). Networking technologies also make sending files to others, and the duplication of files on multiple devices superfluous. Working with a central data source, 'cloud', provides access to your personal files on every location and with multiple devices.

To easily find the information you desire in the ever increasing amount of information that is available, intelligent filters guide your way. Based on your personal profile, they make a pre-selection of information that seems of interest for you. By also representing the selected information in a way that fits your personal needs, time to understand and interpret the information is drastically decreased. A production- and a maintenance employee, looking at the same set of information, might see entirely different things, being a production plan and maintenance manual respectively. And maybe, future information tools are even able to provide you with information, you weren't about to search for yet.

\section{HOLOGRAPHIC VISUALISATION AND INTERACTION}

Virtual reality is becoming to seem increasingly real. In a synthetic environment, where always a combination of real reality and virtual reality is made (in professional terms called 'augmented reality'), the boundary is starting to become more and more indefinite. In this trend, it is obvious that head mounted devices and other disruptive devices are a stage passé; the possibility to act as free and normal as possible is an important condition for an experience to feel 'real'.

The developments in holographic visualisation and interaction are definitely contributing to this experience. Holograms, which are three dimensional objects that can be perceived without the need for computer screens or additional eye ware, will allow stakeholders to walk 360 degrees around a visualisation. Where most of us still consider holograms to 
be a great creative idea of the human mind but only possible in movies, this conception has definitely become antiquated; holographic displays are already being realised. The challenge is already far beyond the visualisation part; current research focuses on making it possible to touch holographic visualisations and to interact with them.

\section{USER RECOGNITION AND UNCONSCIOUS INPUT}

In an ideal situation Virtual Reality tools automatically recognise their user and fluently interpret the user input from the body language that is told; no log-in passwords are required and the input is done so naturally that it is almost done unconsciously, and obviously without any unintended results. In fact you might even already have used technology that is considered a predecessor of the technology in this scenario. Gesture recognition is already widely used in the gaming industry, represented in devices like the Wii, Kinetic, Leap motion and others.

Where Virtual Reality used to be something very exclusive and expensive, it is nowadays used in everyday situations by the man in the street. The fact that most people are not aware of using such high end technology is quite an accomplishment. When people are unaware of the technology as such, this usually means that a tool is functioning quite well.

The adoption of VR technology in the mass gaming industry, which is talking about high figures, has led to an enormous boost in developments that also benefit the employment of the VR-Lab. As the strength of the VR-Lab is characterised by the smart combination of tools and working methods that are used to reach a certain goal, each technology improvement is not only make it possible to create experiences of higher quality; also the range of solutions that can be created is extended.

\section{EFFORTLESS PREPARATION}

Creating new tools for developers is often done combining multiple techniques and tools into a workable new setting or product. Due to the improved possibilities in connecting devices ('hand shaking') and the coherence between them, it will be easier to quickly generate new configurations. This allows for a faster and more flexible integration of new technologies in existing design processes and decreases preparation time for the use of a solution. Decreasing preparation time will provide users with the possibility to apply VR simply and quickly as a real tool to achieve a goal, and not to see the use of VR as a goal in itself. Where current VR solutions only work optimally if all the conditions and characteristics of the use situation seamlessly fit with the method proposed by the manufacturer, new VR solutions will be more based on the need and demands of the user. These new configurations can be created and tested faster and with lower costs and therefore lower risk. This makes Virtual Reality more accessible and affordable for small and medium-sized enterprises. Furthermore increasing possibilities of flexible configuration of different VR-components will permit the reuse of individual VR items in different projects, allowing a more efficient use of the equipment.

\section{REAL-TIME AND ALL-EMBRACING}

To make an experience as real as possible, future synthetic environments need to stimulate all the human senses in a desired extent and way. On the other hand, the environments should be able to interpret and quickly react upon the smallest reactions that a user shows. This requires quite some computer calculation capacity and speed, especially when multiple 


\section{Appendix A}

users and even distance collaboration is concerned. It requires the connection between different locations in and outside the Lab to be extremely fast. The continuous improving (wireless) network capabilities allow for data access and communication possibilities without any noticeable delay.

Knowing what you exactly need at a moment when dedicated solutions are not yet at hand, is a field in which designers are working daily. The tricky points are that knowing what will be useful in the process cannot be predicted completely on forehand, and that some techniques unexpectedly appear to be a success, along the way. The same applies to the development and/or implementation of new tools in the design process itself. From a management perspective it should, at the beginning of a project, be clear what the added value of a specific tool will be. But with the use of new techniques the possible results and advantages of usage are hard to predict. Supporting potential users to find and implement the most appropriate configuration of virtual tools in the proposed process is essential. This includes uncovering the goals that VR should help the user to achieve.

By providing the designer insight in the possibilities, consequences and properties of VR tools, it will enable them to make a solid choice in the wide range of available tools. In addition, it is also possible to simulate and compare the use and outcome of different configurations, or to review already tried configurations based on the outcome of a particular tool in a previous completed project. 



\section{UNIVERSITY OF TWENTE.}

Faculty of Engineering Technology

Department of

Design, Production and Management 